\title{
The Extent to Which Cell Salvage Can Support Patient Blood Management
}

\author{
Crotty, Bernard
}

How to cite:

Crotty, Bernard (2018) The Extent to Which Cell Salvage Can Support Patient Blood Management. Doctoral thesis, Swansea University.

http://cronfa.swan.ac.uk/Record/cronfa48728

Use policy:

This item is brought to you by Swansea University. Any person downloading material is agreeing to abide by the terms of the repository licence: copies of full text items may be used or reproduced in any format or medium, without prior permission for personal research or study, educational or non-commercial purposes only. The copyright for any work remains with the original author unless otherwise specified. The full-text must not be sold in any format or medium without the formal permission of the copyright holder. Permission for multiple reproductions should be obtained from the original author.

Authors are personally responsible for adhering to copyright and publisher restrictions when uploading content to the repository.

Please link to the metadata record in the Swansea University repository, Cronfa (link given in the citation reference above.)

http://www.swansea.ac.uk/library/researchsupport/ris-support/ 


\section{The Extent to Which Cell Salvage Can Support Patient Blood Management}

\section{Bernard Crotty}

A Thesis Submitted to Swansea University in Fulfilment of the Requirements for the Degree of Doctor of Philosophy

\section{Swansea University}

Submitted 2018

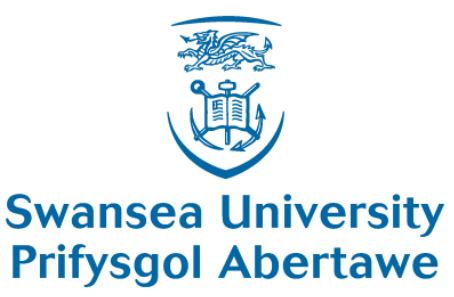




\begin{abstract}
Cell salvage involves the recycling of a patient's own blood shed during or after an operation. The procedure is mainly used in the specialties of orthopaedics, cardiac and obstetrics where high volumes of blood loss are expected. The cell salvage process can therefore obviate the need for a patient to require a blood transfusion using donated (allogeneic) blood.

This thesis examines the cost impacts of cell salvage on overall NHS costs in primary total hip replacement surgery. It compares data for three hospital sites in England; one an extensive user of cell salvage and two sites that do not utilise cell salvage. The thesis adopts a novel approach in sub-dividing the activity into HRGs (Healthcare Resource Groups) and considers the related allogeneic blood and cell salvage costs from both a financial and an economic perspective. The thesis concludes that recent procedural changes and the adoption of published blood management guidance can reduce the need for a patient to require an allogeneic blood transfusion. These changes render both intra-operative and post-operative cell salvage unnecessary to support most primary total hip replacement operations.

This thesis recommends further comparative studies in surgery that are associated with higher potential blood loss to assess the financial and economic impacts of intra-operative cell salvage in a less predictable operating environment.
\end{abstract}




\section{Declarations and Statements}

\section{DECLARATION}

This work has not previously been accepted in substance for any degree and is . not being concurrently submitted in candidature for any degree.

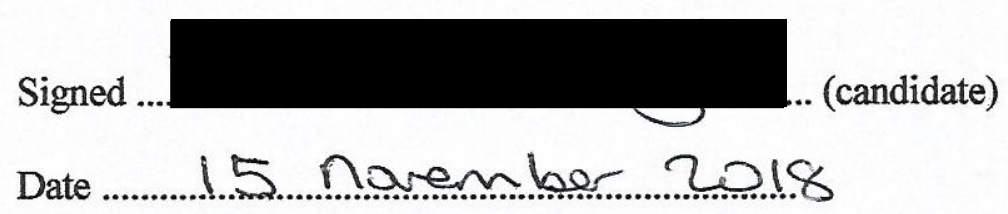

\section{STATEMENT 1}

This thesis is the result of my own investigations, except where otherwise stated.

Other sources are acknowledged by footnotes giving explicit references. A bibliography is appended.

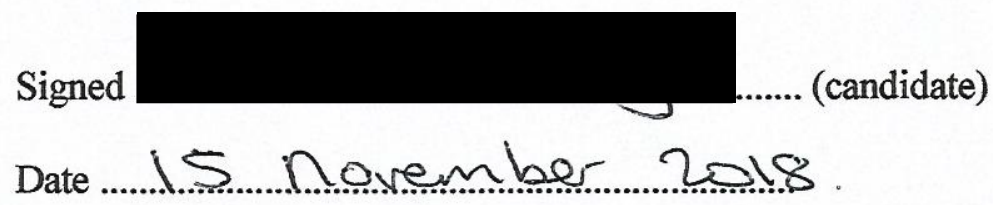

\section{STATEMENT 2}

I hereby give consent for my thesis, if accepted, to be available for photocopying and for inter-library loan, and for the title and summary to be made available to outside organisations.

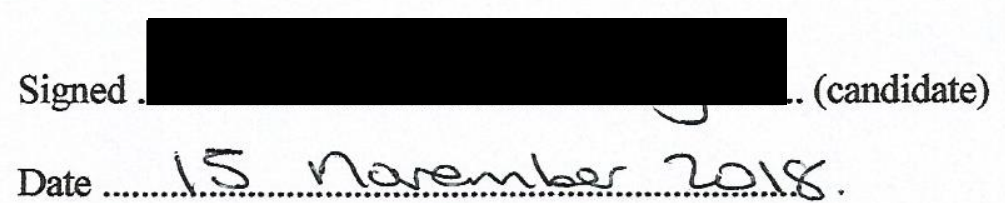




\section{Contents}

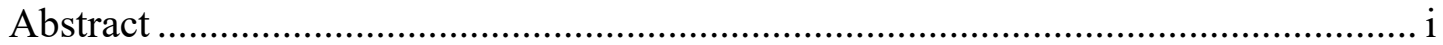

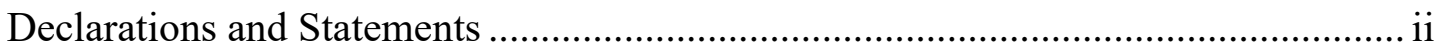

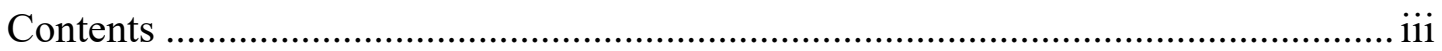

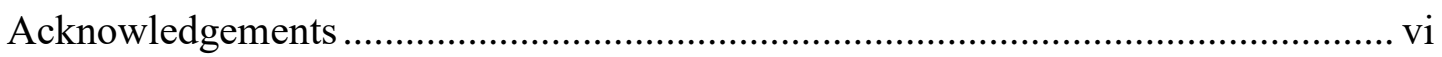

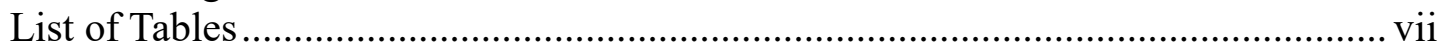

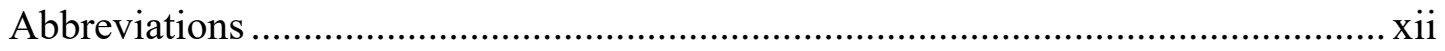

Chapter 1. Introduction and Background ......................................................................... 1

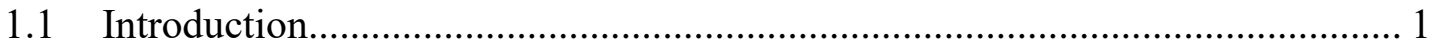

1.2 Challenges of Cell Salvage as Subject to Analyse .......................................... 2

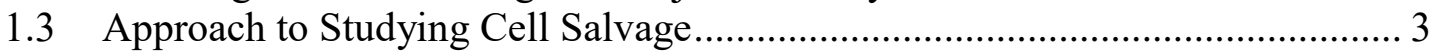

1.4 Allogeneic Blood and Blood Transfusions .................................................... 4

1.5 World Health Organisation Resolution on Allogeneic Blood............................. 6

1.6 Allogeneic Blood Journey - From Donor to Patient .................................... 6

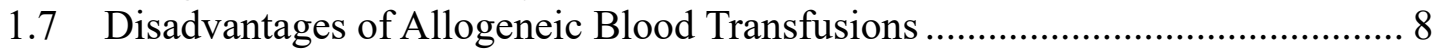

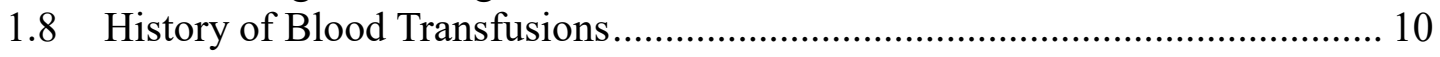

1.9 Application of Allogeneic Blood Transfusions............................................ 12

1.10 Allogeneic Blood Marketing/Collection and Usage in England ..................... 14

1.11 Better Blood Transfusion (BBT) Initiatives …............................................ 18

1.12 International Patient Blood Management (PBM) Initiative............................. 20

1.13 Methodology of Cell Salvage as an Alternative to An Allogeneic

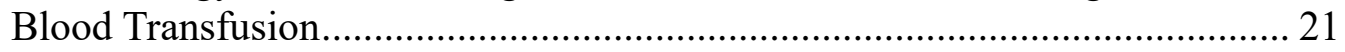

1.14 Evolution and Usage of Cell Salvage in the UK .......................................... 23

1.15 NHSBT Supported Collaborative Work on Cell Salvage ............................... 25

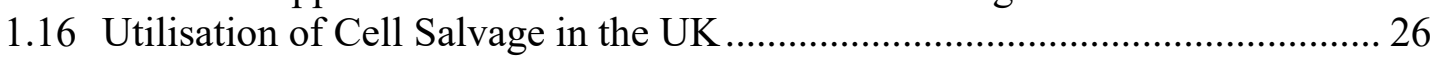

1.17 Jehovah's Witness Beliefs and Support for Cell Salvage ................................ 30

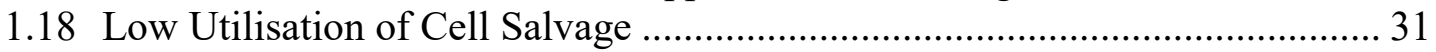

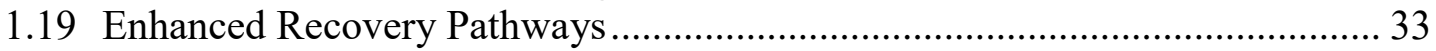

1.20 Choice of Speciality to Study Cell Salvage Applications................................ 36

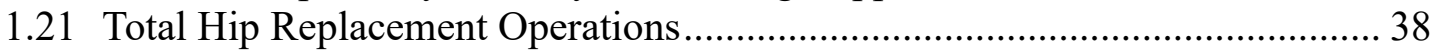

1.22 NHS Trust Financial Regime in England ..................................................... 40

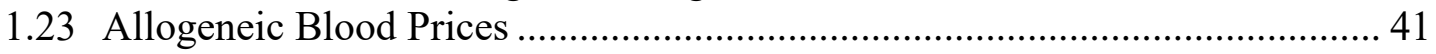

1.24 Allogeneic Blood Transfusions and the Impact on the English NHS

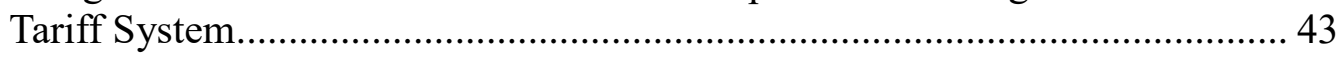

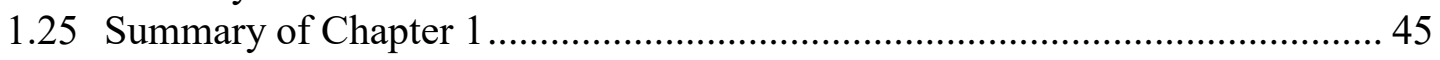

Chapter 2. Financial \& Economic Costing-Allogeneic Blood Transfusions and

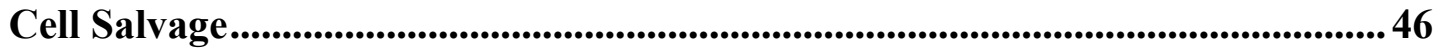

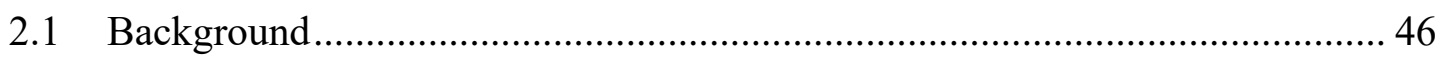

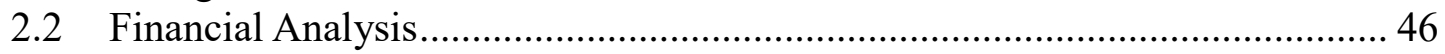

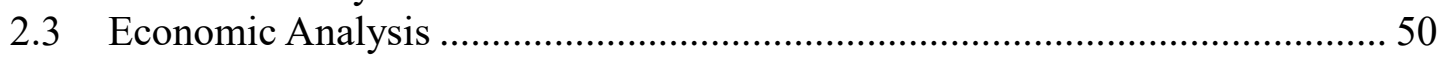

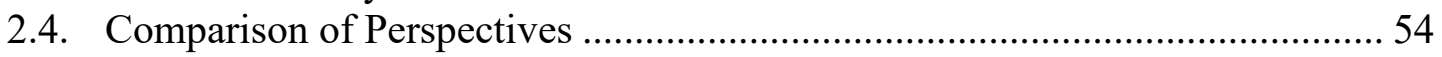

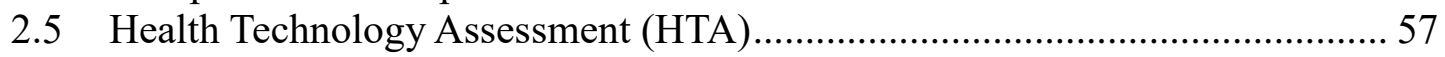

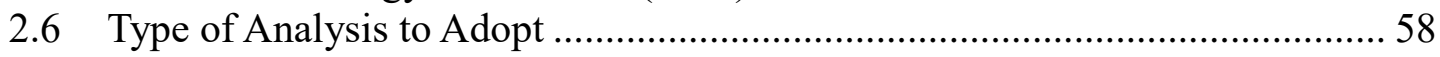

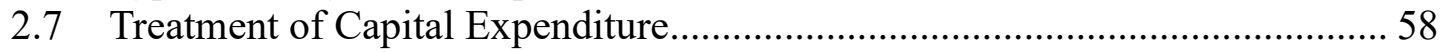

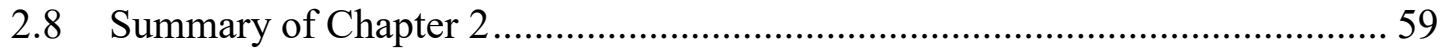




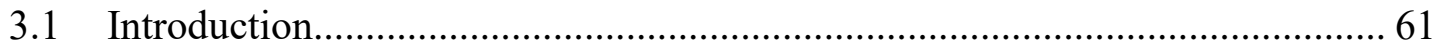

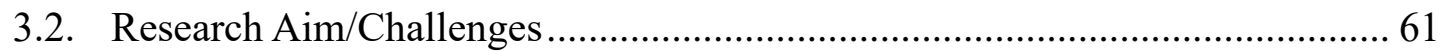

3.3 Statement of Research Question and Objectives of Thesis ........................... 63

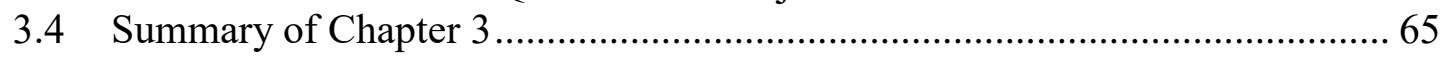

Chapter 4. Literature Review .............................................................................66 6

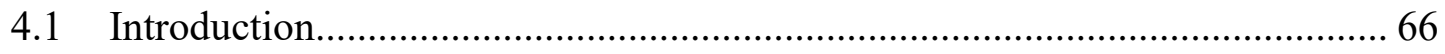

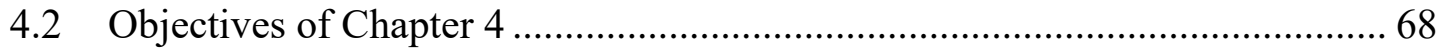

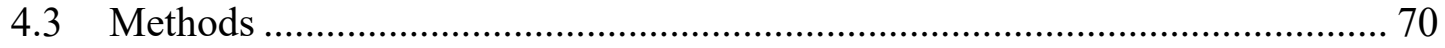

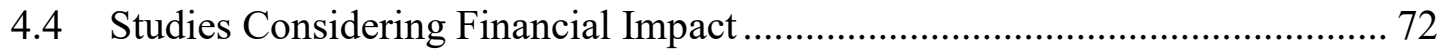

4.5 Main Reference Work-Carless et al (2004) and (2010) .................................. 73

4.6 Discussions Post Carless et al (2004) ............................................................... 78

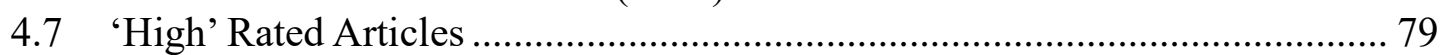

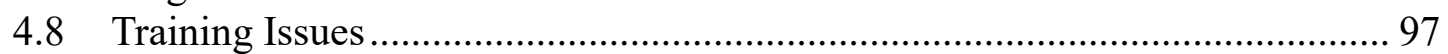

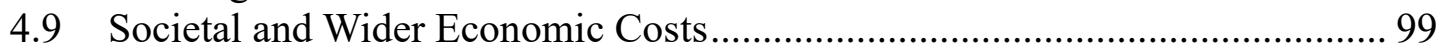

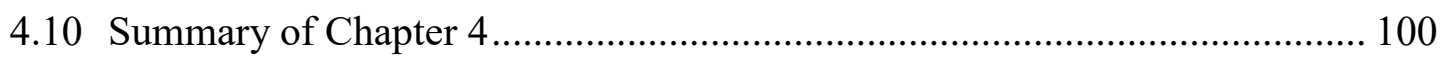

Chapter 5. Methods............................................................................................................ 103

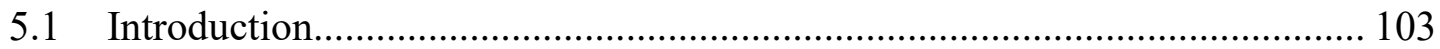

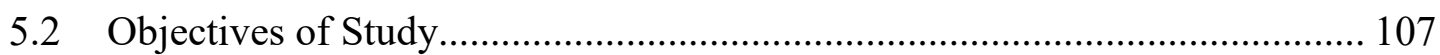

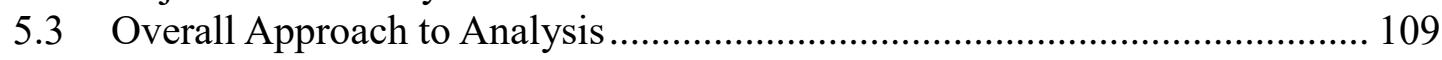

5.4 Dealing with Challenges in Acquiring Information.......................................111

5.5 Preparation-Isolation of Impacts of Cell Salvage .........................................116

5.6 Preparation-Recruiting Study Sites............................................................ 120

5.7 Approach to Designing Study to Measure Patient Group Homogeneity........ 122

5.8 Study to Determine Activity and Actual Costs .............................................. 126

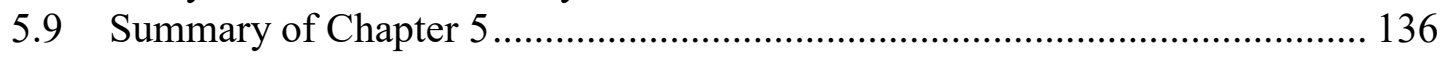

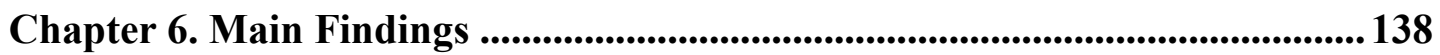

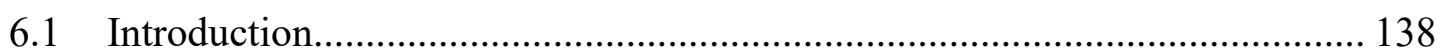

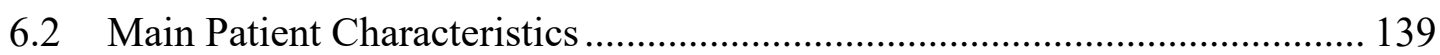

6.3 Healthcare Resource Group (HRG) Analysis ............................................ 140

6.4 Analysis of Post-Operative Hospital Based Activity................................... 147

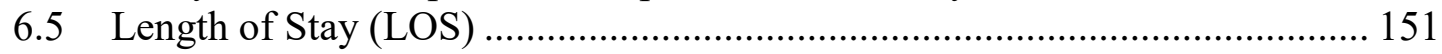

6.6 Comparison with Royal Cornwall Hospitals Patients Not Salvaged .............. 160

6.7 Analysis Where Allogeneic Blood Transfusion Administered ........................ 160

6.8 Financial Impact of Cell Salvage at Royal Cornwall Hospitals NHS

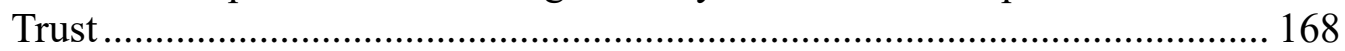

6.9 Comparison of Costs of Salvaging Male Patients ....................................... 174

6.10 Treatment of Depreciation and Opportunity Cost ..................................... 174

6.11 Costs and Income at NHS Blood and Transplant .................................... 175

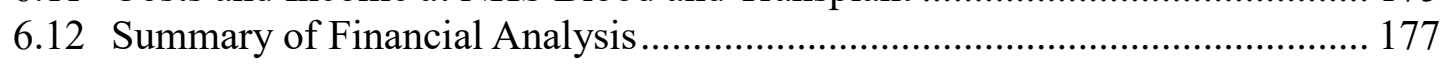

6.13 Development of Donor/Societal Costs Associated with Blood

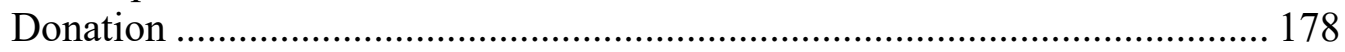

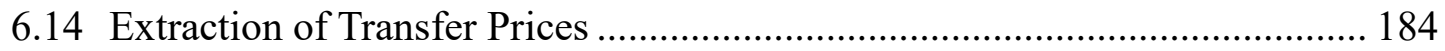

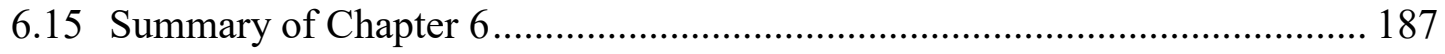




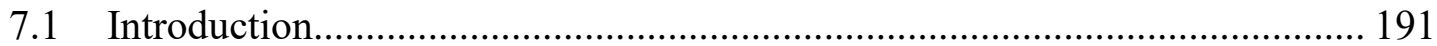

7.2 Objective One: Establish Patient Homogeneity and Compare Data ............. 191

7.3 Objective Two: Evaluation of Cost Impacts and Assessment of the Cost Effectiveness of Cell Salvage ............................................................ 198

7.4 Objective Three: Investigate Other Issues ................................................... 205

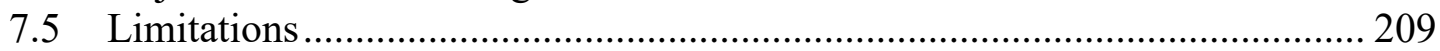

7.6 Reflection and Assessment of Position at April 2018 ................................. 215

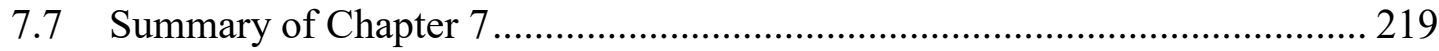

Chapter 8. Conclusions........................................................................................................ 221

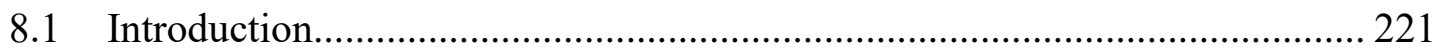

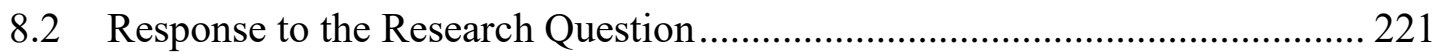

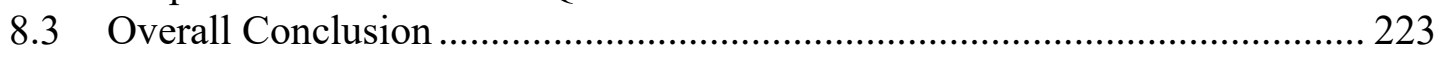

Glossary ...................................................................................................................................... 224

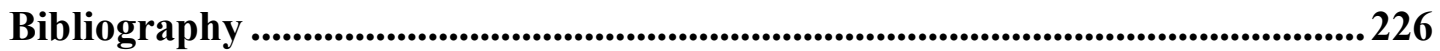




\section{Acknowledgements}

This thesis would have been impossible to develop were it not for the help and support of an awful lot of people. Prof Ceri Phillips from Swansea University provided ongoing support and encouragement from the outset in 2010 up until the present. Dr Dafydd Thomas, Dr Ann Benton and Malcolm Rees (ABM NHS Trust) bounced around my thoughts and ideas prior to commencing. Prof Mike Murphy (NHSBT) and Dr Mike Desmond (Liverpool) added more practical advice. Bev Dawkins at the Princess of Wales Hospital, Bridgend, introduced me to pre-operative assessments well before Patient Blood Management had been rolled out. Bernie Sullivan at Torquay Hospital convinced me how crucial the rehabilitation process was to support a successful outcome.

Joan Jones and Hannah Grainger from the Welsh Blood Service were on hand to support any queries and 'accountant' type questions. Likewise, Alister Jones from NHSBT in Filton provided the same service while I was employed there. Bernie Jones from the Spire Hospital in Bristol supported me with useful comparative data from the private sector and Dr Jon Waters, Dr Mark Yazer and Bob Dyga from UPMC Pittsburgh all gave up time to help me out.

Rob Bradburn, Brigid Newington, Steve Morgan and Dr Tim Wallington from NHSBT supported my initial application and encouraged me through the early days, passing over the baton to Dr Janet Birchall. Steve Brown from the HFMA helped me out in publicising financial issues around blood in the 'Healthcare Finance' magazine and Sharon Ross from NHSBT supported the donor questionnaire. Fiona Boyle (University Hospital Southampton NHS FT) and Jeremy Brinley Codd (Guy's and St Thomas NHS FT) gave me useful background in how the accountants reported blood costs in their general ledgers and costing systems. David Smith from the South West Jehovah's Witness liaison group also kept me posted on developments. More recent support has been gratefully received from Chris Webber from UWE, Tasha Swinscoe, Vanesther Rees and Nathalie Delaney, all from the West of England Academic Health Science Network.

The challenge of collecting the activity data could not have been overcome without the help of Dr Lars Jakt and John Faulds at the Royal Cornwall Hospitals, Dr Sarah Haynes at South Manchester and various individuals associated with the Specialist Elective Orthopaedic Centre.

Big thanks go to my wife, Helen, for her support and putting up with me hiding away in the back room; also, our daughters Mari and Elin who have maintained a polite interest in what I have been doing. My Mum's nursing background meant she kept requesting updates on how the thesis was developing. Sadly, she is not around to see this stage of the thesis.

There are many others at NHSBT, Torbay and Southern Devon NHS FT and the West of England Academic Health Science Network who, in different ways, have directly or indirectly contributed to developing my ideas and understanding. Any errors or omissions are entirely my responsibility. Thank you everyone.

Bernard Crotty

May 2018 


\section{List of Tables}

Table 1. Haemoglobin Levels Indicating Preparedness for Surgery ......................... 13

Table 2. Impact on Allogeneic Requirements of Decrease in Surgical Usage ........... 17

Table 3. Estimate of the Number of Consumables Used in the UK in 2010/11 .........27

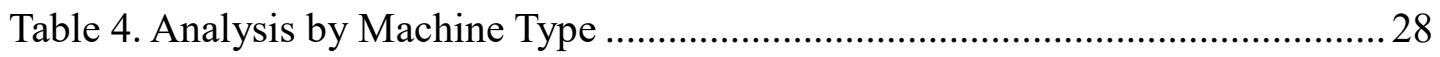

Table 5. Basic Calculation of Savings Avoiding One Allogeneic Blood Transfusion

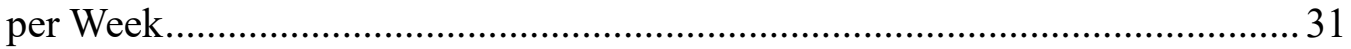

Table 6. Comparison of HRG Procedures in England - Hips v. Knees .................... 38

Table 7. Proportion of Allogeneic Blood Costs to Income in NHS Hospitals ........... 44

Table 8. Cost/Income in the Provision of Allogeneic Blood...................................... 48

Table 9. Standardisation of Reporting of Studies in Economic Evaluation in

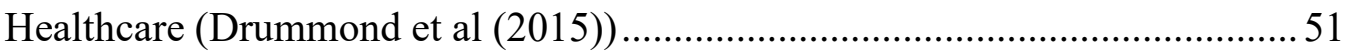

Table 10. Summary of Relevant Cost Concepts....................................................... 60

Table 11. Breakdown of Articles' Country of Origin ................................................... 71

Table 12. Breakdown by Specialty......................................................................... 72

Table 13. Breakdown of Articles by Type/Country of Origin .................................... 72

Table 14. Breakdown of Articles by Specialty and Cost Relevance ......................... 73

Table 15. Breakdown by Specialty by Year .......................................................... 79

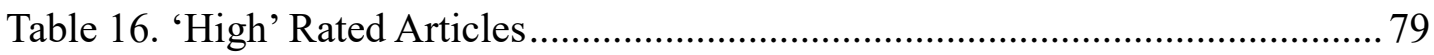

Table 17. Blood Conservation Savings in Ontario ...................................................... 93

Table 18. Summary of Comparative Information Datasets Requested .................... 104

Table 19. Information Required to Compare Pre-Operative Activity Data ............. 105

Table 20. Elective Patients with Length of Stay $>14$ days and Excluded from

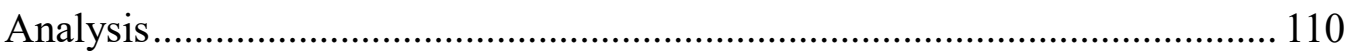

Table 21. Progression of Information Gathering Discussions ................................ 121

Table 22. Summary of Orthopaedic Operations 2010/11 ........................................ 122

Table 23. Non-Trauma Hip Interventions by HRG Code ...................................... 124

Table 24. Summary of Information Required to Analyse Across the Three Hospitals

Table 25. Summary of Key Statistics to be Extracted........................................... 131

Table 26. NHSBT Cost Classification..................................................................... 133

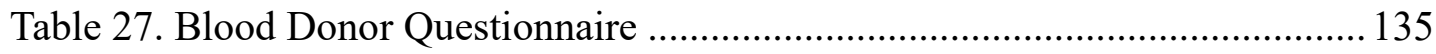


Table 28. Derived Cost of Blood per Patient for Primary Total Hip Replacement

Patients-Financial and Economic Perspective

Table 29. Summary of Patient Statistics Over the Three Organisation (2010/11 Base

Data)

Table 30. Breakdown of Cell Salvage Activity at Royal Cornwall Hospitals 139

Table 31. Analysis of Operations by HRG Category 140

Table 32. Mean Age by Patient by HRG 141

Table 33. Gender Mix of Patient by HRG-Percentage Male Patients

Table 34. Analysis by Gender of Patients $<65$ Years Old Having an Allogeneic

Transfusion

Table 35. Analysis of Cell Salvage on Patients $<65$ Years' Old.

Table 36. Analysis of Mean Pre-Operative Hb Levels by HRG ( $\mathrm{n}=498)$

Table 37. Analysis of Patients with Pre-operative Hb Levels Below WHO Criteria

Table 38. Analysis of Allogeneic Transfused Patients (Pre-Operative Hb Levels below WHO Criteria)

Table 39. Analysis of Mean Post-Operative Hb Levels by Grouped HRG Excluding Allogeneic Transfusions and Excluding Reinfused Patients at Royal Cornwall Hospitals.

Table 40. One Way ANOVA-Comparison of Post-Operative Hb Levels with HRG

Groups 148

Table 41. Split of RCH Patients Without Allogeneic Transfusion

Table 42. Mean Post-Operative Hb Levels for Allogeneic Transfused Patients (no reinfusions)

Table 43. Mean Post-Operative Information for Allogeneic Transfused Patients with

Reinfusions 150

Table 44. Mean Pre- and Post-Operative Hb Levels Excluding Allogeneic

Transfusions and Excluding Reinfused Patients at Royal Cornwall Hospitals $(\mathrm{n}=349)$.

Table 45. Comparison of Mean Length of Stay for Wednesday Surgery (no allogenic transfusions or reinfusions)

Table 46. Comparison of Mean Length of Stay by Gender for Surgery (no allogenic

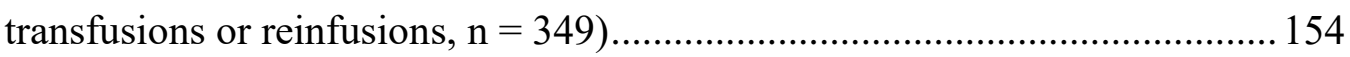

Table 47. Regression on Logarithm of Length of Stay …........................................ 156 
Table 48. Discharge Day and Mean Length of Stay for Patients Having Tuesday

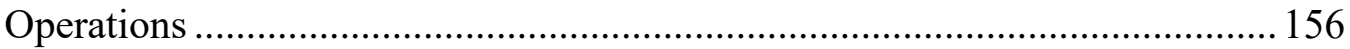

Table 49. Patients Length of Stay for Tuesday Operations .................................... 157

Table 50. Discharge Day and Mean Length of Stay for Wednesday Operations ..... 158

Table 51. Analysis of Length of Stay for Tuesday Discharges ............................... 159

Table 52. Comparison of 33 Patients not Salvaged............................................... 160

Table 53. Number/(Percentage) of Patients Receiving Allogeneic Blood Transfusions 161

Table 54. Number and Mean Length of Stay with Allogeneic Transfusion/No

Reinfusion; Excluding HRG HB12C....

Table 55. Allogeneic Transfusions Undertaken on Patients with Post-Operative Level

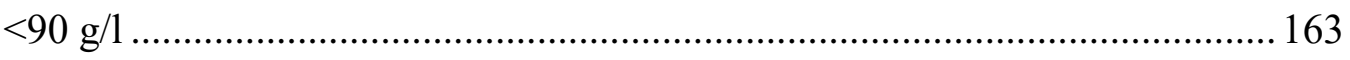

Table 56. Transfusion Rates Excluding HRG HB12C ........................................... 165

Table 57. HRG HB12C Length of Stay Excluding Allogeneic Transfusions and

Excluding Reinfused Patients at Royal Cornwall Hospitals ........................... 166

Table 58. Transfusion Rates by Age and Gender ...................................................... 166

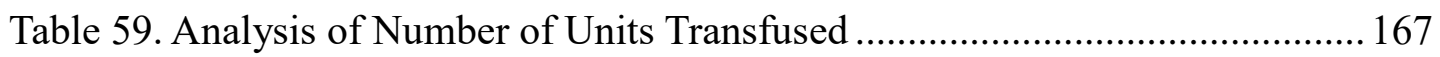

Table 60. Operations by Site and Salvage Machine.................................................. 168

Table 61. Number of Royal Cornwall Patients' Data Collected .............................. 168

Table 62. Number of Royal Cornwall Patients Reinfused after Being Salvaged..... 169

Table 63. Extraction of Primary Hip Element of Cell Salvage Costs ...................... 170

Table 64.Total Allogeneic and Salvaged Blood Costs Including VAT and Transfer

Prices.

Table 65.Running Cost Estimates for Cell Salvage Machines Utilised for Primary

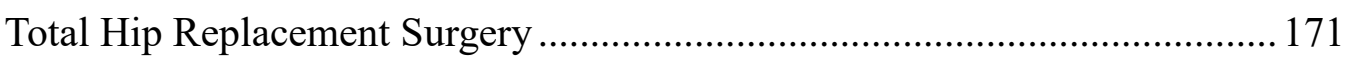

Table 66. Average Blood Cost by Patient/Gender Group....................................... 171

Table 67. Comparison of Average Blood Costs per Operation $(\mathrm{n}=498)$................ 172

Table 68. Summary of Allogeneic Transfused Patients with Cell Salvage/Without

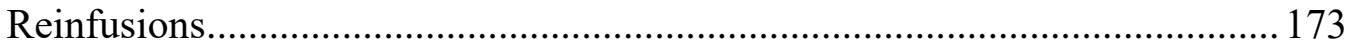

Table 69. Comparison of Discounted Capital Costs ............................................... 175

Table 70. NHSBT Income \& Expenditure from Published 2010/11 Audited Accounts

Table 71. Analysis of the Cost Breakdown of an Allogeneic Unit of Blood ........... 176

Table 72. Comparison of 2003 and 2013 Questionnaire Results ............................ 180 
Table 73. Derivation of Donor Costs and Estimates of Lost Earnings and Production

Table 74. Estimated Total Donor/Societal Cost of a Unit of Allogeneic Blood Including Transfer Prices

Table 75. Derived Cost of Blood per Patient (Including Donor Costs and Transfer

Prices).

Table 76. Adjusted costs for the Provision of Blood Components-NHSBT Annual

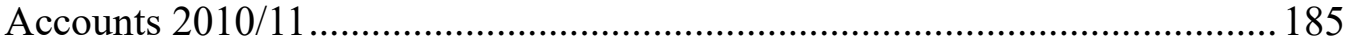

Table 77. Extraction of VAT from Cell Salvage Costs.............................................. 186

Table 78. Derived Unit Cost of Blood per Patient (Excluding Transfer Prices) ...... 187

Table 79. Initial Findings from Analysis................................................................ 187

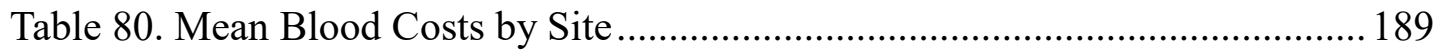

Table 81. Comparison of Transfusion Rate to WHO Defined Anaemia Rate.......... 193

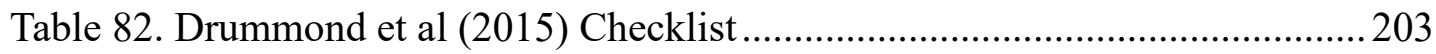

Table 83. Unit Blood Costs for Primary Total Hip Replacement Surgery by Site by Operation. 205

Table 84. Breakdown of HRGs by Site and Extraction of Major HRGs (HB11 Series)

Table 85. Reworked NHSBT 2010/11 Annual Accounts Totals to Verify Internal

Market Price of An Allogeneic Unit 


\section{List of Figures}

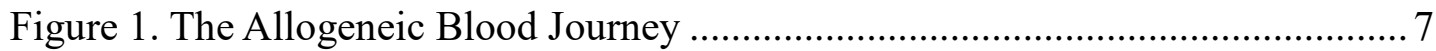

Figure 2. Supply of Allogeneic Blood to Hospitals in England ................................. 15

Figure 3. Analysis of Allogeneic Hospital Blood Use Supplied by NHSBT ............. 17

Figure 4. Intraoperative Cell Salvage Circulation...................................................2 22

Figure 5. Intraoperative Cell Salvage Consumables Used in the UK ....................... 27

Figure 6. Enhanced Recovery Treatment Flow ........................................................ 35

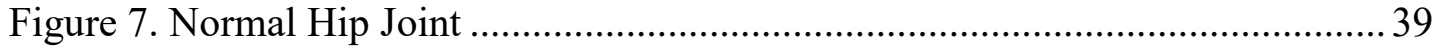

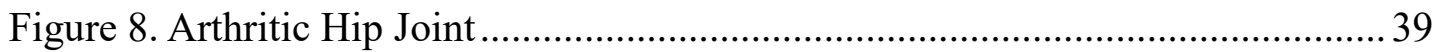

Figure 9. Successful Total Hip Replacement ....................................................... 40

Figure 10. Allogeneic Unit Price Since 2008 (unadjusted for price inflation) .......... 42

Figure 11. Impact of Clinical Coding on Trust Income - Elective Hip Replacement44

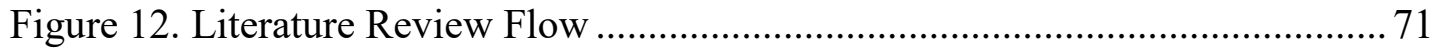

Figure 13. Shander et al (2012) Summary of Patient Blood Management .............. 118

Figure 14. Cell Salvage Cost Groupings ……...................................................... 127

Figure 15. Main Approach to Comparisons .................................................................. 128

Figure 16. Analysis of Percentage of Total Hip Replacement Operations by HRG by

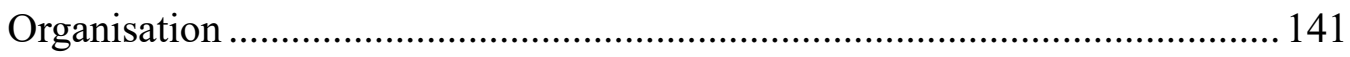

Figure 17. Mean Pre-Operative Hb Levels Across Three Sites .............................. 144

Figure 18. Mean Post-Operative Hb Levels Across Three Sites.............................. 148

Figure 19. Mean Length of Stay (all patients) ....................................................... 152

Figure 20. Mean Length of Stay (all patients) ..................................................... 153

Figure 21. Mean Length of Stay for Patients- 'Baseline' Position (no allogenic transfusions or reinfusions, $\mathrm{n}=349$ )

Figure 22. Mean Post-Operative Hb Level With and Without an Allogeneic

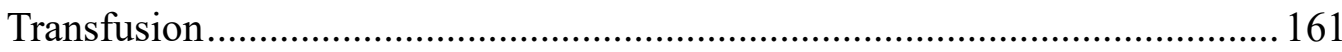

Figure 23. Post-Operative Hb Levels with an Allogeneic Transfusion.................... 163

Figure 24. Mean Length of Stay Without Allogeneic Transfusion ......................... 164

Figure 25. Mean Length of Stay with Allogeneic Transfusion ............................... 164 


\section{Abbreviations}

\section{Abbreviation Phrase}

AAA

$\mathrm{AABB}$

AAGBI

$\mathrm{ABM}$

$\mathrm{ABC}$

ACDA

AHSN

$\mathrm{ANH}$

ANOVA

BBT

BMJ

CABG

$\mathrm{CC}$

CCG

CIPFA

COE

$\mathrm{CS}$

CSAG

$\mathrm{DH}$

EAT

EBA

ECM

EPO

ERP

$\mathrm{Hb}$

HEV

HFMA

HMO

HMRC

HRG

HSJ

HTA

HTC

ICS

ICU

IPG

JW

LOS

NBS

NBTC

NCG
Abdominal Aortic Aneurysm

American Association of Blood Banks

Association of Anaesthetists in Great Britain and Ireland

Abertawe Bro Morgannwg NHS Trust

Activity Based Costing

Anticoagulant Citrate Dextrose Solution 'A'

Academic Health Science Network

Acute Normovolaemic Haemodilution

Analysis of Variance

Better Blood Transfusion

British Medical Journal

Coronary Artery Bypass Graft

Comorbidities and Complications

Clinical Commissioning Group

Chartered Institute of Public Finance and Accountancy

Council of Europe

Cell Salvage

Cell Salvage Action Group

Department of Health

Emergency Autotransfusion

European Blood Alliance

Electronic Cross Match

Erythropoietin

Enhanced Recovery Pathway

Haemoglobin

Hepatitis E Virus

Healthcare Financial Management Association

Health Maintenance Organisation

Her Majesty's Revenue \& Customs

Healthcare Resource Group

Health Service Journal

Health Technology Assessment

Hospital Transfusion Committee

Intraoperative Cell Salvage

Intensive Care Unit

Interventional Procedures Guidance

Jehovah's Witness

Length of Stay

National Blood Service

National Blood Transfusion Committee

National Commissioning Group for Blood and Blood Products 


$\begin{array}{ll}\text { Abbreviation } & \text { Phrase } \\ \text { NHS } & \text { National Health Service } \\ \text { NHSBT } & \text { NHS Blood \& Transplant } \\ \text { NI } & \text { National Insurance } \\ \text { NJR } & \text { National Joint Registry } \\ \text { OBOS } & \text { Online Blood Ordering System } \\ \text { ODP } & \text { Operating Department Practitioner } \\ \text { ONS } & \text { Office for National Statistics } \\ \text { OT } & \text { Occupational Therapist } \\ \text { PAD } & \text { Pre-Operative Autologous Donation } \\ \text { PBM } & \text { Patient Blood Management } \\ \text { PbR } & \text { Payment by Results } \\ \text { POCS } & \text { Postoperative Cell Salvage } \\ \text { PROMs } & \text { Patient Recorded Outcome Methods } \\ \text { QALY } & \text { Quality Adjusted Life Year } \\ \text { RAAA } & \text { Ruptured Abdominal Aortic Aneurysm } \\ \text { RBC } & \text { Red Blood Cells } \\ \text { RCH } & \text { Royal Cornwall Hospitals } \\ \text { RCT } & \text { Randomised Control Trial } \\ \text { SABM } & \text { Society for the Advancement of Blood Management } \\ \text { SAGM } & \text { Saline Adenine Glucose } \\ \text { SCRM } & \text { Scottish Centre for Regenerative Medicine } \\ \text { SHA } & \text { Special Health Authority } \\ \text { SHOT } & \text { Serious Hazards of Transfusion } \\ \text { SLR } & \text { Service Line Reporting and Management } \\ \text { SOC } & \text { Specialist Elective Orthopaedic Centre } \\ \text { SWLEOC } & \text { South West London Elective Orthopaedic Centre } \\ \text { THR } & \text { Total Hip Replacement } \\ \text { UPMC } & \text { University of Pittsburgh Medical Centre } \\ \text { VAT } & \text { Value Added Tax } \\ \text { vCJD } & \text { Variant Creutzfeldt-Jakob disease } \\ \text { VED } & \text { Vehicle Excise Duty } \\ \text { WBS } & \text { Welsh Blood Service } \\ \text { WHO } & \end{array}$




\section{Chapter 1. Introduction and Background}

\subsection{Introduction}

Cell salvage is a surgical technique whereby a patient's shed blood is collected using a drainage system during or after an operation. The blood is then filtered, and the blood cells washed to remove debris. The filtered blood is then reinfused into the patient. It is claimed (e.g. Waters et al (2007) and Carless et al (2010)) that utilising cell salvage will reduce the need for a patient to have a blood transfusion using donated (allogeneic) blood from a blood donor. A transfusion using a patient's own blood is termed an 'autologous transfusion'; this term is often shortened to 'autotransfusion' in the US.

This chapter will:

- Introduce the technique of utilising allogeneic blood transfusions and outline their use and application;

- Introduce the differing interpretations of costs associated with allogeneic blood from a financial and economic perspective;

- Describe the role of NHS Blood \& Transplant (NHSBT) and its predecessor organisations in the development of the blood transfusion service, primarily in England;

- Outline the English healthcare financial tariff system and the impact of the internal market for allogeneic blood on the hospital blood costs;

- Highlight the potential alternatives to allogeneic blood transfusions and their development and support across the National Health Service (NHS) along with other allogeneic blood avoiding techniques;

- Introduce the technique of cell salvage, its development and application in the total hip replacement surgery environment. 


\subsection{Challenges of Cell Salvage as Subject to Analyse}

The researcher's background is as a Chartered Public Finance Accountant who has worked in a number of London hospitals as a management accountant and, from 1998 to 2013, in various roles at NHSBT. Until 2017 he was also a regular blood donor and saw at first hand the changes in the blood donor environment since first donating blood in 1980. In the early 1980s, a clinician (doctor or nurse) had to be present at a blood donation session. By the early 2000 s only a registered phlebotomist needed to be present to insert the needle to draw the donor's blood.

Managing the finances of the blood bank budgets in two hospitals gave the researcher an insight into issues such as stock management of allogeneic blood and the costs associated with its use. It was not until the researcher joined NHSBT in 1998 that he became aware that ways of avoiding a transfusion were possible. The national directive 'Better Blood Transfusion' (BBT1) had recently been published (para 1.11) which recommended that cell salvage be considered and adopted by individual Hospital Transfusion Committees (HTCs). The researcher then began to think through and discuss the potential financial impacts of cell salvage from differing NHS backgrounds. In April 1999 the NHSBT charge for an allogeneic unit was virtually doubled to around $£ 80$ per unit; reflecting the cost of rolling out leucodepletion (the removal of the white cells from donated blood, para 1.14). The discussions with clinicians included the significant potential savings that could accrue to hospitals from avoiding an allogeneic transfusion. These discussions held a resonance with the researcher who saw the 'text book' ideas of internal charging mechanisms he had learned while training for his accountancy exams. There was, however, a wider publicsector dimension with NHSBT effectively levying an internal charge that also included transfer prices such as VAT and national insurance. There were additionally costs that donors incurred and potential costs to the wider society by loss of productive time that the donor would generate by donating blood. The donors would also derive satisfaction of providing a 'gift of life'; this element was also relevant and needed to be included in the discussions. 
This combination of potentially competing interests within the NHS and the wider society sparked the researcher's interest and it was clear that there were competing approaches from both a financial and economic perspective. Given he had a young family around 2000/2001 it was several years before he could devote sufficient time to pursuing this interest in investigating the issues in depth.

\subsection{Approach to Studying Cell Salvage}

The researcher had been involved in rudimentary specialty costing analysis work in his time as a management accountant up to 1998 and kept in touch with developments via his continuing professional development programme. In 2004 a Cochrane Review (Carless et al (2004)) noted the level of bias in most of the published reviews on cell salvage. The researcher felt that a study with more academic rigour would circumvent the challenges and perceptions of bias that Carless et al (2004) highlighted. This, in turn, would lead to additional credibility and a wider debate.

The researcher also felt that the financial discussions around the costs of cell salvage were too narrow and felt it would be advantageous to approach the costing work from a fresh angle. Healthcare Resource Groups (HRGs-a measure of classifying procedures into groups requiring similar levels of resource input) had been rolled out across NHS trusts as part of the English NHS tariff-based system. The researcher felt that HRG information could be utilised to minimise the allegations of selection bias and add more confidence on homogeneity and cross hospital comparison. This comparison had not been undertaken previously in any study on cell salvage.

Academic support was required, as the researcher felt his background as an accountant would need a health economics input. He felt that a project to understand the costs of cell salvage across the NHS would bring new knowledge to allow a wider debate and support the understanding of its impact in a wider, rather than local hospital-based, setting. The academic support would be a base for the extensive collaborative research and information gathering that would be required. NHSBT and the hospital trusts focus on financial issues relating to blood (both allogeneic and salvaged) from a resource perspective, rather than 
from a wider economic perspective. The study therefore needed to encapsulate both interpretations in order to address the challenges from both a professional accounting and an academic perspective.

Cell salvage was an area that was indirectly related to the researcher's day job and, at the time of commencement (2008), the vast majority of discussion favoured the roll out of cell salvage programmes. An academic study from a new and wider angle therefore seemed opportune.

\subsection{Allogeneic Blood and Blood Transfusions}

Blood comprises several components. The main components, according to the Department of Health (DH) website 'NHS Choices' (accessed 27 March 2014), are:

- Red Cells. Red cells transport oxygen around the body and prevent the patient becoming anaemic; this is where oxygen levels are depleted, slowing down the function of the various organs.

- Platelets. Platelets are blood cells that work to ensuring there is sufficient clotting of the blood when a patient is bleeding. Increasingly platelets are collected by a specific donation process known as 'apheresis'. The alternative is for 'pooled platelets' where, on average, four blood donations will have the platelets extracted to form one adult therapeutic dose of platelets.

- Plasma. Plasma is mainly water carrying proteins, electrolytes and other clotting agents.

- White cells. White cells are cells of the immune system, used to fight infections. Following research into variant Creutzfeldt-Jakob disease (vCJD) in the late 1990s, the white cells are now removed from allogeneic blood. This process, known as leucodepletion, contributed significantly to the increased costs of blood collection and processing from 1998.

An 'average adult' will have approximately 5.0 litres of blood circulating in their body. This will vary according to the person's weight/size. In the UK, a typical blood donation requires around $470 \mathrm{mls}$ of blood being taken. Information material produced for blood donors in the UK highlights that the maximum amount of blood 
donated will be $13 \%$ of circulating blood by volume (see 'How the Body Replaces Blood' on www.blood.co.uk accessed 28 Oct 2014).

The prime reason for an allogeneic blood transfusion during and after surgery is to treat anaemia (NHS Choices website accessed 27 March 2014), resulting from insufficient oxygen carrying red cells circulating in the body. Anaemia can be caused by blood loss (this is the main reason in the surgical environment), a medical condition such as various types of cancers, or a specific condition such as sickle cell anaemia.

There are also a number of other issues that relate to infections such as malaria or a toxin overload such as alcohol poisoning that can be treated with an allogeneic blood transfusion.

There is an ethical issue in attempting to assess the effectiveness of allogeneic blood as no clinician would wish to refuse a transfusion of allogeneic blood to a sick patient to make the comparison of benefits from having/not having an allogeneic transfusion. Beliaev et al (2011) circumvented this issue by undertaking a retrospective study comparing the outcomes of 103 Jehovah's Witness (JW) patients who refused allogeneic transfusions against the same number of patients who had received transfusions. The authors concluded that, inter alia, mortality was reduced by $94 \%$ with an allogeneic transfusion. The authors stressed that the study was not a randomised control trial (RCT) but highlighted that "it would be unethical to conduct a(n) RCT in patients with severe anaemia to investigate an effect of (allogeneic) transfusion(s) on mortality". The relationship between transfused blood and treatment of anaemia is therefore not disputed.

Blood donor recruitment campaigns around the world highlight that blood donation, along with organ donation, is 'the gift of life' (US Red Cross website http://www.redcross.org/what-we-do/blood-donation accessed 28 Oct 2014). In a medical environment, this is true as there is no alternative to allogeneic blood. An article in the Guardian newspaper by James Meikle (24 May 2013) on permanent blood donation clinics sums this up succinctly by quoting the NHSBT Medical Director saying, "We expect to see an increase in demand for blood over the next 10 years as a result of an ageing population requiring more complex procedures such as joint replacements and cancer therapies". There are no alternatives for a cancer 
patient who requires an allogeneic blood transfusion; however, there are techniques available to minimise allogeneic blood transfusions in joint replacements.

NHSBT is responsible for the collection, processing, testing, storage and issue of allogeneic blood and related components in England. It is one of the few remaining Special Health Authorities following several reorganisations across the English NHS.

\subsection{World Health Organisation Resolution on Allogeneic Blood}

The World Health Organisation WHO 63.12 (2010) Adopted Resolution urges member states to establish and maintain the capacity, safety and quality of donated blood products. It also stresses member states should "promote the availability of transfusion alternatives including, where appropriate, autologous transfusion and patient blood management". The directive additionally stresses that "before surgery every reasonable measure should be taken to minimise the patient's blood loss and to harness and optimise the patient-specific physiological tolerance of anaemia". The report effectively views the provision of allogeneic blood and avoidance techniques as equal responses to the management of anaemia during and after surgery.

The issues behind this overarching statement by the WHO Adopted Resolution will be covered in this introductory chapter.

\subsection{Allogeneic Blood Journey - From Donor to Patient}

The journey 'from vein to vein'; from donor to patient, is shown in figure 1 below. When a donor donates, his/her blood is drained into a PVC bag. This has a built-in filter with tubing leading to a second bag. When the filter is activated at the processing centre, the blood will filter into the second bag. Both bags will have a unique bar code identifying the donor. All this is linked to NHSBT's PULSE IT and blood tracking system. 


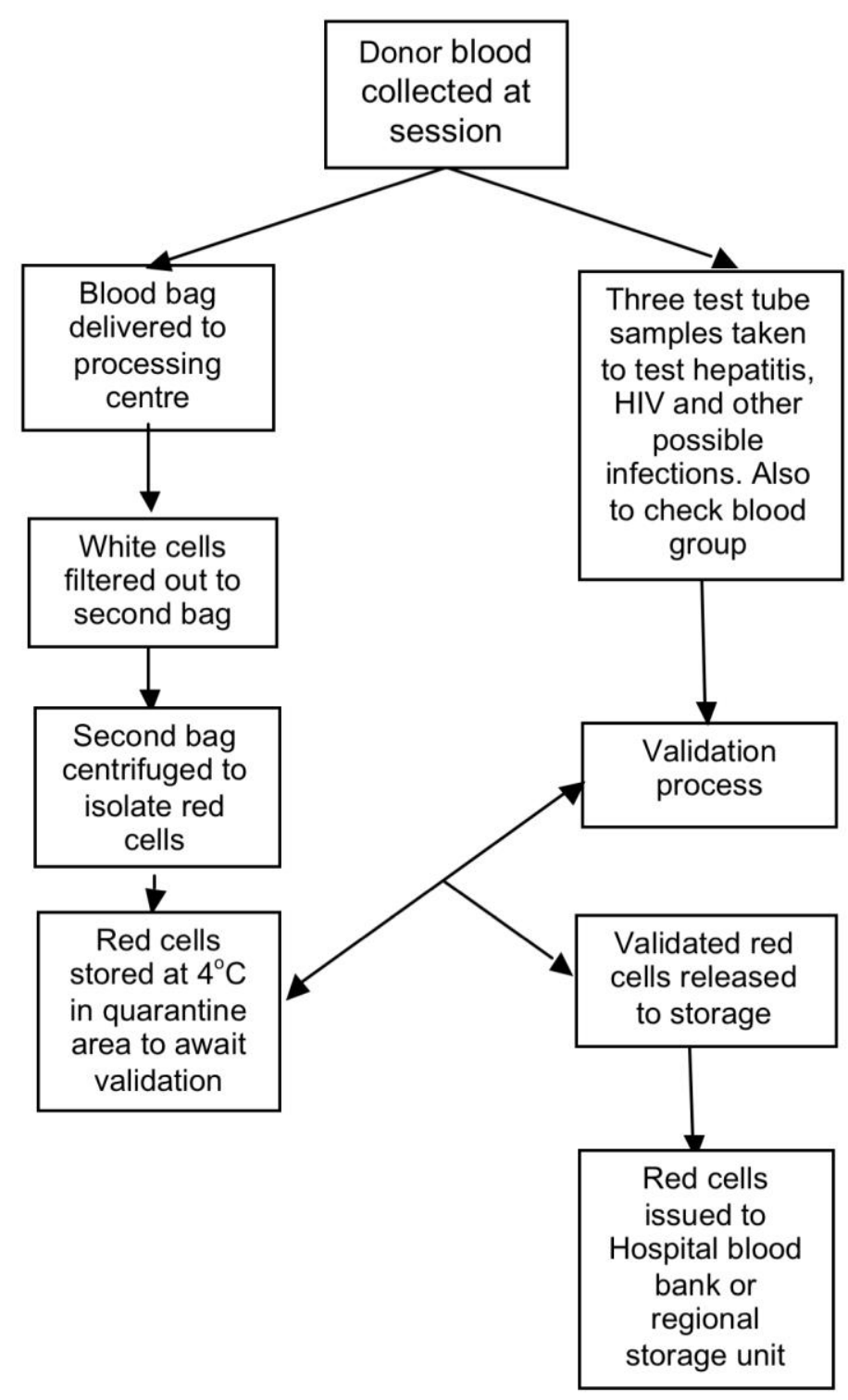

NHSBT relies on a complex logistical infrastructure to transport the allogeneic blood around the country. In the Birmingham area, for example, the allogeneic blood is collected from the various sessions in cool boxes and taken to a stock holding unit in Edgbaston, South Birmingham, where the blood is then stored, awaiting additional blood from other sessions in, for instance, Coventry. Once all deliveries have been received, the blood (up to 500 units) is transported in a refrigerated container lorry to the Filton Blood Centre, near Bristol. This may be between 3.00 a.m. to 5.00 a.m. in the morning following the day of the donations. The blood bags then enter the production cycle, which commences by draining the blood into a separate blood bag 
and using a centrifuge to separate the contents into its constituent elements. The associated test tube samples will be tested by automated analysers. In the event of any positive test result or irregularity arising the blood bag can be isolated in the quarantine area while further tests on the samples are undertaken.

Throughout the cycle the blood is never exposed to the atmosphere, ensuring it maintains the required 'shelf life' of up to 35 days (NHSBT website accessed 28 October 2014). The process is now highly automated and the recent NHSBT strategy has been to focus the processing and testing functions at Manchester, Filton and Colindale in North London. Testing functions (using the three test tubes) can be undertaken separately from the processing functions and the NHSBT contingency plans allow testing to be undertaken additionally at Newcastle and Sheffield if required.

Once an allogeneic unit has passed through the process described in figure 1 the majority remains in stock at one of the three main NHSBT centres (Filton, Colindale or Manchester). Further stocks are dispatched to satellite centres such as Cambridge, Sheffield and Plymouth. The rationale being that no English hospital is more than two hours' drive from a stockholding of allogeneic blood.

\subsection{Disadvantages of Allogeneic Blood Transfusions}

An allogeneic blood transfusion is still a foreign body entering a patient. There is never a perfect blood match. Various 'foreign' antibodies will be absorbed by a patient who has recently undergone surgery and allergic reactions can develop (see the American Cancer Society www.cancer.org website, accessed 28 October 2014). A BBC report entitled 'Blood Donors 'Passing on Hepatitis E' (28 July 2014) highlighted a study in the Lancet that reported 1 in 3,000 blood donations were contaminated with the Hepatitis E virus (HEV). While HEV is not a life-threatening condition it would not, however, support a patient's speedy recovery if $\mathrm{s} /$ he received a contaminated donation. The British Liver Trust website www.britishlivertrust.org (accessed 13 Aug 2014) noted that the impact of HEV is relatively mild unless the patient has a pre-existing liver problem or is pregnant. 
Cost is cited as a disadvantage. An allogeneic unit was priced at $£ 122$ in $2017 / 18$ with the median usage for an NHS hospital being around 6,000 units in a year. The split is approximately 2:1 for medical use of allogeneic blood over surgical requirements (see para 1.10).

There is always the risk of matching an allogeneic unit with the wrong patient and invoking adverse reactions through incompatible blood; this is classed as an NHS 'never event'. The Serious Hazards of Transfusion (SHOT) report for 2012 reported the relative risks of major morbidity as being 46.5 per million of blood components issued. The corresponding figure for mortality was 3.1 per million components used. Additionally, there is also still the theoretical risk of vCJD noted in the SHOT report and the cost associated with the removal of the white cells from allogeneic blood through the leucodepletion process (para 1.4); the indications are that the white cells are the carriers of vCJD. The theoretical risk remains even after the implementation of the leucodepletion process.

Nearly every country in the world has at least one organisation responsible for the collection of allogeneic blood from donors. Not widely publicised is the fact that many countries will refuse to accept blood from donors who have lived in the UK for a period between 1980 and 1996. This is due to the potential risk that donors are still incubating vCJD. Restrictions vary from country to country. The Republic of Ireland, for instance, refuses donations from anyone who has lived for more than one year in the UK (see www.giveblood.ie/become a donor, accessed 18 March 2017). Australia and New Zealand are even more restrictive: potential donors are refused if they have spent over six months at any time living in the UK, France or the Republic of Ireland (see www.nzblood.co.nz/give blood and www.donateblood.com.au, accessed 18 March 2017). While there is still no test to detect whether a donor is incubating vCJD the avoidance of an allogeneic transfusion would prevent any potential spread.

Although shortages of allogeneic blood are now rare, there is still a risk that they might occur. In periods of lower demand, e.g. around Christmas and the summer holiday season, the average age of the allogeneic blood issued to hospitals will tend to be older as stocks are run down more slowly. Older blood will have depleted more oxygen than fresher allogeneic blood. Some studies have shown (e.g. Sanders et al 
(2011)) that there is a strong correlation between older blood (defined in the study as over 14 days old) and longer post-operative length of stay. NHSBT ensures the blood issued to hospitals is significantly below the 35-day threshold. As a result of the recent investments in infrastructure and stock management systems, the issued blood is rarely over 14 days old. The exact age of the blood issued will vary in relation to stock levels and current demand. Stock levels were published weekly on www.blood.co.uk with a key performance indicator being the number of days of stock of each blood type held. In February 2015, the average stock level for $\mathrm{O}+$ and $\mathrm{A}+$ (the two most common types covering two-thirds of the population) was just under seven days. This information is now not regularly available on the National Blood Service website since the level of public interest in national stocks of allogeneic blood has waned.

More recently Waters (2013) has highlighted that more emphasis should be placed on the patient's bleeding rather than the allogeneic transfusion. His editorial in the US publication 'Transfusion' noted that recent evidence is "...showing that many (allogeneic) transfusions provide no benefit to the recipient". Older, more ill, patients will require more transfused blood as they cannot withstand blood loss as effectively as younger, fitter patients. The implication, according to Waters (2013), is that the blood loss may be the main contributor to an increased length of stay, rather than the allogeneic transfusion given.

An article in the British Medical Journal, Goodnough and Murphy (2014) commented similarly to Waters (2013), noting 48\% of hip replacement patients were inappropriately transfused in 2007. This is consistent with a survey at the Gloucestershire Hospitals NHS Foundation Trust (Joy and Bennet (2012)) that recorded the corresponding figure at $46 \%$. These studies effectively questioned the requirement for a high proportion of surgical blood transfusions. The disadvantage lies in the associated cost of the unnecessary allogeneic blood transfused.

\subsection{History of Blood Transfusions}

This section will briefly outline the development of blood transfusions over the past century and examine the changing trends in blood usage. The focus of the study will be on England as, from May 2016, all Welsh allogeneic blood requirements became the responsibility of the Welsh Blood Service, based in Cardiff. 
This historical section is mainly summarised from Thomas et al's (2005) 'A Manual for Blood Conservation' and NHSBT's published literature on www.blood.co.uk. Allogeneic blood transfusions were first attempted, with limited success, in the late 1800s. In 1900 Karl Landsteiner discovered the ABO blood grouping system that identified the different blood groups, allowing further research into allogeneic blood transfusions, especially into the compatibility of the various types. During World War One US surgeons developed the use of anti-coagulants to prevent donated blood clotting. This led to the idea of developing blood 'depots' in strategic locations however the standards of storage were not sufficient to maintain the quality of the donated blood, provoking adverse reactions that led to the 'depot' system falling out of favour.

The first civilian unremunerated donor panel was developed in Camberwell, South London, in 1921 by Percy Lane Oliver. When a hospital needed blood, they would contact Oliver, who would liaise with the donor to go to the hospital. The idea of a 'blood bank' was still in its infancy and further attempts to develop this were introduced during the Spanish Civil War from 1936.

Necessity, due to the Second World War, forced through plans to centralise blood collection and allow its speedy passage to wherever it was required. This proved a success and the National Blood Transfusion Service in England \& Wales was set up in 1946 with the American Association of Blood Banks following in 1947.

NHSBT was formed in 2004 and existed previously as the National Blood Service. Prior to 1994 the responsibility for the supply of allogeneic blood lay with the 14 English regional health authorities and the Welsh Blood Service.

Today, the approach to collecting blood from donors in the UK has changed little from the early 1950s. Blood donors are still unremunerated and there remains a high level of altruistic feelings recorded in donor surveys. An article in The Economist (16 February 2011) entitled 'Blood, Not Money' noted, “Blood donors are stalwarts of the voluntary sector" and suggested that there were two main reasons for giving blood. These are either for altruistic reasons or so that donors, themselves, may benefit from receiving future allogeneic blood transfusions; effectively giving now to allow them to receive in the future. 
Donors have the option of donating in city centre locations ('static sites'), in donation sessions in community venues such as village halls, at the workplace or other locations using NHSBT's fleet of 'bloodmobiles'. These are articulated lorries that hold up to six donor beds to allow donations in any location large enough to accommodate the lorries.

\subsection{Application of Allogeneic Blood Transfusions}

Allogeneic blood is used in the three environments of medical, surgery and obstetrics. This thesis will focus on the use of blood in the surgical environment where blood loss volumes are higher. Within the medical environment there is currently no alternative for allogeneic blood for treatment of conditions relating to anaemia. Cell salvage cannot therefore be used as a treatment. Synthetic blood is a number of years' away, but some developments are happening. For instance, the Scottish Centre for Regenerative Medicine (SCRM) has announced a funding package to continue research into the manufacture of blood via stem cells. The plans are for "...the process to be scalable for manufacture on a commercial scale, with the first in-man trial taking place by late 2016" (SCRM website http://www.crm.ed.ac.uk accessed 14 January 2016). At May 2018 there was no update on this trial. An additional development was announced on 24 March 2017 by the University of Bristol. This was publicised as "Discovery Enables 'Mass Produced Blood"”. See www.bbc.co.uk/news/health-39354627, accessed 24 March 2017.

Within obstetrics the most common area requiring blood transfusions is caesarean sections. There is high blood loss and any blood sparing drugs are not used in order to prevent any issues with the unborn child.

Within surgery, allogeneic blood usage has fallen markedly over the past 10 years (para 1.10). Developments in more minimally invasive surgical techniques that result in less blood loss and initiatives such as the DH 'Better Blood Transfusion' (BBT) programme have led to a fall in allogeneic blood usage across the UK (para 1.13). The first BBT initiative in 1998 championed the use and development of cell salvage.

Older surgical patients are more likely to require an allogeneic blood transfusion. A survey undertaken on patients who received transfusions in the North East of 
England estimated the average age of a recipient of allogeneic blood as being 62.7 years' old (Wells et al (2002)).

The key measure for anaemia is the haemoglobin $(\mathrm{Hb})$ level, measured in grams per litre $(\mathrm{g} / \mathrm{l})$ of blood. The World Health Organisation (WHO) indicator is that patients have sufficient iron levels (i.e. they are not anaemic) when they fall above the thresholds in Table 1 below:

Table 1. Haemoglobin Levels Indicating Preparedness for Surgery

Source: WHO indicators of anaemia

\begin{tabular}{|l|r|}
\hline & \begin{tabular}{l} 
Hb $\quad \begin{array}{c}\text { Level } \\
\text { Less Than }\end{array}$ \\
\hline Males
\end{tabular} \\
\hline Females & $130 \mathrm{~g} / \mathrm{L}$ \\
\hline WHO indicators of anaemia
\end{tabular}

Drugs are now widely administered to minimise blood loss in surgery and lower the requirements for an allogeneic blood transfusion. Tranexamic acid is a drug endorsed by the $\mathrm{DH}$ as the recommended anti-fibrinolytic (blood clotting) agent. The increased use of tranexamic acid has had a significant impact on cell salvage usage. The Chief Executive Officer of the cell salvage machine manufacturer, Haemonetics, Brian Concannon, was quoted in the US investors' website 'Seeking Alpha' as saying, “..we're now seeing a trend that is working against the use of OrthoPat disposables; the growing use of tranexamic acid...that obviates the need for transfusion for some orthopaedic procedures" (29 July 2013 investor conference call). The notes further quote the Haemonetics Chief Finance Officer (Chris Lindop), in relation to the postoperative cell saver OrthoPat machine, as saying, "OrthoPat disposables revenue of $\$ 6$ million was down $10 \%$ in the quarter. The increased use of tranexamic acid and lower transfusion triggers by hospital customers are the market challenges for OrthoPat". In the same article Haemonetics noted that forecast revenues would be lower, but they planned to issue a new machine, the 'OrthoPat Advance' and that "...We expect benefits from introducing the OrthoPat Advance will be more than offset by these market declines and our expectations reflect this trend". Tranexamic acid costs approximately $£ 1-£ 2$ per dosage and therefore has the public acknowledgement of Haemonetics that its use is decreasing associated cell salvage product sales. The OrthoPat Advance has undergone clinical trials but is still not advertised (14 February 2018) on the Haemonetics website. 
Haemonetics still advertise the OrthoPat cell salvage machine. Appendix 1 shows a copy of the advertising material that highlights allogeneic blood has "a price of up to 1,400 USD". This price is quoted in various peer reviewed academic studies.

There is a rough rule of thumb that a unit of allogeneic blood may improve the patient's $\mathrm{Hb}$ level by $10 \mathrm{~g} / \mathrm{L}$ (McClelland (2007) page 8) though there is no definitive study in this area. Contrary to general beliefs, $60 \%$ of allogeneic blood is given to patients on the ward while they are recovering after their operation (Thomas et al 2005), rather than in the operating theatre. Hb levels are monitored and clinicians often prescribe two allogeneic units if the patient's $\mathrm{Hb}$ level falls below a 'transfusion trigger' point of $80 \mathrm{~g} / \mathrm{L}$. Basing the allogeneic transfusion on a specific point is now discouraged (Better Blood Transfusion initiatives and UK Patient Blood Management guidance). Clinicians are encouraged to view the state of the patient's health holistically and e.g. a fit male of around 55 years could generally withstand a temporarily low $\mathrm{Hb}$ level without the need for an allogeneic transfusion (e.g. Shander et al (2012)).

\subsection{Allogeneic Blood Marketing/Collection and Usage in England}

Male blood donors can donate blood up to four times a year, while female donors can donate up to three times a year (www.blood.co.uk). NHSBT has a national marketing function, focusing on recruiting and retaining donors. The 'village hall' approach, where a collection team spends a day in a rural community building to collect a small volume of donations (as few as 15-20) is dwindling. The strategy is now based on quick throughput of a high volume of donors to collect at least 80 units in a single donation session. The researcher donated at a blood donation session on 30 October 2014 in Torquay. Donor slots were available for $53 / 4$ hours in order to achieve the session target of collecting 115 units. These sessions will often be open in the evening to catch donors on their way home from work. Communications and session bookings are supported by call centres run by the outsourcing company, Teleperformance. Modern social media shares details of the local donation session availability. This approach can be intensified or relaxed to meet the demand patterns and ensure that NHSBT's national target of eight days of blood stocks is maintained. 
A recent NHSBT initiative has been to focus on the 'class of 96'. These are young donors who, in 2014, were at least 17 years' old. They are eligible to give blood and were born after the changes in legislation on the treatment of meat following the vCJD issues in the 1980s and 1990s. The theoretical risk of their allogeneic blood being potentially tainted by vCJD noted previously does not therefore apply to younger donors due to the changed legislation affecting the handling and preparation of raw meat for sale. Initiatives such as the 'class of 96' are costly. In terms of both targeting and collection the 'churn' rate is relatively constant, and the long-term strategy is to recruit and retain younger donors who will be invited to donate more often. This cohort of the 'class of 96' donors is being followed as part of an internal study by NHSBT.

Figure 2 below shows the number of allogeneic blood units collected along with the number of allogeneic units issued to hospitals.

\section{Figure 2. Supply of Allogeneic Blood to Hospitals in England}

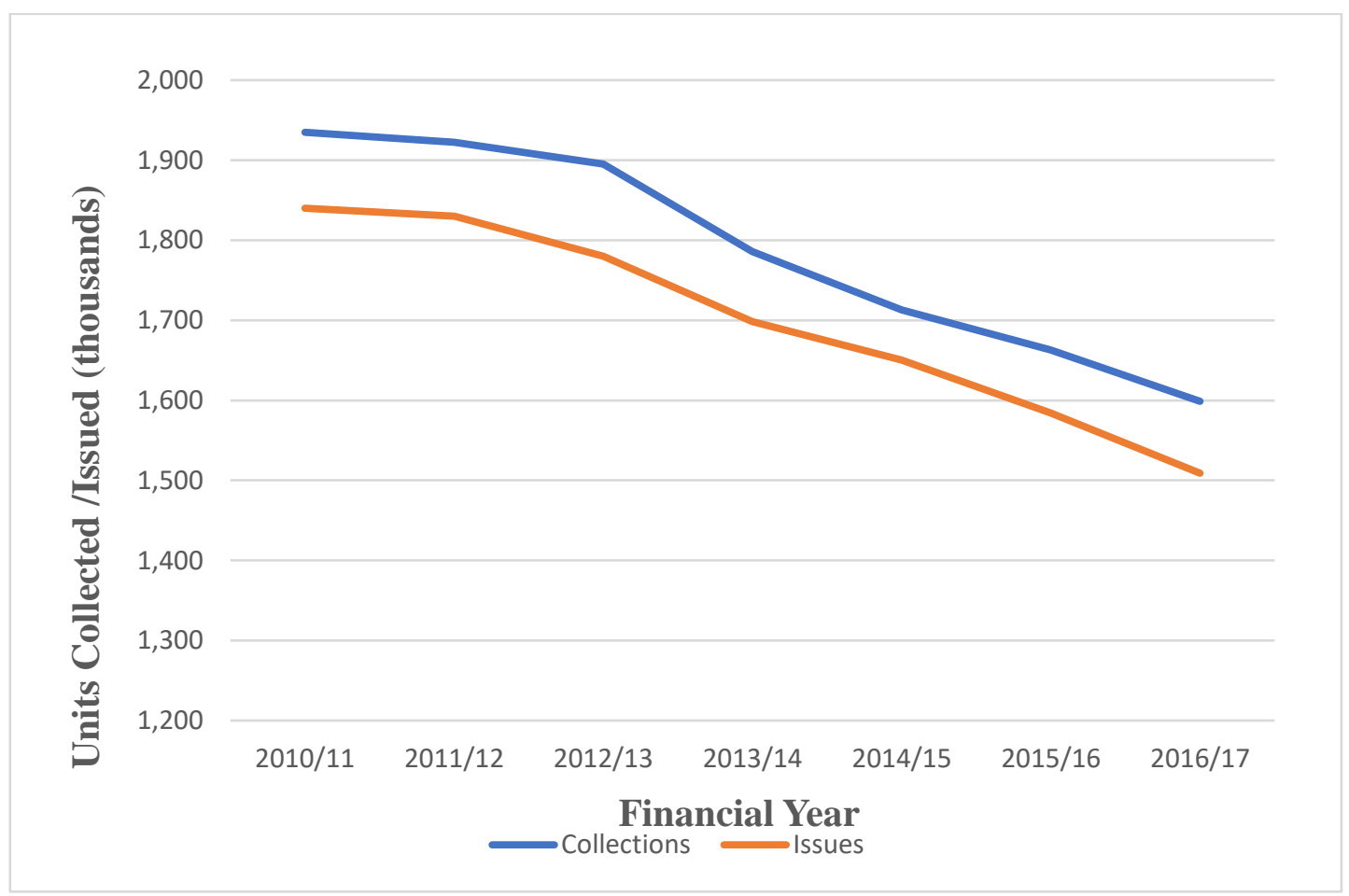

Source: Supplied from NHSBT Corporate Communications January 2018

The volume of allogeneic issues has experienced a marked decline since 2000 when the volume of allogeneic issues was in the region of $2.2 \mathrm{~m}$ units. This decrease in volume of allogeneic issues is due to several reasons: 
- Less invasive surgery. The advances in e.g. keyhole and micro surgery have lowered the requirement for large incisions and, consequently a lower intraoperative blood loss.

- Improved stock management and operation scheduling at hospitals. Allogeneic blood is often kept in the hospital blood bank and is not issued until it is required in the operating theatre or post-operatively in the recovery unit or on the ward. Previously a short notice cancellation of a theatre list would have resulted in a number of allogeneic units being discarded as they had already been issued out to the theatre.

- Application of BBT initiatives and the move to patient blood management (paras 1.11 and 1.12) has resulted in more appropriate use of blood. This would include the impact of cell salvage.

- Use of drugs such as tranexamic acid (para 1.9)

- More advanced blood testing equipment requiring less blood to be taken in hospital to undertake a portfolio of tests.

- No research has been undertaken but it has been suggested the significant rise in the price of allogeneic blood from 1998-2008 acted as a catalyst to encourage better hospital blood bank stock management and more sparing use of allogeneic blood in hospitals (Murphy 2013).

The phenomenon of falling demand for allogeneic blood is not confined to the UK. An article by Matthew L Wald in the New York Times (22 August 2014) entitled 'Blood Industry Shrinks as Transfusions Decline' notes that allogeneic blood usage fell by 'almost one third over the last five years'. The article notes a number of the points above, but also refers to revised recommendations from such organisation as the US Society of Thoracic Surgeons not to give an allogeneic transfusion until the $\mathrm{Hb}$ level falls to less than $70 \mathrm{~g} / 1$.

NHSBT is actively involved in estimating allogeneic blood requirements that therefore translate into collection plans. The overall totals noted in Figure 2 above need to be further analysed. Figure 3 below was supplied by NHSBT and analyses the estimated blood usage over the main specialties. One key feature is the decrease in surgical usage from the $40.7 \%$ estimated by Wells et al (2002) against $30.3 \%$ in 
the 2012 NHSBT study. A rough calculation of the decrease in allogeneic units is shown in Table 2 below.

Figure 3. Analysis of Allogeneic Hospital Blood Use Supplied by NHSBT

\section{Percentage of total blood use in 2011/12}

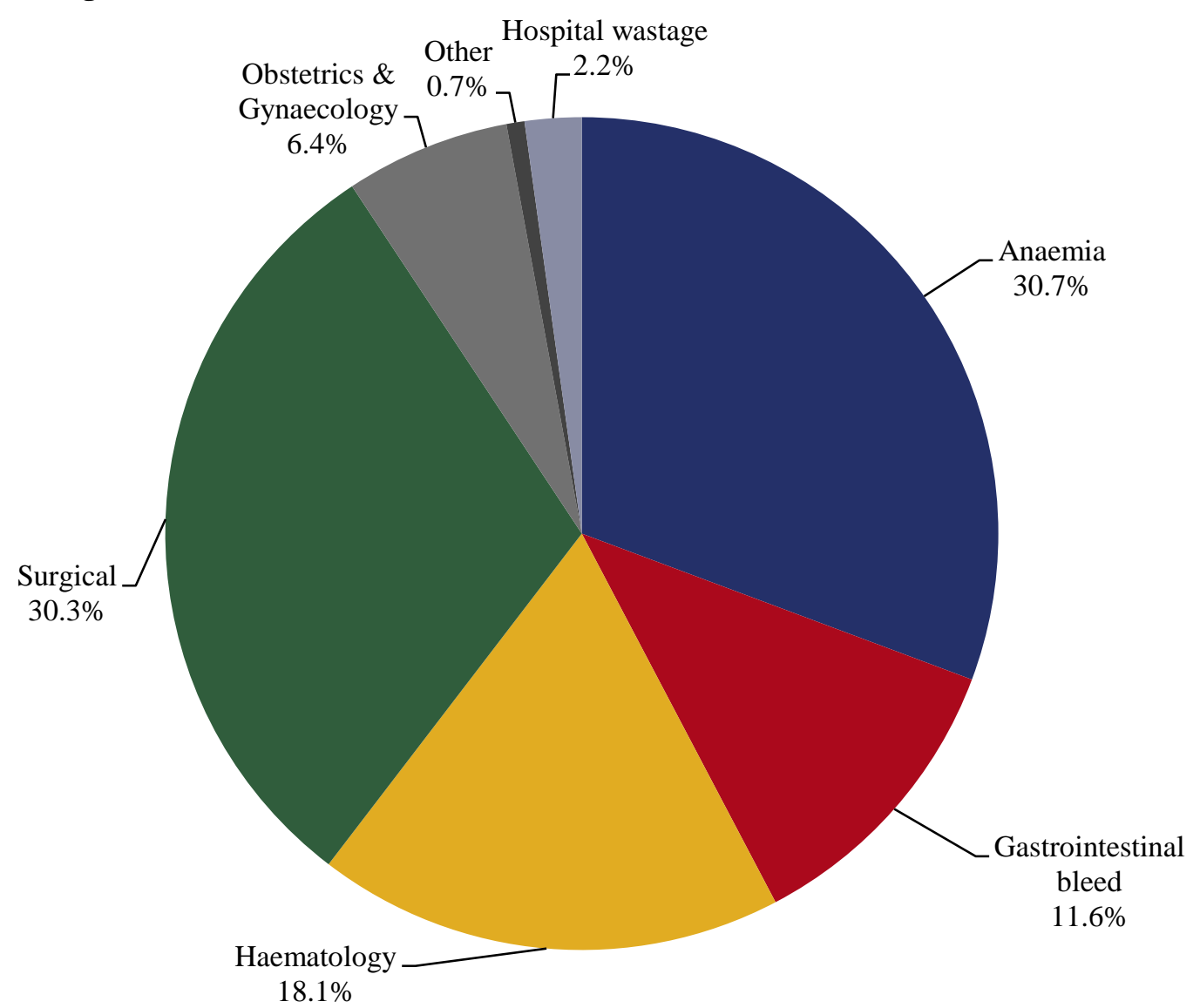

Source. Supplied from NHSBT Demand Planning Team

Table 2. Impact on Allogeneic Requirements of Decrease in Surgical Usage

\begin{tabular}{|l|r|r|r|}
\hline Year & $\begin{array}{c}\text { Total Allogeneic Blood Issued } \\
(\mathbf{0 0 0 s})\end{array}$ & \multicolumn{1}{|c|}{ Percent Surgical } & \multicolumn{1}{c|}{$\begin{array}{c}\text { Notional Surgical } \\
\text { Volume (000s) }\end{array}$} \\
\hline $2002 / 03$ & 2,200 & $40.7 \%$ & 895 \\
\hline $2011 / 12$ & 1,830 & $30.3 \%$ & 554 \\
\hline Decrease & $\mathbf{3 7 0}$ & & $\mathbf{3 4 1}$ \\
\hline
\end{tabular}

Source: NHSBT; note figures exclude South/Mid Wales, Scotland and N. Ireland

The difference in Table 2 is stark. Over $90 \%$ of the overall calculated decrease in allogeneic blood issued (341/370) is due to the fall in surgical usage. At a cost of $£ 122$ per unit the decrease in the overall hospital expenditure on allogeneic blood is approximately $£ 41.6 \mathrm{~m}(341,000 \mathrm{x} £ 122)$. 
The cost of allogeneic blood and the internal market in the NHS will be introduced in para 1.23 and 1.24. Discussions with clinicians and finance staff in NHS trusts pointed to the relatively easy savings to be made in their trust's blood budget by avoiding the use of allogeneic blood. The 2009 McKinsey NHS Productivity Review (see: www.nhshistory.net/mckinsey\%20report.pdf, accessed 25 January 2015) concluded that around $21 \%$ savings had been made in blood products by NHS Trusts between 1997 and 2009. This was the 13th highest saving in the survey of 75 areas undertaken by McKinsey (page 37 of PowerPoint presentation). The workings in this study were not published widely and were released in the form of a PowerPoint presentation following a Freedom of Information Act request by the Daily Mail in May 2010. The report findings were, however, consistent with discussions with users and the notional calculation above.

Trusts can therefore make savings in their allogeneic blood budgets by lower than planned blood usage but NHSBT fixed costs will remain. This impact on NHSBT and the overall NHS expenditure will be examined in Chapter 6 .

\subsection{Better Blood Transfusion (BBT) Initiatives}

Although there is an internal market for allogeneic blood, the National Commissioning Group for blood and blood products (NCG-see para 1.23) maintains collaboration between the NHS organisations to derive the average cost and hence price charged per allogeneic unit. The three initiatives, commencing in 1998, were developed jointly by the four home nations. The main aims were to:

- Avoid the unnecessary use of blood transfusions. The publications stressed there was always a risk of contamination or mix up of the blood group. Reducing the number of transfusions reduced the overall level of risk. It was felt that the 'quick wins' to reduce the volume of transfused blood required (pre-operative patient assessment, patient positioning, less invasive surgery etc.) were sufficiently developed to allow the individual Hospital Transfusion Committees/Teams to audit usage.

- Secure appropriate and cost-effective provision of blood transfusion and alternatives in surgical care. Specifically mentioned in BBT1 was '(Trusts to) develop a blood conservation strategy including ...alternatives to donor blood such as perioperative cell salvage'. 
- Ensure patients who are likely to receive a blood transfusion are informed of their choices. Specific mention was made on disseminating information on 'alternatives available'. References were also made to 'managing Jehovah's Witnesses'. Jehovah's Witnesses believe that shed blood is unclean and will stipulate that they are not to be given allogeneic blood. A proportion of Jehovah's Witnesses will, however, accept cell salvage as the blood is still part of a circuit and has not therefore actually been lost by the patient.

BBT3 (2007) referred to the NHSBT supported website: www.transfusionguidelines.org.uk. This (four country) website made reference to two little-used alternatives to blood transfusion using autologous (patient's own) blood:

- Pre-operative autologous donation (PAD), para 6.1.1. of the Transfusion Handbook. This is where a patient 'banks' some of his/her blood over twothree weeks prior to the operation. Studies have shown that this lowers the patient's $\mathrm{Hb}$ levels markedly with the patient subsequently presenting for surgery in an anaemic condition. They may therefore require allogeneic blood in addition to that which has been banked. The British Committee for Standards in Haematology (2007) recommend its use in only exceptional circumstances.

- Acute Normovolaemic Haemodilution, (ANH) para 6.1.4. of the Transfusion Handbook. Once the patient is anaesthetised, several units of blood are collected in the anaesthetic room. The patient is transfused with crystalloids until surgical haemostasis (bleeding stops) is achieved then post-operatively the patient's own blood is reinfused. ANH was popular in the US, especially for cardiac surgery which often involved high volumes of blood loss. In recent years, surgical advances have reduced blood loss, thereby decreasing its requirement. The UK health bodies do not encourage this technique and the Transfusion Guidelines website states 'the safety of ANH remains unclear'.

There have been no additional BBT initiatives since BBT3 in 2007. The UK Cell Salvage Action Group (CSAG) has taken over the role of encouraging the 
appropriate use of blood and the promotion of blood sparing activities such as cell salvage.

\subsection{International Patient Blood Management (PBM) Initiative}

A recently developed concept, effectively extending the BBT initiatives, is Patient Blood Management (PBM). Shander and Javidroozi (2012) define this as an initiative to "improve patient outcomes while reducing the use of allogeneic blood, through multitudes of strategies relying on optimising RBC (red blood cell) mass, preventing blood loss and optimising the physiologic response to anaemia". Some of the 'strategies' are basic, such as ensuring the patient is well positioned and kept warm during surgery, and that the patient has followed a basic exercise programme to be fit and well before surgery. At the other end of the scale would be cell salvage; relying on a trained member of staff to operate equipment to recycle a patient's own blood. Shander \& Javidroozi (2012) recommend the combined use of all the strategies to maximise the benefits of minimising the risk of having an allogeneic transfusion.

PBM was formally cascaded to hospital trusts by NHS England in June 2014 (see appendix 3). The document, issued by the National Clinical Director of Pathology (NBTC (2014)), defined PBM as "an evidence-based, multidisciplinary approach to optimising the care of patients who might need transfusion. It encompasses measures to avoid transfusion such as anaemia management without transfusion, cell salvage and the use of anti-fibrinolytic drugs to reduce bleeding as well as restrictive transfusion". The document quoted inappropriate use of, inter alia, allogeneic blood at a rate of $15-20 \%$. Specific recommendations include:

- Enhanced training in avoiding unnecessary blood transfusions e.g. to transfuse one allogeneic unit at a time and view the impact rather than transfusing two units immediately.

- Preoperative management of anaemia to ensure the patient is above the World Health Organisation definitions of $\mathrm{Hb}$ levels $>130 \mathrm{~g} / \mathrm{l}$ for men and $>120 \mathrm{~g} / \mathrm{l}$ for women (Table 1 above) prior to commencing surgery.

- Use of cell salvage for appropriate procedures and pharmacologic agents to reduce blood loss, e.g. tranexamic acid. 
The American Association of Blood Banks (AABB) is also implementing its own PBM programme and hosted a national awareness week in November 2014, followed up by a similar initiative in the corresponding weeks in November 2015 and 2016. The AABB's definition of PBM is the same as the NHS England version (see www.aabb.org/pbm accessed 19 January 2016).

The June 2014 document above referred to a 2013 survey of all English NHS trusts. The survey summarised various findings including '... patchy use of intraoperative cell salvage, for example $55 \%$ of Trusts use it for orthopaedic surgery'. It was impossible to reconcile this percentage to the approximate $40 \%$ cell salvage utilisation calculated for England in the cell salvage consumables survey discussed in para 1.14 below. The comment, when associated with the other survey findings, has a negative slant. The assertion is that more cell salvage should be considered since cell salvage is highlighted as a key measure to avoid allogeneic transfusions.

\subsection{Methodology of Cell Salvage as an Alternative to An Allogeneic Blood Transfusion}

Cell salvage collects a patient's shed blood during or after surgery. In the early years of development of cell salvage the blood would immediately be reinfused back into the patient. Developments in techniques and mechanical applications allow the shed blood to be washed prior to reinfusion and there are now two types of equipment available. These offer the options of:

- Intra-operative cell salvage (ICS). This is where the shed blood is collected, washed and immediately reinfused back into the patient during surgery. This is the more common type of cell salvage and is used across the various surgical specialties.

- Post-operative cell salvage (POCS). The post-operative shed blood is collected, washed and reinfused back into the patient after the operation is completed. The actual shed blood collection and continuous reinfusion will carry on for up to six hours after the operation. This technique is mainly used for hip and knee surgery, as a tourniquet would often be used to minimise blood loss during the operation. The suction device will be placed in situ prior to the tourniquet being released. 


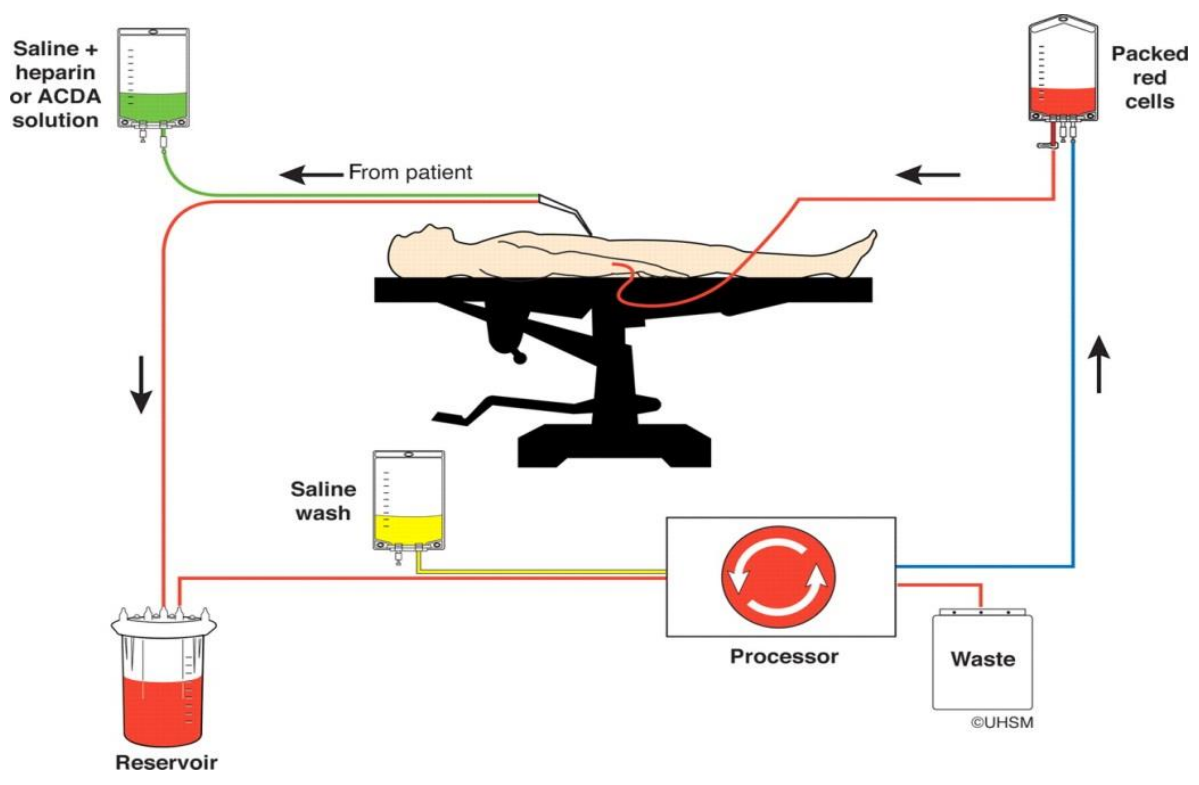

Source. Above diagram provided by UKCSAG

The principle for cell washing is broadly similar for both intraoperative and postoperative techniques. Shed blood is filtered to remove debris and collected in a reservoir (see above). It is already anticoagulated with heparin or citrate to stop clotting. Once sufficient blood is collected in the reservoir it is released into a bowl to be processed (depending on manufacture the volume may be $55 \mathrm{ml}, 125 \mathrm{ml}$ or $225 \mathrm{ml}$ ). The majority of machines will spin (process) the bowl and the centrifugal process will trap the oxygen carrying red cells to generate highly oxygenconcentrated blood to be re-infused. Additionally, blood laden swabs used on the patient can be washed out in saline and poured into the reservoir.

The cycle can be repeated during the operation when each bowl is full. A full bowl is preferable to partial bowls. The decision to open the reservoir is often a matter of judgement by the operator. The locally held, non-scientific view at the Royal Cornwall Hospitals is that the colour and texture of the salvaged blood in the reservoir should look like a blackcurrant drink and resemble a smoothie, rather than Ribena, indicating there is a high concentration of red blood cells. If this is the case, then the contents of the reservoir can be released. This judgement call effectively assesses the haematocrit levels; this is the volume of red cells in the blood. The higher the volume of red cells, the thicker the blood. Newer cell salvage machines will use a light scanner to assess the haematocrit levels and give a more accurate indication when a reinfusion of blood can take place. 
The final 'packed red cells' will then be reinfused into the patient. The cycle can be repeated for the duration of the operation if necessary. With some patients, who are expected to have high blood loss the clinician may feel it safer to keep some allogeneic units on 'stand by', e.g. in a cool box in the operating theatre.

The decision whether to salvage will be made by the clinician. Many hospitals will have information leaflets for patients who may request the use of a cell saver to minimise the chances of requiring an allogeneic blood transfusion.

As noted in para 1.4 the prime reason for undertaking an allogeneic transfusion is to keep the patient's $\mathrm{Hb}$ levels as high as possible to maximise the level of oxygen in the blood. These levels will be depleted in an operation and the cell salvage process will minimise this depletion. Used in conjunction with other blood sparing techniques the patient's $\mathrm{Hb}$ level will be maintained as high as possible. The patient's $\mathrm{Hb}$ level will be monitored regularly and allogeneic blood may be prescribed if the level does not start to rise.

To circumvent the issue of trying to isolate the contribution of cell salvage against other blood sparing techniques, this thesis will undertake a comparison between three sites; only one of which uses cell salvage, but the other two sites describe themselves as assiduous proponents of PBM. The hypothesis is therefore that the respective differences in allogeneic blood utilisation and hence the allogeneic blood costs will be attributable to the utilisation (or non-utilisation) of cell salvage.

Cell salvage is accepted as a highly safe technique. In the UK, it is only used in hospitals where there is an ample supply of available allogeneic blood, should it be required. Hussain (2010) succinctly sums this up, stating if there is a problem with the operation of cell salvage during the operation then the clinician can stop the process and give allogeneic blood instead. This would suffice for any patient, except Jehovah's Witness patients who refuse allogeneic blood (paras 1.11 and 1.17).

\subsection{Evolution and Usage of Cell Salvage in the UK}

Thomas (2005) states 'The first use of blood salvage was reported (in 1818) by James Blundell for the treatment of postpartum haemorrhage'. This involved collecting the blood and injecting it back into the patient. 
Landsteiner's discovery of blood grouping (para 1.8) developed more interest in allogeneic transfusions and consequently interest in cell salvage waned. It was not until research at the Mayo Clinic in the US in the 1960s that interest increased when systems to salvage spilt blood were developed. This coincided with the US involvement in the Vietnam War and studies found that salvaged blood contributed to lower requirements for allogeneic blood. Thomas (2005) believes that these rudimentary attempts at salvaging severe trauma cases from the battlefield sowed the seeds of development in the civilian surgery we see today.

Cell salvage is now utilised, to a varying degree, in most countries in the world. Some basic systems such as the EAT (emergency autotransfusion) SET, developed in Nigeria may be the difference between life and death in cases of postpartum haemorrhage where the nearest hospital may be $100 \mathrm{~km}$ away and no allogeneic blood is available. The EAT SET is a hand operated suction pump that filters shed blood and re-infuses it immediately. It can therefore be used without electricity, often outdoors, in an emergency setting. www.kumatoo.com/dr_oviemo_ovadje.html accessed 28 October 2014.

In the developed countries, four multi-national companies dominate the market for both allogeneic donation and cell salvage related equipment. These are:

- Cobe/Terumo (Japan)

- Fresenius (Germany)

- Haemonetics (USA)

- Sorin (Italy).

A 2011 survey by the UK Cell Salvage Action Group (para 1.16) found the most widely used intra-operative machines are the Sorin Electa and the Haemonetics Cell Saver 5 (CS5). The main post-operative device is the Haemonetics OrthoPat cell saver, which can also be used intraoperatively. At the time of the collection of the data (2010/11) the Royal Cornwall Hospital Trust used seven Haemonetics OrthoPats, three Sorin Electas and two Haemonetics Cell Saver 5s.

The cost of the equipment is usually bound by commercial confidentiality. Generally, the equipment will cost in the region of up to $£ 15,000$ including VAT. The consumables (in the US confusingly termed 'disposables'), mainly the reservoir, 
filter and the tubing, cost c. $£ 68$ per operation for the Electa and are significantly more expensive (c. £170) for the OrthoPat. These costs are negotiated charges from the suppliers at the Royal Cornwall Hospitals. There will be some additional costs (see NICE Costing Report 2015 for the implementation of NICE Guidelines NG24) for heparin (£21.20) and saline (£4.20).

\subsection{NHSBT Supported Collaborative Work on Cell Salvage}

NHSBT actively supports blood conservation measures and is a host organisation for the UK Cell Salvage Action Group (CSAG, introduced in para 1.11 above). NHSBT has also supported the NHS 'Better Blood Transfusion' (BBT) initiatives that commenced in 1998 to encourage the 'safe and appropriate use of blood' (para 1.11). Being part of the NHS, it is in NHSBT's interests to achieve stability in allogeneic blood usage. This helps the organisation to assess hospitals' future allogeneic blood requirements and convert these requirements into collection targets nationally.

The primary role of the CSAG is to encourage the development of cell salvage in conjunction with other blood avoidance techniques. The group is comprised of hospital users (medical, scientific and theatre staff) and representatives from the UK Blood Services. Although there is an internal market for blood, most of the organisations, except for private hospitals, are part of the public-sector NHS. Collaboration on blood sparing initiatives will ensure more certain demand planning which, in turn, will translate to potentially lower blood collection targets and consequent lower collection and marketing costs to recruit and retain allogeneic blood donors.

Responsibilities for data collection, follow up of the BBT initiatives (para 1.11) and estimations associated with the impact of cell salvage were therefore allocated to the CSAG, which was set up in 2006. The 'four country' representatives on CSAG will then report to the individual blood organisations, e.g. the England representative reports to NHSBT's Patient Blood Management Steering Group.

NHSBT International is a division of NHSBT primarily concerned with developing international collaborations and benchmarking initiatives to enhance the efficiency of the service. The basic process from blood donation through to hospital issue is broadly similar in most countries with the responsibility being held within one or 
more large centralised management units. A set of comparative key performance indicators (KPIs) has therefore been developed, comparing, for example, the number of allogeneic donations per member of collection staff employed. Comparative costs obviously vary due to exchange rates and the relative purchasing power of currencies, so the focus is on assessing the non-financial units of measurement. In the event of severe shortages of allogeneic blood (e.g. in national emergencies), member countries of the European Blood Alliance (EBA) have arrangements to supply allogeneic blood across borders. The UK is a partner in this arrangement but is not in a position to 'export' UK blood due to the potential risk of vCJD contamination.

The EBA was approached in 2007 as part of the preliminary work for this thesis. A brief questionnaire was issued, and a summary of the member consultation responses is shown in appendix 5. Broadly it showed interest in cell salvage in a number of member countries. The response from the Bavarian/German blood service was particularly thought-provoking with the view that, since the supply of allogeneic blood was safe and plentiful, there was little incentive to assess and develop alternatives (see comments in appendix 5).

The 2007 EBA survey noted a wide-ranging enthusiasm for cell salvage from member countries. The EBA has since expanded its membership and, in January 2014, the EBA Chair was approached with the request to re-run the survey. The Chair stated that members were too busy and that interest in cell salvage had now waned around Europe. Consequently, the request was refused. This did not come as a great surprise given the vast majority of publications (see analysis in the literature review) relate to the UK or US and not across Europe.

The roles and responsibilities of NHSBT do not therefore stop at managing the supply of allogeneic blood. It provides support for CSAG which, through its related work, encourages alternatives and the efficacious use of allogeneic blood.

\subsection{Utilisation of Cell Salvage in the UK}

Both utilisation and usage of cell salvage are difficult to assess. Companies do not wish to reveal their sales levels for commercial reasons. We are therefore reliant on surveys and general discussions. The 2011 CSAG survey on ICS approached known 
hospital cell salvage users. As a rough guide this was approximately $40 \%$ of English NHS hospital trusts, with a much higher percentage in Scotland and Wales. The response rate was a little disappointing at around $44 \%$. One key question related to the number of consumables used in ICS. The responses are shown in the graph below:

Figure 5. Intraoperative Cell Salvage Consumables Used in the UK

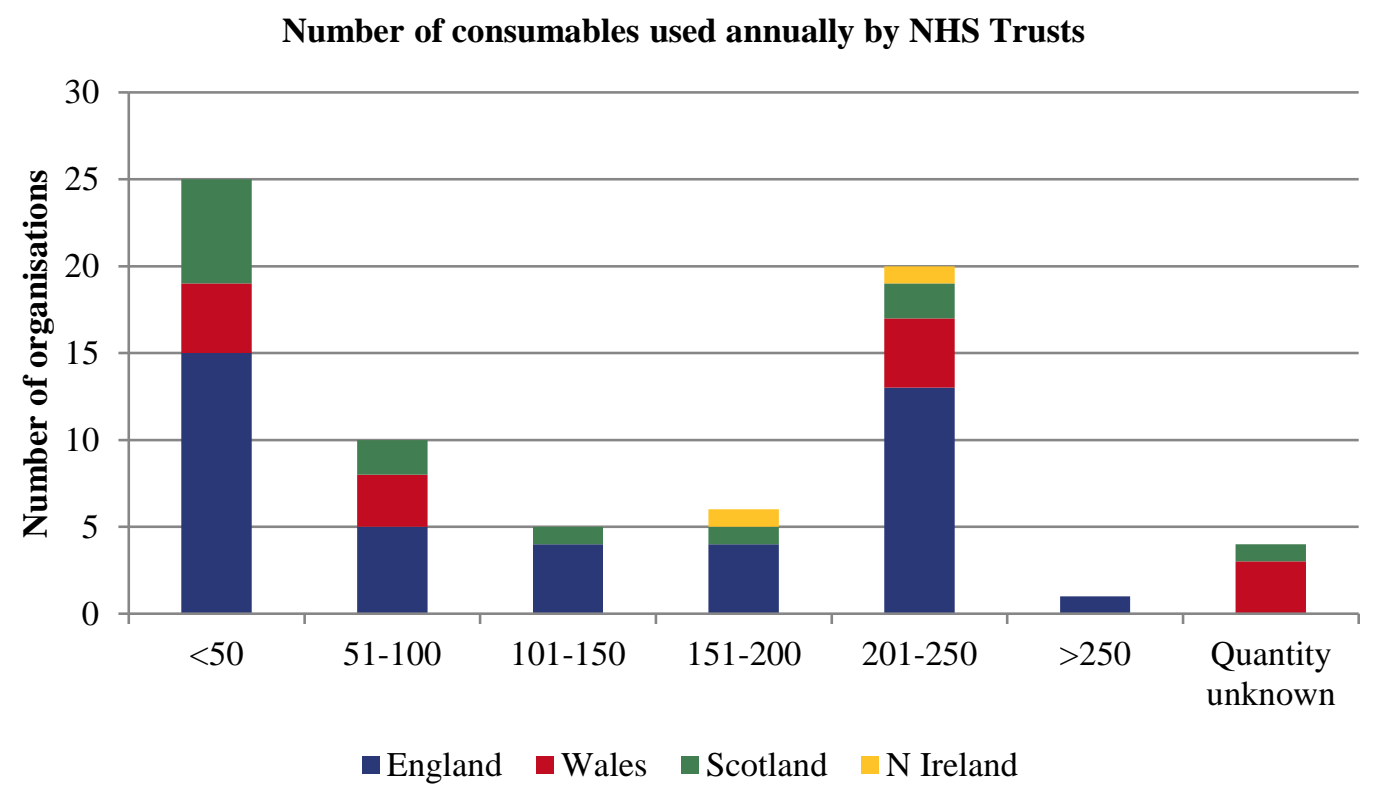

Source. 2011 CSAG Study.

The above information, reproduced from the 2011 survey, estimates the ICS usage at approximately 8,325 operations per annum for the 71 respondents. The basic calculation is shown in Table 3 below:

Table 3. Estimate of the Number of Consumables Used in the UK in 2010/11

\begin{tabular}{|l|r|r|r|r|r|r|r|r|}
\hline Usage p.a. & $\mathbf{< 5 0}$ & $\mathbf{5 1 - 1 0 0}$ & $\mathbf{1 0 1 - 1 5 0}$ & $\mathbf{1 5 1 - 2 0 0}$ & $\mathbf{2 0 1 - 2 5 0}$ & $\mathbf{> 2 5 0}$ & Unknown & Total \\
\hline Estimated Mean & 25 & 75 & 125 & 175 & 225 & 275 & 125 & - \\
\hline $\begin{array}{l}\text { Number of } \\
\text { Hospitals }\end{array}$ & 25 & 10 & 5 & 6 & 20 & 1 & 4 & $\mathbf{7 1}$ \\
\hline Estimated Usage & 625 & 750 & 625 & 1,050 & 4,500 & 275 & 500 & $\mathbf{8 , 3 2 5}$ \\
\hline
\end{tabular}

Table 3 therefore estimates the mean annual usage per hospital for ICS at 117 operations $(8,325 / 71)$. It was highlighted to the survey author that the total number of organisations in the graph (71) did not tally with the number of overall respondents in the questionnaire (53). The response was that the graph referred to sites, so a two- 
site trust would be treated as two entities in the graph but as one respondent in the $44 \%$ overall response rate.

This anomaly aside, the indications are that the estimated ICS annual usage is low. One would expect the respondents in the questionnaire to be the more enthusiastic proponents of ICS and therefore the implication is that the overall usage across (especially) England is still relatively low. A second graph summarised in Table 4 below notes the respondents had the use of 209 ICS machines. A crude average, by dividing the estimated number of operations $(8,325)$ by the 209 machines gives an average machine usage of 40 operations per annum. With 71 organisations, this averages at about three machines per organisation (209/71).

Table 4. Analysis by Machine Type

\begin{tabular}{|l|r|}
\hline Equipment Type & Number \\
\hline Sorin Electa & 91 \\
\hline Haemonetics CS5 & 63 \\
\hline Fresenius CATS & 19 \\
\hline Cobe Brat & 12 \\
\hline Haemonetics OrthoPat & 15 \\
\hline Haemonetics Cardiopats & 6 \\
\hline Medtronic Autologic & 3 \\
\hline Total & $\mathbf{2 0 9}$ \\
\hline
\end{tabular}

Note. The OrthoPat is a dual intra-operative and post-operative machine and, in the survey, used intra-operatively

The crude calculation of derived activity from table 4 above is effectively the best information available, given there is no central NHS wide procurement database of NHS organisations' equipment purchases. The equipment may also have been purchased and provided free of charge by the local Jehovah's Witness community (para 1.17). The calculation therefore equates to an individual machine being utilised, on average, less than once a week (40 times per annum). This assumes that only one consumable set is used per operation so there is no wastage. It is arguable that low usage of cell salvage implies efficiency and sparing use of the consumables only where they are utilised to avoid an allogeneic blood transfusion. One cannot really take machine utilisation as an indicator. From an accounting perspective, if the average cost of consumables is $£ 100$ and two units of allogeneic blood (rounded to $£ 250$ ) are avoided then, 'ceteris paribus' this equates to a cost avoidance of $£ 6,000$ 
$((£ 250-£ 100) \times 40)$ per annum. A brand-new cell saver may cost approximately $£ 15,000$, making the payback period 2.5 years on a very low usage. This is the general argument purported by the sales representatives of the main manufacturing companies. The promotional material for the Sorin Xtra states "the average total cost of transfusing a unit of homologous RBCs (alternative US term for allogeneic units of blood) as \$1,158" (appendix 1), quoting Shander et al (2008) and thereby implying that using the machine would avoid these costs. It ignores issues such as:

- Training costs. Training a cohort of around 15 operating department practitioners (ODPs) from scratch may cost more than $£ 5,000$. This level of training cost for the ODPs may be difficult to justify when total cell salvage usage may only be 120 operations per annum.

- Retaining the practical experience. 120 operations spread equally over 15 ODPs would equate to eight operations each per year. There is an argument that, to be most effective, ODPs (and surgeons) should have more 'flying hours'.

- Transfusion rates. A high cell salvage rate may be combined with a high allogeneic transfusion rate. This may imply inefficiencies in the blood management process in patient treatment (Joy and Bennet (2012)).

While the CSAG have promoted the benefits of cell salvage, the utilisation rate is relatively low. In 2010/11 210 NHS hospitals in England requested at least 2,500 units of allogeneic blood from NHSBT (NHSBT activity information). The 2011 CSAG survey results indicated that a high proportion of English hospitals have either not demonstrated an active interest in the development of cell salvage or are not utilising it. It is this gap in the knowledge of the 'customer' that the CSAG are trying to assess and therefore influence change.

Pulling the crude ratios from the questionnaire is not an exact science, although it does point to a potential for a gap in the market and the potential for companies to sell additional cell saver machines to new customers. Alternatively, there are some organisations that do not utilise cell salvage as they feel it is not cost effective. There are some, but not many, articles that point to this. For instance, Attaran et al (2010) argue that their study in "routine cardiac surgery" identified no lower allogeneic blood usage when cell salvage was used and when it was not. They argued that the 
cost of operating the cell savers effectively generated a loss. These issues will be discussed in the literature review. The approach to the cost effectiveness of cell salvage from all perspectives will be undertaken in subsequent chapters.

\subsection{Jehovah's Witness Beliefs and Support for Cell Salvage}

A key belief of a Jehovah's Witness (JW) member is that their life is contained within their blood. There are a number of biblical passages quoted on the JW website highlighting members' belief in forbidding the use of blood, e.g. Genesis 9:4 "The one thing you must not eat is meat with blood still in it; I forbid this because life is in the blood". Additionally Acts 15:28, 29: "You are to abstain from ...blood.. If you keep yourselves free from these things you will be doing right". (see www.jw.org accessed 18 January 2016).

Many JW members will therefore refuse allogeneic transfusions and the JW website highlights this refusal as being a religious rather than a medical issue. For many JW members, however, intraoperative cell salvage is acceptable as the blood has not been spilt, since the blood remains in a circuit connected to the body. Many JW communities in the UK have funded the purchase of a cell saver machine for their local hospital. This will be used in the event of a JW patient requesting it. Local arrangements may vary but the machines would be made available to all patients regardless of their beliefs.

JW patients will identify themselves as requesting 'no blood' at their pre-operative assessment (para 1.19). Arrangements will be made for a cell saver machine to be made available if the JW patient requests it. Each NHS hospital has a JW liaison officer who can advise and ensure the patient's requirements are met. Antifibrinolytic drugs such as tranexamic acid (see para 1.9) are also utilised by JW patients.

JW members are prominent in supporting initiatives to avoid allogeneic blood transfusions and the umbrella JW organisation in the US actively highlights the consideration of alternatives to allogeneic transfusions, including intraoperative cell salvage. In the south west of England, the joint NHSBT/ University of Bristol MSc in Transfusion and Transplantation Science course includes a training session from the local JW representative as part of the wider approach to transfusion medicine. 


\subsection{Low Utilisation of Cell Salvage}

Advocates of cell salvage have been promoting the technique as an alternative to an allogeneic blood transfusion since the 1990s with many articles highlighting significant savings. A detailed critique will be undertaken in the literature review, however many articles (not just on cell salvage) can achieve publication citing costs that are often based on average costs. A common misconception in the UK is to quote savings associated with lower length of stay (LOS), e.g. Dixon et al (2005). The cost of a hospital stay may average out at $£ 300$ per in-patient day. A study may cite a particular procedure that would reduce LOS by one day, so the study would quote a saving of $£ 300$ a day per patient if the procedure were adopted. In practice the saving would be minimal since, in the short term, virtually all hospital costs are fixed and the savings in avoiding one in-patient day would mainly be in patient meals and other accommodation costs.

Earlier studies would often cite a 1:1 relationship in using cell salvage so that the use of a cell saver would avoid the use of (say) two allogeneic units (Crotty (2006)). 'Ceteris paribus' the savings quoted would be cited as:

Table 5. Basic Calculation of Savings Avoiding One Allogeneic Blood Transfusion per Week

\begin{tabular}{|l|r|r|}
\hline & $\begin{array}{c}\text { Cell } \\
\text { Salvage } \\
\mathfrak{f}^{\prime} \mathbf{0 0 0}\end{array}$ & $\begin{array}{c}\text { Allogeneic } \\
\text { Costs } \\
\mathfrak{£} \mathbf{0 0 0}\end{array}$ \\
\hline Blood Costs Avoided (2.7 units per operation per week) & & 17.5 \\
\hline Consumables & 4.7 & \\
\hline Training & 4.5 & \\
\hline Electricity & 0.2 & \\
\hline Capital Charges & 1.0 & \\
\hline Maintenance & 0.5 & \\
\hline Sub total & & 10.9 \\
\hline Saving & & $\mathbf{6 . 6}$ \\
\hline
\end{tabular}

Source: Table reproduced from HFMA publication 'Healthcare Finance’ September 2010

The savings in Table 5, while focusing on the marginal savings, may not be realisable. One would need to be certain that at least one patient a week was definitely going to require an allogeneic transfusion. The identification of this one patient would be difficult so, for instance, to allow one patient a day to avoid an allogeneic blood transfusion may require salvaging five patients in a list thereby 
requiring five sets of consumables. This would then make using cell salvage more expensive than utilising allogeneic blood if four out of the five patients would not have required an allogeneic transfusion anyway. It is this level of uncertainty that has not been highlighted. Some hospitals, e.g. the Royal Cornwall Hospitals Truro that forms the basis of this study, attempt to salvage all patients and rely on negotiating a better price for using a high volume of consumables. With this level of subjectivity, the cost of ensuring the high volumes of cell salvage may be viewed as prohibitive, especially when compared to the financial benefits of tranexamic acid that even the makers of cell salvage equipment acknowledge (para 1.9).

Other challenges facing cell salvage are:

- The UK CSAG has a list of users but there is no guarantee that it is complete nor is there a more reliable indicator of usage. There is therefore a difficulty in developing convincing cases for or against its use when it is only a small pocket of enthusiastic proponents who regularly contribute to the debate.

- Discussions with hospital staff cite a lowering in emphasis in cell salvage in the BBT series (para 1.11). BBT1 (1998) explicitly cited cell salvage as a concept for hospitals to develop and quoted Morriston Hospital, Swansea, as an exemplar site. Moving forward to BBT3 (2007) and there is little mention of cell salvage. The perception is therefore that the profile of cell salvage has fallen.

- There is a possible political issue that has been raised in general discussions with some clinicians. Blood donors feel very altruistic about donating blood (see paras 1.8 and 6.13) and the act of donating is packaged as a 'gift of life'. If it were widely circulated that there is a high level of unnecessary allogeneic transfusions in surgery due to the availability of cell salvage and other blood avoidance techniques, would this have an impact on the number of donors willing to donate? This may then require further expenditure on marketing to recruit and retain the donors. The assertion has been put forward (in confidence) that this altruism needs to be retained for NHSBT to react to future uncertainties in the blood supply chain. 


\subsection{Enhanced Recovery Pathways}

NHS Hospital trusts are now expected to follow the Enhanced Recovery Pathway (ERP) programme to ensure the patient is adequately prepared for the surgery. (See: http://webarchive.nationalarchives.gov.uk/20130107105354/http://www.dh.gov.uk/en /Healthcare/Electivecare/Enhancedrecovery/DH_117433 Accessed on 19 October 2015.)

The ERP programme was implemented across the NHS from 2008 onwards. The examples on the, now archived, website highlight the reduced length of stay by 'as much as 10 days for colorectal procedures and 4 to 5 days for hip and knee replacements'. The programme noted areas of benefit by optimising the patient prior to surgery using the pre-operative assessments. Additionally, the therapy support (physiotherapists and occupational therapists) before and after the operation was cited as a contributory factor.

There are a number of examples of best practice in ERP programmes, all of which commence with the pre-operative assessment; a standard template form from Abertawe Bro Morgannwg Trust (ABM) is attached as appendix 6. These assessments are generally undertaken by a nurse and the results will form the judgement on whether to go ahead with the operation or refer the patient back to the GP for further assessment. A common referral back would be if the patient is anaemic i.e. their $\mathrm{Hb}$ levels are below the recommended WHO levels of $120 \mathrm{~g} / \mathrm{L}$ for women and $130 \mathrm{~g} / \mathrm{L}$ for men.

In 2011 Torbay and South Devon NHS Foundation Trust undertook a collaborative project with the orthopaedic implant manufacturer, Biomet, to develop the Rapid Recovery orthopaedics programme at Torbay Hospital in Torquay. Here, patients will initially have their pre-operative assessment if clinicians have decided surgery is appropriate. The ERP programme is specifically targeted at total hip replacement surgery. The researcher discussed the procedure with Torbay Hospital staff in 2014 who 'walked through' the process with the researcher.

At Torbay Hospital, if the patient is deemed fit enough to undergo an operation $\mathrm{s} / \mathrm{he}$ is invited to a 'joint school' along with the patient's immediate carer. This 'joint school', held about two weeks prior to the scheduled operation, comprises an 
education session, watching a video and a series of exercises and tasks with the physiotherapist and occupational therapist. The patient will then practice and work on the exercises at home. The expression used locally is 'pre-habilitation'; to be effectively fit for the operation and ready for the recovery process.

After the operation, the aim is to get the patient up and about as early as possible, subject to no adverse psychological impacts. The day of the week is irrelevant as the therapists work over a seven-day week. The patient is likely to be seen by the physiotherapist twice in a day with the aim to establish the patient's independence and mobility as early as possible. This will encompass exercises and techniques to enhance mobility using aids (e.g. frames/sticks) and ensuring the patient is able to tackle stairs. These are the criteria to assess the patient's rehabilitation along with pain control. There are also specific exercises to strengthen muscles and develop the movement in the hip joint. Crucially the patient is taught to get in and out of bed unaided.

Alongside this work the occupational therapist (OT) is assessing the patient's rehabilitation from an independence perspective, e.g. s/he will have met the patient at the joint school and assessed the height of the furniture in the patient's house by undertaking a home visit. Many of the patients live alone and their independence will therefore already have been assessed prior to taking the decision to discharge.

The decision to discharge is made jointly by the nursing and therapy staff, based on their professional judgment. Comorbidities are assessed and, where appropriate, medical staff will be consulted. The process at South Devon is mapped out in the flowchart below.

The key objective is to get the patient mobile as early as time permits. The age range of patients undergoing this type of operation is getting wider (National Joint Registry Annual Report 2013). A younger patient with few or no comorbidities would expect to recover more quickly. With a rigorous pre-operative assessment, the patient's iron levels will be optimised, lowering the likelihood of requiring an allogeneic transfusion. Older patients who are likely to have other comorbidities will be therefore more likely to require a blood transfusion as their iron levels may be more volatile, e.g. the pre-operative nutrients may not have as much beneficial impact. 
Figure 6 below maps out the main pathway 'walk through' of a typical Rapid Recovery programme.

Figure 6. Enhanced Recovery Treatment Flow

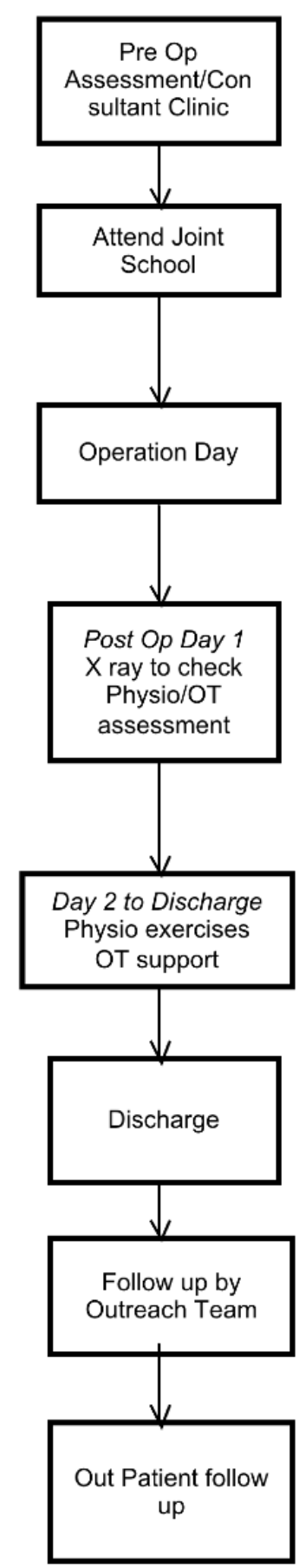

Approx 2-3 weeks prior to operation (not always time specific). Pre-assessment and joint school part of 18 week pathway.

Patient will have been supplied with various nutrients (pre op drinks prior to op taken at home before admission).

Exercise regime will begin.

Possibly two sessions of each per day

Joint decision by Physio/OT and nurse with medical opinion if required.

Within 10-14 days; wound(s) examined and stitches removed at home

6-8 weeks follow up by surgeon, who will sign off or arrange further follow ups if required prior to sign off.

Although the Department of Health guidance on the ERP programme has now been archived, the indications are that all hospitals are not fully adhering to the programme. The English NHS organisation responsible for regulating NHS Foundation Trusts was Monitor (renamed NHS Improvement from April 2016). A 
report produced in October 2015, "Helping NHS Providers Improve Productivity in Elective Care" compares length of stay for, inter alia, elective primary hip replacement surgery at a number of sites in England and around the world. The sites were chosen by Monitor "because they are regarded as delivering high quality care by ...the British Orthopaedic Association". The average length of stay quoted in the document for the selected English hospitals is 5.1 days. Two of the selected NHS organisations in this thesis have 5.1 and 5.2 days' average length of stay. Chapter 6 will discuss the length of stay but the Monitor report gives an additional level of assurance that two of the researcher's chosen sites virtually achieved the Monitor average more than four years prior to the Monitor report being published.

\subsection{Choice of Speciality to Study Cell Salvage Applications}

Cell salvage is mainly utilised in cardiac and orthopaedic surgery. It was decided to focus on assessing the cost effectiveness of cell salvage in orthopaedics due to the lower level of variability in orthopaedics compared to cardiac. Outcomes are more predictable since there are fewer potential complications and therefore costs associated with blood usage will be more visible. The key aspect is to isolate the impacts on the patient if an allogeneic blood transfusion was or was not required. Chapter 5 will introduce the utilisation of HRGs (Healthcare Resource Groups). These group together similar procedures within a specialty and report on activity and costs of the HRG. They are used within the NHS as a tariff-based funding allocation mechanism but can also be used to grade the severity of the operation or the patient comorbidities. With having a small number of HRGs to compare then elective total hip replacement was a logical choice within orthopaedics. This was also consistent with Carless et al's (2004 and 2010) Cochrane Review that recommended comparative trials of cell salvage in orthopaedics. Additionally, the comments in the Guardian newspaper by the NHSBT Medical Director on joint replacements were noted (para 1.4). She had previously given NHSBT approval to support this study and approved the audit documentation from one of the study sites to allow the release of the activity information for analysis and comparison.

The information collected in the three centres is more detailed than in the published studies assessed in the literature review. Most studies use the generic term 'total hip replacement (THR)' rather than analysing activity at HRG level. This study will 
therefore add additional rigour to the analysis and aims to minimise the variability associated with studies focusing on the wider category of 'THR' rather than the more detailed 'HRGs' where figure 11 notes the variation in the tariff price for the HRGs. Finally, using orthopaedics allows the assessment of both intra-operative and postoperative cell salvage usage as the Royal Cornwall Hospitals uses both types, including the OrthoPat which was highlighted in the discussions with the Haemonetics manufacturer (para 1.9). These discussions were significant in that they alerted the researcher to the issue of the expensive consumables. This would have a significant impact on the decision whether or not to transfuse allogeneic blood due to the cost of consumables.

The comment on 'patchy' use of cell salvage in orthopaedics in the National Blood Transfusion Committee (NBTC 2014) report on Patient Blood Management also needs pursuing (para 1.12). Two of the sites analysed in this thesis are particularly vehement in their view that cell salvage is not cost-effective in elective primary hip replacement surgery. They would therefore argue that the absence of cell salvage may be advantageous and the term 'patchy' implies an argument which justifies not utilising cell salvage. The conclusions of this thesis can therefore be shared with the NBTC to inform discussions on the efficacy of cell salvage within orthopaedics.

Finally, with Trusts adhering to the Enhanced Recovery Pathway programme (para 1.19) in orthopaedics it can be reasonably assumed that the majority of preoperative assessments have been undertaken. This will lower the level of subjectivity by minimising the requirement to use cell salvage to correct any omissions in patient assessment planning. As far as possible there will be a straight comparison between cell salvage and allogeneic blood transfusions.

The decision to focus on hip surgery is primarily due to the level of activity undertaken in each area (table 6 below). There were three times as many elective hip procedures as knee procedures recorded by HRG in England in 2013/14 and the hip activity had increased against the comparative data in 2012/13 with the knee activity falling slightly. Changes in blood practice, as a result of blood saving initiatives, were therefore likely to have a higher impact in hip procedures, thereby influencing the choice of area to study. 
Table 6. Comparison of HRG Procedures in England - Hips v. Knees

\begin{tabular}{|l|r|r|r|r|r|r|}
\hline & \multicolumn{2}{|c|}{$\mathbf{2 0 1 2 / 1 3}$} & \multicolumn{2}{c|}{$\mathbf{2 0 1 3 / 1 4}$} & \multicolumn{2}{c|}{ Percentage Increase } \\
\hline Procedure & \multicolumn{1}{|c|}{ Number } & \multicolumn{1}{c|}{ Cost $£ \mathrm{~m}$} & \multicolumn{1}{c|}{ Number } & \multicolumn{1}{c|}{ Cost $£ \mathrm{~m}$} & \multicolumn{1}{c|}{ Number } & \multicolumn{1}{c|}{ Cost } \\
\hline Knee Procedures & 19,635 & 81.5 & 19,065 & 84.2 & $-2.9 \%$ & $3.3 \%$ \\
\hline Hip Procedures & 61,308 & 420.1 & 63,631 & 449.1 & $3.3 \%$ & $6.9 \%$ \\
\hline
\end{tabular}

Source. Analysis of reference cost returns; Department of Health

Aligned to the high number of hip procedures was the relatively high perception of health improvement by the patient questionnaires in the PROMs (patient recorded outcome measures) surveys. More recent statistics for 2012/13 (9 April 2015 publication) now show $96 \%$ of hip replacement patients reported an improvement. The regularly high PROMs measure implies a successful outcome to the operation, thereby allowing more certainty in assuming the operations were successful. The National Joint Registry Annual Report for 2013 noted 92\% of elective primary hip replacement patients were cited as having the primary indication for surgery being osteoarthritis. The inference is that the operation relieves the symptoms and debilitating factors associated with osteoarthritis.

The choice to focus on total hip replacement surgery therefore minimises the level of variability. The proportion of successful surgery is very high. A low variability will improve the ability to identify differences when making comparisons. This issue will be discussed in Chapter 4.

Patient reported outcome measures (PROMs) data above notes the high success rate of the operations. This supports the idea of using total hip replacement surgery as the outcome, thereby using the comparator of allogeneic blood required.

\subsection{Total Hip Replacement Operations}

The NHS Choices website (accessed 18 November 2015) highlights both types of arthritis (osteoarthritis and rheumatoid arthritis) as being the principal reason for hip surgery being required. The website also notes the other main reason being hip fracture 'during a fall or similar accident'. 
Lambden (2015) states that $95 \%$ of people aged over 60 years of age develop arthritic changes in one or more joints. Arthritis can affect all joints but the most common are hips and knees. The diagrams below show the difference between a normal hip joint where the head of femur (the 'ball' on top of the thigh bone) fits into the pelvis socket (the cup-shaped acetabulum). The cartilage, which acts as a lubricant, prevents the bones rubbing and grinding together. Osteoarthritis occurs when the cartilage gets worn away. Rheumatoid arthritis arises when the body's immune system mistakenly attacks the joint lining. The results are similar to osteoarthritis, with the joint getting damaged over time.

Figure 7. Normal Hip Joint

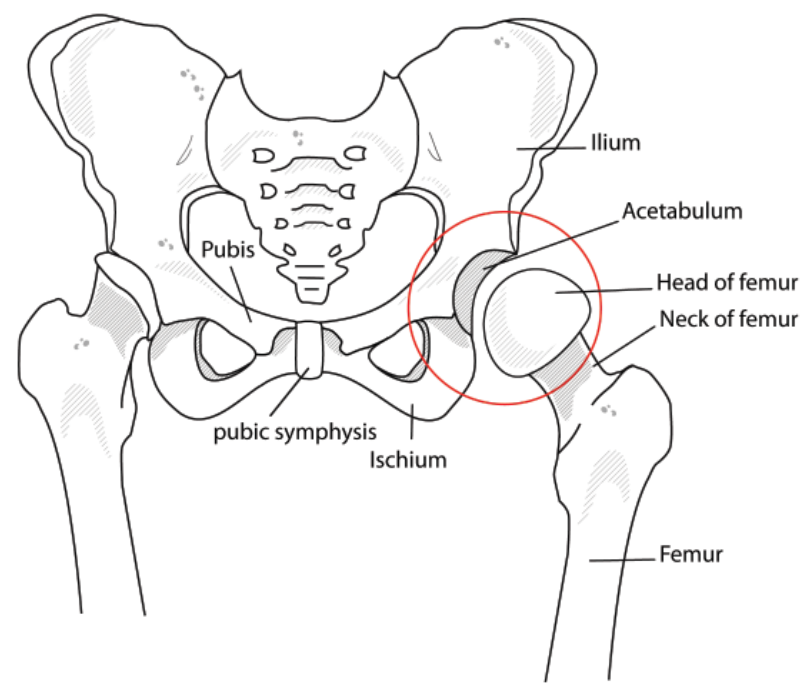

Figure 8. Arthritic Hip Joint

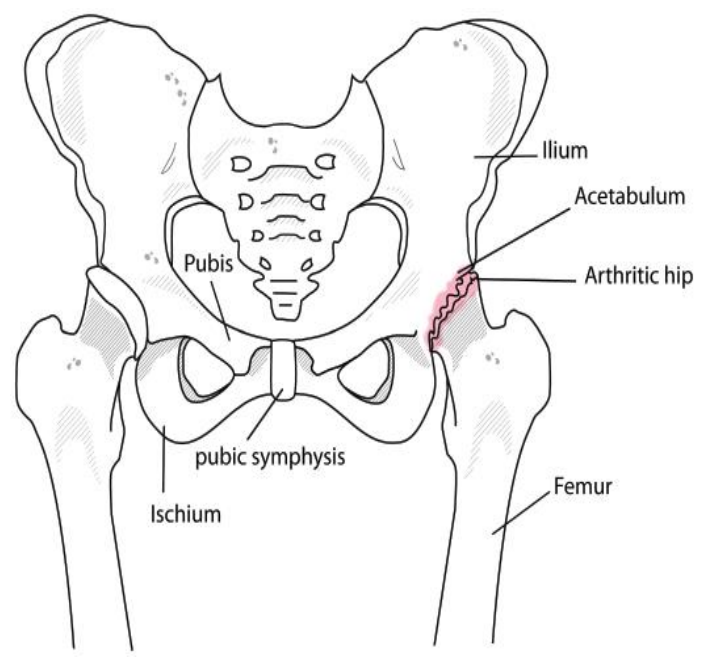

The above diagrams were reproduced with the permission of the UCLH Foundation Trust, London. 
Initial treatment for both types of arthritis is to control the pain and swelling via the administration of drugs along with an exercise programme to support mobility and encourage weight loss. If this is not successful, the decision would be taken to undertake a total hip replacement operation. This is where a metal stem is inserted into the femur. On the end of the stem is a ball which fits into a replacement acetabulum cup. The picture below shows an image of the successful operation.

Figure 9. Successful Total Hip Replacement

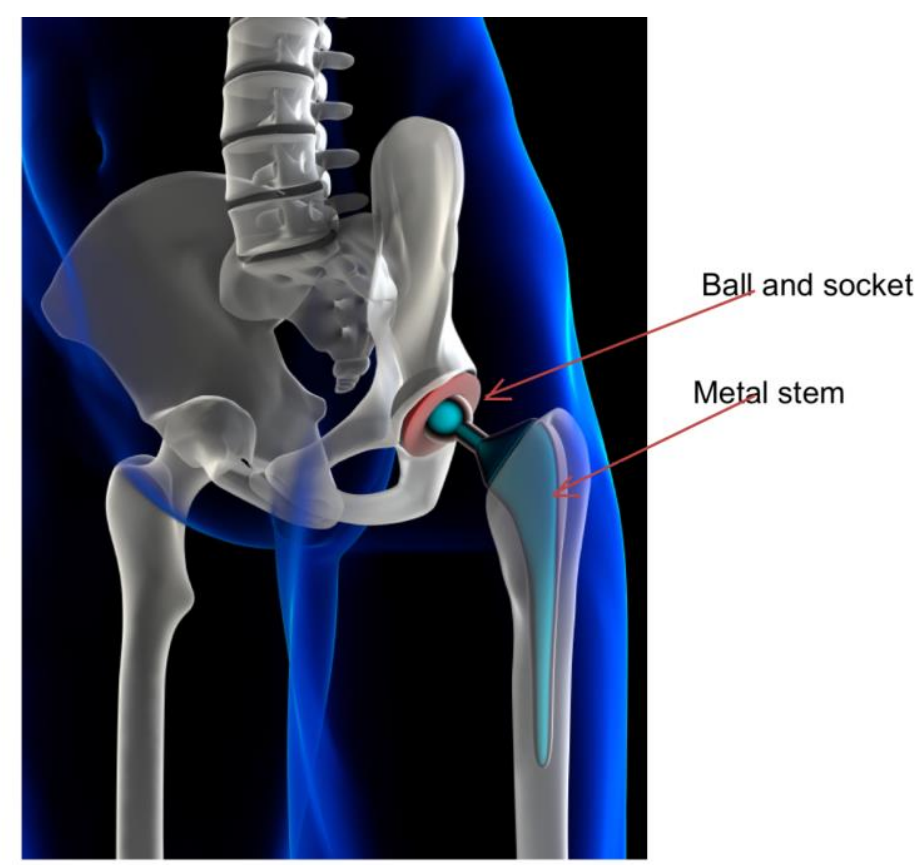

Above image reproduced from West of England Academic Health Science Network Photo library

\subsection{NHS Trust Financial Regime in England}

Hospitals are evolving into more commercially orientated entities. Since 2009 there has been a move to develop Service Line Reporting and Management (SLR) within NHS trusts. The application of the concept can vary across trusts but, broadly, the medical and surgical specialties will be segregated into business units with income and expenditure identified to each unit. Against imposed savings targets, costs and income are regularly reviewed with the focus on the 'profitability' of each business unit (see Service Line Management in www.gov.uk, accessed 25 January 2015). A typical general hospital will use over 5,000 allogeneic blood units per annum with the largest teaching hospitals using over 25,000 units, costing over $£ 3 m$. Most hospitals now charge out their blood costs to the relevant specialties/business units 
and some patient level costing systems are sufficiently sophisticated to charge the blood costs down to individual patient level, e.g. Guy's and St Thomas Hospital NHS Foundation Trust and University Hospital Southampton NHS Foundation Trust.

There have been significant developments in costing of services across the NHS over the past 15 to 20 years. The English NHS system operates on a tariff system whereby trusts are reimbursed for the costs of providing treatment via a single payment system applicable to all trusts. The tariff is essentially a price list of services (HFMA Briefing July 2012). The majority of these services are grouped into healthcare resource groups (HRGs). These are 'the currency used to collate the costs of procedures/diagnoses into common groupings to which prices can be applied' (HFMA/CIPFA definition October 2015). Each HRG is assigned a price and this is the income the trust will receive for performing the HRG. There is therefore the incentive to control costs, given the income per HRG is fixed, in order to increase the 'profitability' under SLR. At a basic level, avoiding allogeneic blood use will, 'ceteris paribus', increase the profit as the patient will still be treated and the trust will avoid paying the $£ 122$ for each unit of allogeneic blood.

\subsection{Allogeneic Blood Prices}

The price NHSBT charges for allogeneic blood each financial year is agreed in discussion with a panel of hospital users and representatives from the Department of Health (the 'National Commissioning Group for Blood'-the NCG), the notification letter on prices is shown in appendix 2. NHSBT's prices for blood and blood components are designed to reflect the cost over a particular level of activity. The changes in price of a unit of allogeneic blood over the past decade are shown in Figure 10 below. 
Figure 10. Allogeneic Unit Price Since 2008 (unadjusted for price inflation)

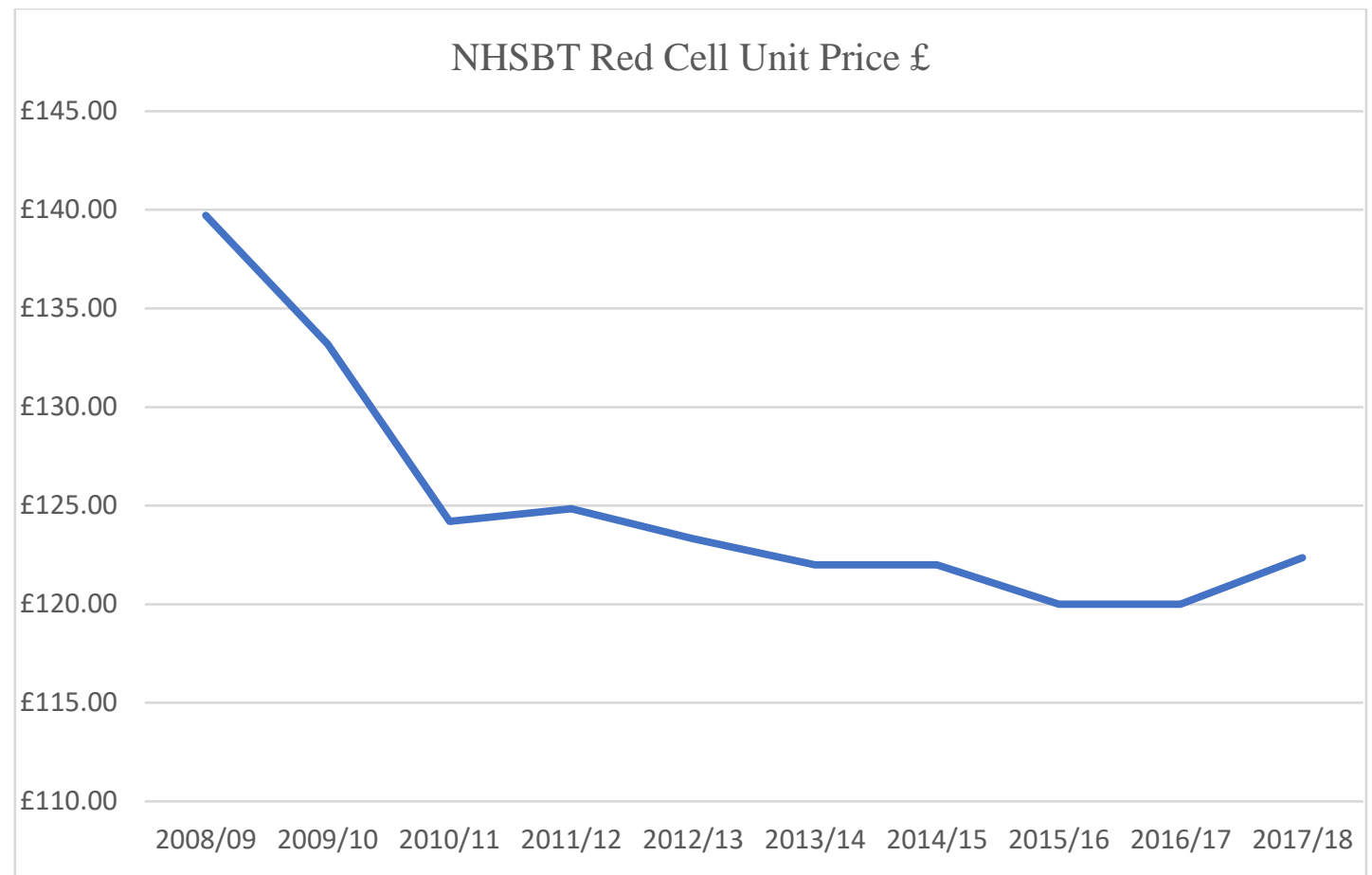

Source. Supplied from NHSBT Demand Planning Team

Table 10 highlights the sharp fall in the price to 2010 and the subsequent small reductions. The relative price (after taking pay and price inflation into account) of the allogeneic blood has therefore fallen significantly over the past decade. The gradual reduction in the price reflects the decreased costs of the operation of NHSBT due to the fall in demand for allogeneic blood of approximately 33\% between 2002/3 to 2017/17 (figure 2). Since 2005 NHSBT has been reviewing its property portfolio and focusing investment on a smaller number of centres while, at the same time, enhancing its transport infrastructure. There have also been a significant number of staff redundancies, thereby reducing NHSBT's cost base in the longer term and allowing the real terms fall in the price over the past nine years.

There is an argument that, if the fall in allogeneic blood usage did not occur in surgical specialties, there would be a greater chance of national blood shortages. This would have required wide-scale, and expensive, campaigns to recruit and retain more blood donors. This would be costly and the benefits of the price falls in Figure 10 would not be likely to have occurred. 


\subsection{Allogeneic Blood Transfusions and the Impact on the English NHS Tariff System}

As noted earlier, NHSBT sells blood at $£ 122$ per unit to hospitals. All blood products supplied by NHSBT are charged for and the prices are set to recover the full cost of NHSBT’s operations. In 2010/11 approximately £308m came from the supply of allogeneic blood and components (NHSBT annual accounts 2010/11, para 6.11). This procedure to recover costs via the internal market is consistent with the NHS tariff system where there is a price list for services provided by NHS organisations. Within NHS hospital trusts, the individual HRG price (Table 7 below) is fixed for the year, based on the average cost of all hospitals providing the HRG in England. This overall average cost is the basis of the tariff price for the HRG. The price will be adjusted by an average 'market forces factor' percentage to reflect areas of higher costs e.g. London. This tariff-based system is referred to as 'Payment by Results (PbR)'.

It is therefore relatively simple to identify the proportion of allogeneic blood costs in relation to the income received for undertaking the HRG. The coding of the HRG is undertaken by the hospital's specialist clinical coders. The standard NHS 'grouper' software will automatically identify a 'base HRG' and utilise the procedures that have been recorded to assign the most relevant HRG code.

Figure 11 below is reproduced from the HFMA's July 2012 briefing on PbR and notes the variation in HRG prices for elective hip replacement. All the clinical coding is undertaken retrospectively in hospitals. The diagram notes that all patients present with previously diagnosed osteoarthritis. The HB12C classification refers to the basic condition of a major hip procedure without any complications or comorbidities (' $\mathrm{CC}$ '). A CC is then introduced (in this case hypertension) and the grouper software will identify the HRG as HB12B; which is a major hip procedure with $\mathrm{CC}$. This revised coding will generate additional income for the Trust of 1138 per operation. Similarly, the HB12A, which has a major CC of dehydration, will attract a significantly higher level of income in recognition of the additional input the patient will require. 


\section{Impact of Clinical Coding on Trust income - Elective Hip Replacement}

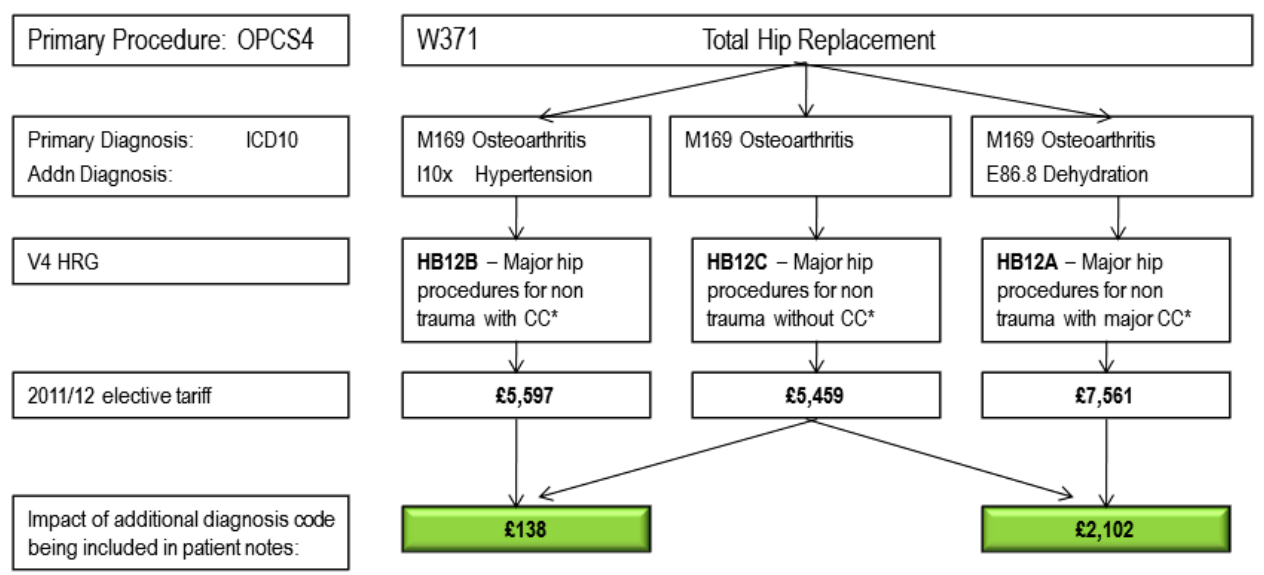

NB 'CC' = Complications and Co-morbidities

Assuming two units of allogeneic blood were required for the HRGs in Figure 11, the proportion of allogeneic blood costs in relation to HRG income would be shown in Table 7 below:

Table 7. Proportion of Allogeneic Blood Costs to Income in NHS Hospitals

\begin{tabular}{|c|c|c|c|}
\hline HRG: & $\begin{array}{l}\quad \text { HB12A } \\
\text { Maj Hip Procedure } \\
\text { with Major CC }\end{array}$ & $\begin{array}{l}\text { HB12B } \\
\text { Maj Hip Procedure } \\
\text { with CC }\end{array}$ & $\begin{array}{l}\qquad \text { HB12C } \\
\text { Maj Hip Procedure } \\
\text { without CC }\end{array}$ \\
\hline Two Allogeneic Units & $£ 244$ & $£ 244$ & $£ 244$ \\
\hline HRG Tariff 2012/13 & $£ 8,305$ & $£ 6,021$ & $£ 5,382$ \\
\hline Proportion & $3.0 \%$ & $4.1 \%$ & $4.5 \%$ \\
\hline
\end{tabular}

Note. CC=Complications and Comorbidities

It should be noted that table 7 outlines an indicative position consistent with a financial 'make v buy' question. The HRG is effectively a national average cost and therefore not used in decision making. Blood costs at hospital specialty level will be absorbed into the tariff price and averaged out nationally. Avoiding allogeneic blood usage will leave the hospital with more potential funds as the charges from NHSBT will be obviously lower. The funding mechanism combined with the internal market for allogeneic blood therefore encourages a hospital to avoid allogeneic blood charges. 


\subsection{Summary of Chapter 1}

This chapter has examined the history and development of allogeneic blood transfusions. It has introduced the role of NHSBT in ensuring the provision of allogeneic blood to (mainly NHS) hospitals in England and briefly highlighted the transfer price mechanism that operates.

There are significant disadvantages in undergoing an allogeneic transfusion and more recent studies highlight the inappropriate usage. Allogeneic blood usage has fallen significantly over the past decade. NHSBT does not operate in a commercial environment and savings in hospital allogeneic blood usage would eventually lead to price reductions though there may be a few years' lead time for the fixed costs (those costs that do not vary with activity) to be released from the NHSBT cost portfolio.

The process of cell salvage has been outlined in this chapter and the assertion is that its utilisation will avoid or minimise the requirements for an allogeneic transfusion being required in surgery. Proponents of cell salvage point to cost savings. Most publications do not focus on the detail of how these 'cost savings' are realised. The longer-term view is that the demand for allogeneic blood will increase, and transfusion avoidance techniques adopted within Patient Blood Management (including cell salvage) will be crucial in ensuring allogeneic blood usage is minimised to allow for its utilisation where no alternative exists. Cell salvage is one tool in the Patient Blood Management armoury and combined strategies may have contributed to the falling demand for blood in the surgical environment over the past decade.

Para 1.2 introduced the challenge of the differing theories around costing from a financial and economic perspective. Most accountants working in the NHS would be focused on their revenue budgets, being part of a financial analysis from an NHS organisational perspective. An economist would undertake an evaluation based on welfare economics (Mogyorosy and Smith (2005)), being concerned with "the impact of any decisions (changes) from a societal perspective".

The next chapter will investigate the theoretical aspects of 'costs' and 'savings' with particular reference to the NHS internal market for allogeneic blood. 


\section{Chapter 2. Financial \& Economic Costing-Allogeneic Blood Transfusions and Cell Salvage}

\subsection{Background}

The literature review will highlight a number of inconsistencies in the interpretation of costs associated with both allogeneic and autologous blood transfusions. This has been compounded by the cost of an allogeneic blood transfusion claimed by manufacturers' advertising literature. Sorin, manufacturers of the Electa cell salvage machine, claim the use of allogeneic blood costs $\$ 1,158$ per unit and Haemonetics, manufacturers of the OrthoPat cell salvage machine, claim the allogeneic blood costs "more than $\$ 1,400$ per unit" (appendix 1). If these high stated costs are correct the incentive to avoid an allogeneic unit is significant.

The actual amount charged for an allogeneic unit by NHSBT in England is $£ 122$. Cost is defined by Horngren et al (2015) as "the resource required to make, do or buy a commodity". This cost is the charge from NHSBT to hospitals (both NHS and private); this $£ 122$ charge has been relatively unchanged in cash terms from the early 2000 's. This section will therefore explore the concepts of costs from both a financial and an economic approach. The starting point in most of the UK literature is the price of an allogeneic unit of blood in the internal market for allogeneic blood within the English NHS. The analysis will commence by outlining the relevant costs relating to blood transfusions from both a financial and economic viewpoint.

\subsection{Financial Analysis}

Horngren et al (2015) initially assign costs as being direct or indirect costs.

- Direct Costs. "Those costs that are related to a particular cost object or product and can be traced to it in an economically feasible (cost-effective) way". Horngren et al (2015) also notes the technique of cost tracing, being the identification and assignment of costs. Direct costs in the hospital surgery setting would include the cost of allogeneic blood, cell salvage operating costs and consumables.

- Indirect Costs. These are other costs that are related to the particular cost objective but cannot be traced to it in an economically feasible (cost 
effective) way. These costs are often apportioned using a particular "cost allocation method". In the NHS, these are often termed 'overhead costs'. The operation of the hospital blood bank, internal portering service, ODP training and depreciation of the cell salvage machines would be relevant to the full costing of blood transfusions.

There are similar cost classifications at NHSBT. It should be noted that NHS accounting conventions report costs as gross, including VAT, where this is not reclaimable and also employers' national insurance and pension costs. NHS costs fall into two main overall categories. These are:

- Fixed Costs. Those costs that 'stay unchanged over stated ranges in the volume of production' (Wood and Sangster (2005) page 658).

- Variable Costs. These costs vary with output levels and, according to Wood and Sangster (2005), "variable costs are usually taken to be in direct proportion to volume' (page 658). The charge for allogeneic blood transfusions would therefore be a variable cost for the hospital. Cell salvage consumables would also fall within this category.

Avoiding an allogeneic blood transfusion will therefore generate a relatively substantial saving in the hospital budget (being a product of the number of allogeneic units avoided multiplied by £122) with 'ceteris paribus' the income received via the NHS tariff system being unchanged for the procedure. This saving is consistent with Table 8 that notes the costs avoided in hospital budgets utilising cell salvage. The key difference is, however, that NHSBT is obviously part of the NHS and therefore payment for allogeneic 'blood costs' at hospital level are viewed as 'income' to NHSBT. Most academic studies ignore this point that the $£ 122$ is an internal NHS transfer price. Table 8 below illustrates the issue if two units of allogeneic blood are avoided in an operation utilising cell salvage with consumable costs of $£ 92$ per unit. 
Table 8. Cost/Income in the Provision of Allogeneic Blood

\begin{tabular}{|c|c|c|c|}
\hline & $\begin{array}{c}\text { NHS } \\
\text { Trust } \\
\text { Level } \\
£\end{array}$ & $\begin{array}{c}\text { NHSBT } \\
\text { Level } \\
\qquad\end{array}$ & $\begin{array}{c}\text { NHS } \\
\text { Aggregate } \\
£\end{array}$ \\
\hline Hospital avoids 2 units & -244 & & -244 \\
\hline NHSBT income 'loss' & & 244 & 244 \\
\hline $\begin{array}{l}\text { Additional consumables (Royal Cornwall Hospitals } \\
\text { Electa costs including heparin/saline for illustration) }\end{array}$ & 92 & - & 92 \\
\hline NHSBT avoiding variable costs $(2 \mathrm{x} £ 18)$ & & -36 & -36 \\
\hline (Decrease)/Increase in Costs to NHS in Short Term & -152 & 208 & 56 \\
\hline
\end{tabular}

In the short term, under the NHS internal market for allogeneic blood, there is therefore an additional net cost of $£ 56$ to the NHS, associated with avoiding two allogeneic units utilising cell salvage. This is effectively the cell salvage cost being offset by the NHSBT variable cost of producing the units of allogeneic blood. NHSBT's variable costs are primarily the costs of the blood bag used to collect the blood from donors. In practice the hospital-based cost would be higher (e.g. including the costs of cell salvage training) however Table 8 highlights that the respective costs should not be viewed in isolation. NHSBT has responded to the fall in demand for allogeneic blood by centralising its services to remove its fixed costs. By working in isolation, the hospital therefore increases the short-term costs to the NHS. The charges for the allogeneic blood avoided by the hospital translate to an immediate offsetting loss of income for NHSBT. NHSBT attempts to mitigate this loss of income by requesting information on forecast usage via the National Commissioning Group for Blood and modelling demand over the forthcoming years to estimate the overall cost requirements. It is against this backdrop of falling activity that the progressive reorganisations have led to three main blood centres being established in England with smaller centres such as Plymouth being effectively stockholding units of blood products receiving daily top ups of products from Filton.

The $£ 122$ transfer price is therefore the average cost of one unit of allogeneic blood provided by NHSBT from the three main centres. Unlike many other manufacturing organisations there is no alternative allogeneic blood product available. To avoid the charge the hospitals therefore need to develop alternatives to the 'traditional' 
allogeneic blood transfusion for patient care. Cell salvage is an established alternative to allogeneic blood transfusions in a number of patient specialties. This therefore allows a comparison for 'make $\mathrm{v}$ buy' decisions. The 'make $\mathrm{v}$ buy' decision becomes more favourable with cell salvage when high volumes of blood loss are forecast. Horngren et al (2015) identify the concept of differential costs where the consumable costs are unchanged irrespective of the volume of shed blood collected and recycled. The cell salvage machine can keep recycling the shed blood until clotting is achieved. This therefore allows a higher equivalent unit of recycled blood compared to allogeneic blood to be salvaged where necessary.

Horngren et al (2015) also highlight the "concept of relevance" stressing the focus should be on "a manager selecting a course of action based on its future expected results". This approach should therefore exclude capital costs of the cell salvage equipment as these capital costs have already been incurred. Arguably the equipment is supplied using the 'razorblade model' where a relatively cheap purchase of a piece of equipment is then followed up by repeated purchases of associated consumables. Hospital departmental budgets are, however, likely to be charged the depreciation costs of the equipment. These charges will be levied regardless of activity since depreciation is regarded as a fixed cost.

From a financial perspective allogeneic blood and cell salvage related costs within hospitals and are therefore a combination of actual direct costs and internal transfer prices. All charges include VAT and other transfer costs, where levied; being consistent with NHS accounting requirements. This significantly adds to the cost profile of NHSBT and therefore, by implication, a proportion of the $£ 122$ charge per allogeneic unit of blood includes VAT. This transfer price is rarely highlighted in published articles. The analysis in chapters 6 and 7 will extract the transfer costs from the $£ 122$ charge and the other costs to facilitate a direct comparison between the costs of cell salvage $\mathrm{v}$ allogeneic blood; consistent with a 'make $\mathrm{v}$ buy' decision.

Within hospitals the 'Blood Bank' is still a feature in Pathology Departments. Often a separate cost centre, the Blood Bank Manager will book in allogeneic blood deliveries and maintain the storage facility in a cool room. Stocks will be monitored, and additional orders placed for allogeneic units when required. National blood stock 
management initiatives developed and led by NHSBT over the past 20 years have had significant impacts on the size of the hospital blood bank and the volume of allogeneic blood held at the hospital. The 'Online Blood Ordering System' (OBOS) automatically manages the hospital stock and reorders from the local blood centre/stock holding unit. At the same time the OBOS system will automatically reassign blood stocks nationally to ensure the average age of the blood stock is uniform across the country. The impact on allogeneic wastage has been significant. From a financial perspective the size and costs incurred by the hospital blood bank are now significantly lower and continue to fall. Often the Blood Bank Manager role is now combined with additional duties and performed by a less experienced member of staff. This obviously has an impact on the blood related costs reported in the hospital.

\subsection{Economic Analysis}

An economist will view the costs associated with allogeneic blood from a wider opportunity cost perspective (Mogyorosy and Smith (2005)). The cost of using the allogeneic blood is obviously relevant. Wider costs e.g. including the donor's travel costs and associated expenses of getting to and from the donation session are also relevant as these costs could be utilised by the donor on an alternative. Similarly, a donor may take time off work to donate. This may have impacts on pay and outputs.

Opportunity cost measures a particular course of action (e.g. donating blood) in terms of opportunities foregone. Arguably this issue may become subjective; many donors derive satisfaction from donating blood which generates a 'feel good' state of mind (see the reference to 'The Economist' para 1.8 with donated blood being regarded as being the 'gift of life'). Donors may place a greater value on these altruistic feelings than the actual costs they incur. A detailed discussion on this issue is beyond the scope of this thesis but the associated donor costs can be viewed as directly relevant and therefore an element of the comparison.

Drummond et al (2015) (page 62) note the development of guidelines for the analysis and presentation of results using standardised categories. The main features were grouped into a 'reference case' and the features are highlighted in table 9 below. The 
potential relevance to allogeneic blood transfusions and cell salvage for each of the elements is also noted in table 9.

Table 9. Standardisation of Reporting of Studies in Economic Evaluation in Healthcare (Drummond et al (2015))

\begin{tabular}{|c|c|}
\hline Element & Relevance to Cell Salvage \\
\hline 1. Adopt a societal perspective. & $\begin{array}{l}\text { Relevant-impact on donor's time, productivity } \\
\text { and opportunity cost in donating blood. }\end{array}$ \\
\hline 2. Estimates to incorporate benefits and harms. & $\begin{array}{l}\text { Relevant-Statistical comparisons of datasets } \\
\text { relating to allogeneic, salvaged blood and no } \\
\text { transfusions can be undertaken. There are very } \\
\text { few "harms" associated with allogeneic blood } \\
\text { (SHOT report) and the vast majority of these } \\
\text { harms relate to human error. }\end{array}$ \\
\hline $\begin{array}{l}\text { 3. Mortality and morbidity consequences should } \\
\text { be combined using QALYS. }\end{array}$ & $\begin{array}{l}\text { Partially relevant. HRG codes can standardise } \\
\text { comorbidity estimates and length of stay (LOS) } \\
\text { can be compared across sites. QALY approach } \\
\text { not relevant as the comparison is not on whether } \\
\text { or not to operate. }\end{array}$ \\
\hline $\begin{array}{l}\text { 4. Effectiveness estimates from best designed and } \\
\text { least biased sources should be used. }\end{array}$ & $\begin{array}{l}\text { Relevant. Literature review notes allegations of } \\
\text { bias (e.g. Carless et al (2010)). Common datasets } \\
\text { utilised to minimise this issue. }\end{array}$ \\
\hline $\begin{array}{l}\text { 5. Costs to include healthcare services, patient } \\
\text { and caregiver time and costs of non-health } \\
\text { impacts. }\end{array}$ & $\begin{array}{l}\text { Relevant. Consistent with societal perspective } \\
\text { and costs incurred by blood donor. }\end{array}$ \\
\hline $\begin{array}{l}\text { 6. Comparison should be made with existing } \\
\text { practice and (if necessary) a viable low-cost } \\
\text { alternative. }\end{array}$ & $\begin{array}{l}\text { Relevant. Undertaking a three-way comparison } \\
\text { between a cell salvage site and two sites who do } \\
\text { not salvage in total hip replacement surgery. }\end{array}$ \\
\hline 7. Discounting of costs should be undertaken. & $\begin{array}{l}\text { Not directly relevant. Overall outcome of surgery } \\
\text { is not directly contingent on the decision to use } \\
\text { allogeneic blood or an alternative. Can, however, } \\
\text { compare allogeneic blood costs directly with cell } \\
\text { salvage without the need to discount since time } \\
\text { periods are not crossed. Can also investigate } \\
\text { capital costs of machine acquisition from a } \\
\text { financial and an economic perspective to } \\
\text { determine whether any significant difference in } \\
\text { impacts. }\end{array}$ \\
\hline $\begin{array}{l}\text { 8. One way and multiway sensitivity analysis (for } \\
\text { important parameters e.g. tolerance to falls in } \\
\text { haemoglobin levels) should be undertaken. }\end{array}$ & $\begin{array}{l}\text { Relevant. Datasets on e.g. patients' pre-operative } \\
\text { Hb levels are pertinent to comparing approaches } \\
\text { to utilising allogeneic blood, cell salvage or } \\
\text { neither option. }\end{array}$ \\
\hline $\begin{array}{l}\text { 9. Composition of incremental cost effectiveness } \\
\text { ratios should be made with those for other } \\
\text { relevant interventions. }\end{array}$ & Not directly relevant. As for "7” above. \\
\hline
\end{tabular}

The economic costs associated with cell salvage and allogeneic blood in the comparisons should therefore be just the relevant elements. These can be analysed over the same headings as for the financial analysis.

- Direct Costs. Drummond et al (2015) classes these costs as those "unambiguously attributable to the treatment or programme in question" 
(page 238). Direct costs relating to allogeneic blood/cell salvage in the hospital surgery setting would include the cost of allogeneic blood, cell salvage operating costs/consumables and cross matching of blood.

- Indirect Costs. Drummond et al (2015) note that the favoured option is to utilise marginal analysis to identify costs that change if there were a change to the overall programme. This is particularly relevant to allogeneic blood transfusion and cell salvage. The costs incurred by the hospital blood bank may change if there were more or less allogeneic blood transfusions.

Both types of costs can then be sub-divided into:

- Fixed Costs. Nechyba (2011) defines a fixed cost as "an economic cost that remains unchanged regardless of how much output is produced" (page 1188). In relation to allogeneic blood transfusions/cell salvage these are mainly confined to the performance of costs at NHSBT. Staffing costs at NHSBT are generally viewed as the main fixed cost with the majority of staff on permanent contracts, having also accrued long periods of employment and pension benefits. It is likely these costs would remain unchanged for the following two years.

- Variable Costs. Nechyba (2011) defines a variable cost as a "cost that changes as the quantity produced changes" (page 1194). An allogeneic unit of blood, utilised in surgery, would be a variable cost in a hospital setting via the internal market (para 1.23) along with the consumables associated with utilising cell salvage.

The above definitions from both an accountant's and an economist's (Horngren and Nechyba) perspective are very similar. Both Horngren et al (2015) and Drummond et al (2015) refer to 'cost-effectiveness'; this is defined by Kobelt (2013) as "the efficient use of scarce resources" (page 3) and Drummond et al (2015) as where "(costs) are related to a single, common effect which may differ in magnitude between the alternative programmes". Kobelt (2013) elaborates by asking the question "is an additional benefit worth an additional cost?"; both questions imply there should be a decision made to justify whether or not to incur an additional cost. 
The operation of the NHS internal market has an impact on the decision making and focus on costs. The tariff funding for HRGs in para 1.24 is based on an average cost basis (i.e. a mix of direct, indirect, fixed and variable costs). This average cost is calculated by aggregating hospital apportioned costs to individual HRGs. These HRG costs and activity are then consolidated across all English hospitals to derive the average costs per HRG. Implicit in this HRG cost, and hence tariff price, will be the cost of allogeneic blood. Some hospitals may have elaborate patient level costing systems that identify allogeneic blood costs to patient and hence HRG; others may just undertake a simple apportionment exercise. These costing methodologies will feed into the NHS wide consolidated HRG cost information at a national level and the national average cost per HRG calculated. Avoiding a transfusion will therefore, 'ceteris paribus', lower the costs to be identified to the specific HRG at hospital level and, in the short term, therefore potentially generate a surplus given the tariff price per HRG is fixed.

As noted in table 8 above, aggregating both the costs and the avoided costs would, in the short term, cause an imbalance. Allogeneic blood costs in primary hip replacement operations are variable for hospitals, but there is an approximate 6:1 split between fixed and variable costs at NHSBT level (table 71, page 176). Timings to match demand for allogeneic blood with supply are therefore crucial. To circumvent this issue, the National Commissioning Group for Blood (para 1.23) meets to agree forecast volumes and prices annually. Arguably this is a market imperfection and perfect competition would ultimately generate an equilibrium price and quantity. The recent trends are towards a steadily declining demand for allogeneic blood and NHSBT is gradually decreasing its cost base to reflect the decreased demand. In recent years, the price (average cost) of a unit of allogeneic blood has remained steady or fallen slightly, this is mainly a consequence of the reduction in fixed costs by NHSBT closing or substantially reducing its scale of operations in Leeds, Birmingham, Southampton, Oxford, Plymouth and Brentwood. Para 1.4 noted that the longer-term outlook is still for an upturn in allogeneic blood requirements. It is planned that this upturn can be accommodated across a smaller number of centres supported by enhanced logistics to deliver the allogeneic blood to its required location. 


\subsection{Comparison of Perspectives}

Overall both financial and economic costs are relevant. From a financial analysis perspective budgetary issues relating to allogeneic blood and cell salvage would need to be highlighted and the overall (holistic) economic impacts could be described in an economic analysis. The choice of methodology of the economic analysis would need to be established and the next section will examine the main options/techniques available.

Morris et al (2007) noted: "Average cost data obscure potentially important issues with respect to the technical efficiency of providers". The 'make $\mathrm{v}$ buy' assertion effectively assumes that an allogeneic transfusion is required, and this can be replaced by cell salvage. What the 'make $\mathrm{v}$ buy' assertion omits is any verification that the approach to deciding whether or not the decision to undertake an allogeneic transfusion is based on a uniform set of comparable characteristics. The focus on the $£ 122$ and calculations of potential units avoided may make cell salvage seem attractive. The calculations are, however, built on average costs that can distract from the actual costs incurred or avoided. Morris et al (2007) recommend a three-point analysis involving:

- "Identify and describe the changes...in resource use that are associated with the options to be evaluated". The questions would therefore be whether or not to utilise an allogeneic transfusion, cell salvage, both (if necessary) or neither.

- "Quantify, in physical units, those changes in resource use". This would obviously involve the number of allogeneic units utilised along with the cell salvage usage where utilised.

- "Value those resources". Costs (adjusted depending on financial analysis or economic analysis) can be identified relating to the relevant option utilised.

This approach can be utilised to incorporate both financial and economic approaches. The issue on achieving uniformity of the need for an allogeneic transfusion will be addressed in chapter 5 (Methods).

\subsubsection{Types of Economic Evaluation}

Drummond et al (2015) note that "the purpose of any type of economic evaluation is to inform decisions about which of the alternative courses of action available ought 
to be recommended....for specific groups of patients". The alternatives available in this analysis are whether or not to utilise cell salvage in a primary total hip replacement operation to reduce the likelihood of the patient requiring an allogeneic blood transfusion. The costs of operating the cell salvage systems can then be compared to the savings in allogeneic blood usage associated with the lower allogeneic transfusion rate. Primary total hip replacement surgery was chosen for this study (paras 1.20) as the outcomes are highly successful and complications/comorbidities are unlikely to be a factor of whether or not a patient had or did not have an allogeneic blood transfusion.

Both Drummond et al (2015) and Kobelt (2013) detail a number of approaches to economic evaluation:

\section{Cost Effectiveness Analysis}

This analyses the costs and impacts of the treatment within the same setting. Drummond et al (2015) use the example of comparing renal dialysis with kidney transplantation. The "outcome of interest" is life years gained allowing the collection of cost data for the two alternatives and calculation of e.g. life years gained per $£ 1,000$ spent on each alternative.

This type of analysis would be partially relevant to a comparison of costs of allogeneic and salvaged blood. Reference is made in studies in the literature review of an association between a patient's length of stay (LOS) and whether s/he had or did not have an allogeneic blood transfusion. This discussion has tailed off in recent years. This study will compare LOS across the three chosen sites to establish whether there is a likely impact on LOS by having an allogeneic blood transfusion.

\section{Cost Minimisation Analysis}

There is a specific variant of cost effectiveness analysis where, according to Drummond et al (2015), the "consequences of two or more treatments or programmes (are) broadly equivalent, so the difference between them reduces to a comparison of costs". The 'treatment' or 'programme' in this thesis is utilising, or not utilising, cell salvage, with a potentially increased allogeneic blood transfusion requirement, in a successful primary total hip replacement operation (the outcome). 
Kobelt (2013) highlights a similar interpretation citing an example of the costs associated with administering two medicines to achieve the same outcome. This therefore allows the limitation of the study to costs alone.

\section{Cost Utility Analysis}

This is another variation of cost effectiveness analysis to study the consequences of the health intervention. The study utilises a generic measure of health gain (the positive impact of the intervention) such as a QALY (quality adjusted life year). This can therefore be used to compare different programmes of healthcare.

Given this study focuses on alternatives for allogeneic blood usage within primary total hip replacement surgery the concept of a health gain comparison is not directly relevant. As noted in chapter 1 the key aim of an allogeneic blood transfusion/cell salvage is to maximise the patient's post-operative $\mathrm{Hb}$ level after surgery. This will speed up recovery. Analysis by QALY or another form of cost utility analysis would not therefore support the comparison as it is not comparing different programmes of healthcare. Instead the analysis will concentrate on a particular set of costs associated with attempting to minimise the use of allogeneic blood.

\section{Cost Benefit Analysis}

This approach, according to Kobelt (2013) "measures costs and benefits in monetary units and computes a net pecuniary loss/gain". This requires the impacts of a particular course of action to be converted into monetary terms. A number of the earlier studies (e.g. Thomas et al (2001)) attempted this approach on total knee replacement surgery, citing the impact of the longer length of stay (LOS) associated with allogeneic blood transfusions. It was argued that this longer LOS generated additional costs e.g. additional accommodation and support costs. The literature review discusses other studies that adopt this approach noting, however, that most of the costs cited are fixed costs and are therefore not directly relevant to the discussion.

The LOS issue is still, however, pertinent. If the analysis in this study concludes, 'ceteris paribus', that increased LOS is likely to be driven by a patient having an allogeneic blood transfusion then an element of the support cost would be relevant to incorporate into the cost comparison i.e. avoiding this cost would be a further 
benefit. A cost benefit analysis approach should therefore not be discounted at this early stage.

\subsubsection{Choice of Approach for Economic Comparison}

Given the focus is on one particular treatment and the comparison is being made between allogeneic blood requirements and cell salvage, a cost minimisation study on the costs of cell salvage is likely to be the most appropriate approach. LOS issues should be investigated to determine whether this analysis should be extended to a cost benefit analysis

\subsection{Health Technology Assessment (HTA)}

The World Health Organisation defines a health technology as "the application of organized knowledge and skills in the form of devices, medicines, vaccines, procedures and systems developed to solve a health problem and improve quality of lives" (http://www.who.int/health-technology-assessment/about/healthtechnology/en/ accessed 6 October 2017). The "health problem" in this thesis is the requirement to increase the patient's post-operative $\mathrm{Hb}$ levels in order to facilitate a quicker recovery and hence support as early a discharge from hospital as possible. The choice is therefore whether or not to use cell salvage as a 'device' to avoid using an allogeneic blood transfusion.

An HTA is defined by the WHO (EB134/30) as "the systematic evaluation of properties, effects and/or impacts of health technologies and interventions. It covers both the direct, intended consequences of technologies and interventions and their indirect, unintended consequences". The WHO list various examples of when HTAs may be used to support decision making; these include "supporting decisions on diagnostic and medical equipment".

The application of cell salvage as a means of avoiding an allogeneic blood transfusion therefore falls within the criteria of an HTA. 


\subsection{Type of Analysis to Adopt}

Given so many of the cost concepts are interrelated the decision was taken to examine the costs associated with allogeneic blood and cell salvage from both a financial and economic perspective. Discussions with NHS accountants note their focus on the 'make v buy' approach. This is highly relevant but, from an economic cost perspective, omits questions on the efficacy of using either process when the 'do nothing' approach of not adopting either an allogeneic transfusion or utilising cell salvage may be an option. Additionally, an economic analysis would take a more holistic approach across the NHS and examine the related donor and societal costs that are rarely covered in the published literature. Separate 'pools' of costs to differentiate between financial and economic approaches can therefore be utilised.

\subsection{Treatment of Capital Expenditure}

Capital costs have a broadly similar definition from both a financial and an economic perspective. From a financial approach Horngren et al (2015) note capital budgeting is "the process of making long-run planning decisions for investments in projects". Drummond et al (2015) define capital from an economic analysis perspective as "the costs to purchase...major assets required by the programme; generally equipment and land". Both definitions note the issue of timing of the relevant expenditure. This timing is longer term and often involves 'up front' payments with the expectancy of a stream of benefits accruing over a number of years.

An economic approach would consider two elements associated with capital expenditure. There is an opportunity cost of the organisation's funds being tied up in the asset. This is usually accounted for by discounting the cash flows associated with the asset as it is being used. The second element is the depreciation of the asset over time. This represents the 'wearing out' of the asset through use or obsolescence. Drummond et al (2015) recommend treating capital costs through the 'equivalent annual cost' method. This method smooths out the two elements over the life of the asset. 
A financial approach will similarly attempt to identify the capital costs over the life of the asset. This is undertaken through depreciation where the capital cost is spread over and therefore charged to the financial years the asset is in use. NHS accounting requirements do not now require any discounting for a comparable opportunity cost charge. Depreciation is generally calculated on a straight-line basis. A typical cell salvage machine would cost around $£ 15,000$ including VAT. Many machines will last at least ten years, so the depreciation charge would be c. $£ 1,500$ per year. This cost in a hospital would generally be charged to the hospital department's operating budget. An apportionment would be required to identify the element of the $£ 1,500$ depreciation charge relating to primary total hip replacement surgery since the machine would also be utilised in other surgical procedures.

At NHSBT the identification of the costs associated with the capital assets utilised on allogeneic blood is more challenging. This will encompass elements of buildings, machinery and 'intangible' assets such as software. An estimate of the depreciation costs can be extracted from the notes to the audited accounts. The equivalent annual cost element will not be appropriate since the many hundreds of assets will have varying lives and depreciation methods however an estimate of the opportunity cost element in an economic evaluation can also be derived by reference to calculated depreciation charge, representing the decrease in the overall balance sheet value.

The calculations for the capital elements from both a financial and economic perspective will therefore be very similar. An adjustment for the transfer price charge for VAT will be also be required in the economic analysis.

\section{$2.8 \quad$ Summary of Chapter 2}

A brief comparison of the Financial and Economic perspective is summarised in table 10 below. There is no 'right' or 'wrong' approach. The hospital accountant will focus on a particular set of circumstances and assumptions within the blood related costs and contract income. This focus will be different to the income and cost focus from the accountants at NHSBT. All these costs and sales income are within the NHS and some of these cancel out. Additionally, the majority of non-pay costs include VAT and other transfer payments such as national insurance. From an economic 
perspective the wider cost impacts can be considered. These may include donor costs that are not recompensed or potentially lost production costs where the donor is given time off work to donate.

Table 10. Summary of Relevant Cost Concepts

\begin{tabular}{|c|c|c|}
\hline Issue & Financial Analysis-Horngren et al (2015) & $\begin{array}{c}\text { Economic Analysis-Drummond et } \\
\text { al (2015) }\end{array}$ \\
\hline Focus & $\begin{array}{l}\text { Expected future costs arising from a particular } \\
\text { course of action. }\end{array}$ & Same. Costs of allogeneic blood \\
\hline Emphasis & $\begin{array}{l}\text { Focus will be on the costs that differ according } \\
\text { to various courses of action e.g. cell salvage } v \\
\text { allogeneic blood. }\end{array}$ & As above. \\
\hline $\begin{array}{l}\text { Common } \\
\text { Costs }\end{array}$ & $\begin{array}{l}\text { Common costs e.g. hospital blood bank costs } \\
\text { are excluded but transfer payments are relevant } \\
\text { for budgetary purposes. }\end{array}$ & $\begin{array}{l}\text { Transfer payments excluded } \\
\text { (includes VAT that is levied across } \\
\text { most non-pay expenditure in the } \\
\text { NHS). }\end{array}$ \\
\hline Sunk Costs & $\begin{array}{l}\text { Sunk costs (past costs) are excluded but } \\
\text { depreciation still utilised in NHS accounts. }\end{array}$ & Excluded as not a relevant cost. \\
\hline $\begin{array}{l}\text { Wider } \\
\text { Costs }\end{array}$ & $\begin{array}{l}\text { Societal and wider non- hospital costs not } \\
\text { included. }\end{array}$ & $\begin{array}{l}\text { Include societal costs e.g. donor } \\
\text { travel costs, environmental costs, } \\
\text { lost productivity/time off work. }\end{array}$ \\
\hline $\begin{array}{l}\text { Capital } \\
\text { Expenditure }\end{array}$ & $\begin{array}{l}\text { Relevant from NHSBT perspective, given } \\
\text { depreciation is included in } £ 122 \text { charge for an } \\
\text { allogeneic unit. Reflects the accounting } \\
\text { 'accruals concept'. }\end{array}$ & $\begin{array}{l}\text { Relevant, reflecting the opportunity } \\
\text { cost of funds being tied up in the } \\
\text { assets. }\end{array}$ \\
\hline
\end{tabular}

Chapter 3 will develop the research question to consider the approach to the differing perspectives of costs highlighted in this chapter. 


\section{Chapter 3. Development of Research Question}

\subsection{Introduction}

The Literature Review will highlight the divergence and subjectivity of studies in the costs associated with cell salvage. The manufacturers (para 2.1) continue to imply significant savings can be made within a hospital when utilising cell salvage to replace an allogeneic blood transfusion. Chapter 2 noted the substantial differences between a financial and economic approach to the costs within the NHS internal market for allogeneic blood; the differing transfer prices and costs can significantly distort the position.

This chapter therefore outlines the development of the research question to incorporate the issues associated with 'costs' and the application of these 'costs' relating to cell salvage along with the impact of cell salvage on the allogeneic blood requirements.

\subsection{Research Aim/Challenges}

A brief background to the development of the researcher's interest in cell salvage was included in para 1.2. The challenges on undertaking the research were further exacerbated when he was made redundant from NHSBT in October 2013. This significantly held back the progression of the thesis as finding and settling into a new job became the priority. The researcher secured employment in the Finance Department at South Devon Healthcare Foundation Trust, Torquay in January 2014. This allowed access back into the NHS wide information systems, access to which had been suspended in October 2013. Work on the thesis recommenced in 2014 when it was time to take stock of how the research was developing.

The main association for accountants working in the NHS is the Healthcare Financial Management Association (HFMA). The researcher had previously written two articles on avoiding blood transfusions in the HFMA's monthly publication 'Healthcare Finance' in 2005 and 2010, however there was little interest generated in the healthcare finance community. Discussions with colleagues at NHS Trusts elicited the general response that the savings generated by cell salvage appeared relatively small. The accountants were looking for more and the emphasis was on 
wider NHS costing initiatives to achieve the savings being demanded by initiatives such as the 2010 Nicholson Challenge in the English NHS.

The 2010 HFMA article drew on the experiences of the researcher's trip to Pittsburgh to meet Dr Jon Waters, a leading proponent of avoiding allogeneic blood transfusions. Dr Waters stressed the importance of the recovery plans and highlighted the interrelationships between many initiatives running concurrently. He stressed that the operation day of the week was important for relatively routine operations to ensure most of the patients were sufficiently recovered to go home by the weekend. Tuesday surgery at Pittsburgh was traditionally the day for relatively minor orthopaedic operations to be undertaken so most patients would be home by Friday afternoon.

The researcher believes the impact of cell salvage goes much wider than savings in hospital blood budgets, with most hospital accountants focusing on the direct budgets as he did in his early days in London. There are few economic analysis studies taking a holistic view of the financial impacts (including transfer prices such as VAT and national insurance) across the whole area of blood transfusions from donor to patient. This study gives the opportunity to research the overall impact of cell salvage and will inform discussions over the wider development of the emerging concept of Patient Blood Management (PBM). The researcher's thoughts have developed significantly since his published article (Crotty (2006)) where, in hindsight, the analysis was simplistic.

Furthermore, the researcher notes the variation in the resources required to undertake a total hip replacement operation (para 1.24 above) using HRG coding to indicate the relative differences. This variation is likely to affect allogeneic blood requirements. To the best of the researcher's knowledge no study on the application of cell salvage in total hip replacement studies has made an assessment based on HRG classification. A study based on this enhanced level of detail will allow an additional level of confidence that the cohorts of patients are readily comparable and minimise the potential variation caused by those patients e.g. a group of patients may require relatively more invasive surgery due to additional complications and comorbidities. 


\subsection{Statement of Research Question and Objectives of Thesis}

This study aims to assess whether the utilisation of cell salvage in total hip replacement surgery will support overall reductions in allogeneic blood costs from both a financial and economic perspective. It will therefore assess the wider costs associated with allogeneic blood transfusions, including costs associated with blood donors and NHS wide costs. Cell salvage will also be assessed to verify whether it is cost effective in reducing the requirements (and hence demand) for allogeneic blood and thereby reducing costs across the NHS and the wider society.

As noted in chapter 2 the choice of specialty is likely to lend itself to a cost minimisation study. This is defined by Kobelt (2013) as being applied "when two or more health care interventions have the same outcomes". Kobelt (2013) quoted the example of a comparison of the cost of alternative drugs being appropriate to utilising a cost minimisation study. With cell salvage, there is an effective choice between using cell salvage to avoid an allogeneic transfusion, in the case of the Royal Cornwall Hospitals NHS Trust, or with South Manchester University Foundation Trust and the SOC (the Specialist Elective Orthopaedic Centre that remains anonymised in this study) not using cell salvage in orthopaedics. South Manchester utilise cell salvage in cardiac operations but believe that they can be equally assiduous in patient blood management without the need to salvage orthopaedic patients.

This cost minimisation approach has an added complication of including an internal recharging mechanism for allogeneic blood combined with alternative methods of avoiding allogeneic transfusions. The challenges associated with attempting to isolate the individual impact of the various allogeneic blood avoidance methods are highlighted in para 5.5.

Para 2.4 noted that, if length of stay (LOS) is likely to be a consequence of an allogeneic blood transfusion then a cost benefit analysis may be more appropriate. LOS will therefore be included in the analysis (para 3.3.3 below).

Additionally, there are even fewer studies that make comparisons between the different types of cell salvage machines available for use. Dusik et al (2014) state in their review of publications, "No studies directly compared transfusion rates among 
cell salvage systems". This thesis has extracted information from two different salvage systems (intraoperative and post-operative cell salvage) and a comparison of the information relating to the two systems' use will be undertaken. Preliminary work undertaken indicated that the running costs of the OrthoPat cell saver machine were significantly more expensive than other cell salvage machines. The Haemonetics investor conference call comments (para 1.9 above) were quite pertinent and reinforced the researcher's motivation to accommodate a comparison of cell salvage machines.

The research question was therefore developed in discussions with clinicians across a number of hospitals. The common theme of the discussions was the often-quoted remark by clinicians "the best transfusion is no transfusion" (Daniels and Bromilow (2014) quoted but widely discussed since the 1990's) and "transfusion has risks but bleeding to death is fatal" (Thomas (2005) page 35)). All means possible should therefore be used to minimise the likelihood of a patient requiring an allogeneic blood transfusion in surgery in accordance with the Department of Health (DH) ‘Better Blood Transfusion’ (BBT) initiatives of 1998, 2002 and 2007.

The research question was therefore finalised as:

"Is cell salvage an appropriate method of blood conservation to support the reduction in costs associated with the collection and utilisation of allogeneic blood?"

The question therefore allows the interrelationship between cell salvage and other blood avoidance techniques to be examined, as well as the wider analysis with costs at hospitals, NHSBT and costs associated with the donation process, including the donor costs. In the UK, in common with most countries, blood donors are unremunerated. The choice of the word "appropriate" was deliberate as this word was used to stress that consideration should be given to alternatives to an allogeneic transfusion "where appropriate and available". The second BBT initiative in 2002 was titled "Appropriate Use of Blood" with the third BBT initiative in 2007 entitled "Safe and Appropriate Use of Blood". The term therefore spanned both the allogeneic usage and the alternatives. The term, along with "inappropriate use of blood" was also stressed in the Patient Blood Management Guidance issued in June 2014. The adjective "appropriate" is defined by the Cambridge English Dictionary as 
"suitable or right for a particular situation". The term is therefore apt in the context of deciding when to administer an allogeneic blood transfusion where the clinician needs to decide on the basis of a number of issues that can be both subjective (e.g. the patient states they are feeling 'unwell') or more certain (e.g. the most recent $\mathrm{Hb}$ level).

The research question will be answered by addressing the following three overarching objectives:

3.3.1. Establish the homogeneity of the patient cohorts selected in order to minimise allegations of bias and compare patient data between sites that use and do not use cell salvage. This will support a valid comparison between the three sites.

3.3.2. Evaluate the cost impacts of cell salvage against using allogeneic blood from both a financial and an economic perspective;

3.3.3. Investigate other possible factors that may impact on comparison across sites such as preparation for surgery and length of stay.

\subsection{Summary of Chapter 3}

The differing approaches relating to the financial and economic analysis are highly relevant. An accountant in a hospital would view the comparison between utilising cell salvage to avoid an allogeneic blood transfusion as a 'make $\mathrm{v}$ buy' discussion where, all other things being equal, the hospital as a separate entity would benefit financially if the cost of operating cell salvage in an operation is less than the cost of the allogeneic blood purchased from NHSBT. The accountant at NHSBT would see the sales level fall with a fall in allogeneic blood usage. At the same time there is no guarantee that cell salvage or allogeneic blood is being utilised optimally with the concomitant impact on the level of costs incurred within the respective organisations. To the best of the author's knowledge no study has been undertaken to compare the overall impact of a mix of allogeneic blood and cell salvage together while, at the same time, investigating the efficacy of whether either type of transfusion is required at all. 


\section{Chapter 4. Literature Review}

\subsection{Introduction}

This chapter will focus on the published literature and will highlight the differing approaches to studies in cell salvage. The aim will be to generate sufficient information to support the work involved in developing the answer to the research question "Is cell salvage an appropriate method of blood conservation to support the reduction in costs associated with the collection and utilisation of allogeneic blood?".

Chapter 2 noted the alternative aspects of financial and economic analysis in relation to allogeneic blood and cell salvage. This literature review will consider the main selected studies from both aspects. 'Cost' is obviously a key attribute in the studies. However, this term can be interpreted in a number of different ways in studies. The aim of this chapter is to identify and highlight the differences in interpretations of costs and activity associated with cell salvage. This will form the basis for the information gathering at the three centres performing the total hip replacement operations.

Prior to developing the literature review, the researcher discussed the draft research question with a consultant anaesthetist at Abertawe Bro Morgannwg (ABM) University Health Board. His views were particularly thought provoking to the researcher. He stressed to the researcher that the 'costs' associated with a patient's treatment not only included direct and indirect costs (highlighted in para 2.2) but the wider societal costs also includes unquantifiable costs. This could be the anxiety of knowing a loved one is in hospital and the general lower productivity of relatives of working age who may take time off from work to visit. This issue is especially relevant to allogeneic blood transfusions where the mean age of the patients receiving an allogeneic transfusion is 62.7 years' old (para 1.9) and the partner may be around the same age with a higher likelihood of facing transport challenges in getting to the hospital to visit. The longer a patient is in hospital the more stress is therefore heaped on friends and relatives. The consultant anaesthetist stressed that length of stay should therefore be a key aspect of the study. This could act as an indicator of the general stress and anxiety levels impacting on others. 
Discussions with colleagues at NHSBT noted potential issues around the NHS internal market and that the true 'saving' of avoiding allogeneic blood would accrue across NHS organisations (table 8). The researcher had a further discussion with the Welsh Lead on the UK Cell Salvage Action Group. She drew the researcher's attention to the costs associated with training of staff to use the cell salvage machines. These were a short term logistical cost but, in time, these would tail off as more staff were trained.

At the hospital level the researcher had spoken to a number of blood bank managers. All were adamant that the NHS internal market could provide an incentive to reduce the cost of allogeneic blood in hospitals. There was a cynical view from one blood bank manager that lower NHSBT allogeneic blood issues would result in an increase in the price of an allogeneic unit to maintain overall cost recovery, but the price fall highlighted in figure 10, along with gradually decreasing allogeneic blood usage, is reassurance that this concern was unfounded.

The different perceptions of costs tended to muddy the waters. A significant challenge was to keep the study focused on cell salvage and attempt to isolate the impact of cell salvage on costs associated with the collection and utilisation of allogeneic blood. Not all costs highlighted were directly relevant to the discussions and this review will consider the efficacy and relevance of the costs.

Chapter 1 introduced the main concepts behind the provision of allogeneic blood and noted that the conditions for an economic analysis were appropriate to undertake a cost minimisation study; as highlighted by Kobelt (2013) where there are alternative treatments, but the outcomes are the same. Kobelt specifically refers to (page 36) "technical improvements in procedures, (that) can lead to fundamental changes to cost structures without affecting outcomes". One would expect a similar (successful) outcome to the operation with the technical improvement being the adoption of cell salvage to minimise the allogeneic blood requirements. The requirement would be whether the patient needed an allogeneic transfusion or, as an alternative, cell salvage; the blood requirement combinations would therefore be:

- patient has an allogeneic blood transfusion.

- adoption of cell salvage as an alternative to an allogeneic blood transfusion.

- a combination of a transfusion utilising both allogeneic and salvaged blood. 
- no transfusion at all with no cell salvage.

\subsection{Objectives of Chapter 4}

The key aim, as described in the research question, will be to identify the relevant financial and economic costs of cell salvage and its impacts on minimising allogeneic blood usage. This chapter therefore builds on the logic behind the development of the research question and reviews the literature associated with cell salvage and other aspects of allogeneic blood costs associated with answering the research question. It explores the differing views of authors, where the approaches and conclusions can contradict each other or where it could be argued the conclusions are based on logic that may not stand up to scrutiny or may be overtaken by developments.

Costs associated with an allogeneic blood transfusion can be grouped into four main headings:

- Hospital associated costs. The main element is the actual charge from NHSBT for a unit of blood (£122). Overall there are 23 different blood groups with over 400 antigenic differences (substances that can produce a specific immune response or reaction). The majority of human blood falls into six main groups. A patient undergoing an operation that will be likely to require an allogeneic blood transfusion will have his/her own blood 'cross matched' to test any incompatibilities between the antigenic differences. This test is undertaken by hospital haematology staff and the cost of this cross matching is borne by the hospital. Over the past ten years, there has been a move to electronic cross matching (ECM) where the results are available within minutes. This is adequate for c. $70 \%$ of all patients. Where a more detailed assessment is required the estimates on the cost vary but, in general; a cross match will cost approximately $£ 10-£ 20$. Additional costs will include the operation of the 'Blood Bank'-the secure area that stores the allogeneic blood and, depending on the size of the hospital and the volume of allogeneic blood required, will have at least one member of staff responsible for allogeneic blood issues. Where cell salvage is utilised, these costs are incurred by the hospitals in the form of the equipment costs (capital costs and 
running costs) and the consumable costs (mainly the reservoir, the tubes/filter and the anticoagulant). These costs are generally included in the published articles on cell salvage.

- Cell salvage equipment manufacturers costs. It is assumed that costs are recovered in the companies' pricing structures for the sale of equipment/consumables. In the US, especially, some manufacturers supply the equipment for no charge and recover their costs via charging for the consumables. In the UK, value added tax (VAT) is levied on all charges for equipment/consumables; this is not reclaimable by hospitals.

- NHS Blood \& Transplant (NHSBT) costs. NHSBT recover costs by levying a charge of $£ 122$ per unit of allogeneic blood ('red cells'). This was the uniform price charged for 2011/12, being held fixed for subsequent years, irrespective of the number of units requested, to all hospitals (both NHS and non-NHS). The price reflects the cost of the whole NHSBT operation from recruiting donors through to blood collection and the processing/testing environment to issuing the blood to the hospitals plus all the NHSBT overheads. The $£ 122$ charge includes transfer prices such as employers' national insurance contributions and VAT. HMRC class VAT as an 'exempt supply' for healthcare in the UK; as such, the VAT incurred on purchases of goods cannot be reclaimed by the NHS, except in specific circumstances. The calculations in this thesis will always include VAT and will be adjusted, where necessary, within chapter 6 .

- Societal Costs. This is a more subjective issue. The donors will give up their time to donate blood. There is an opportunity cost involved since the donors may lose pay through having to take time off work. If their pay is not deducted, then the employer will effectively be making good the loss. Either way, productivity falls. Alternatively, if, e.g. the donor takes a half day off as paid holiday s/he would be forgoing approximately 90 minutes of benefits derived from leisure by going to donate blood. There is also an environmental impact relating to the carbon emissions from the donor's journey to/from the donation location. 
Underpinning all the analysis will be the differences in interpretation between financial and economic analysis as highlighted in chapter 2.

\subsection{Methods}

The start point in the electronic search for information was undertaken by entering the terms 'cell salvage' or 'autotransfusion' (a US shortened form of 'autologous transfusion' and often used interchangeably with the term 'cell salvage') into the Eduserv Athens search engine. These accessed databases of publications including:

- Allied \& Complementary Medicine

- British Nursing Index

- CINAHL

- EMBASE

- Health Business Elite

- Health Management Information Consortium

- Medline

- PsycINFO

As noted in para 3.2 the author was made redundant from NHSBT in 2013, this slowed down the progression of the thesis as finding and settling into a new job became the priority. The search was therefore undertaken in two stages. The original search was undertaken to the end of 2011 however it was felt that this may omit more recent relevant articles. In 2014 it was therefore felt advisable to update the review to cover the additional two years to the end of 2013. In both cases the same search criteria was adopted.

A flowchart of the methodology is shown in figure 12 below: 


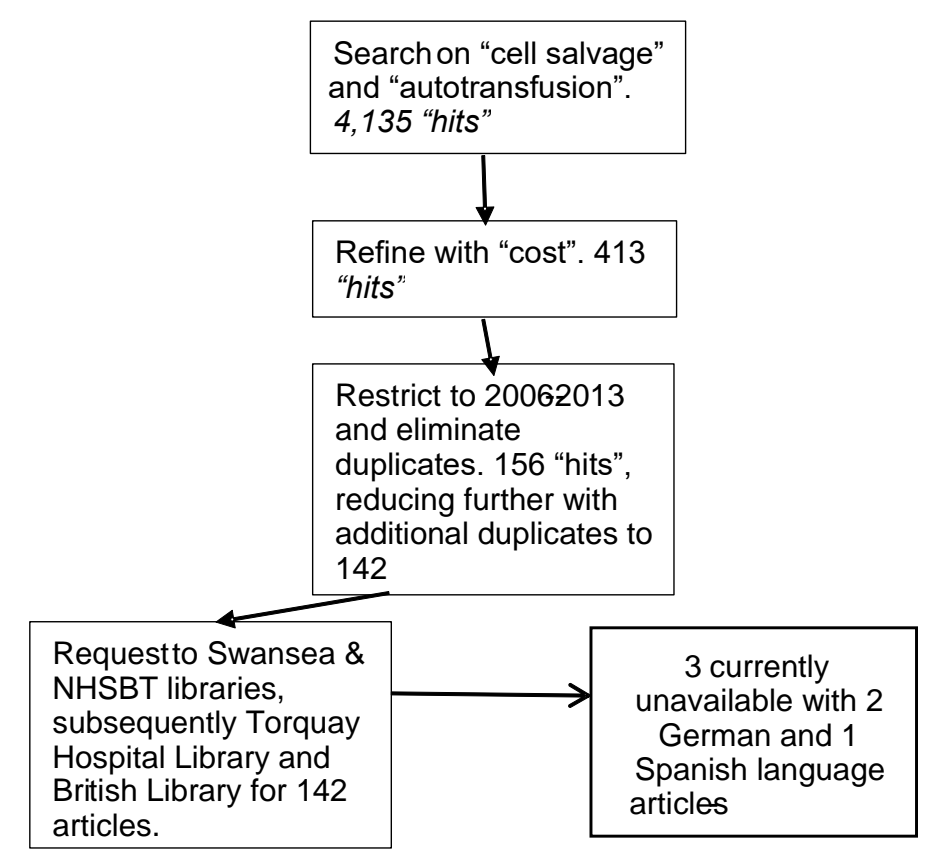

Tables 11 to 15 below have been derived from a Microsoft Excel pivot table analysis. A pivot table is a data summarisation tool that can automatically sift, sort and summarise spreadsheet data into a separate table according to the criteria stipulated. Summary information relating to each of the 142 articles selected was inserted into an Excel spreadsheet and table 11 below summarises the extraction of the data by country of origin and year of publication where the studies were undertaken. Discussions and investigation into cell salvage have been focused on publications from the US and the UK.

Table 11. Breakdown of Articles' Country of Origin

\begin{tabular}{|l|r|r|r|r|}
\hline Year & \multicolumn{1}{l|}{ UK } & \multicolumn{1}{l|}{$\begin{array}{l}\text { US } \\
\text { World }\end{array}$} & \multicolumn{1}{l|}{ Total } \\
\hline 2006 & 5 & 2 & 2 & 9 \\
\hline 2007 & 4 & 2 & 4 & 10 \\
\hline 2008 & 4 & 6 & 3 & 13 \\
\hline 2009 & 7 & 6 & 5 & 18 \\
\hline 2010 & 16 & 8 & 5 & 29 \\
\hline 2011 & 9 & 5 & 5 & 19 \\
\hline 2012 & 10 & 8 & 7 & 25 \\
\hline 2013 & 9 & 5 & 5 & 19 \\
\hline Total & $\mathbf{6 4}$ & $\mathbf{4 2}$ & $\mathbf{3 6}$ & $\mathbf{1 4 2}$ \\
\hline
\end{tabular}


Further sub-dividing these publications by specialty highlights the difference in emphasis in the studies between the UK and the US. This is shown in table 12 below.

Table 12. Breakdown by Specialty

\begin{tabular}{|l|r|r|r|r|}
\hline Specialty & UK & US & $\begin{array}{l}\text { Rest of } \\
\text { World }\end{array}$ & Total \\
\hline Orthopaedics & 10 & 11 & 9 & 30 \\
\hline Cardiac/Cardiothoracic & 8 & 11 & 10 & 29 \\
\hline Obstetrics \& Gynae & 23 & 2 & 1 & 26 \\
\hline Cross Specialty & 13 & 8 & 10 & 31 \\
\hline Other/General Total & 10 & 10 & 6 & 26 \\
\hline \multicolumn{2}{r|}{$\mathbf{6 4}$} & $\mathbf{4 2}$ & $\mathbf{3 6}$ & $\mathbf{1 4 2}$ \\
\hline
\end{tabular}

Analysing the information by article type by country of origin again highlights the dominance of the discussion between the UK/US. This trend may be changing slightly with slightly more articles being produced from other countries. It is therefore difficult to identify the usage of cell salvage across countries and whether the number of articles is a factor of usage or individual's aspirations. The most recent Council of Europe report (2013) on the 'Collection, Testing and Use of Blood and Blood Components in Europe' does not survey cell salvage usage in member states. As such there are few current assessments of the utilisation of cell salvage across countries.

Table 13. Breakdown of Articles by Type/Country of Origin

\begin{tabular}{|c|c|c|c|c|}
\hline Country & $\begin{array}{c}\text { Full } \\
\text { Article }\end{array}$ & $\begin{array}{c}\text { Conf } \\
\text { Abstract }\end{array}$ & Other & Total \\
\hline UK & 36 & 20 & 8 & 64 \\
\hline US & 29 & 11 & 2 & 42 \\
\hline Rest of World & 22 & 8 & 6 & 36 \\
\hline Total & 87 & 39 & 16 & 142 \\
\hline
\end{tabular}

\subsection{Studies Considering Financial Impact}

Each of the articles was reviewed and classed into a category to indicate the level of discussion relating to financial impacts. The criteria adopted was to take all 142 articles and group them into:

Low-no reference or passing general reference to the cost of operating the cell salvage machine or cost of allogeneic blood-no indications of costs that could be avoided. There was little allogeneic blood activity information reported to therefore estimate costs. 
Medium-Made more specific references to operating costs or impact of allogeneic blood costs in the study or some allogeneic blood activity information that would enable an estimate of the blood costs to be derived.

High-Incorporated costs and financial impacts in the conclusion or there was adequate allogeneic blood activity information to generate more detailed blood cost estimates and draw conclusions.

The criteria were, by the nature of the studies, subjective. The focus was initially on the studies that could allow the comparison of costs. Other studies were also accessed as examples to illustrate issues and make comparisons. Very few studies utilised any cost-effectiveness techniques or economic analysis. This criterion was therefore not used as a category to differentiate between the studies. Tables 11 to 13 above were therefore re-analysed in the Excel pivot table and summarised in table 14 below.

Table 14. Breakdown of Articles by Specialty and Cost Relevance

\begin{tabular}{|l|r|r|r|r|}
\hline Specialty\Relevance & \multicolumn{1}{|c|}{ High } & Medium & \multicolumn{1}{c|}{ Low } & \multicolumn{1}{c|}{ Total } \\
\hline Orthopaedics & 15 & 7 & 8 & $\mathbf{3 0}$ \\
\hline Cardiac/Cardiothoracic & 7 & 3 & 19 & $\mathbf{2 9}$ \\
\hline Obstetrics \& Gynae & 4 & 9 & 13 & $\mathbf{2 6}$ \\
\hline Cross Specialty & 8 & 2 & 21 & $\mathbf{3 1}$ \\
\hline Other/General Total & 6 & 4 & 16 & $\mathbf{2 6}$ \\
\hline \multicolumn{2}{|r|}{$\quad \mathbf{4 0}$} & $\mathbf{2 5}$ & $\mathbf{7 7}$ & $\mathbf{1 4 2}$ \\
\hline
\end{tabular}

The focus of the financial discussions is therefore on orthopaedics. 31 out of the 40 'high' categories are from the UK and US. The obstetrics and gynaecology total of 26 is one of the highest in the grouping; however, the 2010 publications were dominated by exchanges in correspondence in the publication, Anaesthesia, on hypotension in child birth and the impact of cell salvage. This made only slight references to costs in relation to the operation of the cell salvage filters used.

\subsection{Main Reference Work-Carless et al (2004) and (2010)}

The main published reference work is the Cochrane Collaboration's "Cell Salvage for Minimising Perioperative Allogeneic Blood Transfusion (Review)" authored by Carless et al (2004) with an update in 2010. Both studies undertook a meta-analysis of the publications relating to studies in cell salvage worldwide. Their specific search 
criteria identified allogeneic blood transfusion trials and randomised controlled trials (RCTs). They noted that there was little advance in the debate on costs. Some of their conclusions e.g. on orthopaedics, were virtually unchanged over the six-year intervening period between 2004-2010. Carless et al (2010) commented on the studies that took the 'traditional' approach to a cell salvage cost comparison. Generally, a hospital would randomly select patients to have cell salvage in a particular type of operation and compare the results against a similar cohort that had the same operation in the hospital but did not have cell salvage.

Carless et al (2010) assessed RCTs comparing allogeneic usage with cell salvage published between 1978 and 2008. They were critical on the low number (6) of nonEnglish language studies (page 12) and bought in a level of doubt over the comparability. They then asserted (page 15) that "technologies such as cell salvage have been introduced without firm evidence to support their use". This seems to be contradictory with the next comment relating to a 2006 Health Technology Assessment (HTA) (Davies et al 2006), this pointed to significant savings by using cell salvage. It is not clear whether Carless et al (2010) are critical of the HTA report. What is clear is the level of subjectivity and divided opinion across the discussion.

Carless et al (2010) noted the potential bias in studies such as Thomas et al (2001). This was also raised by Vamvakas and Blajchman (2001) who pointed to ethical considerations where patients cannot be randomly allocated not to receive a blood transfusion. There would therefore be a tendency to try to avoid giving postoperative allogeneic units to the cell salvage group of patients while feeling more relaxed about giving allogeneic units to the cohort without cell salvage. As noted in chapter 1 this was one of the reasons for the researcher developing a multi-site study to compare information from sites that used or did not use cell salvage in order to ensure this potential for bias is minimised. Given the variation in allogeneic transfusion rates the comparative study needed to be undertaken between sites with low rates of transfusion in order that a 'baseline' transfusion rate for the procedure could be derived. The comparative work would then isolate the costs associated with cell salvage. An article by Joy and Bennett (2012) was published that calculated the allogeneic transfusion rate for total hip replacement operations at $27 \%$ at the Gloucestershire Hospitals Foundation Trust. This is another variation on the theme of bias. Introducing cell salvage at Gloucestershire would be likely to reduce the 
volumes of allogeneic blood required. On the face of it cell salvage would then be banded a success but Joy and Bennett (2012) point to the high rate of 'inappropriate' transfusions $(>50 \%)$. If the blood management policy at the Royal Gloucestershire was enhanced to utilise fewer allogeneic units, savings in allogeneic blood usage would gradually accrue with little or no outlay.

The debate over ethical considerations has evolved over recent years. Catling (2009) noted that "the ethics of randomising patients to receive donor blood when they could chose (sic) autologous blood should be considered" in commenting on points raised in Geoghegan et al (2009). Catling (2009)'s reply to her letter noted that this is an issue that could be put to the relevant hospital ethics' committee. This issue over patient choice is key; Carless et al noted (page 6) the very high risk of selection bias in the studies and therefore the potential conflict between assigning a patient in a study to be in an allogeneic blood group i.e. not being given the opportunity to refuse allogeneic blood.

The conclusion to Carless et al (2010) article is hardly a ringing endorsement of cell salvage: "the use of washed cell salvage appears justified in orthopaedic surgery". The implication is that cell salvage is cost effective but their recommendation, unchanged from 2004, remained that "the principal need is for large, methodologically rigorous comparative trials to assess the (inter alia) cost effectiveness of cell salvage in different surgical procedures". Disadvantages in using cell salvage were highlighted but Carless et al's conclusions were that no advantages were statistically significant. They also highlighted that the difference in hospital length of stay was not statistically significant when comparing cell salvage with allogeneic blood. Their conclusions focused on the negative and did not consider costs in detail though they referred to costs that in some studies were not included e.g. the operator costs or the actual cell salvage kit itself. Davies et al (2006) was quoted noting the net benefit of using cell salvage in an operation as being within the range $£ 112$ to $£ 359$. These were the only detailed costs referred to in Carless et al (2010).

Carless et al (2010) sum up their analysis by stating, "The majority of trials were of poor quality" and of most concern was that "only one trial reported a method of concealing treatment allocation that was judged to be adequate". These (relatively 
scathing) comments were noted and borne in mind by the researcher for the comparative studies to be undertaken. Given no patient allocation was required (all orthopaedic patients were planned to be salvaged at the Royal Cornwall Hospitals and none at South Manchester or the SOC) this thesis will circumvent the allegation of potential bias on patient selection. Additionally, the allocation of the patient to the relevant HRG (para 1.24) is automatically undertaken post-operatively via the national HRG grouper software that identifies the patient to a specific HRG code. This code is allocated utilising the individual procedure codes assigned by the clinical coders who act independently of the whole surgical process.

A number of articles highlight the potential disadvantages of cell salvage but state that, on balance, the advantages of avoiding an allogeneic transfusion outweigh the disadvantages. Liumbruno et al (2011) highlighted a more recently discussed disadvantage of having an allogeneic blood transfusion; the increased risk of alloimmunization. This is where the patient's blood effectively becomes immune to the benefits of the allogeneic blood. Recycling as much of the patient's own blood as possible would minimise the requirement to use allogeneic blood. They stress the advantages of cell salvage far outweigh the disadvantages and focus on alloimmunization as the main disadvantage of having the allogeneic blood transfusion. This article (page 2251) showed a level of subjectivity by including a caveat "although to the knowledge of the authors.." that "most likely the risk of maternal alloimmunization by allogeneic blood transfusion is much greater than that caused by fetal RBCs". The authors also noted, "evidence from comparative studies is still lacking". The key recommendation was that patients at higher risk of haemorrhage should be targeted with CS. On a related issue, Hussain (2010) stresses that, where there is an indication of any adverse issue e.g. increased blood loss then the simple solution is to stop the cell salvage and give an allogeneic transfusion. This can be undertaken in minutes. Some hospitals take several allogeneic units from the blood bank and keep them in a cool box in the operating theatre as a safeguard. If the units are not required, then they are returned to the blood bank.

On a related issue para 1.9 notes the administration of tranexamic acid as a method of slowing down the blood loss. A Cochrane Review, Perel et al (2013) concluded that "tranexamic acid reduces the probability that a patient will receive a blood transfusion by around 30\%". This review was undertaken on studies relating to 
"emergency or urgent" surgery. Arguably the volume of blood loss may be higher in emergency cases (also pre-operative $\mathrm{Hb}$ levels would not have been managed) but the total is indicative of how tranexamic acid has impacted on the discussions on allogeneic transfusions and the effect it has on manufacturers of cell salvage equipment (para 1.9). Tranexamic acid is now included on the World Health Organisation's (WHO) Model List of Essential Medicines. Essential medicines are "those that satisfy the primary health needs of the population" and "are intended to be available within the context of functioning health systems at all times" (WHO website www.who.int accessed 8 November 2015). The main proposal for the inclusion came from Dr Paul Carless in 2008 who saw the benefits of combining a number of blood avoidance techniques. It is interesting to note that little cross reference is made to combining allogeneic blood avoidance techniques in Carless et al (2010).

On balance, Carless et al (2010) were highly critical of the studies they reviewed. They did not consider the background of the significant decline in the use of allogeneic blood in the period 2001 to 2010 (para 1.10). A number of the authors whose work was critiqued by Carless et al were most probably significant contributors to developing systems to avoid the unnecessary use of allogeneic blood, thereby providing a benefit to the population. This issue is not recognised in Carless et al (2010) where the authors could have addressed and highlighted the fall in overall usage in their analysis. Carless et al (2010) could therefore have shown a degree of empathy, highlighting that the publicity around the articles may well have contributed to the success by the UK NHS bodies in increasing the number of operations and, at the same time, decreasing the surgical use of allogeneic blood.

Carless et al (2010) were consistent with other studies in that they did not differentiate between the financial and economic costs. Their plain language summary notes "the financial costs associated with providing a safe and reliable blood product are escalating". It is unlikely that the authors were deliberately differentiating between 'financial' and 'economic' costings in this context. 


\subsection{Discussions Post Carless et al (2004)}

Since 2004 the main author of articles proposing expansions in cell salvage and other blood sparing techniques is Dr Jon $\mathrm{H}$ Waters from the University of Pittsburgh Medical Centre (UPMC). Waters et al (2007) points to significant savings resulting from paying for less blood utilised and the resultant shorter LOS associated with not having an allogeneic blood transfusion. There is a wider debate on whether or not an allogeneic blood transfusion contributes to a longer LOS. This is cited in the conclusion, but no attempt is made in the article to justify the assertion. Waters et al (2007) include staff costs that are viewed as a necessity such as three ODP staff dedicated to operating the five machines used in the study; other articles such as Brown (2010) also take this view and allocate costs. The key assumption is that “...every cell salvage unit would replace an allogeneic unit” (page 871). This is a sweeping assumption and may only apply to systems such as the OrthoPat machine; this will re-infuse the patient after his/her operation. Since the blood has been collected and washed then there is the obvious incentive to re-infuse the patient anyway. There is a higher probability that, if cell salvage was not undertaken, an allogeneic transfusion may be required but there is no 'one for one' theoretical replacement. This has the effect of increasing the perceived savings reported. Dixon et al (2004) also adopted this approach, citing intra-operative cell salvage avoiding c. 410,000 units of allogeneic blood with a saving of c. $£ 100$ per unit i.e. $£ 41 \mathrm{~m}$.

It is interesting to note that the majority of UK studies assume the operator of the equipment will not be in addition to the usual complement of staff. This contradicts the detailed calculations undertaken by Waters et al (2007) who included dedicated staff to manage the cell salvage equipment. Discussions with members of the UK Cell Salvage Action Group elicit the unanimous view that no additional staff are required, and the training provided in-house and by the manufacturers is sufficient for the needs of the existing staff to cope with the workload.

Later in the 2000's there was wider discussion in the use of cell salvage in Obstetrics. As noted in chapter 1 there has been a marked move in allogeneic blood usage from surgical to medical. The proportion of allogeneic blood utilised in obstetrics has remained fairly static at around 5\% (NHSBT surveys). This has, most likely, stimulated the discussion of the application of cell salvage in caesarean 
sections where blood loss can be relatively high but predictable. The analysis of the articles by year and specialty is shown in table 15 below:

Table 15. Breakdown by Specialty by Year

\begin{tabular}{|l|r|r|r|r|r|r|r|r|r|}
\hline Specialty & $\mathbf{2 0 0 6}$ & $\mathbf{2 0 0 7}$ & $\mathbf{2 0 0 8}$ & $\mathbf{2 0 0 9}$ & $\mathbf{2 0 1 0}$ & $\mathbf{2 0 1 1}$ & $\mathbf{2 0 1 2}$ & $\mathbf{2 0 1 3}$ & \multicolumn{1}{c|}{ Total } \\
\hline Orthopaedics & 2 & 3 & 1 & 4 & 4 & 2 & 8 & 6 & 30 \\
\hline Cardiac/Cardiothoracic & 1 & 2 & 7 & 6 & 3 & 4 & 4 & 2 & 29 \\
\hline Obstetrics \& Gynae & & 1 & 2 & 4 & 8 & 3 & 4 & 4 & 26 \\
\hline Cross Specialty & 5 & 4 & 3 & - & 3 & 5 & 5 & 6 & 31 \\
\hline Other/General & 1 & - & - & 4 & 11 & 5 & 4 & 1 & 26 \\
\hline Grand Total & $\mathbf{9}$ & $\mathbf{1 0}$ & $\mathbf{1 3}$ & $\mathbf{1 8}$ & $\mathbf{2 9}$ & $\mathbf{1 9}$ & $\mathbf{2 5}$ & $\mathbf{1 9}$ & $\mathbf{1 4 2}$ \\
\hline
\end{tabular}

The discussions around cell salvage in Obstetrics peaked in 2010. There is currently (2018) a large-scale, multi-site, cell salvage study in obstetrics (the 'Salvo' study) being undertaken across the UK. In part, this was undertaken as an impact of the earlier discussions and wider debate in the obstetrics field. This was originally a twoyear study that was originally intended to complete in 2015. The study timescales were significantly extended due to the need for a more even split of data between cell salvage and non-cell salvaged activity. The initial publication from the study, Khan et al (2017) noted there was "modest evidence for an effect of routine use of cell salvage during caesarean section on donor blood transfusion".

\section{7 'High' Rated Articles}

The articles rated 'high' in para 4.4. are summarised below:

Table 16. 'High' Rated Articles

\begin{tabular}{|c|c|c|c|c|c|c|}
\hline Ref & $\begin{array}{l}\text { First } \\
\text { Author }\end{array}$ & Year & Country & Specialty & $\begin{array}{l}\text { Article } \\
\text { Type }\end{array}$ & Summary of Discussion \\
\hline $\mathrm{A} 04$ & Samnaliev & 2013 & US & Paeds & Full & $\begin{array}{l}\text { CS cheapest when compared } \\
\text { to allogeneic and pre-deposit } \\
\text { and combinations. }\end{array}$ \\
\hline A05 & Solomon & 2013 & $\begin{array}{l}\text { South } \\
\text { Africa }\end{array}$ & Obstetrics & Full & $\begin{array}{l}\text { Converted salvaged blood to } \\
\text { equivalent allogeneic units. } \\
\text { Concluded very little } \\
\text { difference. }\end{array}$ \\
\hline A06 & Bigsby & 2013 & UK & Orthopaedics & Full & $\begin{array}{l}\text { Estimated volume of } \\
\text { allogeneic blood needed to } \\
\text { replace salvaged blood. } \\
\text { Concluded cell salvage cost } \\
\text { effective. }\end{array}$ \\
\hline A16 & Canan & 2013 & US & Orthopaedics & Full & $\begin{array}{l}\text { CS not cost effective in single } \\
\text { level lumbar decompression } \\
\text { and fusion surgery. }\end{array}$ \\
\hline A19 & Offierski. & 2013 & Canada & Orthopaedics & Conf Abs & Compared allogeneic \\
\hline
\end{tabular}




\begin{tabular}{|c|c|c|c|c|c|c|}
\hline Ref & $\begin{array}{l}\text { First } \\
\text { Author }\end{array}$ & Year & Country & Specialty & $\begin{array}{l}\text { Article } \\
\text { Type }\end{array}$ & Summary of Discussion \\
\hline & & & & & & $\begin{array}{l}\text { transfusion requirements after } \\
\text { introduction of tranexamic } \\
\text { acid. Concluded allogeneic } \\
\text { requirements fell. } \\
\end{array}$ \\
\hline A23 & Odak & 2013 & UK & Orthopaedics & Full & $\begin{array}{l}\text { Assessed the theoretical fall in } \\
\text { Hb levels if cell salvage was } \\
\text { not adopted and estimated the } \\
\text { cost of allogeneic blood } \\
\text { required to alleviate the fall. }\end{array}$ \\
\hline A29 & Brearton & 2012 & UK & Obstetrics & Full & $\begin{array}{l}\text { Estimated the number of } \\
\text { allogeneic units avoided by } \\
\text { using cell salvage. Concluded } \\
\text { small savings were possible. }\end{array}$ \\
\hline A36 & Rao & 2012 & US & Orthopaedics & Full & $\begin{array}{l}\text { Compared notional volumes } \\
\text { of blood avoided. Savings in } \\
\text { THR. }\end{array}$ \\
\hline A41 & Munoz & 2012 & Spain & Orthopaedics & Conf Abs & $\begin{array}{l}\text { Concluded that LOS one day } \\
\text { longer if a patient had an } \\
\text { allogeneic transfusion. }\end{array}$ \\
\hline 2 & Kelleher & 2011 & UK & Cardiac & Full & $\begin{array}{l}\text { QA aspects to increase } \mathrm{Hb} \\
\text { levels and decrease reliance } \\
\text { on allogeneic blood. }\end{array}$ \\
\hline 3 & Frank & 2011 & US & General/Cross & Editorial & $\begin{array}{l}\text { Introduced additional costs to } \\
\text { be included. }\end{array}$ \\
\hline 4 & Liumbruno & 2011 & US & Obstetrics & Full & $\begin{array}{l}\text { Cites risks of immunity to } \\
\text { benefits of allogeneic blood } \\
\text { and cost impact. }\end{array}$ \\
\hline 5 & Portsmore & 2011 & UK & Emergency & Conf Abs & $\begin{array}{l}\text { Focus on trauma/massive } \\
\text { haemorrhage. Indicates cell } \\
\text { salvage cost effective with } \\
\text { larger volumes of blood loss. }\end{array}$ \\
\hline 7 & Buckley & 2011 & UK & AAA & Conf Abs & $\begin{array}{l}\text { Average reduction of } 1 \text { unit of } \\
\text { allogeneic blood per operation } \\
\text { where cell salvage utilised. }\end{array}$ \\
\hline 8 & Thurer & 2011 & US & General/Cross & Conf Abs & $\begin{array}{l}\text { Significant reduction in } \\
\text { transfusion rate and costs with } \\
\text { CS. Stressed the combination } \\
\text { of blood avoidance } \\
\text { techniques. }\end{array}$ \\
\hline 13 & Yarham & 2011 & UK & Evaluation & Full & $\begin{array}{l}\text { Evaluation of Sorin Electa } \\
\text { machine. Stresses the } \\
\text { disadvantages of allogeneic } \\
\text { transfusions. }\end{array}$ \\
\hline 14 & Attaran & 2011 & UK & Cardiac & Full & $\begin{array}{l}\text { Challenged use of cell salvage } \\
\text { in routine cardiac surgery. } \\
\text { Argued differences between } \\
\text { allogeneic v cell salvage not } \\
\text { significant. Pointed to intraop } \\
\text { cell salvage potentially } \\
\text { offsetting falls in Hb. }\end{array}$ \\
\hline 16 & Waldron & 2011 & UK & Obstetrics & Conf Abs & $\begin{array}{l}\text { Obstetric study noting savings } \\
\text { of } £ 220 \text { per operation using } \\
\text { CS. }\end{array}$ \\
\hline 17 & Butchart & 2011 & UK & Orthopaedics & Conf Abs & $\begin{array}{l}\text { Noted potential tail off in } \\
\text { usage of CS. }\end{array}$ \\
\hline 19 & Ubee & 2011 & UK & Urology & Full & $\begin{array}{l}\text { Small sample study pointing } \\
\text { to savings in blood costs and } \\
\text { lower LOS associated with }\end{array}$ \\
\hline
\end{tabular}




\begin{tabular}{|c|c|c|c|c|c|c|}
\hline Ref & $\begin{array}{l}\text { First } \\
\text { Author }\end{array}$ & Year & Country & Specialty & $\begin{array}{l}\text { Article } \\
\text { Type }\end{array}$ & Summary of Discussion \\
\hline & & & & & & CS. \\
\hline 22.1 & Waters & 2010 & US & Orthopaedics & Conf Abs & $\begin{array}{l}\text { Significant variation in } \\
\text { transfusion rates between } \\
\text { surgeons. LOS higher with } \\
\text { allogeneic transfusions. }\end{array}$ \\
\hline 22.2 & Thurer & 2010 & US & Orthopaedics & Conf Abs & $\begin{array}{l}\text { Same surgeons involved in } \\
\text { TKR ops in } 2007 \text { (no CS) and } \\
2009 \text { (with CS). Allogeneic } \\
\text { transfusions fell by 33\%. }\end{array}$ \\
\hline 22.3 & Waters & 2010 & US & Orthopaedics & Conf Abs & $\begin{array}{l}\text { Discussed variations in blood } \\
\text { usage between surgeons and } \\
\text { questioned whether cell } \\
\text { salvage was beneficial in } \\
\text { THRs. }\end{array}$ \\
\hline 23 & Jaben & 2010 & US & General/Cross & Conf Abs & $\begin{array}{l}\text { Studied long term survival } \\
\text { rates following surgery where } \\
\text { a transfusion was needed. } \\
\text { Found the lower the } \\
\text { transfusion rate the longer } \\
\text { survival. }\end{array}$ \\
\hline 25 & Spahn & 2010 & $\begin{array}{l}\text { Multi } \\
\text { Nat }\end{array}$ & Orthopaedics & Full & $\begin{array}{l}\text { Large analysis of studies, } \\
\text { many of which had different } \\
\text { criteria. Looked at anaemia } \\
\text { and concluded cell salvage } \\
\text { generally reduced the need for } \\
\text { allogeneic transfusion. }\end{array}$ \\
\hline 27 & Brown & 2010 & US & Trauma & Full & $\begin{array}{l}\text { Study of trauma patients with } \\
\text { and without CS. External } \\
\text { perfusionist dedicated to cell } \\
\text { salvage costed into cell } \\
\text { salvage group. }\end{array}$ \\
\hline 50 & Vieira SD & 2009 & Brazil & Cardiac & Conf Abs & $\begin{array}{l}\text { Assess likelihood of } \\
\text { allogeneic transfusion with } \\
\text { having cell salvage. }\end{array}$ \\
\hline 51 & Savvidou & 2009 & Greece & Orthopaedics & Full & $\begin{array}{l}\text { Small study. Costs used a } \\
\text { "local price" for allogeneic } \\
\text { unit of } € 450 \text {. Twice as likely } \\
\text { to have allogeneic transfusion } \\
\text { w/out CS. }\end{array}$ \\
\hline 55 & Staber M & 2009 & UK & Orthopaedics & Conf Abs & $\begin{array}{l}\text { Mix of elective and } \\
\text { emergency. Average of } 2.8 \\
\text { allogeneic units transfused. }\end{array}$ \\
\hline 58 & $\begin{array}{l}\text { Scannell } \\
\text { B.P. }\end{array}$ & 2009 & US & Orthopaedics & Full & $\begin{array}{l}\text { Study of acetabular fracture } \\
\text { patients. Lower LOS when } \\
\text { cell salvage used; cell salvage } \\
\text { cheaper if }>=2 \text { allogeneic } \\
\text { units required. }\end{array}$ \\
\hline 66 & $\begin{array}{l}\text { Markovic } \\
\text { M }\end{array}$ & 2009 & Serbia & Cardiovascular & Full & $\begin{array}{l}\text { Study of ruptured AAA } \\
\text { patients. cell salvage does not } \\
\text { need to wait for cross match; } \\
\text { more cost effective when }>3 \\
\text { allogeneic units required. }\end{array}$ \\
\hline 71 & Klein A & 2008 & UK & Cardiac & Full & $\begin{array}{l}\text { Study of routine cardiac } \\
\text { surgery patients. Half group } \\
\text { selected for CS-noted little } \\
\text { difference in transfusion rates. }\end{array}$ \\
\hline 80 & Tawfick W & 2008 & Ireland & $\mathrm{AAA}$ & Full & Study spanning nine years. \\
\hline
\end{tabular}




\begin{tabular}{|c|c|c|c|c|c|c|}
\hline Ref & $\begin{array}{l}\text { First } \\
\text { Author }\end{array}$ & Year & Country & Specialty & $\begin{array}{l}\text { Article } \\
\text { Type }\end{array}$ & Summary of Discussion \\
\hline & & & & & & $\begin{array}{l}\text { Based on average costs. } \\
\text { Ignored potential } \\
\text { improvements over the study } \\
\text { period. }\end{array}$ \\
\hline 81 & Freedman J & 2008 & Canada & Orth/Cardiac & Full & $\begin{array}{l}\text { Appointment of Transfusion } \\
\text { Co-ordinators achieved a fall } \\
\text { in allogeneic usage. Used } \\
\text { average costs to measure } \\
\text { savings in reduced LOS. }\end{array}$ \\
\hline 91 & Waters J & 2007 & US & General/Cross & Full & $\begin{array}{l}\text { Estimated the costs for a } \\
\text { hospital to set up a cell } \\
\text { salvage programme. }\end{array}$ \\
\hline 92 & $\begin{array}{l}\text { Blanchette } \\
\text { C }\end{array}$ & 2007 & US & Orthopaedics & Full & $\begin{array}{l}\text { Multi-site study. Concluded } \\
\text { that cell salvage reduced the } \\
\text { probability of needing an } \\
\text { allogeneic transfusion. }\end{array}$ \\
\hline 101 & Bird C & 2006 & UK & General/Cross & Full & $\begin{array}{l}\text { Basic 'opinion' style article } \\
\text { highlighting most Trusts } \\
\text { spend between } £ 1 \mathrm{~m} \text { and } £ 4 \mathrm{~m} \\
\text { on allogeneic blood. Ignores } \\
\text { medical/surgical split. }\end{array}$ \\
\hline 102 & Phillips SD & 2006 & UK & Liver Tx & Full & $\begin{array}{l}\text { Large-scale liver transplant } \\
\text { study. Associated low pre-op } \\
\text { Hb with higher rate of } \\
\text { allogeneic transfusion. } \\
\text { Concluded staffing costs } \\
\text { associated with cell salvage } \\
\text { would breakeven at } 80 \text { cases } \\
\text { per year. }\end{array}$ \\
\hline 103 & Davies L & 2006 & UK & General/Cross & Full & $\begin{array}{l}\text { HTA. Assessed a number of } \\
\text { allogeneic blood avoidance } \\
\text { techniques. Highlighted role } \\
\text { and cost impact at NHSBT } \\
\text { and need for consistent } \\
\text { application of costs to } \\
\text { facilitate accurate } \\
\text { comparisons. }\end{array}$ \\
\hline 105 & Crotty B & 2006 & UK & General/Cross & Full & $\begin{array}{l}\text { Basic comparison of running } \\
\text { costs associated with cell } \\
\text { salvage and assuming } 2.6 \\
\text { allogeneic units avoided each } \\
\text { time cell salvage is utilised. }\end{array}$ \\
\hline
\end{tabular}

The selected articles in table 16 were chosen due to their focus on the financial impacts. A theme that emerged in 2012/13 was the calculation of equivalent units of allogeneic blood that may have been required if cell salvage was not utilised. The newer versions of the cell salvage machines will now record the volumes of blood shed and salvaged blood reinfused. Solomon et al (2013), Bigsby et al (2013), Brearton et al (2012) and Rao et al (2013) all adopted this approach; converting the volumes reinfused to equivalent units of allogeneic blood. They then compared these 
equivalent units at a particular cost per allogeneic unit against the cost of operating the cell salvage machines. Solomon et al (2013) noted there was little difference in the derived costs but stressed that there were other benefits such as addressing issues of the non-availability of allogeneic blood. This study was undertaken in South Africa where allogeneic blood supply may not be constantly available as in the Europe/US. Bigsby et al (2013) and Odak et al (2013) utilised McClelland's (2007) rule of thumb of one allogeneic unit raising $\mathrm{Hb}$ levels by $10 \mathrm{~g} / \mathrm{l}$ (para 1.9). The 'transfusion trigger' is assumed to be a post-operative $\mathrm{Hb}$ level of $80 \mathrm{~g} / \mathrm{l}$. By calculating the mean blood loss from the information generated in the cell salvage machines the notional units of allogeneic blood required can be calculated. Both these studies were based on acetabular fracture and separately concluded that cell salvage was cost effective. Both studies, however, calculated notional amounts of allogeneic blood avoided. Patients' blood loss tolerance can differ markedly; and younger, fitter patients can withstand greater falls in their $\mathrm{Hb}$ levels than older patients (para 1.9). The idea of a notional allogeneic blood requirement based on a fall in $\mathrm{Hb}$ levels is a relatively new argument and may be open to differences of opinion. The implication is that the financial costs rather than economic costs were incorporated in the analysis though this was not made clear by any of the authors.

Rao et al (2013) noted a pertinent point that the majority of blood loss in total hip replacement operations was intraoperatively (i.e. during the operation). The study included the OrthoPat cell saver that can be utilised to collect both intraoperative and post-operative blood loss. The operating cost of this machine is significantly more expensive than the single intraoperative machines. This would raise a question on the efficacy of using the OrthoPat compared to other, cheaper, machines in intraoperative cell salvage since the OrthoPat has no 'collect first' option available. The 'collect first' option would allow the termination of the cell salvage process if it was looking unlikely to recover an adequate level of shed blood. Again, this may be an indication of the challenges that Haemonetics are facing with falling sales (para 1.9).

There are other theoretical studies undertaken; Samnaliev (2013) concluded cell salvage in the US in paediatric surgery was, on a sliding scale, the cheapest compared to pre-deposit or allogeneic transfusions. The study utilised a "mathematical decision tree of hypothetical identical control groups" and calculated the lifetime costs avoided by assigning probabilities and costs associated with 
reactions or infections caused by an allogeneic blood transfusion. The analysis seemed simplistic and verged on the sensational. The article's opening statement was "red blood cells are a scarce resource with demand outstripping supply". In some lesser developed countries, this may be the case but in developed countries there is now rarely any shortage of allogeneic blood. The last time there was any shortage of allogeneic blood in the UK was in 1994.

Canan et al (2013) also highlighted the combination of cell salvage and allogeneic blood transfusion where it is difficult to assess the benefits attributable to each of the two elements. Canan et al (2013) however conclude that, in single level lumbar spine surgery, cell salvage is "unnecessary" and "not cost effective". They did however recommend further research be undertaken to identify patients who would be likely to benefit from undergoing cell salvage rather than salvaging all patients in a list.

Tranexamic acid was highlighted in a poster by Offierski et al (2013) who noted that, prior to 2009, the allogeneic transfusion rate in total hip replacements at Niagara hospital was $19 \%$. With the introduction of tranexamic acid, the transfusion rate dropped to $11 \%$; primarily due to higher rates of $\mathrm{Hb}$ levels being maintained. As noted in para 1.9 tranexamic acid appears to significantly lower the allogeneic transfusion rate. This can therefore cloud the comparisons and potentially distort the contribution made by cell salvage to minimising allogeneic blood transfusions in surgery.

The trend towards highlighting the impact of cell salvage on length of stay has tailed off recently. Munoz et al (2012) highlighted that LOS was one day longer if a patient had an allogeneic transfusion. The assertion was that the post-operative allogeneic transfusion would be required because the patient was not recovering as quickly due to a lower $\mathrm{Hb}$ level. The allogeneic transfusion is therefore an indicator of how the patient is recovering rather than being a contributor towards the increasing LOS. By using cell salvage the chances of an allogeneic transfusion are lowered as the $\mathrm{Hb}$ fall would be ameliorated.

The studies mainly related to retrospective analysis of data under the auspices of a service development thereby not requiring any ethical clearance from the relevant hospital ethics' committee. Kelleher (2011), based at the Royal Brompton Hospital in London, adopted this approach, analysing data for over 7,000 cardiac patients 
between 2001 and 2007. An interesting aspect of the study was that Kelleher noted how "operator behaviour" and "progressive machine deterioration" affected the intermediate results (and hence the measurement of cost impacts). Carless et al (2010) did not refer to these types of issues that would be unlikely to become apparent in a traditional short-term comparative study. A long term, more dynamic, study therefore highlighted these two significant principles. Chapter 6 of this thesis will note that the researcher has circumvented this issue by taking a snapshot of activity over a relatively short period and only used one centre utilising cell salvage. This centre now (2018) has a rigorous training regime that ensures all theatre staff are trained to operate the equipment. Additionally, there are service contracts in place to ensure all machines are regularly maintained and tested.

Waters (2011) undertook a similar study to Kelleher et al (2011). Waters (2011) led a review of almost 20,000 operations in 12 hospitals in the West Pennsylvania area. His conclusions were that cell salvage was not cost effective in all cases. This was based on the c.16,500 patients of the 20,000 who received cell salvage. The study was published in the October 2011 edition of the publication 'Transfusion' and the conclusions were critiqued in the introduction by the editor, Dr Steven Frank. Frank (2011) highlighted that stand by set up costs were not included in the costings; he then used average costs to demonstrate a point that, where only low volumes of shed blood were recovered, and the patient did not need an allogeneic transfusion anyway, it may therefore have been more cost effective not to have used cell salvage and rely on an allogenic transfusion where necessary. This is one of the issues that was considered in the Royal Cornwall Hospital study where, as far as possible, all shed blood is collected. When utilising the Sorin Electa the shed blood can be collected in a reservoir allowing time to decide if there is sufficient salvaged blood available to reinfuse. The 'collect first' option costs c. $£ 50$ regardless of whether or not the blood is reinfused.

The articles by Kelleher et al (2011) and Waters (2011)/Frank (2011) highlight, in differing ways, the difficulties in adhering to the Carless criteria for randomised controlled trials (RCTs). High volume salvage with well-maintained machinery is required to ensure sufficient allogeneic blood is avoided to cover the capital/maintenance costs along with the operator/consumable costs. This would therefore minimise the allogeneic blood costs. A related issue is that there is also a 
base level of knowledge and skills that the operator (generally a nurse or an ODP) needs to acquire and maintain. Though an individual group of cases may not generate savings they contribute, indirectly, to developing the skills of the operators. Frank's (2011) assertion to be more selective on adopting cell salvage may provide savings but there still needs to be a critical mass of work to develop and maintain the operators' skills and provide a range of training opportunities.

The Carless implication that RCTs should be adopted may, in practice, not be the most efficient methodology. The operators would need to have the requisite 'flying hours' of experience and the machinery would need to be sufficiently utilised to perform at an optimum rate.

Staff training issues are also highlighted by Buckley et al (2011) and Thurer et al (2011). Buckley et al (2011) studied the reasons why cell salvage was not adopted for patients undergoing elective abdominal aortic surgery. In $44 \%$ of cases cell salvage was not used. In $81 \%$ of these cases the reason cited was the lack of trained staff. Their study noted that average allogeneic transfusion requirements were approximately one unit higher per operation where cell salvage was not used. They argued that the cost of investment in staff is key to developing a successful cell salvage programme. Thurer et al (2011) noted that "successful interventions to reduce transfusion are either multidisciplinary ....and multimodality (utilising many techniques)". They studied an initiative in orthopaedics to reduce the "transfusion trigger" (the patients' $\mathrm{Hb}$ level indicating iron levels are falling too rapidly) and discontinue the use of pre-operative autologous donation (PAD, para 1.11) while, at the same time, introducing cell salvage. They observed that allogeneic transfusions fell from $44 \%$ within the six-month period prior to the change, to $25 \%$ in the sixmonth period after the change. They concluded that it would be difficult to assess which procedural change (the change in the transfusion trigger, the move away from PAD or the introduction of cell salvage) contributed the most towards the reduction in allogeneic usage. These two studies emphasise the aspect that it is difficult to assess the contribution of cell salvage in isolation. The team at the Royal Cornwall Hospitals also reiterate the message that, in their view, cell salvage is only one of the 'tools in the armoury' and most of the benefits of avoiding an allogeneic transfusion accrue when as many blood avoidance techniques as possible are running together. This argument is consistent with the Patient Blood Management approach (para 
1.12). An earlier study by Thurer et al (2010) noted a significant reduction in the allogeneic transfusion rate (from $39.5 \%$ to $26.5 \%$ ) when a cell salvage programme was introduced by the same orthopaedic surgeons undertaking total knee replacement surgery. Though there was no evidence of bias two of the authors (including R. L. Thurer) disclosed commercial interests with the cell salvage equipment manufacturer, Haemonetics.

One interesting conclusion emerged from a large-scale retrospective multi-site study undertaken in the US (Blanchette et al (2007)). Patients with non-Medicaid insurance (primarily private or employer provided health insurance) had a lower risk of having an allogeneic blood transfusion than a patient funded by Medicare. Given patients funded by Medicare are older, this conclusion is not new. The older a person is, then the more likely they are to have an operation making it more likely that a transfusion will be required. Blanchette et al (2007) concluded that cell salvage resulted in the probability of a lower allogeneic transfusion and there was significant variability in its application in spinal surgery. They stressed the variability in approaches with some hospitals being enthusiastic about adopting a range of blood sparing techniques and others that were not. They additionally speculated that the varying levels of enthusiasm may be due to reasons "... associated with cost, potential adverse effects or lack of strong clinical evidence". The first and third reasons are still pertinent today.

The theme of clinicians' willingness to utilise cell salvage techniques and their perceived impact on reducing LOS by speeding up the recovery process was highlighted in two conference abstracts in volume 50 of the publication 'Transfusion'. Waters et al (2010a and b) noted the massive variation in transfusion and readmission rates with LOS not appearing to correlate with whether a patient had or did not have an allogeneic transfusion in total hip replacements. The authors concluded that the results were unclear and "...might pose a challenge to future efforts to standardise RBC (red blood cell) transfusion practice". What is novel is the issue of readmission rates being raised. Readmissions for primary total hip replacement surgery due to transfusion issues are rare; Waters et al (2010a) quoted a readmission rate of $6.2 \%$ with an allogeneic transfusion $\mathrm{v} 0.8 \%$ without a transfusion. The reasons for the readmissions in the UK are mainly due to wound problems with the $10^{\text {th }}$ National Joint Registry estimating readmissions at $7.6 \%$ using 
Patient Reported Outcomes Measures (PROMS) rather than anything due to blood transfusions so this assertion may not reflect any causality.

Waters et al (2010b) led on the same theme of variation but based this on a survey of surgeons in total knee replacements and total hip replacements. The key reason for a transfusion was if the surgeon felt the patient was anaemic (para 1.4). This was generally indicated at an $\mathrm{Hb}$ level of $<80 \mathrm{~g} / \mathrm{l}$ and there was a strong correlation between a lower pre-operative $\mathrm{Hb}$ level and a patient requiring an allogeneic transfusion. Waters et al (2010b) noted that by post-operative day 2 the patients who had used PAD had a lower Hb level than those that had not; thereby increasing the chances of requiring an allogeneic transfusion. The above two articles were conference abstracts and were difficult for the reader to assess the impact of the detail. There was a common theme in that it was accepted that the higher the $\mathrm{Hb}$ level the less likely the patient would require an allogeneic transfusion (or cell salvage). The articles do not, however, give any indication of how many surgeons were invited to answer the questionnaire; instead focusing on the responses of the 17 who took part. The timing of this coincided with the analysis of the activity of $\mathrm{c}$. 1,100 patients undergoing total hip and knee replacement surgery. There is therefore the possibility of bias with the 17 respondents being potentially more likely to be enthusiastic about blood avoidance techniques than a non-respondent. Given no reference is made to the total number of potential respondents this could affect the consistency of the responses to the reported views on anaemia. Waters et al (2010b) conclude "Cell salvage might not be beneficial in THR (total hip replacement)". Based on the evidence this seems an over-generalization. It does, however, add a further level of interest to whether the analysis in this thesis could support the debate by developing a mechanism to breakdown the overarching term 'total hip replacement'. The aim would be to identify whether there is an equal spread of allogeneic blood over more or less intensive total hip replacement operations.

As noted earlier the primary reason for an allogeneic transfusion is to increase the patients $\mathrm{Hb}$ levels. Spahn (2010) undertook an analysis of studies comparing various patient factors such as age, pre-and post-operative $\mathrm{Hb}$ rates and transfusion rates in hip or knee studies. The analysis included a number of the comparative factors developed in chapter 5. Spahn (2010)'s focus on pre-operative Hb levels identified levels below $120 \mathrm{~g} / \mathrm{l}$ for females and $130 \mathrm{~g} / \mathrm{l}$ for males as being "unmet medical 
need" as defined by the World Health Organisation. His conclusion to the study was unequivocal "Anaemia in the orthopaedic perioperative setting was frequent and was associated with increased ABT (allogeneic blood transfusion) rates and with adverse clinical outcomes". Spahn (2010)'s analysis could be criticised in that there was not a common dataset of factors to undertake the comparisons e.g. some studies had a gender split, others did not, some had an age breakdown, others omitted this. Though the conclusion was based on a wide number of studies it again fell foul of Carless et al's (2004 and 2010) classification of the "methodological rigour" requirement.

A similar conclusion to Spahn (2010) was noted by Jaben et al (2010). This study followed up patients who had received a transfusion between 1991-1998. It concluded that the smaller the volume of allogeneic blood utilised the better the survival rates. Factors such as age, gender and LOS were incorporated into the model with the Charlson co-morbidity index. This area is quite subjective. It could be argued that one would expect this outcome given there would be a tendency for sicker patients to have a higher allogeneic blood transfusion requirement. There was also no analysis of patients who had the same operations but no allogeneic blood transfusion. The article, however, indicates the complexity of the challenges and level of variability in the patients; thereby increasing the likelihood of any conclusions attracting criticism.

Some of the studies attempted to evaluate where the use of cell salvage would work out cheaper compared to using units of allogeneic blood. Varney \& Guest (2003) estimated that, where an allogeneic transfusion was required, an average 2.7 units would be utilised. This average crossed all specialties and was therefore indicative in 2003. Table 2 (page 17) highlights the significant changes in the split between medical and surgical requirements for allogeneic blood. Combining this with the $\mathrm{c}$. $33 \%$ fall in the number of allogeneic units issued between 2003 (2.25m units issued) and 2017 (1.51m units) would imply that the average of 2.7 units may now be significantly lower. Scannell et al (2009) noted that cell salvage is cheaper if two or more allogeneic units were required in acetabular fracture (where the femur is forced into the pelvis). This study was retrospective, and the article compared the price of allogeneic blood and a "flat rate transfusion fee" against the "flat rate fee" for using cell salvage. This was a US study and would therefore have utilised the published price lists for charging via a Health Maintenance Organisation (HMO) or via an 
insurance company. Scannell et al (2009) made a major caveat that, in practice, patients were not formally pre-selected to have either cell salvage or an allogeneic transfusion. It can often be a combination of the two; and the authors noted that there was "no formal protocol for blood transfusion at our institution". Effectively the two units that were required to breakeven on cell salvage costs was therefore only a notional amount and could not be used as a definitive target. LOS was quoted in a different way from other studies. The authors noted that patients having cell salvage were likely to be in intensive care for a longer period implying they were more severely injured so there was a potential bias in allocating those patients to have cell salvage. Waldron et al (2011) undertook a similar approach in obstetrics citing the NICE guidelines in interventional procedures guidance (IPG) 144. Out of 100 patients in their sample, eight needed allogeneic transfusions, totalling 50 allogeneic units. They assumed that the potential cost saving was the difference between the cost of operating the cell salvage machine and the cost of allogeneic blood. Waldron et al (2011) assumed that all of these 50 allogeneic units could be avoided if cell salvage were utilised. This would not necessarily be the case and the basic cost comparison was arguably too simplistic.

A similar type of study in Serbia was undertaken by Markovic et al (2009). This compared 90 prospective patients who underwent abdominal aortic aneurysm (AAA) surgery utilising cell salvage against 90 consecutive patients who underwent the same operations prior to the hospital introducing cell salvage. The authors noted that ruptured abdominal aortic aneurysms (RAAAs) involved high blood loss, cell salvage would therefore need to be utilised quickly. Given the hospital did not use electronic cross matching (ECM, para 4.2) there would be a delay of 30-60 minutes before an allogeneic transfusion could be administered. This would be a significant distortion and, effectively, give cell salvage a head start with the patients in the allogeneic blood group needing to be stabilised to stem the blood flow. This was therefore likely to make the comparison between the two groups disparate. Most UK hospitals would utilise ECM thereby allowing an allogeneic transfusion within minutes. Markovic et al (2009) calculated the breakeven point as three units of allogeneic blood. This analysis only compared the costs of the cell salvage consumables against the costs of three allogeneic units. It did not include the capital costs of the cell salvage machine, the operating costs or the costs of training. To 
include these factors in the analysis would take the comparison to over four units as a breakeven point in a financial analysis. Portsmore et al (2011) highlighted that the breakeven level (i.e. the point when cell salvage was cost effective) was when over 250-500 mls of blood was salvaged. This is the equivalent of up to approximately three allogeneic units.

One factor noted in Markovic et al (2009) was that the cost of an allogeneic unit was $€ 46.30$ (2005 price level). A study in Greece by Savvidou et al (2009) used the cost as being $€ 450$ per unit. It is unclear what year's price level was adopted but there is an almost 10 -fold variation in the cost. This illustrates the difficulty in undertaking the international comparisons. The costs may not reflect actual costs incurred but may be pitched at a notional level to influence usage. The Greek price in question was "..determined by the Greek ministry of health and applied in a public urban hospital" (page 203). The massive variation and notional prices may therefore make one hospital (or country's) approach to costs skew the conclusions against or in favour of cell salvage. In Savvidou et al's (2009) case the conclusion, using a similar notional cost of $€ 370$ for cell salvage, made the case that "the cell saving technique is cost-effective in a European Union country". This statement assumes the cost base and costing assumptions of each country are similar. This assumption would be open to debate. The above issue is significant given the international discussions and, again, was not an issue considered by Carless et al in either 2004 or 2010 . Shander et al (2010) highlight this issue and urge caution when comparing prices between countries.

Klein et al (2008) focused on first time coronary artery bypass graft (CABG) and cardiac valve surgery. The authors critiqued and noted weaknesses in earlier studies and believed these could be circumvented by using a study of elective CABGs/cardiac valve surgery. These accounted for the majority of elective cardiac surgery at Papworth Hospital, where the study was based. The authors quoted Carless et al (2004) stating they would undertake a cost benefit analysis.

Klein et al (2008) concluded that the incidence and volume of post-operative bleeding was lower within the cell salvage group. The patients undergoing cell salvage would receive the reinfusion in ICU immediately after the operation. The authors noted that the post-operative $\mathrm{Hb}$ levels were similar on admission to ICU but 
were higher $(10.4 \mathrm{v} 10.1 \mathrm{~g} / \mathrm{dl})$ for the cell salvage group 24 hours after. The authors did not investigate this difference stating (page 1494) "our study was not powered to detect haemoglobin concentration between groups". It is disappointing that the authors did not pursue this element; they noted that there was a marked reduction in the number of allogeneic units given to the cell salvage patients in ICU after six hours. They concluded that cell salvage "may reduce the demand for blood products during cardiac surgery" but this came at an increased cost.

Costs were presented in a table with little breakdown or analysis. The operating room cost difference of c. $\$ 9,100$ for a cell salvage patient v c. $\$ 8,700$ for a non-cell salvage patient were not explained. The difference may be a function of the cost of consumables and the cost of an ODP (Operating Department Practitioner) dedicated to cell salvage. Similarly, the corresponding costs of c. $\$ 4,300$ v $\$ 4,100$ for the ICU costs are not explained. The "cell salvage equipment" cost is shown in a separate line in the table. The cost of the "ward stay" was reported as being just over $\$ 100$ cheaper for the cell salvage group. Overall, the authors concluded the average cost for a patient utilising cell salvage was $\$ 17,785$ against $\$ 17,046$ without cell salvage.

Though Klein et al (2008) banded their study a "cost benefit analysis", the comparison was effectively an analysis of average costs that were not classified into fixed/variable or direct/indirect (paras 2.2 and 2.3). As such, the authors could leave themselves open to criticism of their findings. They did stress, however, that this study was undertaken on a relatively "routine" procedure and cell salvage could prove more cost effective in more involved cardiac procedures. Significantly, the authors pointed to the "public health implications" of the costs associated with collecting and making donated blood available. There are few studies that highlight this issue and the authors overall conclusion was that, even though they calculated cell salvage was more expensive than allogeneic blood, it would offset the costs generated by the blood institutions. This is one of the key areas of investigation in this thesis. Klein et al (2008) are contradicted by Attaran et al (2011) who viewed the 'collect first' principle without reinfusion as incurring a 'loss' rather than being deemed a potential 'insurance policy'. Their retrospective study highlighted a transfusion rate of $35.6 \%$ where cell salvage was not used against $30.3 \%$ where cell salvage was utilised. They concluded there was no significant difference in the number of allogeneic units transfused for patients that had, or did not have, cell 
salvage. It was unclear in the article when $\mathrm{Hb}$ readings were taken; they could have been taken after a reinfusion of salvaged blood. If this were the case, then the authors would not have identified the beneficial impacts of cell salvage.

A study based in Ontario, Freedman et al (2008), examined the whole approach to blood conservation rather than just cell salvage individually. They concluded that cell salvage was one of the four main contributors to blood conservation; the other three being education, PAD (pre-operative autologous donation-see para 1.11) and EPO (Erythropoietin-this stimulates the production of red blood cells in the bone marrow). Costs were rounded to the nearest $\$ \mathrm{~m}$ and the net savings in the blood conservation programme were grouped into:

Table 17. Blood Conservation Savings in Ontario

\begin{tabular}{|c|c|c|}
\hline Ref & Category & $\begin{array}{l}\text { Saving } \\
\$ \mathrm{\$ m}\end{array}$ \\
\hline 1 & Reduction in allogeneic blood costs & 8.6 \\
\hline 2 & Reduction in LOS & 5.3 \\
\hline 3 & $\begin{array}{l}\text { Reduced work in hospital transfusion } \\
\text { laboratories and nursing units }\end{array}$ & 0.7 \\
\hline & Forecast Saving & 14.6 \\
\hline
\end{tabular}

The third element, staffing costs, had not been considered in this thesis methodology. The authors estimated the savings in time associated with the technologists/nurses not needing to undertake tests in the laboratory, take blood from patients for testing, blood stock management etc. These tasks are often the responsibility of a number of hospital staff and it is highly doubtful, especially in the short to medium term, that the staffing costs could be removed as the staff would still be required to perform other duties. Staff would need to be on a contract similar to a 'zero hours' basis to be reactive to the peaks and troughs of work requirements. In reality having a large number of staff in a hospital on these types of contracts would be viewed as too risky.

Similarly, an average saving of $\$ 1,000$ a day for the shorter LOS was used. Again, the majority of hospital-based costs are fixed in the short to medium term. Virtually none of these costs would be realisable until after a significant time had elapsed. They may, however, increase capacity and free up space for additional use. Using similar logic, the reduction in allogeneic blood costs may be a direct (and variable) 
cost for the hospital but there will be fixed costs that will remain for the blood collection institution.

Overall, the cost of running the programme in Ontario was $\$ 1.8 \mathrm{~m}$. It is impossible to examine the breakdown of the costs from the information available. Given 23 transfusion co-ordinators were appointed these costs may be in the region of $\$ 1 \mathrm{~m}$. This would not leave much funding left for cell salvage; assuming $\$ 150$ for consumables then the balance of costs would fund c. 5,300 sets of consumables with no funds left for PAD, EPO or education. Though the conclusions seem optimistic, the costs and benefits do not seem to be realistic or realisable.

A number of the articles extracted from the literature review search referred to the generally lower LOS in patients who have not had an allogeneic transfusion in addition to those quoted earlier. LOS at the three sites in this study will be discussed more fully in chapter 6. It is difficult to make a judgement on whether the LOS is increased by a patient having an allogeneic transfusion. The transfusion may be seen as being a symptom of the patient recovering more slowly and hence staying in hospital longer. Ubee (2011) asserts the improved LOS in the cell salvage group was “..probably attributable to the fact that circulating volume and Hb levels were better maintained at near optimum levels through the perioperative period..”. He further suggests that the allogeneic transfusions were given post-operatively, therefore taking some time to take effect, implying an increased chance of a higher LOS. Dunn et al (2010) pointed to a fall in LOS of 3 days in radical cystectomy when the service was centralised in Exeter using cell salvage against the average LOS prior to centralisation. What is not clear is how other factors due to centralisation of the service e.g. staff availability, enhanced training, working practices, specialist equipment availability etc., impacted on the LOS rather than any positive impacts of cell salvage. Phillips et al (2006) arrived at broadly the same conclusion with a reduced LOS of 2.8 days. They highlighted the use of both cell salvage and tranexamic acid impacted favourably on the $\mathrm{Hb}$ levels. They then asserted, "the savings attributable to the reduced LOS by avoiding transfusion was $£ 756$ per patient, or 2.8 days at $£ 270$ per day”. This $£ 270$ is an average cost developed by apportioning all types of costs, both fixed and variable, into an average cost per inpatient day. The majority of this cost is unlikely to be avoided if the LOS was shortened. Again, with Phillips et al (2006), there was no attempt at answering the 
assertion that, the more ill the patient, the more likely s/he would be to require an allogeneic transfusion and therefore the more likely they would be to stay in hospital longer to be observed as well as the recovery period taking longer.

A 2011 NHS initiative in England 'Innovation, Health and Wealth' cited the Conquest Hospital, East Sussex's short length of stay. What was not highlighted in the publication was the assertion by Royal Cornwall Hospital staff that some of the Conquest patients were discharged into residential accommodation, managed by the Conquest Hospital. Patients continued their recovery in a non-hospital environment thereby shortening hospital LOS; but still under NHS care. For the purposes of this study, it was therefore felt advisable to investigate any differences in discharge patterns in the three sites prior to undertaking any costing work on LOS (chapter 6). This would minimise subjective issues of differing measurements of LOS.

On a related note, Tawfick et al (2008) stressed the shorter LOS and used average hospital in patient costs to highlight savings by using cell salvage in AAA surgery. Patients were allocated to the salvage group if a skilled operative was available. If none were available, then an allogeneic transfusion was the only option. This would leave the study open to bias e.g. cell salvage support would be less likely at weekends where the majority of admissions would be emergencies. Additionally, the study was undertaken over a nine-year period up to June 2006. It is likely that there were advances in surgical techniques, changes in the surgeons' experience, approaches to patient management etc over the period making the comparison of blood usage open to distortion by these factors. This lengthy duration convinced the researcher to have a short window to extract details of consecutive patients undergoing surgery.

Overall Carless et al (2010) concluded that the LOS with cell salvage was "not statistically significantly reduced compared to control". The articles quoted above exhibit a varying level of bias (a common theme in the Carless report) in that they assert the absence of an allogeneic transfusion is the reason for the lower LOS. This argument is not conclusive and, when tagged to average costs, can lead to a significantly distorted financial conclusion. 
One associated issue with LOS is that any fall would potentially free up time for nursing staff. In the current climate of patient safety and 'safe staffing levels' there would ('ceteris paribus') be a favourable movement in the staffing ratios.

Given the duration of this thesis the researcher felt it prudent to update the literature search to cover the period from January 2014 to December 2016. The other parameters remained unchanged. The search was undertaken in January 2017 using the NHS Athens system. This generated a number of duplicates and these were manually excluded with 29 being selected for consideration. A summary of the main issues is shown in note format in appendix 7. Orthopaedics was still the most common specialty, followed by Obstetrics. Some of the articles continued to convert salvaged blood to equivalent units e.g. Bellam et al (2014). The consumables costs were also relatively low; however, the conclusion was that the success factor was avoiding the allogeneic transfusion rather than comparing costs. It was noticeable that the adoption of this equivalent unit calculation tailed off after 2014 as more cross referencing to 'Patient Blood Management' was highlighted e.g. Pendry et al (2015).

Training was also emphasised as part of the international Patient Blood Management initiative with Yeung et al (2016) highlighting that regular use of cell salvage keeps "the team up to date with the skills required". Allied to this was the noting of the difficulties in predicting which patient will benefit from cell salvage (e.g. Tio et al (2016)) and how this impacts on costs if a high number of patients are salvaged. Son et al's (2014) study in obstetrics noted “...cell salvage set up appears to be cost effective only when reinfused, but clinical characteristics cannot predict accurately which women will require reinfusion of cell salvaged blood".

Overall the more recent articles still tend to be more in favour of cell salvage and its impact on costs however there is more reference to other blood-sparing techniques being used together. This is the essence of Patient Blood Management and the recent literature implies clinicians are bearing the issues in mind. 


\subsection{Training Issues}

Konstantinou (2011) used the relatively high transfer price of allogeneic blood in Greece to demonstrate that cell salvage was not cost effective unless more than two allogeneic units were required. This study used a simplistic cost model, assuming the volume of blood reinfused was a like for like substitute for allogeneic blood. This is not the case as allogeneic blood contains anticoagulants and the active red cells gradually diminish over time. Allogeneic blood is generally at least a week old when utilised in a transfusion, salvaged blood is therefore a much richer product requiring less volume than allogeneic blood to provide the same $\mathrm{Hb}$ benefits.

Training costs are highlighted by the US Society for the Advancement of Blood Medicine (SABM) in so far as they are classed as being a 'generic cost'. Very few of the articles accessed in this review focus on cell salvage training. Training costs will be relevant, but a more dynamic model would assert that these costs would decrease over the medium term as all staff will be trained. (Waters (2010b) notes that lack of education in cell salvage is a reason for inconsistency in use and variation in transfusion rates). In the UK, Grainger et al (2008) detailed the training sources and packages available. In time the wider adoption of the techniques would mean most ODPs, theatre nurses and surgeons had cell salvage in their skillset only therefore requiring cheaper and less time-consuming refresher training.

The level of skills can impact on the conclusions. Bridgens et al (2007) compared a group of 47 revision hip arthroplasty operations using cell salvage with a control group of 47 operations without using cell salvage. Allogeneic blood usage was significantly higher in the control group (mean of 6.4 allogeneic units v 2.6 units). The authors noted, however that "(the operations) were not well matched for the operating surgeon because the operations in the control group took place when fewer arthroplasty fellows were on staff (shift)". An associated difficulty is that revision hip operations are becoming more infrequent as the primary (i.e. the first) hip replacements are lasting significantly longer and are more reliable than hip replacement operations undertaken 20-30 years' ago. Bridgens et al (2007)'s study was undertaken between 1999 and 2003 implying a low volume of throughput with an increased likelihood of less experienced staff being available. This is borne out by the quote. It is also interesting to note that this article was not picked up by Carless et 
al (2010) in their study. There was potential for bias in the study that one would have expected Carless et al (2010) to identify and highlight.

The concept of Patient Blood Management (PBM), where a more holistic view is taken of the various blood-sparing techniques, was introduced in para 1.12. Again, this is consistent with the Royal Cornwall Hospital view of cell salvage being just one of the 'tools in the armoury'. It remains to be seen whether PBM will initiate a change in emphasis on studies to e.g. trying to isolate the benefits of cell salvage while ignoring other opportunities to avoid a transfusion. An article by Shaz et al (2013) noted that PBM's goals should be to "improve patient care and quality while reducing spending". It is interesting to note that one of the article's co-authors was Dr Jon Waters; who, as noted earlier, wrote prolifically and specifically about cell salvage through the mid-late 2000's, post Carless 2004.

Additional issues on potential bias in a way not highlighted by Carless et al are noticeable in Yarham et al (2011). The Sorin Xtra (the updated Electa, now in use at the Royal Cornwall Hospitals) was evaluated at the Essex Cardiothoracic Centre. The price of an allogeneic unit was inflated by the group and screen test (to determine blood group and $\mathrm{Rh}$ ) and the cost of cross matching (the check for antibodies). These two tests are often undertaken on patients anyway and, additionally, an electronic cross match is significantly cheaper than the $£ 30.54$ quoted in the article. Furthermore, an evaluation of the machine should have included the energy requirements (and hence an accurate assessment of the potential running costs) of the machine. This was not supplied nor was a cost of consumables. It was interesting to note at the end of the article that it was stated the Sorin Xtra could be used post-operatively as a direct competitor to the Haemonetics OrthoPat cell salvage machine that was the established market leader in post-operative cell salvage.

An issue experienced at the Royal Cornwall Hospitals where, when protocols on cell salvage are relaxed, was mirrored in the Queen Elizabeth Hospital, King's Lynn. Butchart and Abdy (2011) noted an increase and then a decline in cell salvage usage in orthopaedics over the period 2004 to 2010. They noted that "this did not correlate with increased donor transfusion" i.e. allogeneic blood usage. The implication was that cell salvage was not required to avoid an allogeneic transfusion. The authors, 
however, stated that record keeping was incomplete and "the majority (of entries) had significant information missing".

\subsection{Societal and Wider Economic Costs}

Little consideration has been given to the wider costs associated with blood donation and how these would be avoided if the demand for allogeneic blood fell due to an uptake in blood avoidance techniques. The main UK article is Varney \& Guest (2003) that attempted to derive a total cost for the supply of a unit of allogeneic blood. A Canadian article (Amin et al (2004)) was similar in that it attempted to measure the blood donor's opportunity cost. This study used an average wage to calculate a notional cost irrespective of whether the donor was part of the labour force or if they were taking time off work.

A US article, "The Cost of Blood: Multidisciplinary Consensus Conference for a Standard Methodology" (2003) attempted to segregate all costs associated with allogeneic blood from the recruitment of donors through to the assessment of the allogeneic "transfusion outcome". This article was based on a symposium held in 2003 by the US Society for the Advancement of Blood Medicine (SABM) and does not have a quoted author though the address for correspondence was to Dr Aryeh Shander (para 1.16). The article attempted to identify and categorise the costs rather than undertake a study to assess and quantify them. It highlighted "lost donor wages" and "lost productivity borne by the donors' employers". Costs relating to donor travel were not included and Varney \& Guest's (2003) costs were dismissed as "costs incurred by a nationalised system are not likely to apply to the rest of the world; thus, the generalizability of their estimate is limited". Arguably this is a simplistic view, regardless of the overarching national blood collection system. Donors will still be required and there will be an associated costs and opportunity costs.

The Consensus document only scratched the surface and did not initiate any detailed discussion in this area. Shander et al (2007) followed up with a paper entitled "Estimating the Cost of Blood: Past, Present and Future Directions". The authors led a working group to standardise an estimate of the costs associated with blood. They pointed out that their work was still in progress and needed much more refinement. They estimated that the cost of an allogeneic unit was c. \$1,400 with the implication 
that the estimate could rise with the incorporation of additional costs such as donors' costs, lost productivity and the "cost of treating transfusion transmitted disease". This cost of $\$ 1,400$ is the cost highlighted in the OrthoPat marketing material discussed in para 1.9. It is interesting to note that a Google search of the terms "societal costs of blood transfusion" or using replacement words/expressions such as "society" and "associated with" did not pull out any results (search undertaken and refreshed on 2 February 2016). Shander et al (2007) costs of c $\$ 1,400$ have been revisited in Shander et al (2008) at $\$ 1,158$ and Shander et al (2010) quoting a range between $\$ 522$ and $\$ 1,183$.

Varney \& Guest's (2003) study was far more in-depth than the Consensus document and subsequent studies by Shander, assessing the occupation of the donor and if they were giving up time from work to donate. Additionally, other costs not borne by NHSBT (e.g. travel expenses to attend a donation session) were also considered. These costs were considered relevant to the whole allogeneic donation process and therefore the Varney \& Guest (2003) study was re-visited as part of the Methods chapter 5 in order to update the costs.

The impact on NHSBT's costs due to an expansion in cell salvage was highlighted by Phillips SJ et al (2006). This article and Davies et al (2006) are the only references found that makes any detailed reference to the impacts on the costs at the relevant blood collection organisation. Davies et al (2006) noted that, at the time, the demand for allogeneic blood had fallen. Due to the nature of the high level of fixed costs they asserted the fall in demand actually drove up the price of a unit to maintain the 'cost $=$ price' maxim and allow NHSBT to plan to recover all its costs and break even. Given the significant changes in the structure of the costs in NHSBT since 2006, a reassessment of this assertion seemed opportune.

\subsection{Summary of Chapter 4}

Overall, there are difficulties and inconsistencies in highlighting the benefits of cell salvage due to:

- The perception that it would be unethical for a clinician to withdraw an established blood avoidance technique (e.g. withdraw tranexamic acid or a course of iron tablets) just to isolate the benefits of cell salvage. Tse (2011) 
additionally notes the difficulties in isolating the effectiveness of individual blood-sparing techniques when a number of them are used together.

- No study made verifiable attempts to undertake any comparison between the differences between a financial and an economic appraisal (para 2.8). As such it is difficult to draw any robust conclusions over cell salvage supporting the reduction in costs associated with the collection and utilisation of allogeneic blood.

- All studies have differing populations, differing judgements and differing working practices making it difficult to derive an objective comparison. The application of cell salvage in different specialties is likely to have different conclusions. It is significant that Waters (2010b) appears to have altered his view over the application of cell salvage in orthopaedics (para 4.7). Given Carless et al (2004 and 2010) state "the use of washed cell salvage appears justified in orthopaedic surgery" there is some irony that the leading proponent of cell salvage is now heading towards the other end of the spectrum of opinion with cell salvage in orthopaedics.

- Carless et al's (2010) conclusions changed little in the six years between their two reports. Their views were highly critical of most studies and did not address the key point that most studies reported a fall in the allogeneic blood requirements when a cell salvage programme was introduced. This would have a benefit to society that Carless et al (2010) did not encompass in their analysis.

- Given the paucity of detailed costing and activity information in this area, it was felt that the true 'costs' of any developments in cell salvage would need to incorporate an up to date estimate of the wider costs to society of donating blood. Additionally, these 'costs' needed to be developed from both a financial and an economic evaluation standpoint. No studies considered the difference in interpretation between the two perspectives.

- There will be time lags between the recent announcements on Patient Blood Management and the studies the announcements may initiate. This thesis is 
therefore well-placed to contribute to the role of cell salvage in the discussions.

- There was a marked change in the approach to the studies in 2012 and 2013. More studies were examining cell salvage in the wider hospital blood management context rather than the earlier 'traditional' approach to isolate costs associated with cell salvage and comparing these against the estimated volume and cost of allogeneic blood avoided. Associated with this was the trend to convert the salvaged/reinfused blood into equivalent units of allogeneic blood and attributing costs to the calculated units. This seems likely to have been initiated by newer pieces of cell salvage equipment that can capture information relating to volumes of blood salvaged and reinfused. McClelland's (2007) formula of one allogeneic unit to raise the $\mathrm{Hb}$ level by $10 \mathrm{~g} / \mathrm{l}$ is therefore quick and easy to attach to the volumes. In practice the volumes derived are notional and do not indicate whether the reinfusion is appropriate to the individual patient or whether an allogeneic transfusion would have been required anyway. The most recent literature search, up to December 2016, noted fewer studies adopting this approach and enthusiasm for this interpretation may be wearing off.

In conclusion, the articles highlight that there is much more support for cell salvage than dissentient views though this difference should be viewed with caution. It may be that those holding unfavourable views just do not participate in discussions or utilise cell salvage equipment. The Patient Blood Management discussions raise the profile of avoiding allogeneic blood transfusions; but it is up to the individual organisations and the enthusiasm of individuals within these organisations to decide if they wish to utilise cell salvage in surgery. 


\section{Chapter 5. Methods}

\section{$5.1 \quad$ Introduction}

The literature review highlighted three separate key factors that have had (and continue to have) an impact on the objectivity of a study into the financial impacts of cell salvage:

- Carless et al (2004 and 2010)'s issues on the high level of bias in studies and the consequent recommendation to develop a large-scale comparative approach to a study on cell salvage.

- The lack of emphasis placed on approaches to costs from both a financial and economic perspective.

- The isolation of the impact of cell salvage when other blood avoidance techniques are running concurrently. Few studies (with the exception of Thurer (2011) and Phillips SJ et al (2006)) considered this issue. Discussions with clinicians from a number of hospitals (para 5.4 below) stressed the potential benefits of cell salvage to avoid allogeneic blood transfusions. Some clinicians highlighted however that, with some operations, the benefits of allogeneic blood avoidance could be replicated by simply dispensing a packet of iron tablets in the two weeks prior to surgery.

The above recommendation from the clinicians on iron tablets was partly said in jest and not based on literature. However, the message was that a viable comparison of patients undergoing or not undergoing cell salvage needed to address the above factors in order to establish a baseline set of viable comparative data.

A preliminary literature search in 2009 gave an indication of the level of discussion around the hospital-based costs. The researcher initially felt the challenge would be relatively straightforward and the work would primarily involve a simple 'make $\mathrm{v}$ buy' type comparative study building on his previous research (Crotty (2006)). It was soon apparent that answering the research question would be a significant challenge. In particular, there were a number of significant, confounding factors, highlighted in 
the literature review. These would potentially distort the outcome of results, and therefore conclusions on costs, at hospital level leading to assertions of potential bias. These confounding factors included:

- Level and quality of patient preparation for the surgery.

- How invasive the total hip replacement operation was and any associated patient comorbidities. These would consume a greater amount of resource and potentially require more allogeneic blood.

- Day of week of surgery that may potentially impact on the patient's recovery programme when recovering over the weekend. This, in turn, may therefore affect the patient's length of stay for primary total hip replacement surgery.

- The quality of the financial information reported.

The researcher felt that the priority was to avoid the investigations falling foul of the criticisms of Carless et al (2004 and 2010). At the same time, the researcher should undertake a "large, methodologically rigorous" (para 4.5) study to study the costs and follow the spirit of the Carless et al (2004 and 2010) conclusions.

This chapter starts with a background of the key issues associated with the choice of data to extract in order to ensure the impacts of cell salvage are isolated and measurable. The chapter subsequently describes the approach to be employed and then highlights the organisational and personal challenges in collecting the data. An overall summary of the comparative information datasets requested is shown in table 18 below.

Table 18. Summary of Comparative Information Datasets Requested

\begin{tabular}{|l|l|l|}
\hline Information Required & Purpose & Method of Collection \\
\hline Patient identifier & $\begin{array}{l}\text { Extract relevant data for } \\
\text { primary total hip replacement } \\
\text { operations from hospital } \\
\text { patient systems. }\end{array}$ & $\begin{array}{l}\text { Information Department } \\
\text { extract information by } \\
\text { operation code. }\end{array}$ \\
\hline HRG code & $\begin{array}{l}\text { Categorise patient into level of } \\
\text { invasiveness/severity of } \\
\text { operation. }\end{array}$ & $\begin{array}{l}\text { Lookup table generated by } \\
\text { relevant Information } \\
\text { Department }\end{array}$ \\
\hline Pre-operative Hb level & $\begin{array}{l}\text { Record patient's iron level } \\
\text { prior to the operation. } \\
\text { Indication of 'preparedness' } \\
\text { for operation. }\end{array}$ & $\begin{array}{l}\text { Manually extracted from } \\
\text { patient record. }\end{array}$ \\
\hline Lowest post-operative $\mathrm{Hb}$ & Record patient's iron level & Manually extracted from \\
\hline
\end{tabular}




\begin{tabular}{|c|c|c|}
\hline Information Required & Purpose & Method of Collection \\
\hline level & $\begin{array}{l}\text { after the operation. Indication } \\
\text { of how well patient has } \\
\text { managed the trauma. }\end{array}$ & patient record. \\
\hline Patients date of birth/gender & $\begin{array}{l}\text { To test for patient } \\
\text { homogeneity in age/gender } \\
\text { across the three sites. }\end{array}$ & $\begin{array}{l}\text { Manually extracted from } \\
\text { patient record. }\end{array}$ \\
\hline $\begin{array}{l}\text { Date of operation/date of } \\
\text { discharge. }\end{array}$ & $\begin{array}{l}\text { To test for any day of week } \\
\text { association and calculate } \\
\text { length of stay. }\end{array}$ & $\begin{array}{l}\text { Manually extracted from } \\
\text { patient record. Spreadsheet } \\
\text { formulae would calculate } \\
\text { the relevant day of week } \\
\text { and the length of stay. }\end{array}$ \\
\hline Consultant/Firm & $\begin{array}{llr}\text { Extract comparisons } & \text { of } \\
\text { allogeneic blood usage for } \\
\text { internal discussion. }\end{array}$ & $\begin{array}{l}\text { Manually extracted from } \\
\text { patient record. }\end{array}$ \\
\hline $\begin{array}{l}\text { If allogeneic transfusion how } \\
\text { much allogeneic blood } \\
\text { transfused? }\end{array}$ & $\begin{array}{l}\text { To isolate number of } \\
\text { allogeneic transfusions and the } \\
\text { volume of allogeneic blood } \\
\text { required. }\end{array}$ & $\begin{array}{l}\text { Manually extracted from } \\
\text { patient record. }\end{array}$ \\
\hline $\begin{array}{l}\text { At the Royal Cornwall } \\
\text { Hospitals, for each patient, } \\
\text { verify if cell salvage used } \\
\text { and if shed blood reinfused }\end{array}$ & $\begin{array}{l}\text { To quantify utilisation of cell } \\
\text { salvage and estimate } \\
\text { associated costs. Allow } \\
\text { comparison of different types } \\
\text { of machine utilised. }\end{array}$ & $\begin{array}{l}\text { Manually extracted from } \\
\text { patient record. }\end{array}$ \\
\hline
\end{tabular}

The main focus on studies in the literature review is on the impact of cell salvage on minimising allogeneic blood transfusions. This thesis builds on ideas generated from the literature review and comments received from clinicians. It adopts a more holistic approach by undertaking a multi-site comparison of patients who have not had an allogeneic blood transfusion in primary total hip replacement surgery. This compares one organisation (the Royal Cornwall Hospitals NHS Trust) that uses cell salvage against two organisations (University Hospital of South Manchester NHS Trust and a specialist orthopaedic centre) that do not utilise cell salvage in primary total hip replacement surgery. The objective was to establish the baseline of patient data that could be readily compared over a number of sites; only then introducing cell salvage into the discussion. The key challenges to be addressed are summarised in table 19 below.

Table 19. Information Required to Compare Pre-Operative Activity Data

\begin{tabular}{|l|l|}
\hline Challenges & Addressed by: \\
\hline Potential bias in selection & $\begin{array}{l}\text { Take a series of consecutive patients at a site where cell } \\
\text { salvage utilised for total hip replacement. Compare these } \\
\text { against a series of consecutive patients at two sites where no } \\
\text { cell salvage is utilised. }\end{array}$ \\
\hline Homogeneity of patients & $\begin{array}{l}\text { Statistically verify the different patient cohorts are } \\
\text { homogeneous using age and gender. }\end{array}$ \\
\hline
\end{tabular}




\begin{tabular}{|c|c|}
\hline Challenges & Addressed by: \\
\hline $\begin{array}{l}\text { Difficulty in isolating } \\
\text { impact of cell salvage } \\
\text { from other blood saving } \\
\text { techniques }\end{array}$ & $\begin{array}{l}\text { Patients need to be homogenous and pre-operative statistics } \\
\text { should indicate adequate preparation for the operation. Clarify } \\
\text { with the selected centres they adopt best practice under Better } \\
\text { Blood Transfusion and subsequently Patient Blood } \\
\text { Management techniques. }\end{array}$ \\
\hline $\begin{array}{l}\text { Preparedness of patients } \\
\text { for surgery }\end{array}$ & Collect and statistically test pre-operative $\mathrm{Hb}$ reading. \\
\hline Homogeneity of surgery & $\begin{array}{l}\text { Obtain patient healthcare resource group (HRG) codes to } \\
\text { analyse the total hip replacement operation in more detail. This } \\
\text { level of detail has not previously been adopted in a cell salvage } \\
\text { study. }\end{array}$ \\
\hline Operation Day & $\begin{array}{l}\text { Experiences at UPMC Pittsburgh indicate operations } \\
\text { undertaken earlier in the week have an impact on patient } \\
\text { length of stay. }\end{array}$ \\
\hline
\end{tabular}

The approach to gather the information in table 19 would allow the researcher to:

- Establish the level of age and gender homogeneity in the groups of patients and develop a strong indication of the preparedness of the patients for surgery. The less prepared the patient the more likely there would be a need for an allogeneic blood transfusion.

- Establish if the patient comorbidities are uniformly distributed in each of the chosen sites. The more severe the surgery the more likely an allogeneic blood transfusion will be required. By extracting and comparing the relevant healthcare resource group (HRG) category a comparison could be made on the severity of the surgery and associated treatment. If the profile of the HRGs was similar across the sites, then patient comorbidities could be discounted as a factor in influencing differences in allogeneic blood transfusion rates.

- Identify whether any other factors may explain differences in transfusion rates.

If the three patient cohorts are homogenous this will support a direct comparison between the pre-and post-operative patient data across the three sites. Comparisons can then be undertaken between patients who have had their blood reinfused at the Royal Cornwall Hospitals, utilising cell salvage, with the other two sites where cell salvage is not utilised. 'Ceteris paribus'; the differences in the post-operative statistics would be caused by lower allogeneic transfusions at the Royal Cornwall Hospitals resulting from the utilisation of reinfused blood from adopting cell salvage. 
Further comparisons on patients who have had allogeneic transfusions can subsequently be extracted. The key aim, therefore, is to establish this 'baseline' where the same profile of procedures is undertaken on a set of homogeneous patients over three organisations. Once this baseline is established the focus can move to answering the research question:

Is cell salvage an appropriate method of blood conservation to support the reduction in costs associated with the collection and utilisation of allogeneic blood?

This chapter highlights the information required and the approach to answering the research question. It is crucial therefore to, as far as possible, isolate the impact and cost of cell salvage from the other allogeneic blood avoidance techniques that are running concurrently across the three sites. This strategy has been omitted from most of the studies discussed in chapter 4 .

\subsection{Objectives of Study}

This approach differs significantly from the majority of other studies noted in the literature review. In particular, it adopts a novel approach in assessing the costs associated with cell salvage in relation to:

- The varying resource inputs required to achieve a successful operation and the associated severity of the primary hip replacement surgery. This is highlighted by analysing HRG activity information that can classify the operations and treatment into varying levels of resource requirements and costs. All other studies only focus on the generic term 'primary hip replacement surgery'. To the best of the researcher's knowledge no other study has studied primary hip replacement surgery in this level of detail by utilising HRGs. This will therefore facilitate an additional method of comparison between hospitals. A Google search on the terms 'hip replacement surgery' and 'cell salvage' and 'HRG' with no date restrictions, undertaken on 10 April 2016, only gave 19 'hits'. None of these references were directly relevant to this thesis.

- Segregating the impact of enhanced recovery pathway programmes (para 1.19) such as identifying the potential impact of weekend discharges on 
patient length of stay and the adequacy of the pre-operative assessments by comparing patients' haemoglobin $(\mathrm{Hb})$ levels. Additionally, the analysis should address the length of stay differences by comparing patients who have not had an allogeneic blood transfusion or had their salvaged blood reinfused. This generates a 'baseline' of comparative data that will not be affected by the impacts of allogeneic blood transfusions or re-infused blood (the 'yellow route' in figure 15 on page 128).

- Addressing one of the key recommendations of Carless et al (2004 and 2010) on developing a large-scale comparative approach to a study on cell salvage. Additionally, with the Royal Cornwall Hospitals collecting information relating to patients who did not have their blood reinfused, there is the ability to extract some intra-hospital comparisons. This can provide additional reassurance that the three centres' operational procedures are uniform, allowing a further comparison with the cell salvage patient cohort.

- Segregating the costs and undertaking comparisons from both a financial and an economic approach.

In late 2009 the researcher secured funding from NHSBT trust funds to visit the University of Pittsburgh Medical Centre (UPMC), Pennsylvania, USA. This is the hospital where the author of a number of cell salvage articles, Dr Jon Waters, is based and this gave the researcher an opportunity to see the environment where Dr Waters based most of his studies and articles. The researcher spent four days with clinicians, seeing cell salvage in the surgical environment and shadowing members of staff. At first hand the operating procedures were similar to those the researcher had observed in operating theatres at the Morriston Hospital, Swansea. The main difference was that, at Pittsburgh, there were dedicated operating department practitioners (ODPs) who moved between operating theatres to manage the operation of cell salvage equipment.

The overall objectives of the study to answer the research question can be summarised as undertaking a comparison that minimises potential allegations of bias in order to: 
5.2.1 Establish the homogeneity of the patient cohorts selected in order to minimise allegations of bias and compare patient data between sites that use and do not use cell salvage. This will support a valid comparison between the three sites.

5.2.2 Evaluate the cost impacts of cell salvage against using allogeneic blood from both a financial and an economic perspective;

5.2.3 Investigate other possible factors that may impact on comparison across sites such as preparation for surgery and length of stay.

Data to underpin these objectives is therefore crucial to ensure valid comparisons between patients and across different sites are undertaken. The data from all three sites would be a consecutive series of patient details extracted from the patient admission system. This information would then be supplemented by additional data held in the respective departments.

\subsection{Overall Approach to Analysis}

The approach was planned as:

5.3.1 Extract the main activity data by site for elective primary total hip replacement patients and identify the reasoning behind generating the particular results, grouping these by:

- Pre-operative indicators for elective patients who have not had an allogeneic transfusion by hospital site.

- Compare post-operative indicators for the non-transfused (or nontransfused and non-reinfused at Royal Cornwall Hospitals) group.

- Analysis of length of stay (LOS) for patients who have not had an allogeneic blood transfusion to estimate the underlying mean length of stay at each site without being influenced by any allogeneic blood impacts. 
- These pre- and post-operative indicators will therefore generate a series of 'baseline' comparisons not affected by the impact of allogeneic transfusions.

- Patients with a LOS over 14 days would be excluded in order to minimise any distortions. A longer LOS may imply difficulties in discharging the patient or other complications arising. This excluded 20 patients in table 20 below:

Table 20. Elective Patients with Length of Stay >14 days and Excluded from Analysis

\begin{tabular}{|l|r|r|r|r|}
\hline \multicolumn{1}{|c|}{$\begin{array}{c}\text { Hospital/ } \\
\text { Category }\end{array}$} & \multicolumn{1}{c|}{$\begin{array}{c}\text { South } \\
\text { Manchester }\end{array}$} & $\begin{array}{c}\text { Royal } \\
\text { Cornwall }\end{array}$ & $\begin{array}{c}\text { Specialist } \\
\text { Orthopaedic } \\
\text { Centre }\end{array}$ & Totals \\
\hline Number of Records & 153 & 218 & 147 & 518 \\
\hline Records Excluded & 5 & 5 & 10 & 20 \\
\hline $\begin{array}{l}\text { Number of Records for } \\
\text { Analysis }\end{array}$ & 148 & 213 & 137 & 498 \\
\hline
\end{tabular}

5.3.2 Undertake statistical comparisons with the data extracted, subsequently comparing results where allogeneic blood transfusions are undertaken.

5.3.3 For the Royal Cornwall Hospitals, only, generate comparative information on the use of cell salvage (180 from a total of 213 patients) and especially where the blood was reinfused (104 from the 180 patients who were salvaged).

5.3.4 Derive estimates of expenditure associated with cell salvage and allogeneic blood usage.

5.3.5 Outline the calculations from NHSBT and the estimated costs attributable to the blood donation process (costs incurred by blood donors but not recompensed) and derived societal costs.

5.3.6 Estimate a unit cost of blood requirements (allogeneic and/or salvaged) per operation. This will include an estimate of the associated societal cost. Transfer prices can also be calculated and, where necessary, excluded from the analysis for a comparison from both a financial and an economic perspective.

5.3.7 The analysis plan was based on discussions with clinicians in 2008/09 and reference to articles in the literature review. The information requirements were then 
developed in conjunction with the clinicians' assessments on what datasets would provide the researcher with the requisite information to undertake comparisons across sites.

\subsection{Dealing with Challenges in Acquiring Information}

The researcher had access to the NHSBT costs and activity information. As highlighted earlier the main stumbling block was the collection of the hospital/patient data. The finalised schedule of hospital information requirements in table 18 was agreed in early 2010 . Consultants from the three hospitals below were keen to support the work:

- Abertawe Bro Morgannwg (ABM) University Health Board.

- Guy’s Hospital London.

- Oxford University Hospitals NHS Trust.

Morriston Hospital, part of Abertawe Bro Morgannwg (ABM) University Health Board, agreed to commence the pilot of the information gathering in March 2010. A list of patients who had undergone primary total hip replacement operations was to be generated. The relevant information would then be accessed from the patient record system using the patient identification number. The intention was for a foundation level doctor to undertake the extraction of the information and the researcher to develop it into a service evaluation for the Hospital Transfusion Committee (HTC). The researcher would receive the information suitably anonymised thereby not requiring any local Ethics' Committee approval. Several foundation level doctors expressed an interest to the lead consultant but were put off by the Morriston information systems requiring each patient record to be accessed individually and the data manually transferred to a spreadsheet. The researcher was advised to wait until August 2010, to await the next post rotation. Again, however, interest from the new cohort of junior doctors waned and in early 2011 the researcher agreed with the lead consultant that Morriston was unable to collect the required information. 
In mid-2010 the researcher met with a consultant orthopaedic surgeon at Guy's Hospital in London. The surgeon was keen to introduce the elements in table 18 into Guy's and agreed to take the request to the Orthopaedics Management Board of the Trust in late 2010. The Management Board, following liaison with the Information Technology Department, did not feel it appropriate to support the request citing the significant volume of work that would be required to collect the information. The researcher offered to be placed on an honorary contract and be supervised by the surgeon. It was pointed out that the information needed to be extracted by individual patient (this issue was similar to the issues at Morriston Hospital); this would be time consuming and the researcher would need to be constantly supervised to ensure no individual patient could be identified. This was viewed as unworkable by the Orthopaedics Management Board at Guy's.

By early 2011 the researcher was also not getting positive messages from the Oxford University Hospitals Trust. Again, the initial enthusiasm waned as the same issues emerged with collection of data and the researcher had to discount Oxford as a potential site on which to base his study.

The researcher was then introduced to the Spire private hospital in Bristol. The Pathology manager kept most of the information in table 18 however these were only readily available for patients who had received an allogeneic blood transfusion. New salvage machines had recently been acquired and these could record the majority of the relevant information. Key data on allogeneic transfusions and the HRG code were not recorded. This was a further disappointment, but it was a short move in the right direction to note that the information could actually be generated.

The researcher was almost at a point of giving up. He realised, in harsh reality, the issues of potential bias evolving that Carless et al (2004 and 2010) had highlighted. The idea of a large-scale cross-site comparative study seemed very challenging to coordinate if there was not the enthusiasm and resource to gather a common set of data within each particular site. At the same time, the researcher needed to overcome the significant obstacles of data gathering and managing the associated patient confidentiality.

In September 2010, the researcher succeeded in getting an article published in the Healthcare Financial Management Association (HFMA)'s monthly publication 
'Healthcare Finance'. This related to a joint project on costs associated with cell salvage undertaken with the Welsh Blood Service's Cell Salvage Coordinator. The title of the article, chosen by the editor with a recycling emphasis, was "When Blood Turns Green". This did not create any stir in the world of cell salvage but proved useful in providing a crucial introduction in 2011. In March 2011, the researcher read an article on preparedness for surgery in the Health Service Journal by an anaesthetist at the Royal Devon \& Exeter (RDE) Hospital ((Berry et al 2011)). The author noted, inter alia, the impact of pre-operative assessments on allogeneic blood usage. The researcher contacted the anaesthetist with a copy of his HFMA article. This facilitated an introduction to the clinical blood conservation coordinator at the RDE. In turn it was suggested a meeting with the transfusion coordinator at the Royal Cornwall Hospitals NHS Trust would be useful to assess their level of information availability. This was the breakthrough the researcher was hoping for, as Royal Cornwall Hospitals' team had been collecting most of the information the researcher required. In early 2012 the transfusion coordinator at the Royal Cornwall Hospitals introduced the researcher to his counterpart at South Manchester University Hospital Trust who was a co-author of the HTA study (Davies et al (2006)). South Manchester were happy to release similar data recently collected to be incorporated into a comparative study.

By mid-2012 the researcher now had two sets of comparative information. There were, however, still gaps in the information for both organisations:

- The operation date. Both hospitals used the patient admission date which could be the day prior to the operation if, for whatever reason, the patient was admitted early.

- Neither hospital extracted the HRG coding system to classify the operation as to its resource requirements.

The researcher met again with the transfusion coordinators at the Royal Cornwall Hospitals and South Manchester to discuss the potential collection of the additional information. The researcher again suggested being employed on an honorary contract and extracting the information himself under supervision. Again, the issue of patient confidentiality was raised. The researcher agreed with the two transfusion coordinators that they (or their staff) would extract the relevant information. This 
proved to be very slow, but the final elements of the information were made available to the researcher in late 2014 .

The researcher had previously discussed pre-operative assessments with clinicians at NHSBT. One of the clinicians held a joint post as a consultant haematologist with an NHS Trust. The operations of this Trust included a Specialist Elective Orthopaedic Centre (SOC). The consultant had previously undertaken studies in pre-operative $\mathrm{Hb}$ levels. She was a strong advocate of deferring a patient's surgery if their Hb levels were low (para 1.19). She therefore had first-hand experience of how difficult it was to collect the information and could empathise with the researcher's problem in acquiring the relevant information.

The consultant offered to support the researcher in extracting information from the Trust relating to patients at the SOC.

The SOC did not utilise cell salvage for primary hip replacement operations so, along with South Manchester University Hospital, would provide a benchmark to assess against the data from the Royal Cornwall Hospitals who salvage all elective primary total hip replacement patients.

A list of consecutive elective primary total hip replacement patient identifiers was obtained from the Information Department for the SOC. Also generated was the operation date, the date of discharge and the HRG code. The rest of the information from table 18 needed to be extracted from the individual patient record, using the patient identifier. The consultant offered to sit with the researcher and extract the information by accessing the patient records system and calling out the specific details to the researcher who would enter the information in a spreadsheet. The requisite documentation was sent to the Trust's Ethics' Committee who approved the process subject to the SOC being anonymised in the published study. The researcher agreed to call the organisation the Specialist Orthopaedic Centre or 'SOC' in any narrative and the consultant agreed to be directly involved in the data collection.

The consultant suggested the data extraction work be undertaken in mid-late evenings when there were fewer users accessing the information system and response times were faster. Monday evenings were traditionally quieter, and this work commenced in autumn 2012; being completed prior to Christmas 2012. 
Perversely, though the information collection commenced last, it was completed first. In early 2013 the researcher was able to analyse the SOC information over HRGs and share this anonymised information with the Royal Cornwall Hospitals and South Manchester. The aim of sharing the information was to show the higher level of certainty and reassurance on homogeneity the HRG information would provide. It slowly helped encourage the other two organisations to eventually deliver the HRG information.

The researcher was invited to present his provisional findings to the Hospital Transfusion Special Interest Group (HOTSig) conference in Birmingham in May 2013. The researcher took part and presented on variations in transfusion rates and length of stay. Though the presentation was well received and there was useful feedback he came away feeling he had not added a great deal to the overall discussions. He felt the comparison on HRGs would add more analysis to the discussion and adopt a new angle to the discussion.

The researcher had been employed at NHSBT, and its forerunner, the National Blood Service (NBS) since 1998. He had a wide exposure to the discussions on blood conservation. He had been an active blood donor since his undergraduate days and conceived and developed the project at work both in discussions with colleagues and being involved with the setting up of the UK Cell Salvage Action Group (para 1.15. The researcher supported the Group on developing spreadsheet models of activity and provided financial input into various papers. This was mainly on an informal basis and undertaken in the researcher's spare time.

Running concurrently with the research work in gathering information for the thesis was the evolving strategic plans for NHSBT. In 2011 the researcher's post and the rest of the NHSBT Finance Department posts based in Bristol were placed 'at risk'. There was a long period of uncertainty and a high number of redundancies to facilitate the centralisation of support services in Leeds. The justification of the centralisation was to cut costs in the light of lower activity. The researcher secured a new post, based at Bristol, in the organisation however the disruption impacted on the ability to devote much time to the thesis in 2011. 2013 was also a challenging year as the researcher's new post was then declared 'at risk' in March 2013. There then followed an arduous consultation period culminating in the researcher finally 
being made redundant in October 2013. Again, the thesis had to be put to one side while the researcher looked for another job. He commenced a new role in the NHS in Torquay in January 2014. It took a couple of months to settle down before he could resume serious work on the thesis and build up lost momentum. Family life also suffered, and the researcher felt that home life and securing paid employment had to be the priority in this uncertain period.

In December 2014, the researcher moved to a permanent position as Corporate Development Manager at the West of England Academic Health Science Network in Bristol. A family bereavement in March 2015 again took time to come to terms with and it was not until late-2015 that the researcher felt that his studies were again picking up momentum.

\subsection{Preparation-Isolation of Impacts of Cell Salvage}

As noted previously, a key challenge is to isolate the impact of cell salvage as a technique to avoid an allogeneic blood transfusion. Many allogeneic blood avoidance techniques are adopted simultaneously in surgery and a plan to isolate the impact of cell salvage required a wide-ranging discussion with key proponents of cell salvage. Some slightly less enthusiastic clinicians' views were also sought to ensure, as far as possible, an objective approach to a comparative study was maintained. The recurring point raised was that a packet of iron tablets cost only a few pennies. Cell salvage utilisation in an operation would cost at least $£ 100$. Both strategies would potentially reduce allogeneic transfusion rates. The main advice from these discussions was that cell salvage should be adopted after cheaper blood conservation methods had all been utilised. One of the main challenges for staff would therefore be when to set up and run the cell salvage equipment, thereby incurring costs. Given the timings it may have been uncertain whether the equipment would be required since the cheaper strategies had actually proved to be effective.

From the literature review Thurer et al (2011) highlighted the issue of a number of blood avoidance techniques running concurrently, concluding "Further study is needed to better understand the relative contribution of each of these modalities". Similarly, Phillips S et al (2006) undertook a combined study of utilising cell salvage and tranexamic acid, concluding the joint contribution was significant. They noted, 
however, that they did not study the two techniques in isolation. Without further study, there was no way for Phillips S et al (2006) to conclude which of the two techniques had been the more effective. Carless et al (2010) also concluded "To delineate the efficacy of the various techniques used in non-cardiac settings is rather difficult as the current available evidence is equivocal". Most other studies did not highlight this issue of the impact of utilising different blood avoiding strategies.

Initial discussions had been held in 2008/2009 with clinicians from Liverpool, Swansea, Oxford, London and Bristol. Additionally, the author discussed issues on cell salvage with colleagues in NHS Blood \& Transplant (NHSBT) while employed there up to October 2013. Wider ranging discussions were also held with a consultant haematologist at Basildon. The haematologist had forthright views on the logistics required to support electronic cross matching to speed up the checking of any incompatibilities in the patient's own blood (para 4.2). He suggested the researcher liaise with the South West London Elective Orthopaedic Centre (Swleoc), who were extensive users of cell salvage. The researcher tried on several occasions but failed to elicit any response from the Swleoc.

Opinions on the use of cell salvage from those contacted were generally in favour of its introduction and development. All the clinicians stressed that the researcher would have a challenging task in answering the research question. As noted above the challenge was to isolate the benefits cell salvage offered if an array of other allogeneic blood avoidance techniques were also being adopted at the same time. Chapter 1 makes references to the development of blood clotting drugs (para 1.9) and the Better Blood Transfusion Initiatives along with the more recent Patient Blood Management Initiative (paras 1.11 and 1.12). These elements are discrete and tangible. There are other factors that are considered best practice e.g. keeping the patient warm or positioning the patient correctly during surgery to allow the surgeon access which would minimise blood loss. These factors are less tangible and would not be directly associated with an allogeneic blood avoidance initiative however the operating staff would be expected to follow these procedures. Shander et al (2012) summarise the differing issues in their "three pillar approach". The pillars involve adopting: 
- approaches to ensure the patient's blood cells are maximised when presenting for surgery.

- during surgery ensuring the patient's blood loss is minimised

- post-surgery effectively managing the patient recovery to minimise the chances of anaemia progressing. Minimising the progression of anaemia would thereby support the recovery process and contribute to minimising blood loss.

Shander et al's (2012) schematic is reproduced below:

Figure 13. Shander et al (2012) Summary of Patient Blood Management

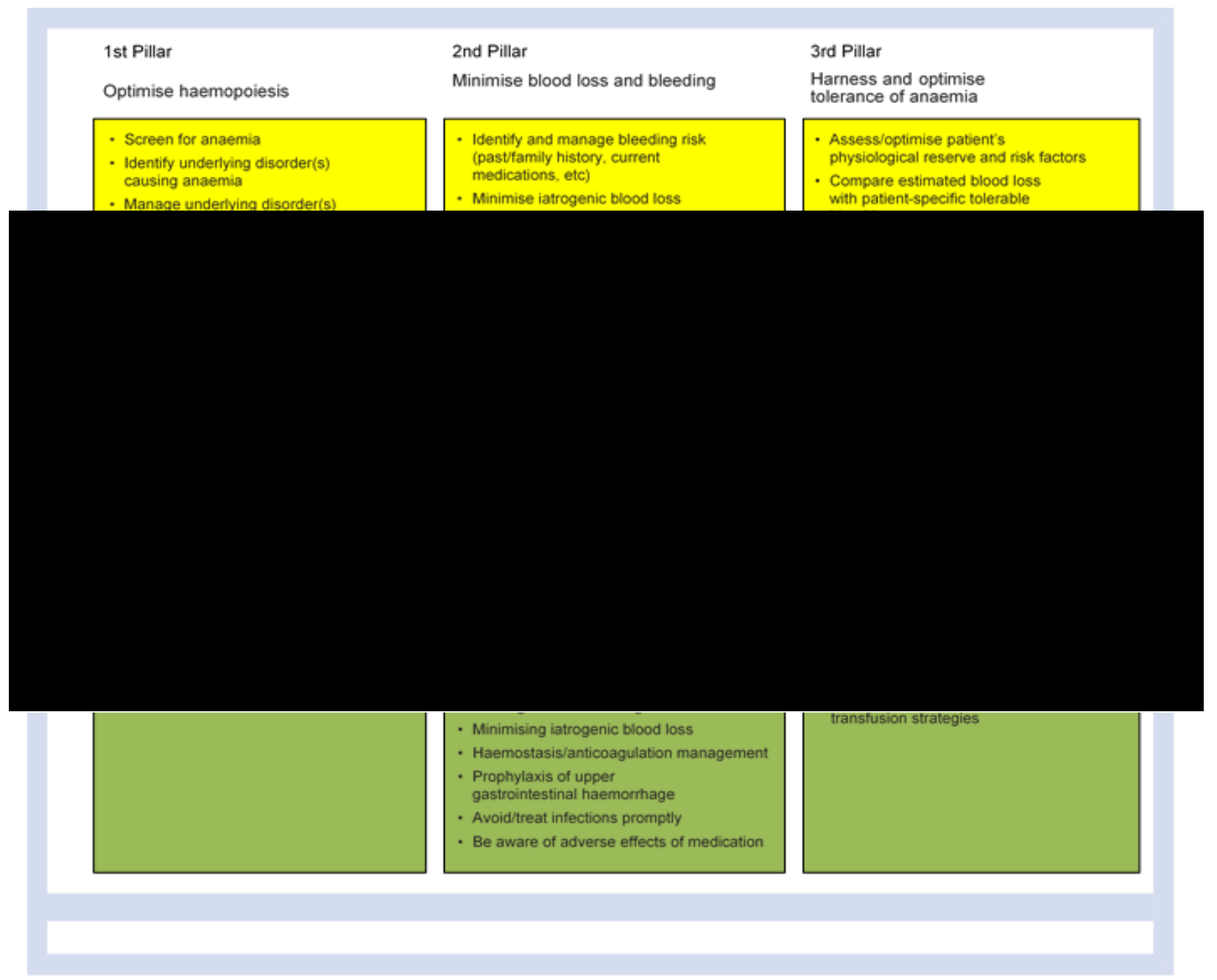

Key:

\begin{tabular}{|l|l|}
\hline & Pre-Operative Stage \\
\hline & Intra-Operative Stage \\
\hline & Post-Operative Stage \\
\hline
\end{tabular}


Shander et al's (2012) schematic attempts to capture the main potential surgical processes and covers both elective and non-elective surgery. As would be expected, managing anaemia crosses all the pillars and operation stages. Cell salvage features in the 'autologous blood options' in the second pillar's intra-operative stage and the 'autologous blood salvage' in the post-operative stage (e.g. utilising the OrthoPat post-operative cell salvage machine). What is significant is the number of potential areas that could influence the process. Though Shander et al's (2012) article had not been published when the researcher commenced discussions with the various clinicians the message from the clinicians was consistent and repetitive; the researcher would be faced with a major challenge to isolate the impact of cell salvage. In all studies, there would be a level of subjectivity and the researcher needed to develop a plan to satisfy Carless et al's (2010) conclusion that "large, methodologically rigorous comparative trials" were required to "assess the cost effectiveness of cell salvage..".

The conclusion from the discussions with the clinicians was to undertake a comparison of patient information over the three areas of:

- Pre-operative assessments. The key indicator as to their impact would be the patients' Hb levels.

- Intra-operative. The level of resource required in the operation. This approach was novel. The more severe the HRG category the more likely a requirement for an allogeneic blood transfusion or a potential longer associated length of stay. A more detailed explanation of HRGs is outlined in para 5.7 below.

- Post-operative. Factors such as discharge day that may point to differing trends in post-operative therapy support for primary total hip replacement patients. These are highlighted in para 1.19 on enhanced recovery pathways.

This approach followed the emphasis of Shander et al (2012). All the clinicians stressed the need to ensure the researcher could, as far as possible, verify patient 
group homogeneity and suggested a number of datasets to form the basis of an analysis to verify this was the case.

The discussions with the clinicians were invaluable in framing the researcher's thoughts on how to approach the collection of information to develop an answer to the research question. The choice of operation to consider was developed in chapter 1. The researcher believed that a multi-site study was required to compare primary total hip replacement at two or more hospitals to minimise any of the Carless et al (2010) criticisms (para 4.5). The hospitals needed to have, as far as possible, a homogeneous cohort of patients. At least one of the hospitals needed to utilise cell salvage. All the hospitals needed to be assiduous in minimising the exposure to allogeneic blood. The hospital or hospitals not utilising cell salvage in primary total hip replacement surgery would therefore provide a baseline for cell salvage to measure against. 'Ceteris paribus' lower allogeneic blood usage in the hospital utilising cell salvage would therefore be assumed to be due to the impact of cell salvage decreasing the allogeneic blood requirements. Hospital based costs could then be segregated to allow a comparison between patients undergoing cell salvage and those that did not. In addition, ensuring the usage of allogeneic blood is kept to a minimum allows a comparison between different cell salvage machine costs in the same organisation.

This approach, though challenging, was viewed as the optimal way of isolating the impact of cell salvage. By assuming homogeneity of patients, procedures and assessments the only difference in the allogeneic blood requirements of the patients would therefore be due to the contribution of cell salvage.

\subsection{Preparation-Recruiting Study Sites}

As noted above the researcher had discussed issues around cell salvage with clinicians around England and Wales. His initial discussions were at Abertawe Bro Morgannwg (ABM) University Health Board, Swansea and at the Royal Liverpool and Broadgreen University Hospitals NHS Trust in 2008. This led to further discussions/development of plans. A brief chronology of the progression is shown in table 21 below: 
Table 21. Progression of Information Gathering Discussions

\begin{tabular}{|l|l|}
\hline Year & Main Events \\
\hline 2008 & $\begin{array}{l}\text { Discussions with ABM. Met with Royal Liverpool to discuss cell salvage } \\
\text { applications in cardiac. Discussions with staff at NHSBT noted } \\
\text { expectancy of increased orthopaedics activity and consequent increased } \\
\text { use of allogeneic blood. Decided to focus on orthopaedics following } \\
\text { discussions with NHSBT medical staff (para 1.20). }\end{array}$ \\
\hline 2009 & $\begin{array}{l}\text { Preliminary discussions at Oxford and Basildon. Both noted the high use } \\
\text { of cell salvage at the Nuffield Orthopaedic Centre (NOC) in Oxford and } \\
\text { the South West London Elective Orthopaedic Centre (SWLEOC). }\end{array}$ \\
\hline 2010 & $\begin{array}{l}\text { Guy's agreed to take part and collect data. ABM and Oxford also agreed } \\
\text { to commence collecting data. The researcher was planning for a three- } \\
\text { way comparison. } \\
\text { Guy's then stated the resources required to extract the information were } \\
\text { too costly and pulled out. ABM finally highlighted the difficulty in } \\
\text { getting foundation level doctors to support the data collection and stated } \\
\text { they felt they could not support the researcher. }\end{array}$ \\
\hline 2011 & $\begin{array}{l}\text { Oxford and ABM formally pulled out, citing difficulties in collecting the } \\
\text { information. Introduced to the Royal Cornwall Hospitals NHS Trust; a } \\
\text { keen user of cell salvage in orthopaedics. They were confident of being } \\
\text { able to extract most of the data. Introduced to South Manchester who } \\
\text { utilised cell salvage in cardiac but not in orthopaedics. South Manchester } \\
\text { had been collecting anonymised total hip replacement data that they were } \\
\text { willing to share with the researcher. }\end{array}$ \\
\hline 2012 & $\begin{array}{l}\text { Discussions within NHSBT identified a specialist elective orthopaedic } \\
\text { centre (SOC). The SOC stated the information would be made available if } \\
\text { the researcher undertook the information gathering under the supervision } \\
\text { of the consultant haematologist. The SOC information gathering was } \\
\text { completed immediately prior to Christmas 2012. }\end{array}$ \\
\hline
\end{tabular}

The final choice of sites on which to base the study was therefore:

- Royal Cornwall Hospitals NHS Trust. Orthopaedic services are delivered in the main Royal Cornwall Hospital in the Treliske area of Truro and St Michael's Hospital in Hayle, Cornwall. St Michael's is approximately 17 miles south west of Truro.

- University Hospital of South Manchester NHS Foundation Trust ('South Manchester'), based in Wythenshawe, approximately nine miles south of the centre of Manchester.

- The specialist orthopaedic centre (SOC). The SOC undertakes extensive elective and non-elective orthopaedic work on behalf of five clinical 
commissioning groups (CCGs). This organisation currently wishes to remain anonymous.

All three sites undertake orthopaedic work in both elective and non-elective settings. The published HRG statistics for the three sites for total 2010/11 orthopaedic operations was:

Table 22. Summary of Orthopaedic Operations 2010/11

\begin{tabular}{|l|r|r|r|r|}
\hline $\begin{array}{c}\text { Sitel } \\
\text { Classification }\end{array}$ & \multicolumn{1}{|c|}{$\begin{array}{c}\text { South } \\
\text { Manchester }\end{array}$} & $\begin{array}{c}\text { Royal } \\
\text { Cornwall }\end{array}$ & $\begin{array}{c}\text { Spec Orth } \\
\text { Centre }\end{array}$ & \multicolumn{1}{c|}{ Total } \\
\hline Day Case & 345 & 310 & 135 & 790 \\
\hline Elective & 252 & 759 & 959 & 1,970 \\
\hline Non-Elective & 36 & 134 & 106 & 276 \\
\hline \multicolumn{1}{r|}{ Total } & 633 & 1,203 & 1,200 & 3,036 \\
\hline
\end{tabular}

Extracted from Department of Health National Schedule of Reference Costs 2010/11

The main emphasis of the study would be on the analysis of elective primary total hip replacement surgery. On overall totals the orthopaedic activity at South Manchester is significantly lower than the other two sites. Part of this may be explained by the geographical nature of the location of South Manchester where there are a number of specialist and other large teaching hospitals in close proximity. The Royal Cornwall Hospitals is the only orthopaedic service in a wide catchment area. Similarly, the SOC specialises in orthopaedic cases with CCGs encouraging their patients to travel to the SOC for elective orthopaedic surgery.

\subsection{Approach to Designing Study to Measure Patient Group Homogeneity}

The researcher discussed with the various clinicians how to measure the key elements influencing a requirement for an allogeneic blood transfusion before, during and after the operation. These elements were key to establishing a number of currencies to support the objectives in para 3.3. These key factors were:

Patient Preparation. As noted in para 1.9 the pre-operative $\mathrm{Hb}$ levels are crucial in determining the patients' readiness to undergo an operation. The English NHS Enhanced Recovery Programme highlights the need for the pre-operative assessment to gauge whether the patient is 'match fit' to present for surgery. If the patient is anaemic then the pre-operative assessment, held generally two to three weeks prior to the operation, will recommend the patient be referred to their GP for investigation 
prior to surgery. Discussions with the clinicians noted that patients with a lower preoperative $\mathrm{Hb}$ level would be more likely to require an allogeneic transfusion. It was highlighted by clinicians at the Morriston Hospital, Swansea and others, however, that cell salvage effectively slows down the fall in $\mathrm{Hb}$ levels during and after surgery. This would therefore give the impression that its contribution was effective in lowering the requirement for an allogeneic blood transfusion. The patient's initial $\mathrm{Hb}$ level, however, may have been too low at the outset and the elective operation should not have taken place. Clinicians stressed that the researcher should therefore address the key issue of cell salvage masking inefficiencies in the patients' pre-operative assessments in elective surgery.

Post-operative Hb Levels. These are a strong indicator of the progression in recovery. A higher level of oxygen will stimulate organs to support the recovery process. Clinicians unanimously advised that the post-operative reading must be available. Post-operative $\mathrm{Hb}$ levels are typically taken using a portable or a hand-held point of care device. This involves taking a pin prick sample of blood onto a slide and placing this slide onto a portable analyser which is not much bigger than a large mobile phone.

The lowest available post-operative $\mathrm{Hb}$ reading would therefore give a strong indication of the recovery rate and indicate the 'worst state' the patient was in after the operation. The reading may not be the actual lowest $\mathrm{Hb}$ point the patient reached. It is reasonably safe, however, to assume that if the $\mathrm{Hb}$ level continued to fall the patient would start to show signs of distress and interventions would be required. If this was the case, then the additional procedures would categorise the patient into a higher graded HRG code. The post-operative $\mathrm{Hb}$ reading is therefore a reasonable indicator of recovery.

Invasive Level of Primary Total Hip Replacement Operation. Para 1.24 introduced the concept of the HRG (healthcare resource group) with software that groups together similar surgical procedures and assigns an HRG code to the operation. This code effectively separates operations that require different levels of intervention. HRG classifications are used as a funding currency in the English NHS internal market. The suggestion to sub-analyse the total hip information in this level of detail was put to the clinicians; none of whom had previously undertaken any analysis of 
operations in this level of detail. The researcher had attempted to find a cell salvage study including this level of detail however he failed to uncover any. The researcher also noted how unfamiliar the clinicians were with the term 'HRG'. None of the clinicians used this currency to record and quantify their own, and their teams', activity. This seemed surprising and some of the clinicians also expressed surprise that there was no HRG code for total hip replacements. There was only, as described in table 23 below, a coding system to reflect the severity of the operation/associated comorbidities, grouping together procedures. The individual procedures may be e.g. a primary (first) hip replacement, a secondary (subsequent) hip replacement or a revision of an existing hip replacement operation undertaken previously. These three, significantly different, operations could be identified to the same HRG category depending on the relative severity/comorbidity.

The level of detail that can be generated by the HRG coding is extracted from the English NHS national schedule of reference costs and shown in table 23 below. The aim was to gather the detailed HRG information for primary total hip replacement operations by each site. This would be statistically tested to check any significant difference in the composition of procedures between the comparative sites. Again, the aim would be to avoid any potential bias in the selected patient details and seek reassurance that the patients considered were from homogeneous groups.

Table 23. Non-Trauma Hip Interventions by HRG Code

\begin{tabular}{|l|l|}
\hline $\begin{array}{c}\text { HRG } \\
\text { Ref }\end{array}$ & \multicolumn{1}{|c|}{ Description } \\
\hline HB11A & Major Hip Procedures for Non-Trauma Category 2 with Major CC \\
\hline HB11B & Major Hip Procedures for Non-Trauma Category 2 with CC \\
\hline HB11C & Major Hip Procedures for Non-Trauma Category 2 without CC \\
\hline HB12A & Major Hip Procedures for Non-Trauma Category 1 with Major CC \\
\hline HB12B & Major Hip Procedures for Non-Trauma Category 1 with CC \\
\hline HB12C & Major Hip Procedures for Non-Trauma Category 1 without CC \\
\hline HB13Z & Intermediate Hip Procedures for Non-Trauma Category 2 \\
\hline HB14B & Intermediate Hip Procedures for Non-Trauma Category 1 with CC \\
\hline HB14C & Intermediate Hip Procedures for Non-Trauma Category 1 without CC \\
\hline HB15D & $\begin{array}{l}\text { Minor Hip Procedures for Non-Trauma Category } 219 \text { years and over } \\
\text { with CC }\end{array}$ \\
\hline HB15E & $\begin{array}{l}\text { Minor Hip Procedures for Non-Trauma Category } 219 \text { years and over } \\
\text { without CC }\end{array}$ \\
\hline HB15F & $\begin{array}{l}\text { Minor Hip Procedures for Non-Trauma Category } 218 \text { years and under } \\
\text { with CC }\end{array}$ \\
\hline HB15G & $\begin{array}{l}\text { Minor Hip Procedures for Non-Trauma Category } 218 \text { years and under } \\
\text { without CC }\end{array}$ \\
\hline HB16B & Minor Hip Procedures for Non-Trauma Category 1 with CC \\
\hline HB16C & Minor Hip Procedures for Non-Trauma Category 1 without CC \\
\hline Note CC = comorbidities and complications
\end{tabular}


Day of week/Length of Stay (LOS) Relationship. As noted in para 4.7 the discussion on length of stay has tailed off in later articles. Earlier articles noted a correlation between allogeneic blood transfusions and longer length of stay. Correlation, however, does not imply causation and the patients may have been older, the patients may have presented as anaemic, the surgery being more invasive or patients having experienced reactions to the surgery with these issues ameliorated by the allogeneic blood transfusion rather than the transfusion actually causing the longer length of stay. When in Pittsburgh the researcher examined the activity statistics for primary hip replacement operations and noted that the majority of the primary hip replacement operations were undertaken on a Tuesday morning. This was raised with the Pittsburgh team who stated that this was deliberate, the patient would have had their pre-operative assessment up to three weeks' prior and be given a date/time to attend for surgery. This would generally be a Tuesday and the time to attend would be between 0400 and 0600 . Operations were generally all finished by 1400 on the day. With an average length of stay of 3-4 days the majority of patients would commence their rehabilitation as early as possible and usually be back home by the Friday afternoon/evening. Therapy support would continue to be available but, crucially, UPMC would not bear the costs of caring for the majority of patients over the weekend as they would have already been discharged. In a Danish study on elective primary hip replacement surgery, Husted et al (2007) also concluded the length of stay increased when surgery was undertaken later in the week.

It soon became apparent that the length of stay was both a challenging issue to interpret and highly subjective as to whether there is any causal relationship between allogeneic blood transfusions and length of stay. In order to scrutinise further, the researcher decided that the date of operation and the date of discharge would need to be extracted in his analysis. The difference between the two dates would automatically generate the length of stay and, by using Microsoft Excel formula, the day of the week of the operation and subsequent discharge day.

Other Comparative Factors to Gauge Homogeneity. There were other factors that may have distorted the comparison between groups of patients. It was highlighted to the researcher in his discussions with clinicians that he would need to establish the age and gender of each of the patients selected. Additionally, it would be of interest to the selected hospitals to identify internally the data by consultant/firm to get an 
indication in emerging trends in decisions on blood usage. This information, though gathered, was felt to be of more use after the thesis had been completed in order to continue the dialogue.

As noted above the relevant information was not available at the press of a button from a computerised system though some steps have been taken at the Royal Cornwall Hospitals to automate the process. UPMC utilised a blood ordering system that generated management information to e.g. automatically match up $\mathrm{Hb}$ levels to allogeneic blood requests. The availability of data at UPMC was far superior to that available in the three sites studied reflecting significant levels of investment in information technology.

An emerging issue, discussed with the Transfusion Coordinators, was could hospitals effectively manage their allogeneic blood usage monitoring on a day to day basis as the UPMC information was from such disparate sources? Hospital Transfusion Committees meet monthly or quarterly with the information analysis being manually extracted. The level of resource to extract the information would need to be considered.

\subsection{Study to Determine Activity and Actual Costs}

The viewpoint from the clinicians was primarily associated with allogeneic blood costs in the hospital setting. As noted in para 4.2 there are also costs incurred at NHSBT and the costs incurred by the donor who is unpaid for donating. Donors are also not recompensed for the costs of getting to/from the donation centre. Other costs, not considered, are the costs incurred by the various companies who supply the cell salvage equipment and the consumables. Given these costs will be passed on (plus a profit margin) to the hospitals these are effectively a transfer price.

As this study investigates the differences in blood usage the common costs across the three sites can be excluded from the analysis so, e.g. the costs of cross matching (para 4.2), the operation of the blood bank (para 1.10), operating theatre staff (para 1.18) and the administration of tranexamic acid (para 1.9) do not need to be considered. These costs will be incurred in all three sites and will not be affected by the volume of cell salvage at the Royal Cornwall Hospitals. 
The costs associated with the utilisation of cell salvage and avoiding allogeneic blood transfusions are summarised in figure 14 below:

Figure 14. Cell Salvage Cost Groupings

\begin{tabular}{|l|l|}
\hline \multicolumn{1}{|c|}{$\begin{array}{c}\text { Hospital Based } \\
\text { Costs }\end{array}$} & $\begin{array}{l}\text { Costs at NHSBT } \\
\text { Cost associated } \\
\text { with providing } \\
\text { allogeneic blood } \\
\text { or cell salvage (or } \\
\text { both). }\end{array}$ \\
\end{tabular}

$\quad \begin{aligned} & \text { Donor/Societal } \\ & \text { Costs }\end{aligned}$
Costs of donors
taking time off work
to donate, travel to
the session.
Opportunity cost of
time not spent
elsewhere.

Activity information relating to patients, allogeneic blood usage and cell salvage (at the Royal Cornwall Hospital only) from the three sites was compared and analysed. This analysis followed the pattern:

- Baseline. For each of the three centres the activity data would be analysed to gain assurance that the patients are homogenously grouped, and they are adequately prepared for the operation. The HRG information (para 5.7) would also be tested to ensure the operations required a similar level of intervention as defined by the HRG Grouper software. Activity data on 'before' and 'after' the operations would be compared and analysed.

- Segregate the Royal Cornwall Hospital activity into those patients who had their shed blood salvaged and those that did not. For the salvaged group this is sub-divided into those patients that had the salvaged blood reinfused and those patients whose own blood was not reinfused. This therefore segregates the impact of the reinfusion and allows a direct comparison of statistics relating to reinfused patients against patients who have not had cell salvage at Royal Cornwall Hospitals or the other two centres. A diagram of the flow of information leading to the relevant comparisons is shown below. The main comparator route is in the green pathway: 


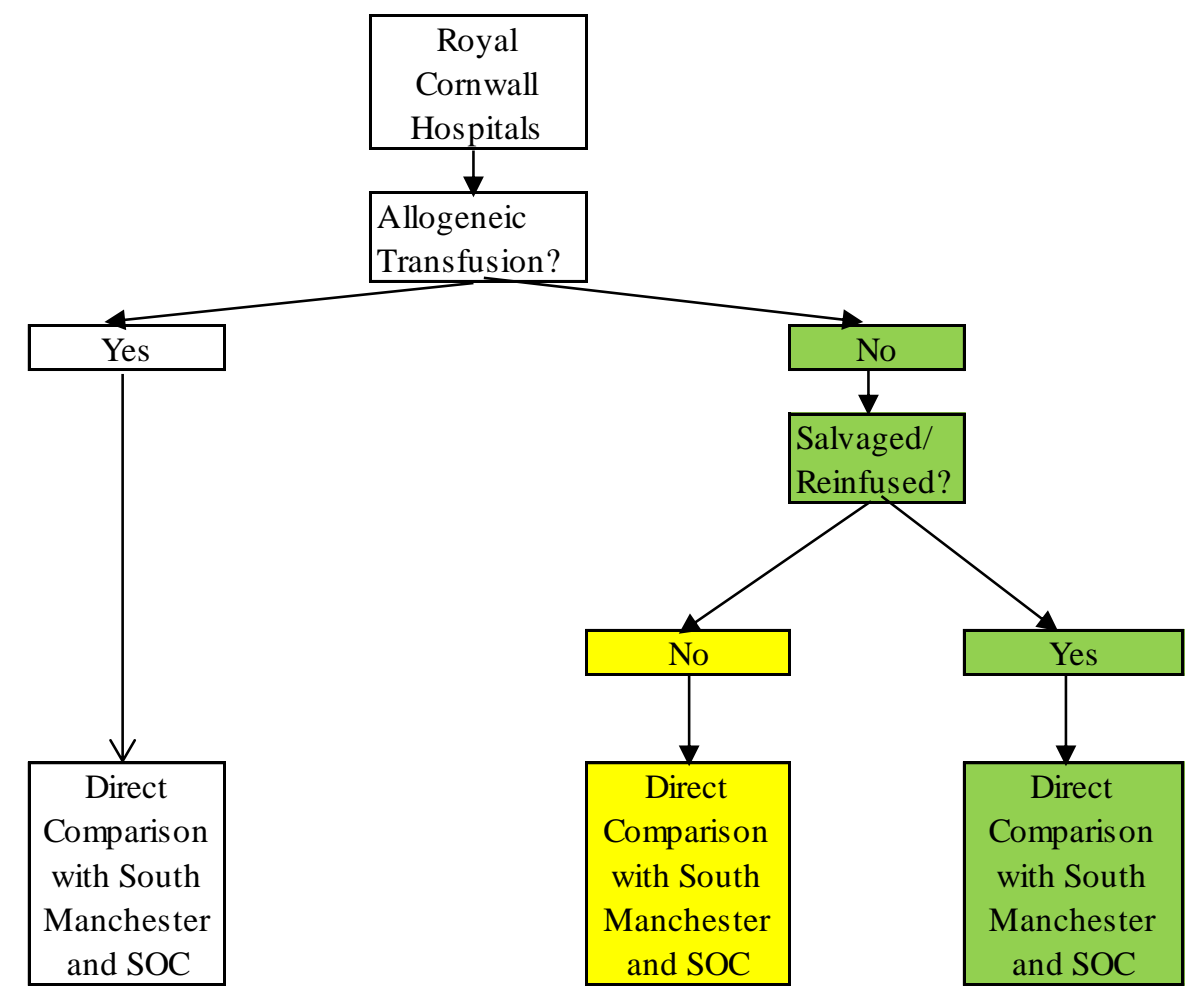

\section{Hospital Based Costs and Activity}

The analysis of the required hospital information to undertake the study can be summarised in table 24 below:

Table 24. Summary of Information Required to Analyse Across the Three Hospitals

\begin{tabular}{|c|c|c|}
\hline Objective & Comparative Data & $\begin{array}{l}\text { Statistical or Other Method } \\
\text { of Calculation where } \\
\text { Relevant }\end{array}$ \\
\hline $\begin{array}{l}\text { Develop costs of operating } \\
\text { cell salvage. }\end{array}$ & $\begin{array}{l}\text { Derive costs for cell } \\
\text { salvage. }\end{array}$ & $\begin{array}{l}\text { Actual costs of consumables } \\
\text { at Royal Cornwall Hospitals. } \\
\text { NICE Costing Statement } \\
\text { (November 2015). }\end{array}$ \\
\hline $\begin{array}{l}\text { Reconciliation of price of } \\
\text { allogeneic unit to income in } \\
\text { published accounts for } \\
2010 / 11 \text {. }\end{array}$ & $\begin{array}{l}\text { Use } £ 122 \text { unit price with } \\
\text { activity from NHSBT } \\
\text { annual report. }\end{array}$ & $\begin{array}{l}\text { Calculate allogeneic blood } \\
\text { cost as a percentage of total } \\
\text { NHSBT costs. }\end{array}$ \\
\hline $\begin{array}{l}\text { Extract transfer price from the } \\
£ 122 \text { unit price. Challenge the } \\
\text { efficacy of using the 'gross' } \\
\text { price in all the studies. }\end{array}$ & $\begin{array}{l}\text { Derive from published } \\
\text { accounts VAT, income tax } \\
\text { and national insurance } \\
\text { elements. }\end{array}$ & $\begin{array}{l}\text { Apportionments based on } \\
\text { headcounts and } \mathrm{HMRC} / \mathrm{NHS} \\
\text { data on tax/national } \\
\text { insurance. }\end{array}$ \\
\hline $\begin{array}{l}\text { 'Sell' HRG concepts to staff } \\
\text { in three sites. }\end{array}$ & $\begin{array}{l}\text { Compare the splits of } \\
\text { HRG data at each site. }\end{array}$ & $\begin{array}{l}\text { Rely on the relevant hospital } \\
\text { information department to } \\
\text { extract using patient } \\
\text { identification number. }\end{array}$ \\
\hline $\begin{array}{l}\text { Estimate wider costs of } \\
\text { donating by generating a } \\
\text { societal cost and costs to } \\
\text { donors. }\end{array}$ & $\begin{array}{l}\text { Generate data from donor } \\
\text { questionnaire issued in } \\
2013 .\end{array}$ & \begin{tabular}{lcr} 
Analysis & of & responses. \\
NHSBT's & electronic survey \\
system & \multicolumn{2}{c}{ automatically } \\
stratifies donors.
\end{tabular} \\
\hline
\end{tabular}




\begin{tabular}{|c|c|c|}
\hline Objective & Comparative Data & $\begin{array}{l}\text { Statistical or Other Method } \\
\text { of Calculation where } \\
\text { Relevant }\end{array}$ \\
\hline $\begin{array}{l}\text { Compare patients at the three } \\
\text { sites to isolate any significant } \\
\text { difference in their profile. }\end{array}$ & $\begin{array}{l}\text { HRG breakdown } \\
\text { Gender split } \\
\text { Age profile }\end{array}$ & $\begin{array}{l}\text { Chi Square } \\
\text { Chi Square } \\
\text { ANOVA }\end{array}$ \\
\hline $\begin{array}{l}\text { Achieve a level of confidence } \\
\text { that the patients are } \\
\text { adequately prepared for } \\
\text { surgery. }\end{array}$ & $\begin{array}{l}\text { Compare pre-operative } \mathrm{Hb} \\
\text { levels statistically and in } \\
\text { relation to } \mathrm{WHO} \\
\text { thresholds. }\end{array}$ & $\begin{array}{l}\text { ANOVA } \\
\text { Segregate patients over/under } \\
\text { WHO thresholds (para 1.9). }\end{array}$ \\
\hline $\begin{array}{l}\text { Highlight potential slower } \\
\text { recovery and potential impact } \\
\text { on length of stay }\end{array}$ & $\begin{array}{l}\text { Compare post-operative } \\
\text { Hb levels } \\
\text { Compare length of stay }\end{array}$ & $\begin{array}{l}\text { ANOVA } \\
\text { ANOVA }\end{array}$ \\
\hline $\begin{array}{l}\text { Compare other potential } \\
\text { influences on length of stay }\end{array}$ & $\begin{array}{l}\text { Develop a linear } \\
\text { regression to investigate } \\
\text { potential } \\
\text { between factors and length } \\
\text { of stay. }\end{array}$ & $\begin{array}{l}\text { Linear regression using the } \\
\text { 'stepwise' approach. }\end{array}$ \\
\hline $\begin{array}{l}\text { For each hospital compare the } \\
\text { number of allogeneic } \\
\text { transfusions. }\end{array}$ & $\begin{array}{l}\text { Compare percentage of } \\
\text { allogeneic blood } \\
\text { transfusions } \\
\text { Compare number of units } \\
\text { used }\end{array}$ & $\begin{array}{l}\text { Chi Square } \\
\text { ANOVA }\end{array}$ \\
\hline $\begin{array}{lll}\text { Royal } & \text { Cornwall } & \text { Hospitals } \\
\text { only } & & \\
\end{array}$ & $\begin{array}{l}\text { Compare } \\
\text { operation } \\
\text { reinfused/ nota fon-reinfused } \\
\text { patients } \\
\text { Compare cell salvage rates } \\
\text { Compare } \\
\text { utilisation rates machine }\end{array}$ & $\begin{array}{l}\text { ANOVA and extraction of } \\
\text { percentage splits combined } \\
\text { with costs. }\end{array}$ \\
\hline
\end{tabular}

Once the data was collected it required adjustment and manipulation. For example, the mean length of stay for each patient was generated by calculating "the difference in days between the date the patient was discharged from hospital and the date they were admitted". This is the NHS Choices definition. In this thesis, the researcher requested the operation date be accessed to replace the admission date. This would more accurately generate the time the patient spent recovering from their operation. In turn these two dates could be used to generate the day of the week of the operation and the day of week of discharge.

The data was checked for obvious input errors e.g. a date of birth after 2000 or before 1910 would not be expected. Outliers were excluded as these would distort the results and may be a result of other health issues having arisen while in hospital. The cut off for an outlier was identified as a patient length of stay being greater than 14 days. This removed 20 patients' records from the analysis (table 20), leaving 498 remaining to analyse. 
The majority of the patient data relates to operations undertaken in 2010. There were no financial problems noted in any of the three organisations at the time. Additionally, there were no directives from the then English Department of Health to require any changes to procedures in operations for primary hip replacement surgery. As noted previously, extraction of the relevant data was challenging and timeconsuming. This was due to the hospital information systems not being set up in a way to readily output the datasets. The Royal Cornwall Hospital have subsequently requested their patient record system extract the data monthly to facilitate additional analysis by HRG. This project is currently being developed in liaison with the Royal Cornwall Hospital IT Department. There are various separate systems that capture elements of information and this amalgamation of information is a relatively large project.

The information was collated into an overall Microsoft Excel spreadsheet and subsequently imported into SPSS v 20 which was then upgraded to v 22 at Swansea University. The statistical analysis was undertaken using SPSS supported by Excel pivot tables. Excel pivot tables allow the information to be analysed and presented in many ways with the advantage over SPSS that all users in the NHS have access to Microsoft Excel. This made the sharing of the information and analysis with users easier, facilitating wider discussions.

The information extracted in table 24 would be statistically tested to ensure the cohorts of patients were homogeneous. This would allow a comparison on the preoperative and post-operative data when no allogeneic transfusion or cell salvage is utilised (cell salvage data at the Royal Cornwall Hospitals only). Further analysis would be undertaken to test any differences in results using appropriate statistical analysis. The length of stay differences were therefore investigated further by utilising linear regression with a stepwise approach to derive a potential number of factors that could explain the actual variations in length of stay. This would then allow discussions with the relevant site on potential contributory factors.

This statistical work would be instrumental in establishing a rigorous comparison to minimise any potential accusation of bias raised in Carless et al (2004 and 2010).

A summary of the data for analysis is shown in table 25 below: 
Table 25. Summary of Key Statistics to be Extracted

\begin{tabular}{|c|c|c|}
\hline Factor & Comparative Data & $\begin{array}{l}\text { Technique } \\
\text { Adopted }\end{array}$ \\
\hline \multirow[t]{3}{*}{$\begin{array}{l}\text { Patient and Operation } \\
\text { Comparison }\end{array}$} & HRG breakdown & $\begin{array}{l}3 \text { x } 3 \text { Chi } \\
\text { Square }\end{array}$ \\
\hline & Gender split & $\begin{array}{l}2 \times 3 \text { Chi } \\
\text { Square }\end{array}$ \\
\hline & Age profile & ANOVA \\
\hline \multirow[t]{3}{*}{ Patient Preparation } & $\begin{array}{l}\text { Pre-operative Hb levels } \\
\text { All patients }\end{array}$ & ANOVA \\
\hline & $\begin{array}{l}\text { Pre-operative Hb levels: } \\
\text { Patients not undergoing } \\
\text { allogeneic transfusion or } \\
\text { reinfusion }\end{array}$ & ANOVA \\
\hline & $\begin{array}{l}\text { Separate pre-operative } \\
\text { patients below WHO } \\
\text { anaemia levels }\end{array}$ & $\begin{array}{l}2 \text { x } 3 \text { Chi } \\
\text { Square }\end{array}$ \\
\hline \multirow[t]{2}{*}{ Patient Recovery } & $\begin{array}{l}\text { Compare post-operative } \mathrm{Hb} \\
\text { levels excluding allogeneic } \\
\text { transfusions and reinfusions }\end{array}$ & ANOVA \\
\hline & Compare length of stay & ANOVA \\
\hline \multirow[t]{2}{*}{$\begin{array}{l}\text { Allogeneic Blood } \\
\text { Usage }\end{array}$} & $\begin{array}{l}\text { Compare percentage of } \\
\text { allogeneic blood transfusions }\end{array}$ & ANOVA \\
\hline & $\begin{array}{l}\text { Compare number of } \\
\text { allogeneic units used }\end{array}$ & ANOVA \\
\hline \multirow{5}{*}{$\begin{array}{l}\text { Comparison of } \mathrm{RCH} \\
\text { patients not salvaged } \\
\text { (33) with those patients } \\
\text { salvaged (180) }\end{array}$} & HRG breakdown & $\begin{array}{l}3 \quad \text { x } 2 \text { Chi } \\
\text { Square }\end{array}$ \\
\hline & Gender split & $\begin{array}{l}2 \times 2 \text { Chi } \\
\text { Square }\end{array}$ \\
\hline & Age profile & t test \\
\hline & $\begin{array}{l}\text { Compare Pre-operative } \mathrm{Hb} \\
\text { levels }\end{array}$ & $\mathrm{t}$ test \\
\hline & $\begin{array}{l}\text { Compare post-operative } \mathrm{Hb} \\
\text { levels }\end{array}$ & $\mathrm{t}$ test \\
\hline \multirow[t]{4}{*}{$\begin{array}{l}\text { Factors potentially } \\
\text { influencing length of } \\
\text { stay across sites }\end{array}$} & Patient age & $\begin{array}{l}\text { Linear } \\
\text { regression }\end{array}$ \\
\hline & Operation day & $\begin{array}{l}\text { Linear } \\
\text { regression }\end{array}$ \\
\hline & Discharge day & $\begin{array}{l}\text { Linear } \\
\text { regression }\end{array}$ \\
\hline & Other factors & $\begin{array}{l}\text { Linear } \\
\text { regression }\end{array}$ \\
\hline
\end{tabular}


All the data was in a form that was readily comparable over the three sites, this would allay one of the Carless et al (2004 and 2010) criticisms of the low quality of comparative studies. Two other criticisms from Carless et al (2004 and 2010) were that the "methodological quality of the trials was poor" and un-blinded trials "lacked adequate concealment of treatment allocation". The data extracted was retrospective and there was no decision on whether or not to salvage at South Manchester or the SOC as the two organisations did not utilise cell salvage anyway. At the Royal Cornwall Hospitals, the decision not to salvage the 33 patients identified was due to non-availability of trained staff or the actual cell salvage machines not being available at the time. None of this was pre-planned and would therefore not introduce any level of bias into the analysis. The pre-and post-operative data can be used as an additional comparator in the Royal Cornwall Hospitals to check whether there is any significant difference between the 33 non-salvaged and 180 salvaged patients at the Royal Cornwall Hospitals as this could, arguably, point to potential bias.

\section{NHS Blood \& Transplant Costs}

The total cost of the NHSBT operation in 2010/11 was approximately $£ 420 \mathrm{~m}$ (NHSBT 2010/11 audited accounts). NHSBT's role is to supply allogeneic blood and related products for use in hospitals. These include blood and specialist haematological products along with operating the UK-wide organ donation and transplant service. NHSBT uses an activity-based costing (ABC) system to map its costs and support the forecasting of the impact of activity changes on its future costs. $\mathrm{ABC}$, according to Wood and Sangster (2005), is "the process of using cost drivers as the basis for the apportionment of indirect manufacturing costs to individual products". Within NHSBT there are discrete cost drivers and a suitably aligned general ledger coding structure to capture the costs to categories. The costs associated with the collection, processing, testing and issue of allogeneic blood are highly relevant. Any changes in allogeneic blood requirements e.g. through an expansion in cell salvage usage will have an impact on the costs associated in the NHSBT supply chain. Most of the NHSBT costs have been collected and reported by the researcher's former colleagues in NHSBT. Additional information was provided on numbers of donors in 2018. 
The above costs would need to be adjusted to reflect e.g. transfer payments that are included from a financial perspective but need to be excluded from an economic costing perspective (chapter 2). Depreciation is charged to cost centres for capital assets utilised. These are a mix of building and infrastructure costs, where the property is owned by NHSBT, and equipment/vehicle costs where owned.

Table 26 below summarises the identification and treatment of the costs incurred by NHSBT using its ABC system.

Table 26. NHSBT Cost Classification

\begin{tabular}{|c|c|c|}
\hline $\begin{array}{l}\text { ABC Cost } \\
\text { Element }\end{array}$ & Fixed/Variable? & Justification of Treatment \\
\hline Source Donors & Fixed & $\begin{array}{l}\text { The majority of costs are fixed in the medium term. TV and radio } \\
\text { campaigns are booked at least } 18 \text { months in advance. There is a } \\
\text { long-term contract with the US communications company, } \\
\text { Teleperformance, for donor recruitment/retention via call centre } \\
\text { and on-line support. }\end{array}$ \\
\hline $\begin{array}{l}\text { Blood } \\
\text { Collection- } \\
\text { fixed elements }\end{array}$ & Fixed & $\begin{array}{l}\text { Staffing costs are regarded as fixed for two years. A high } \\
\text { proportion of staff have a long NHS service record with high } \\
\text { associated redundancy costs. Blood collection teams are based in } \\
\text { leased premises with the typical lease contracts involving a five- } \\
\text { year lease with a break clause at three years. Refrigerated } \\
\text { deliveries transport the collected blood overnight to the three } \\
\text { main blood centres for processing. }\end{array}$ \\
\hline $\begin{array}{l}\text { Blood } \\
\text { Collection- } \\
\text { blood bags and } \\
\text { test kits }\end{array}$ & Variable & $\begin{array}{l}\text { The blood collection bags and test kits are supplied by at least } \\
\text { three suppliers to maintain certainty and continuity of supply. } \\
\text { Contracts are for a minimum guaranteed amount (typically } 80 \% \\
\text { of requirements) with a variable element charged on use. Over a } \\
\text { range of activity, they are therefore regarded as variable. }\end{array}$ \\
\hline Processing & Fixed & $\begin{array}{l}\text { All the blood processing is undertaken in three NHSBT centres } \\
\text { with the majority of the work automated. See para } 1.6 \text { relating to } \\
\text { the donated blood 'journey'. }\end{array}$ \\
\hline Testing & Fixed & $\begin{array}{l}\text { Automated analysers will undertake the first level of testing. It is } \\
\text { only if issues are raised e.g. if there is a contaminated donation } \\
\text { that a specialised member of staff will intervene. }\end{array}$ \\
\hline $\begin{array}{l}\text { Order } \\
\text { Processing, } \\
\text { Storage and } \\
\text { Dispatch }\end{array}$ & Fixed & $\begin{array}{l}\text { The majority of staff perform a warehousing function that is } \\
\text { required. Changing volumes over the short term will not free up } \\
\text { staff. }\end{array}$ \\
\hline Distribution & Fixed & $\begin{array}{l}\text { Delivery to customers is provided by NHSBT's in-house transport } \\
\text { service. The majority of hospitals will require at least one } \\
\text { delivery per day and the routes are planned by NHSBT's transport } \\
\text { management system. In the short term the vehicles (leased for a } \\
\text { minimum of three years) and driver costs are fixed. }\end{array}$ \\
\hline $\begin{array}{l}\text { Contribution to } \\
\text { Overheads }\end{array}$ & Fixed & $\begin{array}{l}\text { These are the traditional overheads (estates costs, support } \\
\text { departments) that are generally fixed in the short to medium term. }\end{array}$ \\
\hline
\end{tabular}

\section{Donor/Societal and Wider Economic Costs}

As noted in para 4.9 very little consideration was given to the wider costs of allogeneic blood transfusions in academic studies. This thesis revisits the main UK 
study (Varney \& Guest (2003)) and estimates the wider costs associated with a fall in demand for blood due to the expansion in cell salvage.

Varney and Guest (2003)'s study derived the costs associated with blood transfusions in the UK. The basis of the donors' costs was undertaken by a telephone survey that involved interviewing respondents to advertisements placed in selected newspapers. In early 2013 the researcher met with NHSBT's Head of Market Research and Analysis and the Assistant Head to discuss costs associated with donors attending sessions to donate blood. The original aim was to extract information similar to that analysed by Varney \& Guest (2003). The Market Research and Analysis team felt, however, that the wider views of the donors should also be sought for the team's separate analysis and both sets of requirements be combined in one questionnaire. This, in part, was initiated by a discussion on the views expressed in the 16 February 2011 Economist article on the level of altruism felt by blood donors (para 1.8).

Technology has obviously developed to support marketing/customer services since 2003 and discussions with the Market Research Team led to their support for the development and issue of a questionnaire to re-visit the conclusions of the 2003 survey. To the best of the author's knowledge there has been no subsequent published study or follow up of the information in the 2003 study in the UK. The researcher contacted Catalyst Health Economics (Prof Julian Guest is Managing Director) in early 2013. There was no interest on the company's part to become involved in a re-visit of the 2003 findings.

NHSBT's donor management system (part of the overall PULSE information management system) can extract stratified random samples of donors. A series of questions was developed (table 27) with the Assistant Head. The questions were aimed at estimating:

- The level of altruistic feelings and 'feel good' expressed by blood donors.

- The costs associated with donating that were incurred by the donor that were not recompensed.

- Costs of lost productivity by the donor who was donating rather than being in paid employment. 
- Any additional costs e.g. environmental costs associated with vehicle emissions.

NHSBT's Marketing Department holds blood donor information on a centralised database. There were c. $1.28 \mathrm{~m}$ active donors at March 2013 when the survey was being discussed. The database can extract a stratified sample of donors and e-mail questionnaires to them using Survey Monkey. In 2013 an 'active donor' was one who had made one donation in the previous year. This was subsequently redefined as a donor who had made at least two donations in the past year. The corresponding figure for 2017 was c. $0.5 \mathrm{~m}$.

For the questionnaire, a randomised stratified sample of 5,000 active blood donors was extracted from the database and the questionnaire was issued via e-mail by the NHSBT Marketing Department under the guise of a customer relations survey. The number of responses to the questionnaire was 1,161 indicating a 'hit rate' of $23.2 \%$; this was viewed as a typical response rate for NHSBT e-mail surveys.

The final set of 13 questions agreed is shown in table 27 below:

Table 27. Blood Donor Questionnaire

\begin{tabular}{|r|l|}
\hline No & Question \\
\hline 1 & Have you attended a blood donation session or clinic in the last four months? Y/N? \\
\hline 2 & $\begin{array}{l}\text { Which of the reasons explains why you haven't attended a blood donation session in the last four } \\
\text { months? Tick box. }\end{array}$ \\
\hline 3 & $\begin{array}{l}\text { Which of the statements below apply to you and your reasons for attending your last donation } \\
\text { session? Tick box. }\end{array}$ \\
\hline 4 & How likely are you to give blood in the future? Y/N \\
\hline & $\begin{array}{l}\text { On a scale of one to ten, where one is "strongly disagree" and ten is "strongly agree", please say how } \\
\text { strongly you agree with the following statements. }\end{array}$ \\
& $\begin{array}{l}\text {-Giving blood is important to me. } \\
\text {-I have so many commitments it is sometimes hard to give blood. }\end{array}$ \\
\hline 6 & -I really enjoy giving blood. \\
\hline 7 & How many minutes did you spend travelling to your last donation session from your starting point? \\
\hline 8 & What was your main mode of transport to your last donation session? \\
\hline 9 & Which of the following best describes you (tick as many as relevant)? \\
\hline 10 & Which of the following best describes your employment (Tick as many as relevant)? \\
\hline 11 & Does your employer deduct pay because you attend a blood donation session? \\
\hline 12 & Are you expected to make up the time in your work for attending a blood donation session? \\
\hline 13 & What actual costs did you incur in order to allow you to donate at your last donation session (Tick as \\
\hline
\end{tabular}

The main aim of the data collection was to compare the cost of allogeneic blood usage at South Manchester and the SOC against the aggregated cost of the allogeneic blood and operation of cell salvage at the Royal Cornwall Hospitals. The estimated 
societal costs associated with the allogeneic blood usage could then be included to generate overall comparative costs. A comparison of the aggregation of these costs would therefore answer the research question.

\subsection{Summary of Chapter 5}

A robust set of comparative data for the three sites was finally collected and available for analysis in late 2014. The consecutive data for the Royal Cornwall Hospitals was also detailed enough to identify patients who were/were not salvaged and subsequently were/were not reinfused. This amount of comparative data, though taking a long time to extract, would be sufficient to support the analysis and combine with the cost information.

The data had the unique trait of being identifiable by HRG. This allowed an additional check on the homogeneity of the severity of the operation and associated comorbidities and would allow additional analysis of the allogeneic blood requirements across the sites.

Para 5.7 noted the discussions with clinicians regarding the assertion that cell salvage could mask inefficiencies in the pre-operative assessments of the patients. The patients would present while being anaemic. This issue was also highlighted in Enhanced Recovery Pathways in para 1.19. The comparative information on $\mathrm{Hb}$ levels would address this issue.

As noted in para 5.8 the costs fall into three categories (hospital, NHSBT and societal). Combining the three sets of costs would give a total estimated cost of supplying one unit of allogeneic blood. The rationale was to calculate the allogeneic blood costs at each site and add in the cell salvage costs at the Royal Cornwall Hospitals. Utilising an average cost incurred by the donor and the derived societal cost would then give a total associated blood cost. This would then be a direct comparator between the costs associated with the higher allogeneic units against utilising cell salvage. The basic calculation is shown in table 28 below. This will comprise two tables; one to reflect the costs from a financial perspective (the accountants' view at the Hospitals and NHSBT) and an overarching schedule from 
an economic analysis perspective excluding e.g. transfer payments and the charges via the NHS internal market for allogeneic blood.

Table 28. Derived Cost of Blood per Patient for Primary Total Hip Replacement Patients-Financial and Economic Perspective

\begin{tabular}{|c|c|c|c|}
\hline $\begin{array}{c}\text { Hospital } \\
\text { |Category }\end{array}$ & $\begin{array}{c}\text { South } \\
\text { Manchester }\end{array}$ & $\begin{array}{c}\text { Royal } \\
\text { Cornwall } \\
\end{array}$ & $\begin{array}{c}\text { Specialist } \\
\text { Orthopaedic } \\
\text { Centre }\end{array}$ \\
\hline Allogeneic Blood Costs & $\sqrt{ }$ & $\sqrt{ }$ & $\sqrt{ }$ \\
\hline Cell Salvage Cost & $\mathrm{X}$ & $\sqrt{ }$ & $\mathrm{X}$ \\
\hline Donor Cost & $\sqrt{ }$ & $\sqrt{ }$ & $\sqrt{ }$ \\
\hline Societal Cost & $\sqrt{ }$ & $\sqrt{ }$ & $\sqrt{ }$ \\
\hline Total Derived Cost & $\sqrt{ }$ & $\sqrt{ }$ & $\sqrt{ }$ \\
\hline Total Patients & 148 & 213 & 137 \\
\hline Unit Cost of Blood per Patient & $f x$ & $f x$ & $f x$ \\
\hline
\end{tabular}

Table 28 is designed to generate an overall average cost. This can be used for indicative purposes. Most of the non-allogeneic blood costs are relatively fixed in the short to medium term and it is unlikely there will be immediate savings if the allogeneic blood requirements fell nationally. Chapter 6 extracts and derives the costs in order to populate table 28 above. Discussions of these costs can subsequently be undertaken in chapter 7.

Table 28 is unique as it derives an overall cost of blood. This adopts a similar approach to the Varney and Guest (2003) analysis but the key difference is that this thesis includes cell salvage in the calculations. As highlighted in the literature review the wider adjusted economic costs were ignored in virtually all studies. To the best of the researcher's knowledge the researcher's approach is unique and will therefore support the answer to the research question:

Is cell salvage an appropriate method of blood conservation to support the reduction in costs associated with the collection and utilisation of allogeneic blood?

The time and effort invested in finding the sites and collecting the information finally paid off and a firm foundation for a detailed analysis of the activity and costs was now possible. In hindsight, the researcher was too optimistic in relying on hospitals to extract the information. It was a salutary lesson to learn that, though the NHS has extensive IT systems, the ability to drill down and collect a series of common datasets in table 25 required many days of manual information gathering. 


\section{Chapter 6. Main Findings}

\subsection{Introduction}

Chapter 5 noted the planned approach to collecting and utilising the relevant data to generate a comparison of costs associated with operating cell salvage as an alternative to utilising allogeneic blood. A key aim was to minimise the subjectivity noted in the literature review where authors undertook comparative studies on patients using cell salvage with corresponding cohorts of patients who were not salvaged. The differences in allogeneic transfusion rates were often assumed to be due to cell salvage.

Chapter 5 additionally noted the approach adopted to identify any differences in the patients' profiles, variations in the severity of accompanying comorbidities and level of invasiveness of the operation by utilising the HRG coding. Any differences may contribute to a differing level of allogeneic blood required irrespective of whether any allogeneic blood avoiding techniques were adopted. The data also utilises patients' pre-operative $\mathrm{Hb}$ levels as an indication of general preparedness of the patient for surgery.

The approach in this thesis differs from the above 'traditional' approach. The focus is on a multi-site comparison that initially compares a common set of data for patients who have not had an allogeneic transfusion or, in the case of the Royal Cornwall Hospitals, had their own blood reinfused. This comparison (figure 15 on page 128) would establish a 'background count', allowing a direct comparison between patient statistics. Any differences would be highlighted, and it could therefore be stated with $100 \%$ confidence that the differences were not due to allogeneic blood transfusions since any patient who had received an allogeneic blood transfusion would be excluded from the initial analysis.

The analysis would then be extended to incorporate allogeneic blood transfusions and cell salvage/blood reinfusions at the Royal Cornwall Hospitals. Any further differences would more likely be due to the impacts of the allogeneic blood transfusion; being potentially ameliorated by cell salvage at the Royal Cornwall Hospitals. 
Following this, the financial and economic costs would be calculated. These costs will be an amalgam of actual running costs and supplier charges at the Royal Cornwall Hospitals. The costs supplied by NHSBT would then be incorporated into the comparison, with adjustments where appropriate.

\subsection{Main Patient Characteristics}

The profile of the patient information is summarised in table 29 below:

Table 29. Summary of Patient Statistics Over the Three Organisation (2010/11 Base Data)

\begin{tabular}{|l|r|r|r|r|}
\hline \multicolumn{1}{|c|}{$\begin{array}{c}\text { Hospital/ } \\
\text { Category }\end{array}$} & \multicolumn{1}{c|}{$\begin{array}{c}\text { South } \\
\text { Manchester }\end{array}$} & \multicolumn{1}{c|}{$\begin{array}{c}\text { Royal } \\
\text { Cornwall }\end{array}$} & \multicolumn{1}{c|}{$\begin{array}{c}\text { Specialist } \\
\text { Orthopaedic } \\
\text { Centre }\end{array}$} & \multicolumn{1}{c|}{ Totals } \\
\hline Number of patients & 148 & 213 & 137 & 498 \\
\hline Mean (SD) Age (years) & $67.5(10.9)$ & $67.7(11.3)$ & $67.4(11.9)$ & $67.5(11.3)$ \\
\hline $\begin{array}{l}\text { Mean (SD) Length of Stay } \\
\text { days) }\end{array}$ & $6.3(2.5)$ & $5.2(2.0)$ & $5.1(2.0)$ & $5.5(2.2)$ \\
\hline $\begin{array}{l}\text { Mean (SD) Pre-Op Hb level } \\
\text { g/l) }\end{array}$ & $135(14.6)$ & $137(11.5)$ & $135(12.4)$ & $136(12.7)$ \\
\hline $\begin{array}{l}\text { Mean (SD) Lowest Post Op } \\
\text { Hb Level (g/l) }\end{array}$ & $104(14.9)$ & $102(15.9)$ & $100(15.3)$ & $102(15.5)$ \\
\hline Fall in Mean Hb Level (g/l) & 31 & 35 & 35 & 34 \\
\hline $\begin{array}{l}\text { Number of Patients } \\
\text { Transfused }\end{array}$ & 14 & 13 & 23 & 50 \\
\hline $\begin{array}{l}\text { Number of Allogeneic Units } \\
\text { Transfused }\end{array}$ & 27 & 26 & 47 & 100 \\
\hline Allogeneic Transfusion Rate & $43.5 \%$ & $38.5 \%$ & $39.4 \%$ & $40.4 \%$ \\
\hline Percent Male & & $6.1 \%$ & $16.8 \%$ & $10.0 \%$ \\
\hline
\end{tabular}

The activity at the Royal Cornwall Hospitals is further analysed into the categories of the utilisation of cell salvage in table 30 below:

Table 30. Breakdown of Cell Salvage Activity at Royal Cornwall Hospitals

\begin{tabular}{|c|c|c|c|c|c|c|}
\hline $\begin{array}{l}\text { Gender / } \\
\text { Category }\end{array}$ & \multicolumn{2}{|c|}{ Males } & \multicolumn{2}{|c|}{ Females } & \multicolumn{2}{|c|}{ Total } \\
\hline & $\mathrm{n}$ & $\begin{array}{c}\text { Number } \\
\text { Transfused }\end{array}$ & $\mathrm{n}$ & $\begin{array}{c}\text { Number } \\
\text { Transfused }\end{array}$ & $\mathrm{n}$ & $\begin{array}{c}\text { Number } \\
\text { Transfused }\end{array}$ \\
\hline Not Salvaged & 16 & - & 17 & 3 & 33 & 3 \\
\hline $\begin{array}{l}\text { Salvage-No } \\
\text { Reinfusion }\end{array}$ & 21 & - & 55 & 5 & 76 & 5 \\
\hline $\begin{array}{l}\text { Salvage-With } \\
\text { Reinfusion }\end{array}$ & 45 & 1 & 59 & 4 & 104 & 5 \\
\hline Total & 82 & 1 & 131 & 12 & 213 & 13 \\
\hline
\end{tabular}




\subsection{Healthcare Resource Group (HRG) Analysis}

As noted in para 5.1, the primary total hip replacement operations will be subdivided into HRGs. The tariff price and therefore the resource requirement of undertaking the specific HRG can vary markedly. The start point in the analysis was to assess whether the split of HRGs was similar between the three sites. If this was the case, then the assumption could be made that both the resources required, and the level of comorbidities would be similar. This would therefore allay fears that the comparison between blood requirements would differ significantly due to e.g. the number of operations being more complicated or invasive in one of the centres, thereby causing a distortion.

The breakdown of operations by HRG at the three sites is shown in table 31 below:

Table 31. Analysis of Operations by HRG Category

\begin{tabular}{|c|c|c|c|c|}
\hline $\begin{array}{l}\text { Hospital: } \\
\text { IHRG }\end{array}$ & $\begin{array}{c}\text { South } \\
\text { Manchester }\end{array}$ & $\begin{array}{c}\text { Royal } \\
\text { Cornwall } \\
\end{array}$ & $\begin{array}{l}\text { Spec Orth } \\
\text { Centre }\end{array}$ & Total \\
\hline HB11A & 1 & 1 & - & 2 \\
\hline HB11B & 2 & 6 & 4 & 12 \\
\hline $\mathrm{HB} 11 \mathrm{C}$ & - & 3 & 1 & 4 \\
\hline HB12A & 8 & 12 & 8 & 28 \\
\hline HB12B & 108 & 137 & 95 & 340 \\
\hline HB12C & 27 & 54 & 29 & 110 \\
\hline HB13Z & 2 & - & - & 2 \\
\hline Total & 148 & 213 & 137 & 498 \\
\hline
\end{tabular}

The resource requirements are the highest for HB11A with requirements decreasing down to HB13Z. On first assessment, most of the activity is clustered around the two HRGs HB12B and HB12C (non-trauma category 1 with and without comorbidities and complications-CCs). This is not surprising since, generally, elective hip replacement surgery would not be expected to have any major CCs. A very high level of CCs would be likely to categorise the operations as non-elective (emergency) operations, without the associated pre-operative planning and assessments.

Figure 16 below analyses the percentage split of primary hip replacement operations by HRG by hospital. The pattern follows a similar distribution with HB12B dominating the activity figures and $\mathrm{HB} 12 \mathrm{C}$ taking most of the remaining cases. 
Figure 16. Analysis of Percentage of Total Hip Replacement Operations by HRG by Organisation

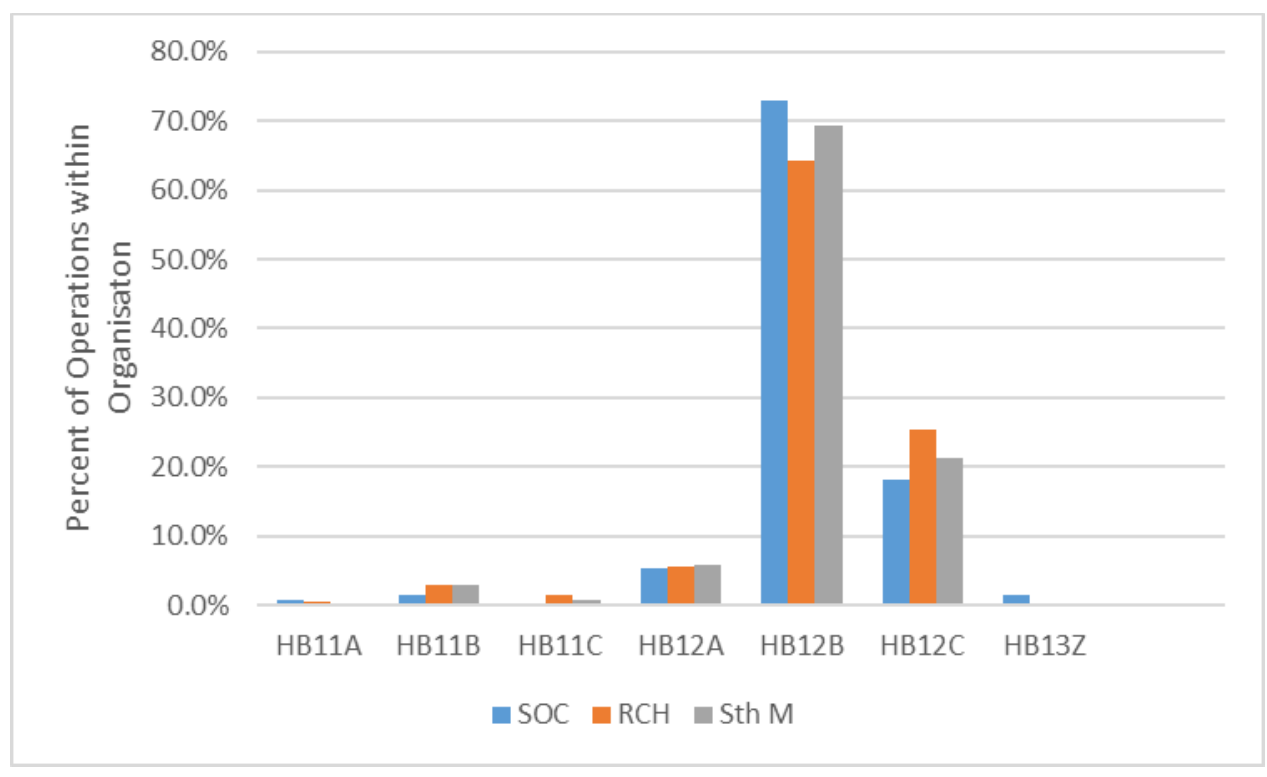

The proportions of HRGs appear consistent across the hospitals. The HRGs were then grouped into three groups; one group each for the HRGs commencing HB12B and $\mathrm{HB} 12 \mathrm{C}$ and the remainder into a separate group.

The Pearson Chi-square value was calculated at 3.281 with a $p$ value of 0.512 ; this is not significant i.e. there appears to be no association between HRG grouping and hospital. It can therefore be assumed that there is no significant difference in the morbidity of patients presenting at each hospital.

\subsubsection{Age and Gender Profile}

These splits are shown in the tables 32 and 33 below. ANOVA and post hoc tests indicate that the mean age is similar across the three hospitals $(\mathrm{p}=0.974)$ but with a significant difference between the two main HRG (HB12B and HB12C) categories $(\mathrm{p}<0.0005)$.

Table 32. Mean Age by Patient by $H R G$

\begin{tabular}{|c|c|c|c|c|}
\hline $\begin{array}{l}\text { Hospital: } \\
\text { JHRG }\end{array}$ & $\begin{array}{c}\text { South } \\
\text { Manchester }\end{array}$ & $\begin{array}{c}\text { Royal } \\
\text { Cornwall } \\
\end{array}$ & $\begin{array}{c}\text { Spec Orth } \\
\text { Centre }\end{array}$ & $\begin{array}{l}\text { Mean } \\
\text { Age }\end{array}$ \\
\hline HB12B & 67.9 & 69.0 & 69.1 & 68.7 \\
\hline HB12C & 64.5 & 64.3 & 60.6 & 63.4 \\
\hline Other & 71.0 & 67.2 & 69.6 & 68.9 \\
\hline Total & 67.5 & 67.7 & 67.4 & 67.5 \\
\hline
\end{tabular}


HB12B requires more supporting procedures and hence being more likely to be associated with older patients.

With gender, there are a slightly higher proportion of males at South Manchester than the other two hospitals. The national average across all types of hip surgery is $40 \%$ male patients.

Table 33. Gender Mix of Patient by HRG-Percentage Male Patients

\begin{tabular}{|c|r|r|r|r|}
\hline $\begin{array}{c}\text { Hospital: } \\
\text { LHRG }\end{array}$ & \multicolumn{1}{|c|}{$\begin{array}{c}\text { South } \\
\text { Manchester }\end{array}$} & $\begin{array}{c}\text { Royal } \\
\text { Cornwall }\end{array}$ & $\begin{array}{c}\text { Spec Orth } \\
\text { Centre }\end{array}$ & \multicolumn{1}{c|}{ Total } \\
\hline HB12B & $45.4 \%$ & $40.9 \%$ & $34.7 \%$ & $40.6 \%$ \\
\hline HB12C & $44.4 \%$ & $40.7 \%$ & $44.8 \%$ & $42.7 \%$ \\
\hline Other & $30.8 \%$ & $18.2 \%$ & $61.5 \%$ & $33.3 \%$ \\
\hline Mean & $\mathbf{4 3 . 9 \%}$ & $\mathbf{3 8 . 5 \%}$ & $\mathbf{3 9 . 4 \%}$ & $\mathbf{4 0 . 4 \%}$ \\
\hline
\end{tabular}

The Pearson chi-square result on the numbers within the overall gender mix is not significant $(\mathrm{p}=0.567)$ indicating that there is no significant difference in the gender split across the three sites.

Of potentially more interest is the mean age of the patients by HRG. As noted in para 1.9 older patients are more likely to require an allogeneic blood transfusion. Only two patients (one male HB12C HRG, one female, HB12B HRG) below 65 years' old received allogeneic blood transfusions at the Royal Cornwall Hospitals. Both patients were salvaged on Electa machines and both had shed blood reinfused. There was a total of 66 patients under 65 years' old who were salvaged (11 patients under 65 were not salvaged). Statistically the two transfused patients (utilising a total of three allogeneic units) were too small to undertake any comparison but the question could be asked whether, given the low transfusion rates, was it necessary to salvage as many as the 66 patients below age 65 ? The table below shows the gender and transfusion comparison over the three sites:

Table 34. Analysis by Gender of Patients <65 Years Old Having an Allogeneic Transfusion

\begin{tabular}{|l|r|r|l|r|}
\hline Gender/Hospital & Male & Female & $\begin{array}{l}\text { Total } \\
\text { Patients } \\
<\mathbf{6 5} \\
\text { years }\end{array}$ & $\begin{array}{l}\text { Transfusion } \\
\text { Rate for } \\
<\mathbf{6 5} \text { years }\end{array}$ \\
\hline South Manchester & - & 2 & 60 & $3.3 \%$ \\
\hline Royal Cornwall & 1 & 1 & 77 & $2.6 \%$ \\
\hline SOC & - & 4 & 46 & $8.7 \%$ \\
\hline Total & $\mathbf{1}$ & $\mathbf{7}$ & $\mathbf{1 8 3}$ & $\mathbf{4 . 4 \%}$ \\
\hline
\end{tabular}


South Manchester also exhibits a low transfusion rate for patients aged under 65 years' old. The SOC transfusion rate, though higher is significantly lower than its overall transfusion rate of $16.8 \%$ (table 29). For the Royal Cornwall Hospitals, the variable costs of the cell salvage operation can be calculated by identifying the machine types utilised. These are:

Table 35. Analysis of Cell Salvage on Patients $<65$ Years' Old

\begin{tabular}{|l|r|r|r|}
\hline $\begin{array}{l}\text { Machine Type/ } \\
\text { Reinfusion }\end{array}$ & Electa & OrthoPat & \multicolumn{1}{l|}{ Total } \\
\hline Not Reinfused & 18 & 7 & 25 \\
\hline Reinfused & 15 & 26 & 41 \\
\hline Total & $\mathbf{3 3}$ & $\mathbf{3 3}$ & $\mathbf{6 6}$ \\
\hline
\end{tabular}

\subsubsection{Pre-Operative Hb Level}

As highlighted in para 5.7 a key indicator of patient preparedness is the Hb level, this indicates a patient's iron levels and, in turn, the level of oxygen circulating in the bloodstream. The higher the $\mathrm{Hb}$ level the more oxygen rich the patient's blood (para 1.4). The boxplot in figure 17 below groups the mean $\mathrm{Hb}$ levels; these are clustered around the $135 \mathrm{~g} / \mathrm{l}$ mark. $135 \mathrm{~g} / \mathrm{l}$ is comfortably above the WHO recommended $\mathrm{Hb}$ level for preparedness for surgery (130g/l for men and $120 \mathrm{~g} / \mathrm{l}$ for women, para 1.9). An analysis of mean $\mathrm{Hb}$ levels by HRG is shown in table 36 below.

Table 36. Analysis of Mean Pre-Operative Hb Levels by HRG $(n=498)$

\begin{tabular}{|c|c|c|c|c|}
\hline $\begin{array}{l}\text { Hospital: } \\
\text { IHRG }\end{array}$ & South Manchester & Royal Cornwall & Spec Orth Centre & Total \\
\hline HB12B & 134.6 & 136.6 & 133.8 & 135.2 \\
\hline HB12C & 135.8 & 139.1 & 138.4 & 138.1 \\
\hline Other & 132.2 & 133.5 & 134.6 & 133.5 \\
\hline Total & 134.6 & 136.9 & 134.8 & 135.6 \\
\hline
\end{tabular}


Figure 17. Mean Pre-Operative Hb Levels Across Three Sites

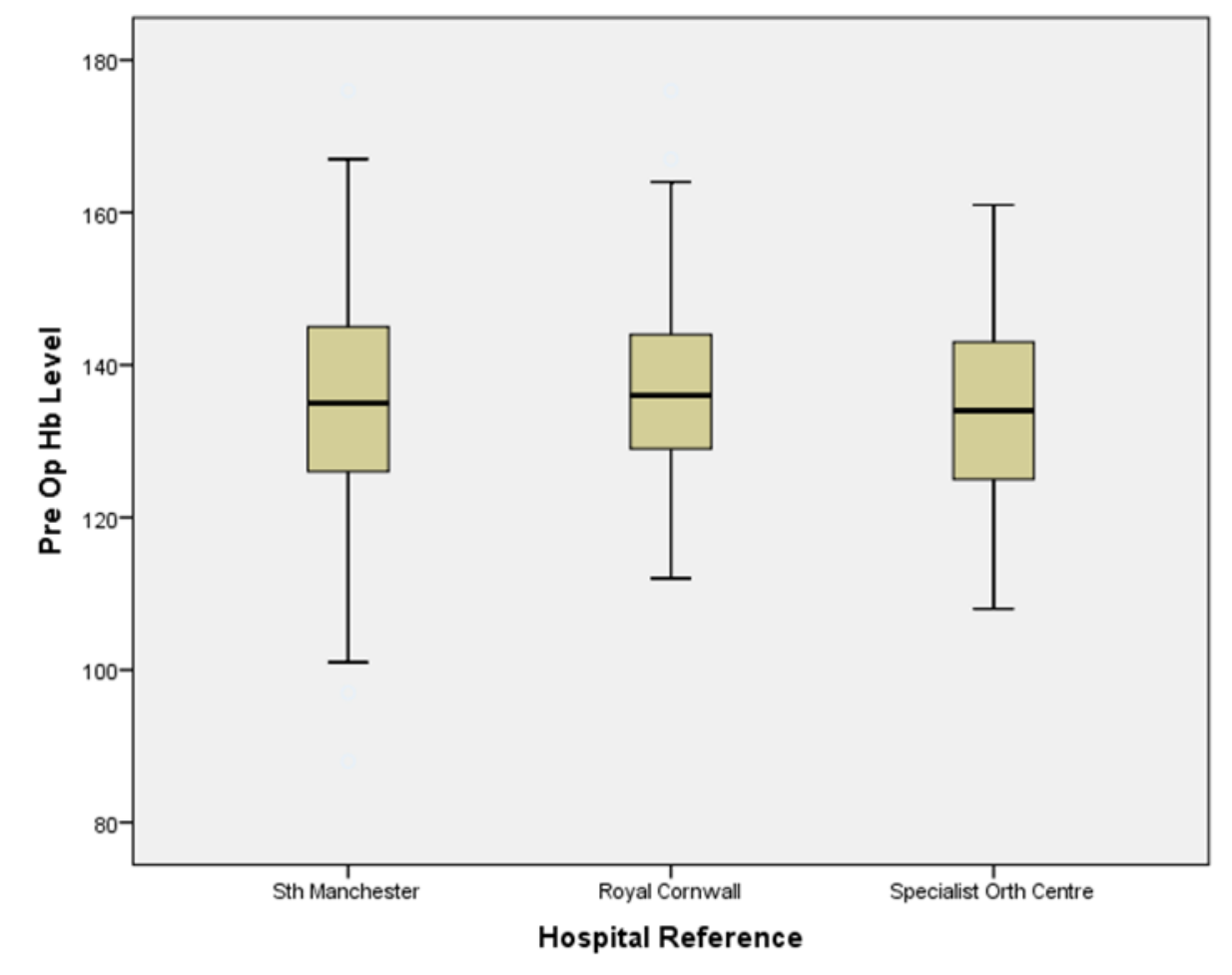

The initial indications are therefore that the patients are optimised and ready for surgery. Procedurally, the patients will have undergone a pre-operative assessment (para 1.19) where, inter alia, blood tests will have been undertaken and results would be available for the clinician to assess.

The box plot in fig 17 above and the mean pre-operative $\mathrm{Hb}$ levels indicate a strong level of similarity between the patients at the three sites. Mean $\mathrm{Hb}$ levels are all above the WHO anaemia thresholds for males and females however, the standard deviation is higher at South Manchester (14.6 g/l) than the Royal Cornwall Hospitals (11.5 g/1) or the Specialist Orthopaedic Centre (12.4 g/l). It should be noted, however, that the WHO definition is wide ranging. An Hb level of 125 in a 50-yearold man would, on its own, be of less concern than the same level in a 75-year-old man. The numbers of patients falling below the thresholds at the three organisations is shown in table 37 below. 
Table 37. Analysis of Patients with Pre-operative Hb Levels Below WHO Criteria

\begin{tabular}{|l|r|r|r|r|r|r|r|r|r|}
\hline $\begin{array}{l}\text { Indicator } \\
\text { /Hospital }\end{array}$ & $\begin{array}{c}\text { Mean } \\
\text { Age } \\
\text { Male }\end{array}$ & $\begin{array}{c}\text { Mean } \\
\text { Pre-op } \\
\text { Hb } \\
\text { Male }\end{array}$ & $\begin{array}{c}\text { No of } \\
\text { Males } \\
\text { Hb } \\
\text { Below } \\
130 \mathrm{~g} / 1\end{array}$ & $\begin{array}{c}\text { Mean } \\
\text { Age } \\
\text { Fem }\end{array}$ & $\begin{array}{c}\text { Mean } \\
\text { Pre-op } \\
\text { Hb } \\
\text { Fem }\end{array}$ & $\begin{array}{c}\text { No of } \\
\text { Fems Hb } \\
\text { Below } \\
120 \mathrm{~g} / 1\end{array}$ & $\begin{array}{c}\text { Total } \\
\text { Below } \\
\text { WHO } \\
\text { Criteria }\end{array}$ & $\begin{array}{c}\text { Total } \\
\text { Patients }\end{array}$ & $\begin{array}{c}\% \\
\text { Anaemi } \\
\text { c } \\
\text { (WHO } \\
\text { Criteria) }\end{array}$ \\
\hline $\begin{array}{l}\text { South } \\
\text { Manchester }\end{array}$ & 72.6 & 122 & 15 & 71.2 & 111 & 18 & 33 & 148 & $22.2 \%$ \\
\hline $\begin{array}{l}\text { Royal } \\
\text { Cornwall } \\
\text { Hospitals }\end{array}$ & 70.7 & 123 & 10 & 80.1 & 117 & 10 & 20 & 213 & $9.3 \%$ \\
\hline $\begin{array}{l}\text { Spec Orth } \\
\text { Centre }\end{array}$ & 72.0 & 116 & 7 & 77.8 & 114 & 8 & 15 & 137 & $10.9 \%$ \\
\hline Total & $\mathbf{7 1 . 9}$ & $\mathbf{1 2 1}$ & $\mathbf{3 2}$ & $\mathbf{7 5 . 1}$ & $\mathbf{1 1 3}$ & $\mathbf{3 6}$ & $\mathbf{6 8}$ & $\mathbf{4 9 8}$ & $\mathbf{1 4 . 5 \%}$ \\
\hline
\end{tabular}

Patients, falling within the WHO definition as anaemic, present at over twice the rate at South Manchester compared to the other two hospitals. This indicates that the South Manchester patients may not be as adequately 'prepped' as the other two hospitals and the preparation may be a contributor to the increased length of stay at South Manchester due to a slower recovery or an indicator of a separate comorbidity. This relatively high level of patients not meeting the WHO criteria will by now (spring 2018) have been addressed by South Manchester who have developed a more assiduous patient blood management programme.

A Chi square analysis indicated that there was a significant association between hospital and proportion of patients not meeting the WHO criteria $(p=.001)$. The implication is therefore that the issue of anaemia can be controlled locally. The data can be analysed further in table 38 by extracting the patients who received an allogeneic transfusion and were below the WHO pre-operative criteria by gender.

Table 38. Analysis of Allogeneic Transfused Patients (Pre-Operative Hb Levels below WHO Criteria)

\begin{tabular}{|l|r|r|r|r|r|r|r|}
\hline \multicolumn{1}{|c|}{$\begin{array}{l}\text { Indicator } \\
\text { /Hospital }\end{array}$} & $\begin{array}{c}\text { Mean } \\
\text { Pre- } \\
\text { op } \\
\text { Hb } \\
\text { Male }\end{array}$ & Male & $\begin{array}{c}\text { Mean } \\
\text { Pre-op } \\
\text { Hb } \\
\text { Female }\end{array}$ & Female & $\begin{array}{c}\text { Total } \\
\text { Patients }\end{array}$ & $\begin{array}{c}\text { Overall } \\
\text { Transfused }\end{array}$ & $\begin{array}{c}\text { Percent } \\
\text { below } \\
\text { WHO } \\
\text { Threshold }\end{array}$ \\
\hline South Manchester & 106 & 1 & 105 & 7 & 8 & 14 & $57.1 \%$ \\
\hline $\begin{array}{l}\text { Royal Cornwall } \\
\text { Hospitals }\end{array}$ & - & 113 & 1 & 1 & 13 & $7.7 \%$ \\
\hline Spec Orth Centre & 112 & 4 & 112 & 5 & 9 & 23 & $39.1 \%$ \\
\hline Total & $\mathbf{1 1 1}$ & $\mathbf{5}$ & $\mathbf{1 0 8}$ & $\mathbf{1 3}$ & $\mathbf{1 8}$ & $\mathbf{5 0}$ & $\mathbf{3 6 . 0 \%}$ \\
\hline
\end{tabular}

It is immediately apparent from tables 37 and 38 that the Royal Cornwall Hospitals have a significantly lower proportion of patients presenting with WHO defined anaemia. The mean pre-operative $\mathrm{Hb}$ level for the Royal Cornwall Hospitals patients 
is also higher than the other two sites. This therefore suggests that the Royal Cornwall Hospitals' pre-operative programme is more effective in managing anaemia with the impact of only one patient requiring an allogeneic transfusion. 13 of the 23 patients at the Royal Cornwall Hospitals who were below the WHO criteria had salvaged blood reinfused (average pre-operative Hb level of $119 \mathrm{~g} / \mathrm{l}$ ); only three (mean of $121 \mathrm{~g} / \mathrm{l})$ out of the 23 were not salvaged leaving seven $(120 \mathrm{~g} / \mathrm{l})$ patients who were salvaged but their salvaged blood was not reinfused. The mean preoperative $\mathrm{Hb}$ levels for the Royal Cornwall Hospitals over salvaged/reinfused patients are very similar implying the pre-operative $\mathrm{Hb}$ level was not a factor in dictating whether or not the patient should be reinfused with their own salvaged blood. It is likely the 'Ribena' v 'Smoothie' criteria used in para 1.13 took precedent over reference to pre-operative the $\mathrm{Hb}$ level.

A further ANOVA comparison of the pre-operative $\mathrm{Hb}$ levels of all the patients from South Manchester and the Specialist Orthopaedic Centre along with the corresponding data from Royal Cornwall Hospitals patients who did not have their blood reinfused (tables 29 and 30) was undertaken. This excluded $104(5+99)$ patients from the Royal Cornwall Hospitals activity. The rationale being that this comparison would be the 'background count' and a comparison of the $\mathrm{Hb}$ position before and after the operation would facilitate a direct comparison without any influence or impact of cell salvage. The resultant ' $p$ ' value of 0.64 implies, again, that there is no significant difference between the mean pre-operative Hb levels after excluding the Royal Cornwall Hospitals patients who had their shed blood reinfused.

\subsubsection{Overall Pre-Operative Position}

The conclusion from the analysis of the above factors is that the overall profile of patients is very similar, and, except for the WHO anaemia definitions, there are no obvious factors that appear to contribute to one set of patients being more likely to require an allogeneic transfusion than another. Elective primary total hip surgery is classed as 'high volume/low risk' (Aylin et al (2013)). This low risk implies less volatility and variation. This therefore supports a comparison between the effectiveness of cell salvage as a means of minimising allogeneic blood transfusions. Three very similar sets of patients underwent the same routine operation. The outputs were effectively the same (a successful hip replacement) therefore the only 
significant difference in the whole process would be the use of cell salvage at the Royal Cornwall Hospital contributing to a planned lower utilisation of allogeneic blood compared to the other two organisations.

The higher rate of WHO defined anaemia at South Manchester may potentially explain the longer length of stay compared to the Royal Cornwall Hospitals and the SOC.

\subsection{Analysis of Post-Operative Hospital Based Activity}

\subsubsection{Post-Operative Hb Analysis}

As noted in para 1.4, the main reason for a clinician prescribing an allogeneic blood transfusion is to improve the patient's $\mathrm{Hb}$ level. The $\mathrm{Hb}$ level will fall due to the blood loss during the operation but the techniques highlighted in Patient Blood Management practices and earlier Better Blood Transfusion initiatives (paras 1.11 and 1.12) should mitigate the fall between the pre-and post-operative levels. This section will exclude all patients who have had an allogeneic blood transfusion in the three centres (50 patients) and the Royal Cornwall Hospitals patients who had their blood reinfused (104, 5 of whom also had an allogeneic transfusion).

Table 39. Analysis of Mean Post-Operative Hb Levels by Grouped HRG Excluding Allogeneic Transfusions and Excluding Reinfused Patients at Royal Cornwall Hospitals

\begin{tabular}{|l|r|r|r|r|r|}
\hline $\begin{array}{c}\text { Hospital: } \\
\text { LHRG }\end{array}$ & \multicolumn{1}{c|}{$\begin{array}{c}\text { South } \\
\text { Manchester }\end{array}$} & $\begin{array}{c}\text { Royal } \\
\text { Cornwall }\end{array}$ & $\begin{array}{c}\text { Spec Orth } \\
\text { Centre }\end{array}$ & Mean & \multicolumn{1}{c|}{ No } \\
\hline HB12B & 106.1 & 104.8 & 103.7 & 105.0 & 240 \\
\hline HB12C & 107.8 & 103.1 & 107.2 & 106.0 & 83 \\
\hline Other & 98.8 & 104.1 & 99.5 & 100.5 & 26 \\
\hline Overall Mean & $\mathbf{1 0 5 . 9}$ & $\mathbf{1 0 4 . 3}$ & $\mathbf{1 0 4 . 3}$ & $\mathbf{1 0 4 . 9}$ & $\mathbf{3 4 9}$ \\
\hline
\end{tabular}

Using an ANOVA comparison, the overall differences are not significant $(\mathrm{p}=0.56)$ for non-transfused patients i.e. post-operative $\mathrm{Hb}$ levels are relatively uniform so the non-transfused (and non-reinfused) patients have very similar outcomes after surgery to support their recovery.

The box plot in figure 18 below represents post-operative $\mathrm{Hb}$ readings for all 498 patients. 


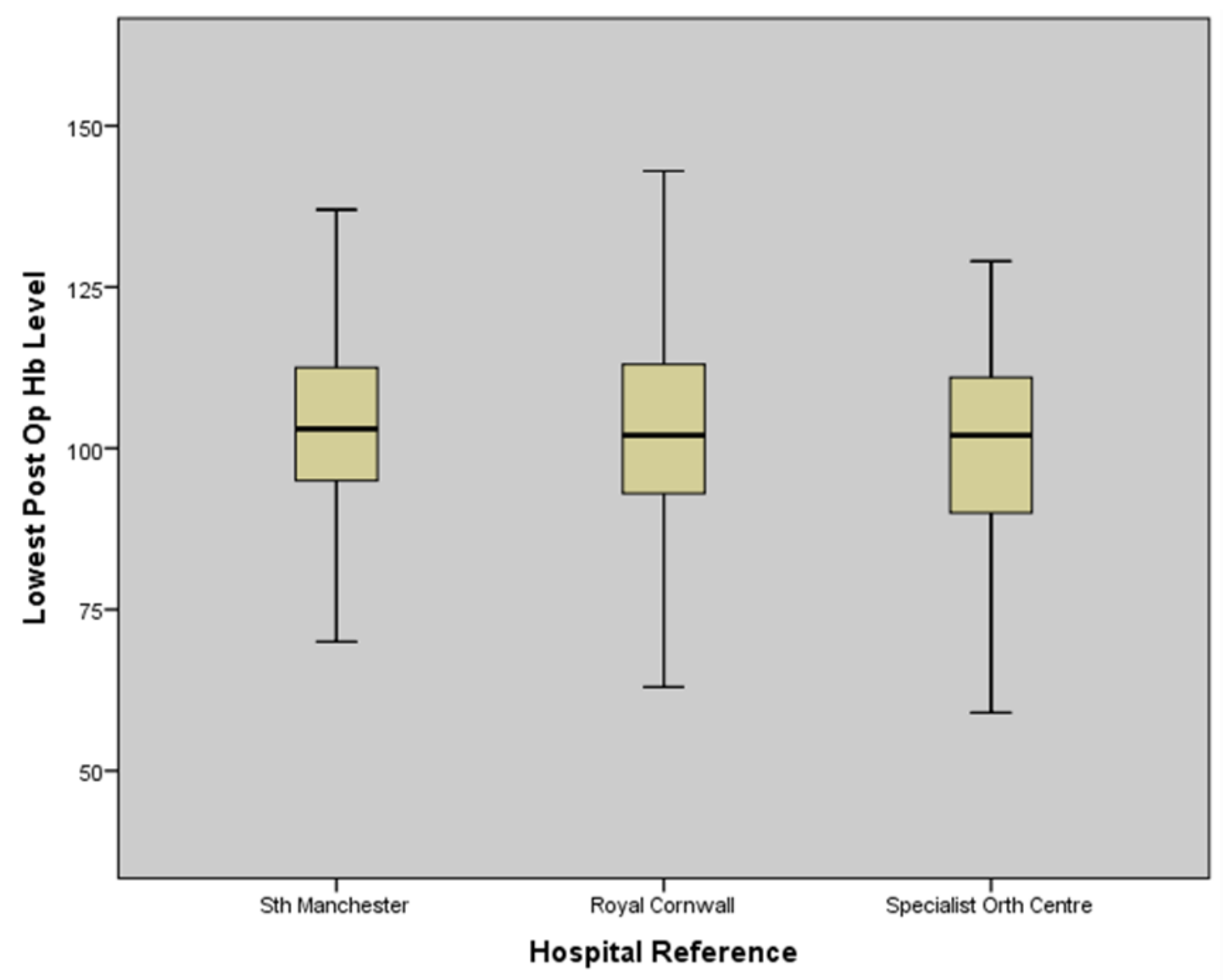

The corresponding output for an ANOVA comparing post-operative Hb levels as the independent variable against the three HRG groupings shows:

Table 40. One Way ANOVA-Comparison of Post-Operative Hb Levels with HRG Groups

\begin{tabular}{|l|r|r|r|}
\hline \multicolumn{1}{|c|}{$\begin{array}{c}\text { Hospital: } \\
\text { I'p' value }\end{array}$} & $\begin{array}{c}\text { South } \\
\text { Manchester }\end{array}$ & $\begin{array}{c}\text { Royal Cornwall } \\
\text { Hospitals }\end{array}$ & Spec Orth Centre \\
\hline $\begin{array}{l}\text { 'p' Value for all 498 } \\
\text { patients }\end{array}$ & .049 & .232 & .023 \\
\hline $\begin{array}{l}\text { 'p' Value for 349 patients } \\
\text { no allogeneic transfusion or } \\
\text { re-infusion }\end{array}$ & .162 & & \\
\hline $\begin{array}{l}\text { 'p' Value for 99 Royal } \\
\text { Cornwall Hospitals patients } \\
\text { reinfused, no allogeneic } \\
\text { transfusion }\end{array}$ & & .854 & .226 \\
\hline
\end{tabular}

For all patients, at the $\mathrm{p}<.05$ level, there was a significant difference in the mean post-operative $\mathrm{Hb}$ level at both South Manchester and the SOC within the HRG groupings, irrespective of whether allogeneic blood transfusions or reinfusions were utilised. The test was run again to eliminate the Royal Cornwall Hospitals patients 
reinfused and any patient at the three sites that had an allogeneic transfusion. On this occasion, there were no significant differences within or between the three sites. This would be expected given the lower likelihood in variations in post-operative $\mathrm{Hb}$ levels triggering a decision to undertake an allogeneic blood transfusion or, in the case of the Royal Cornwall Hospitals, a reinfusion.

The test was run for a third time on the 99 patients who had a reinfusion (excluding the five patients who had both a reinfusion and an allogeneic transfusion) at the Royal Cornwall Hospitals $(\mathrm{p}=.040)$. In this case, there was a significant difference between the HRG category HB12C (25 patients, mean $\mathrm{Hb}$ of 109) and the 'other' group (14 patients, mean $\mathrm{Hb}$ of 97). The corresponding $\mathrm{Hb}$ levels without a reinfusion were $\mathrm{HB} 12 \mathrm{C}$ (28 patients, mean $\mathrm{Hb}$ of 103) against the 'other' group (7 patients, mean $\mathrm{Hb}$ of 104). This implied the reinfusions helped to offset the fall in $\mathrm{Hb}$ level by a mean of $5.5 \mathrm{~g} / 1$ in the more minor cases (HB12C) but had a negligible impact on the patients with greater comorbidities and complications. The full comparison is shown in table 41 below.

Table 41. Split of RCH Patients Without Allogeneic Transfusion

\begin{tabular}{|l|r|r|r|r|r|r|}
\hline \multicolumn{1}{|c|}{$\begin{array}{c}\text { Categoryl } \\
\text { HRG }\end{array}$} & \multicolumn{1}{|c|}{ Without Reinfusion } & \multicolumn{2}{c|}{ With Reinfusion } & \multicolumn{2}{c|}{ Totals } \\
\hline & $\begin{array}{c}\text { Mean } \\
\text { Post Op } \\
\text { Hb }\end{array}$ & $\begin{array}{c}\text { Number } \\
\text { of } \\
\text { Patients }\end{array}$ & $\begin{array}{c}\text { Mean Post } \\
\text { Op Hb }\end{array}$ & $\begin{array}{c}\text { Number } \\
\text { of } \\
\text { Patients }\end{array}$ & $\begin{array}{c}\text { Mean Post } \\
\text { Op Hb }\end{array}$ & $\begin{array}{c}\text { Number } \\
\text { of Patients }\end{array}$ \\
\hline HB12B & 104.8 & 66 & 104.5 & 60 & 104.7 & 126 \\
\hline HB12C & 103.1 & 28 & 108.6 & 25 & 105.7 & 53 \\
\hline Other & 104.1 & 7 & 96.9 & 14 & 99.3 & 21 \\
\hline Mean/Total & $\mathbf{1 0 4 . 3}$ & $\mathbf{1 0 1}$ & $\mathbf{1 0 4 . 3}$ & $\mathbf{9 9}$ & $\mathbf{1 0 4 . 3}$ & $\mathbf{2 0 0}$ \\
\hline
\end{tabular}

Across all three sites the post-operative $\mathrm{Hb}$ level is relatively uniform with a slightly wider variation at the Royal Cornwall Hospitals. The mean post-operative $\mathrm{Hb}$ level for patients who have had an allogeneic blood transfusion is lower at the Royal Cornwall Hospitals than the other two sites (table 42 below). This is consistent with a more restrictive transfusion regime. Note that, at the Royal Cornwall Hospitals, the mean post-operative $\mathrm{Hb}$ level is lower for allogenic transfused patients who were reinfused (mean $\mathrm{Hb}$ 64.4, SD 5.6) than those who were not reinfused $(72.8,7.5)$. The numbers of patients are low $(5+8=13)$ but suggest that the reinfusions may have taken place in order to further decrease the chances of requiring additional allogeneic 
units being transfused. This may not have been successful as the four females who had allogeneic transfusions and reinfusions all received two allogeneic units each.

The NHS Patient Blood Management directive (June 2014) is not prescriptive on a specific $\mathrm{Hb}$ level to initiate an allogeneic blood transfusion highlighting instead "the use of appropriate dose and thresholds for transfusion". The American Association of Blood Banks (AABB) guidelines (appendix 4) notes "a restrictive threshold (7.0g/dl$8.0 \mathrm{~g} / \mathrm{dl}$ i.e. $70-80 \mathrm{~g} / \mathrm{l})$ should be used for stable patients". Table 42 below extracts the mean post-operative $\mathrm{Hb}$ level by gender for transfused patients. The smaller table 43 highlights the Royal Cornwall Hospitals patients who were also reinfused.

Table 42. Mean Post-Operative Hb Levels for Allogeneic Transfused Patients (no reinfusions)

\begin{tabular}{|c|c|c|c|c|c|c|c|c|}
\hline \multirow[t]{2}{*}{\begin{tabular}{l} 
Hospital\} $\\
{\text { Gender }}$ & \multicolumn{2}{|c|}{ South Manchester } & \multicolumn{2}{|c|}{ Royal Cornwall } & \multicolumn{2}{|c|}{ Spec Orth Centre } & \multicolumn{2}{|c|}{ Total } \\
\hline & $\mathbf{H b}$ & n & $\mathbf{H b}$ & n & Hb & n & $\mathbf{H b}$ & n \\
\hline Male & 79.0 & 2 & - & - & 84.4 & 5 & 82.9 & 7 \\
\hline Female & 82.1 & 12 & 72.8 & 8 & 80.4 & 18 & 79.3 & 38 \\
\hline Mean/Total & 81.6 & 14 & 72.8 & 8 & 81.3 & 23 & 79.9 & 45 \\
\hline
\end{tabular}}
\end{tabular}

Table 43. Mean Post-Operative Information for Allogeneic Transfused Patients with Reinfusions

\begin{tabular}{|c|r|r|l|r|r|r|}
\hline & \multicolumn{2}{|c|}{ By Gender } & \multicolumn{4}{c|}{ By Machine Type } \\
\hline & Hb & $\mathbf{n}$ & $\begin{array}{c}\text { Machine } \\
\text { Type }\end{array}$ & Hb & $\mathbf{n}$ & Mean LOS \\
\hline Male & 67.0 & 1 & Electa & 61.5 & 2 & 8.5 \\
\hline Female & 63.8 & 4 & OrthoPat & 66.3 & 3 & 8.7 \\
\hline Totals & $\mathbf{6 4 . 4}$ & $\mathbf{5}$ & Totals & $\mathbf{6 4 . 4}$ & $\mathbf{5}$ & $\mathbf{8 . 6}$ \\
\hline
\end{tabular}

Patients numbers are relatively small in table 42 however the indications are that the Royal Cornwall Hospitals are comfortably within the 70-80 g/l AABB restrictive threshold. The other two sites fall slightly outside of this range implying the Royal Cornwall Hospitals clinicians will wait longer to administer an allogeneic transfusion. This is further reinforced by table 43 where, when reinfusions are undertaken, the $\mathrm{Hb}$ level is allowed to fall even further. The post-operative $\mathrm{Hb}$ level is lower for the five patients who were also reinfused. The sample size is small but suggests that the recovery for these patients was taking longer, necessitating the allogeneic transfusion. Average LOS was also higher than the average of 7.9 days for Royal Cornwall Hospitals patients who had an allogeneic transfusion. 
A comparison of the pre and post-operative $\mathrm{Hb}$ levels across the three hospitals is shown in table 44 below.

Table 44. Mean Pre- and Post-Operative Hb Levels Excluding Allogeneic Transfusions and Excluding Reinfused Patients at Royal Cornwall Hospitals $(n=349)$

\begin{tabular}{|l|r|r|r|r|}
\hline $\begin{array}{l}\text { Hospital/ } \\
\text { Hb }\end{array}$ & \multicolumn{1}{|c|}{$\begin{array}{c}\text { South } \\
\text { Manchester }\end{array}$} & $\begin{array}{c}\text { Royal } \\
\text { Cornwall }\end{array}$ & $\begin{array}{c}\text { Spec Orth } \\
\text { Centre }\end{array}$ & Total \\
\hline $\begin{array}{l}\text { Mean Pre-Op } \\
\text { Hb }\end{array}$ & 136.5 & 136.5 & 137.2 & 136.7 \\
\hline $\begin{array}{l}\text { Mean Post-Op } \\
\text { Hb }\end{array}$ & 105.9 & 104.3 & 104.3 & 104.9 \\
\hline Decrease & 30.6 & 32.2 & 32.9 & 31.8 \\
\hline
\end{tabular}

The difference in the mean fall in the Hb level across the three sites is minimal. This implies the majority of the patients who have not had an allogeneic transfusion (or additionally, no reinfusion at the Royal Cornwall Hospitals) have had a successful outcome to their operation. The difficulty arises in attempting to explain the differences in LOS where, even without an allogeneic transfusion, South Manchester's LOS is significantly longer.

\subsection{Length of Stay (LOS)}

The LOS information collected is now standardised. The initial information received from South Manchester used the standard NHS Choices definition. Following discussions with the lead transfusion coordinator in South Manchester it was agreed that the operation date would be provided (table 18 on page 104). There were a number of cases where the patient was admitted the day before surgery; this gave the appearance that the recovery period was longer when comparing the two dates. The adjusted information was subsequently provided to the researcher.

The box plot below notes the difference in LOS between the three centres: 


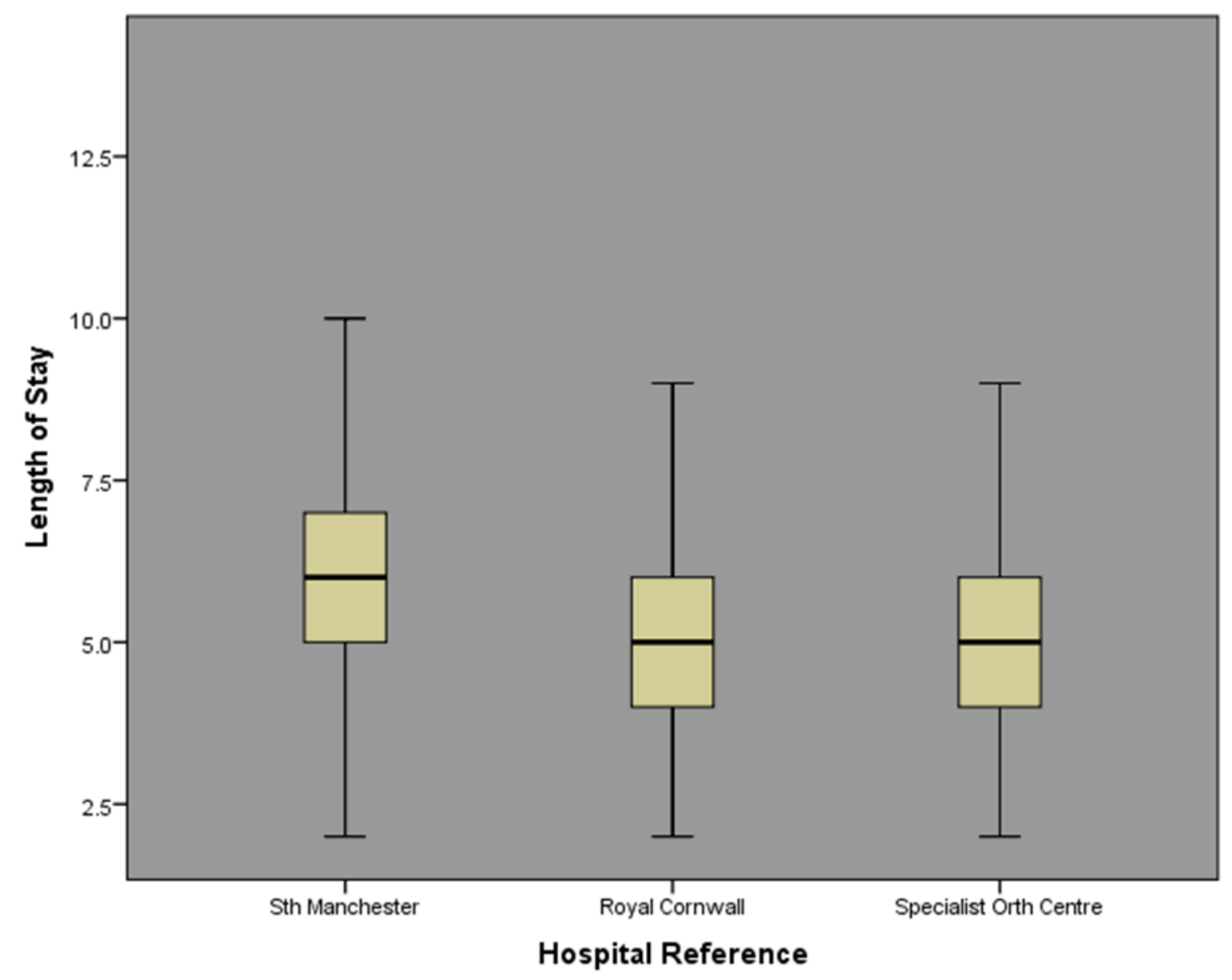

The mean length of stay can be extracted for patients with or without an allogeneic blood transfusion having been undertaken. This was outlined in para 5.8. The overall difference noted the mean length of stay was 1.1 days longer at South Manchester than the Royal Cornwall Hospitals and 1.2 days longer at the SOC.

ANOVA and Dunnett T3 post hoc analysis was undertaken, implying the mean LOS at South Manchester was significantly longer at the 5\% significance level $(p<.001)$ from the two other hospitals. There was no significant difference between the Royal Cornwall Hospitals and the Specialist Orthopaedic Centre.

Continuing to segregate the patients who did not have an allogeneic transfusion, or, in the case of the Royal Cornwall Hospitals, allogeneic blood reinfused the LOS is 6.2 days for South Manchester and 4.9 days each for the Royal Cornwall/SOC. Looking at the day of the week of the operation then Wednesday (day 3 ) is by far the 
busiest with over $60 \%$ of patients undergoing their operations at South Manchester on this day.

The graphs in figure 20 below compare the percentage of patients' operation days by hospital.

Figure 20. Mean Length of Stay (all patients)
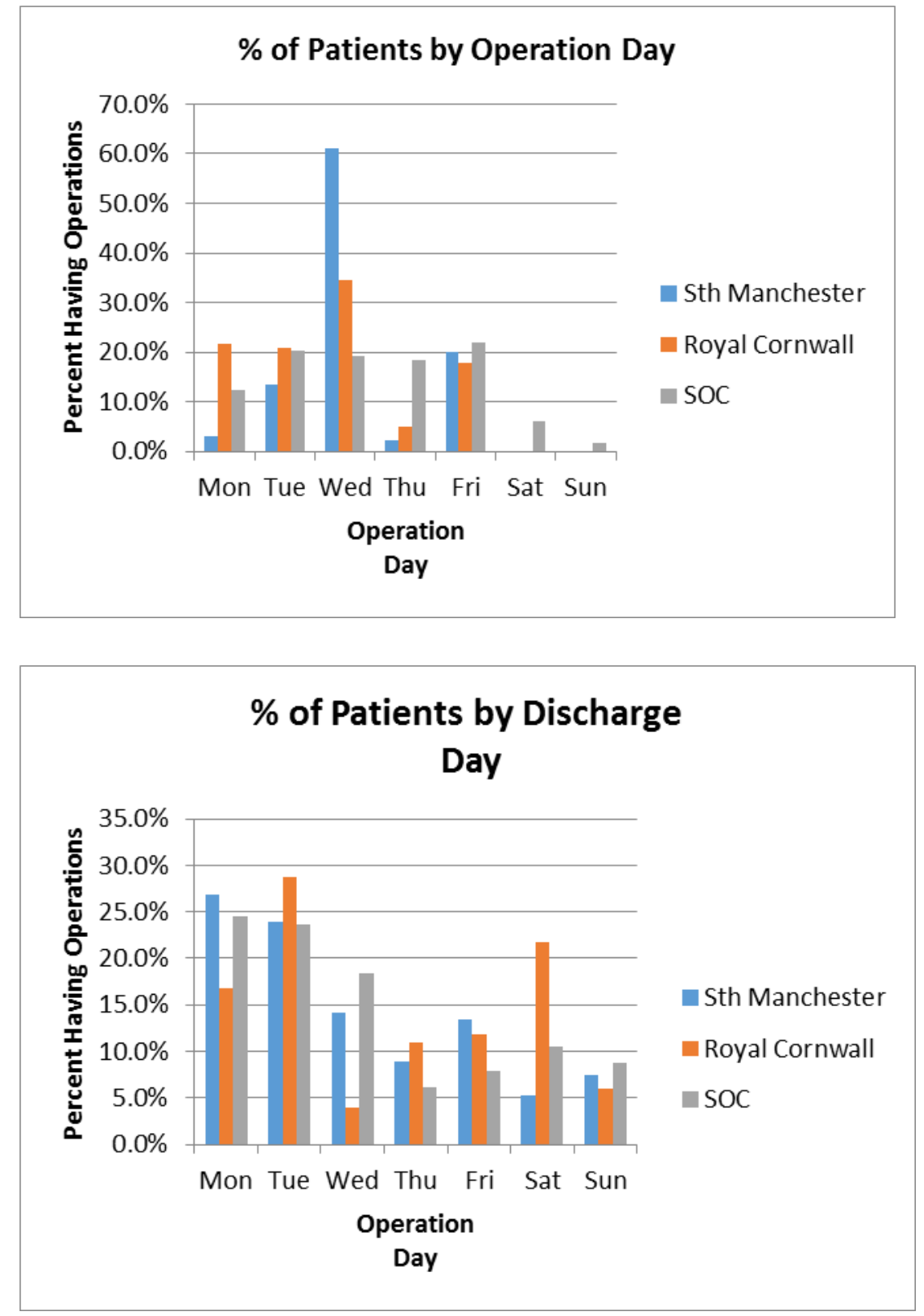

It is clear that South Manchester admits a higher percentage of patients in mid-week and discharge a lower proportion of their patients on the weekend than the other two hospitals. 
It is likely the main rehabilitation work under the Enhanced Recovery Programme (para 1.19) would commence on a Friday following Wednesday surgery; if therapy support is unavailable on the weekend this would almost certainly impact on the progress of recovery. Table 45 below extracts the patients at the three sites who have had surgery on Wednesdays. It excludes the patients who have had allogeneic transfusions or, in the case of the Royal Cornwall Hospitals, reinfusions.

Table 45. Comparison of Mean Length of Stay for Wednesday Surgery (no allogenic transfusions or reinfusions)

\begin{tabular}{|l|r|r|r|}
\hline $\begin{array}{l}\text { Category } \\
\text { /Hospital }\end{array}$ & $\begin{array}{l}\text { South } \\
\text { Manchester }\end{array}$ & $\begin{array}{l}\text { Royal } \\
\text { Cornwall }\end{array}$ & \multicolumn{1}{l|}{ SOC } \\
\hline Number of patients on Wednesday & 82 & 35 & 134 \\
\hline Total patients (no transfusion or reinfusion) & $61.1 \%$ & $34.7 \%$ & $19.2 \%$ \\
\hline Percentage of total & 6.3 & 4.6 & 4.5 \\
\hline Mean length of stay for patients & $39(63)$ & $11(37)$ & $12(46)$ \\
\hline $\begin{array}{l}\text { Males on Wed (Total males not transfused or } \\
\text { reinfused) }\end{array}$ & $47.5 \%$ & $31.4 \%$ & $54.5 \%$ \\
\hline$\%$ males on Wed & & & \\
\hline
\end{tabular}

Patients' recovery and their consequent LOS will therefore be impacted by the lower level of therapy support to aid recovery on a weekend. Reinfusions at the Royal Cornwall Hospitals and allogeneic blood transfusions have been excluded from table 45 above.

Table 45 implies there is a wide variation in the numbers of male patients. Para 6.3.1. above asserted that there was no significant difference in the gender split of patients in the three hospital groups. A breakdown of mean length of stay by gender for the 349 patients with no allogeneic transfusions or reinfusions is shown in table 46 below:

Table 46. Comparison of Mean Length of Stay by Gender for Surgery (no allogenic transfusions or reinfusions, $n=349$ )

\begin{tabular}{|l|r|r|r|r|}
\hline $\begin{array}{l}\text { Hospital/ } \\
\text { Gender }\end{array}$ & \multicolumn{1}{|c|}{$\begin{array}{c}\text { South } \\
\text { Manchester }\end{array}$} & \multicolumn{1}{c|}{$\begin{array}{c}\text { Royal } \\
\text { Cornwall }\end{array}$} & \multicolumn{1}{c|}{ SOC } & \multicolumn{2}{c|}{ Total } \\
\hline Male & 6.0 & 4.5 & 4.6 & 5.1 \\
\hline Female & 6.4 & 5.1 & 5.2 & 5.6 \\
\hline Total & 6.2 & 4.9 & 4.9 & 5.4 \\
\hline
\end{tabular}

A one-way ANOVA test was undertaken to explore the difference between hospital on LOS for Wednesday operations. The differences between the mean LOS were significant $(\mathrm{p}<.001)$. A Tukey HSD analysis found significant differences in LOS between South Manchester and both the Royal Cornwall and the SOC $(p<.001)$. 
There were no significant differences in LOS between the Royal Cornwall and the SOC for Wednesday operations.

The graphical output is shown in figure 21 below:

Figure 21. Mean Length of Stay for Patients- 'Baseline' Position (no allogenic transfusions or reinfusions, $n=349$ )

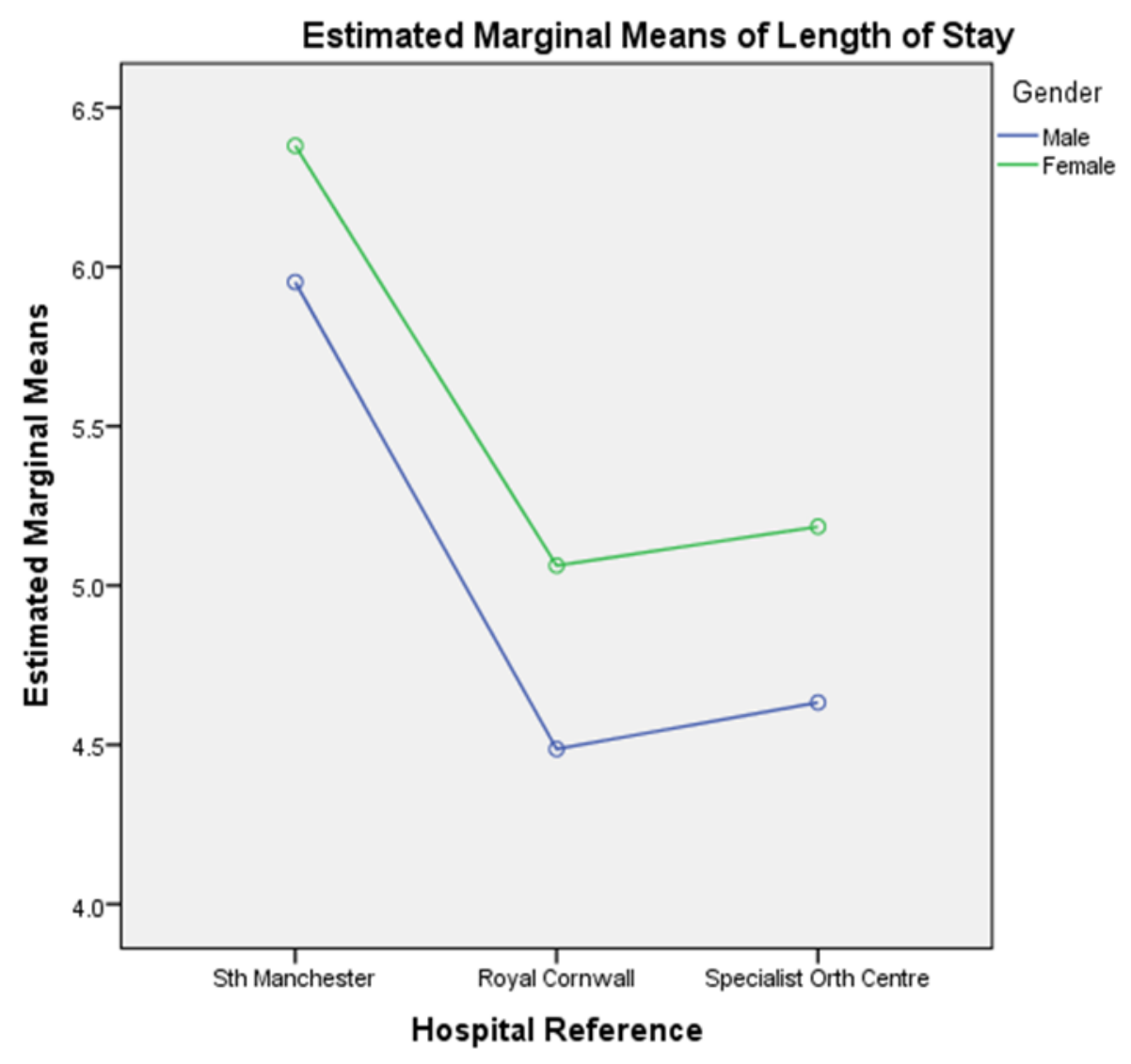

Figure 21 and table 46 above therefore reflect a 'baseline' position with the LOS for patients having surgery on any particular day of the week not being affected by a patient having an allogeneic blood transfusion. The difference in LOS is therefore likely to be a factor not related to the surgical process.

This analysis was expanded to incorporate a regression analysis, using the logarithm of LOS as the dependent variable to mitigate against heteroscedasticity. A dummy control of South Manchester was set up to facilitate interpretation of the impact of selected variables on LOS. The R square value was calculated at 0.363 . This implies approximately $36 \%$ of the variation is explained by the variables included. Other factors must therefore contribute to the remainder of the variation; these will be considered in chapter 7 . The output from the analysis is shown in table 47 below: 
Table 47. Regression on Logarithm of Length of Stay

\begin{tabular}{|l|r|r|}
\hline \multicolumn{1}{|c|}{ Variable } & \multicolumn{1}{c|}{$\begin{array}{c}\text { B } \\
\text { Coeff }\end{array}$} & \multicolumn{1}{c|}{ 'p' } \\
\hline (Constant) & 1.783 & $<.0005$ \\
\hline Discharge Day=Saturday & -.240 & $<.0005$ \\
\hline HRG No=HB12C & -.199 & $<.0005$ \\
\hline Age & .006 & $<.0005$ \\
\hline Lowest Post Op Hb Level & -.005 & $<.0005$ \\
\hline Hosp No=Specialist Orth Centre & -.178 & $<.0005$ \\
\hline Hosp No=Royal Cornwall & -.180 & $<.0005$ \\
\hline Op Day=Sunday & .782 & $<.0005$ \\
\hline Op Day=Tuesday & .204 & $<.0005$ \\
\hline Discharge Day=Tuesday & .142 & .001 \\
\hline Discharge Day=Thursday & .164 & .009 \\
\hline Op Day=Wednesday & .095 & .020 \\
\hline
\end{tabular}

Note-Excludes patients who received allogeneic blood transfusions or reinfused blood

Negative coefficients on the 'Hosp no' for the SOC and Royal Cornwall in table 47 imply LOS at South Manchester is longer. One would expect LOS to generally increase as a patient gets older however this is at a slightly faster rate than the other two sites. There are no operations undertaken on a Sunday at South Manchester or the Royal Cornwall Hospitals therefore the Sunday entry can be ignored.

A Tuesday operation day giving a longer LOS is not consistent with the view held in Pittsburgh (para 3.2). This was investigated further and table 48 below profiles out the discharge day for patients having their operation on a Tuesday.

Table 48. Discharge Day and Mean Length of Stay for Patients Having Tuesday Operations

\begin{tabular}{|l|r|r|r|r|r|r|r|r|r|}
\hline $\begin{array}{c}\text { Discharge Day } \\
\text { /Hospital }\end{array}$ & $\begin{array}{c}\text { Mean } \\
\text { LOS }\end{array}$ & Wed & Thu & Fri & Sat & Sun & Mon & Tue & Total \\
\hline South Manchester & 6.4 & - & - & 6 & 2 & 3 & 3 & 4 & 18 \\
\hline Royal Cornwall Hospitals & 5.3 & 2 & 1 & 2 & 4 & 3 & 5 & 4 & 21 \\
\hline Spec Orth Centre & 6.0 & 3 & 1 & 2 & 5 & 4 & 4 & 4 & 23 \\
\hline
\end{tabular}

Note-Excludes patients who received allogeneic blood transfusions or reinfused blood. Wednesday will be day 8 i.e. the week later.

The analysis was further extended to identify days per patient in table 49 below. 
Table 49. Patients Length of Stay for Tuesday Operations

\begin{tabular}{|r|r|r|r|r|}
\hline $\begin{array}{l}\text { Length of Stay } \\
\text { (Days) }\end{array}$ & South Manchester & $\begin{array}{l}\text { Royal } \\
\text { Cornwall } \\
\text { Hospitals }\end{array}$ & SOC & Total \\
\hline 2 & - & 1 & - & 1 \\
\hline 3 & 5 & 2 & 2 & 9 \\
\hline 4 & 2 & 4 & 5 & 11 \\
\hline 5 & 3 & 3 & 4 & 10 \\
\hline 6 & 2 & 5 & 4 & 9 \\
\hline 7 & 2 & 4 & 3 & 5 \\
\hline 8 & - & 2 & 3 & 1 \\
\hline 9 & - & - & 1 & 1 \\
\hline 10 & 1 & - & - & 1 \\
\hline 13 & 1 & - & - & 3 \\
\hline 14 & 2 & - & 1 & $\mathbf{6 2}$ \\
\hline Total & $\mathbf{1 8}$ & $\mathbf{2 1}$ & $\mathbf{2 3}$ & $\mathbf{8 2 \%}$ \\
\hline Wischarge & $\mathbf{7 8 \%}$ & $\mathbf{9 0 \%}$ & $\mathbf{7 8 \%}$ & \\
\hline
\end{tabular}

Note-Excludes patients who received allogeneic blood transfusions or reinfused blood

There is a noticeably wider range that impacts on the average LOS. In particular, four patients at South Manchester had a LOS of over nine days against two for the Royal Cornwall Hospitals and one for the SOC. It is interesting to note that six patients at South Manchester were outside the WHO anaemic thresholds in the pre-operative $\mathrm{Hb}$ readings against two at the Royal Cornwall Hospitals and one at the SOC. This variable, however, did not show as significant in the stepwise analysis.

Analysis of the three hospitals' discharges on a Saturday/Sunday verified all the patients had undergone their operations on the previous Tuesday. One cannot therefore extract any definitive conclusions from this analysis. The $\mathrm{R}$ squared value implies there are other factors that influence the LOS.

The Wednesday surgery at South Manchester was subsequently analysed. An operation undertaken on a Wednesday accounted for over $61 \%$ of all the week's primary hip replacement operations at South Manchester. Table 50 below profiles the position for the three hospitals, noting the average length of stay. Again, this excludes those patients having received an allogeneic transfusion. 
Table 50. Discharge Day and Mean Length of Stay for Wednesday Operations

(excludes patients who have had allogeneic transfusions or reinfusions)

\begin{tabular}{|c|c|c|c|c|c|c|c|c|c|}
\hline \multirow[b]{2}{*}{ Site } & \multirow[b]{2}{*}{ Indicator } & \multicolumn{7}{|c|}{ Discharge Day } & \multirow[b]{2}{*}{ Total } \\
\hline & & Thu & Fri & Sat & Sun & Mon & Tue & Wed & \\
\hline \multirow[t]{3}{*}{$\begin{array}{l}\text { South } \\
\text { Manchester }\end{array}$} & Number of patients & 5 & 9 & 3 & 6 & 29 & 17 & 13 & 82 \\
\hline & Mean LOS & 8.0 & 7.4 & 5.3 & 4.0 & 5.5 & 6.4 & 7.5 & 6.3 \\
\hline & Patients with LOS +1 week & 5 & 7 & 1 & - & 2 & 1 & 1 & 17 \\
\hline \multirow[t]{3}{*}{$\begin{array}{l}\text { Royal } \\
\text { Cornwall } \\
\text { Hospitals } \\
\end{array}$} & Number of patients & 2 & 1 & 15 & 2 & 6 & 9 & - & 35 \\
\hline & Mean LOS & 8.0 & 9.0 & 3.0 & 4.0 & 5.0 & 6.2 & - & 4.7 \\
\hline & Patients with LOS +1 week & - & 1 & - & - & - & - & - & 1 \\
\hline \multirow[t]{3}{*}{ SOC } & Number of patients & 1 & 1 & 3 & 6 & 10 & 1 & - & 22 \\
\hline & Mean LOS & 8.0 & 2.0 & 3.0 & 4.0 & 5.0 & 6.0 & - & 4.5 \\
\hline & Patients with LOS +1 week & 1 & - & - & - & - & - & - & 1 \\
\hline
\end{tabular}

The implication is that the factors noted previously on the therapy support and staff availability to discharge patients at weekends have an impact on LOS. These factors, combined with more patients falling within the WHO definition of anaemia, are likely to increase the upward pressure on LOS at South Manchester. Only four out of 59 patients discharged between a Monday and Wednesday $(29+17+13)$ had stayed for longer than a week at South Manchester implying recovery, as indicated by postoperative $\mathrm{Hb}$ levels, is not dissimilar to the other two hospitals. The implication is that a number of the 29 patients discharged on a Monday could possibly have been discharged on the weekend thereby lowering the average LOS. This is, however, only speculation but there is a relatively high proportion of patients remaining over the weekend until Tuesday $(46 / 82,56 \%)$. Comparing this to the other two sites implies there is likely to be a backlog in discharging patterns at South Manchester or a delay in therapy support to facilitate the patient's return home as early as possible.

Within the stepwise analysis above the discharge day is likely to be a proxy for some other factor. An analysis of the Tuesday discharges (the highest day for discharges) for the three sites was undertaken and the output is summarised in table 51 below. 
Table 51. Analysis of Length of Stay for Tuesday Discharges

(excludes patients who have had allogeneic transfusions or reinfusions)

\begin{tabular}{|l|l|r|r|r|r|r|r|}
\hline Site & \multicolumn{1}{|c|}{$\begin{array}{c}\text { Operation Day } \\
\text { /Indicator }\end{array}$} & Mon & \multicolumn{1}{c|}{ Tue } & \multicolumn{1}{c|}{ Wed } & \multicolumn{1}{c|}{ Thu } & \multicolumn{1}{c|}{ Fri } & \multicolumn{1}{c|}{ Total } \\
\hline South Manchester & Number of patients & 1 & 4 & 17 & 2 & 8 & 32 \\
\hline & Mean LOS & 8.1 & 10.5 & 6.4 & 5.0 & 5.8 & 6.7 \\
\hline $\begin{array}{l}\text { Royal Cornwall } \\
\text { Hospitals }\end{array}$ & Number of patients & 3 & 4 & 9 & 3 & 10 & 29 \\
\hline & Mean LOS & 8.7 & 6.8 & 6.2 & 4.7 & 3.9 & 5.6 \\
\hline SOC & Number of patients & - & 4 & 1 & 9 & 13 & 27 \\
\hline & Mean LOS & - & 8.8 & 6.0 & 5.0 & 4.0 & 5.1 \\
\hline All Sites & Total Patients & 4 & 12 & 27 & 14 & 31 & 88 \\
\hline & Overall Mean LOS & 8.5 & 8.7 & 6.3 & 4.9 & 4.4 & 5.9 \\
\hline
\end{tabular}

A one-way ANOVA was undertaken to explore the impact of Tuesday discharges by site on LOS. There was a statistically significant difference $(p=.02)$ in the mean LOS between the three sites. The effect size, calculated using eta squared, was .09, implying a relatively large proportion of the variance in LOS for Tuesday discharges is explained by differences in the three sites.

The above analysis was all undertaken on the data relating to patients who did not have an allogeneic transfusion or, in the case of the Royal Cornwall Hospitals, an allogeneic transfusion or shed blood being reinfused. The implication is that there are significant underlying reasons why there is a longer LOS at South Manchester. It can be safely said that these reasons are not connected with patients having allogeneic blood transfusions or reinfusing blood as the above comparisons have been made on patients that did not fall into these categories. Chapter 2 noted that a cost benefit analysis approach may support the comparison. It therefore seems highly likely that an allogeneic blood transfusion is not a factor in impacting on LOS. The most appropriate method of economic appraisal is therefore a cost minimisation study focusing on the blood (both allogeneic and salvaged) related costs. 


\subsection{Comparison with Royal Cornwall Hospitals Patients Not Salvaged}

As highlighted in table 30 there were 33 Royal Cornwall Hospitals patients who were not salvaged. This group of patients provides an additional comparison. The SPSS analysis is summarised in table 52 below:

Table 52. Comparison of 33 Patients not Salvaged

\begin{tabular}{|l|l|r|r|r|r|}
\hline Factor Tested & \multicolumn{1}{|c|}{ Test } & \multicolumn{1}{c|}{$\begin{array}{c}\text { 'p' } \\
\text { Value }\end{array}$} & $\begin{array}{c}\text { Not } \\
\text { Salvaged }\end{array}$ & $\begin{array}{c}\text { Total } \\
\text { Salvaged }\end{array}$ & \multicolumn{1}{c|}{ Patients } \\
\hline Pre-Op Hb Level & t-test & .41 & 33 & 180 & 213 \\
\hline Post-Op Hb Level & t-test & .58 & 33 & 180 & 213 \\
\hline Age & t-test & .58 & 33 & 180 & 213 \\
\hline Gender & Chi-square & .28 & 33 & 180 & 213 \\
\hline HRG & Chi-square & .27 & 32 & 159 & 191 \\
\hline
\end{tabular}

Note-Initial HRG test violated minimum cell frequency test. The test was therefore restricted to HRGs HB12B and HB12C.

The independent samples t-tests established that there was no significant difference between the two groups of salvaged and non-salvaged patients. The Chi-square test for independence (with Yates Continuity Correction in both cases) indicated no significant association between gender in the salvaged/non-salvaged category and also no significant association between the HRG group and the salvaged and nonsalvaged patients. The allogeneic transfusion rate is consistent between the two groups though the number of allogeneic transfusions in the non-salvaged patients was $3 / 33$, thereby violating the 'minimum expected cell frequency' of the Chi-square test.

\subsection{Analysis Where Allogeneic Blood Transfusion Administered}

Toleration of a lower Hb level (Goodnough and Murphy (2014)) can be an effective method for a patient to avoid an allogeneic blood transfusion. Table 40 (page 149) indicates a fairly uniform post-operative $\mathrm{Hb}$ level. The graph in figure 22 below breaks down the post-operative $\mathrm{Hb}$ levels over whether or not the patient had an allogeneic transfusion. What is noticeable in table 42 (allogeneic transfusions without reinfusions, page 150) is the much lower post-operative $\mathrm{Hb}$ level for a patient undergoing an allogeneic transfusion at the Royal Cornwall Hospital (mean of 72.8) than South Manchester or the Specialist Orthopaedic Centre (81.6 and 81.3 
respectively). The indications are that the decision to transfuse is therefore made on a lower rate at the Royal Cornwall Hospital.

Figure 22. Mean Post-Operative Hb Level With and Without an Allogeneic Transfusion

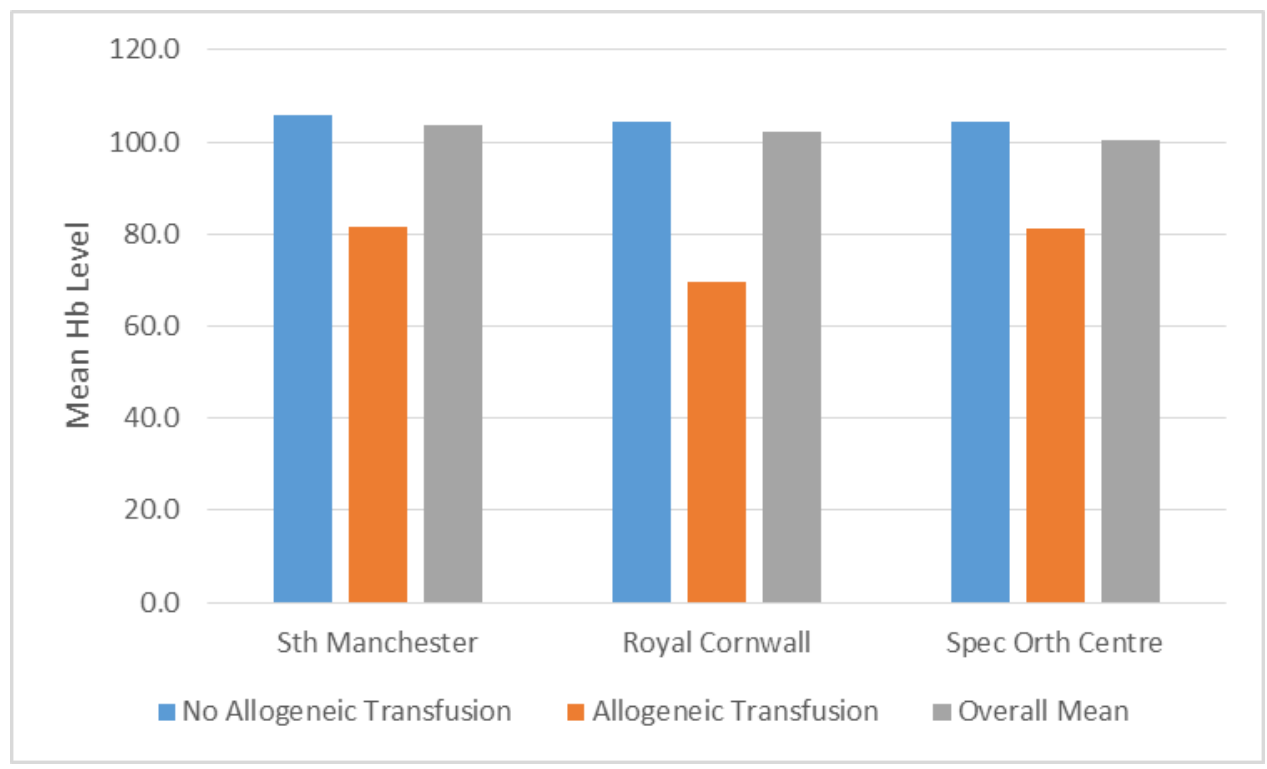

The table below extracts the number of patients who have received an allogeneic blood transfusion. Given the differing sample sizes table 53 below converts the numbers to percentages, although caution should be exercised due to the small numbers. The most striking feature is the low proportion of $\mathrm{HB} 12 \mathrm{C}$ patients who receive an allogeneic transfusion.

Table 53. Number/(Percentage) of Patients Receiving Allogeneic Blood Transfusions

\begin{tabular}{|l|r|r|r|r|}
\hline $\begin{array}{c}\text { Hospital: } \\
\text { IHRG }\end{array}$ & $\begin{array}{c}\text { South } \\
\text { Manchester }\end{array}$ & $\begin{array}{c}\text { Royal } \\
\text { Cornwall }\end{array}$ & $\begin{array}{c}\text { Spec Orth } \\
\text { Centre }\end{array}$ & \multicolumn{1}{c|}{ Total } \\
\hline HB12B & $11(10.2 \%)$ & $11(8.0 \%)$ & $18(18.9 \%)$ & $40(11.8 \%)$ \\
\hline HB12C & $1(3.7 \%)$ & $1(1.9 \%)$ & $0(0.0 \%)$ & $2(1.8 \%)$ \\
\hline Other & $2(15.4 \%)$ & $1(4.5 \%)$ & $5(38.5 \%)$ & $8(16.7 \%)$ \\
\hline Total & $14(9.5 \%)$ & $13(6.1 \%)$ & $23(16.8 \%)$ & $50(10.0 \%)$ \\
\hline
\end{tabular}

As expected the mean post-operative $\mathrm{Hb}$ level is noticeably lower where an allogeneic transfusion is administered. Given the main reason for an allogeneic transfusion is to increase the patient's $\mathrm{Hb}$ level it is reasonable to assume that the transfusions were given after the readings were taken.

Excluding the two HB12C patients and the patients reinfused at the Royal Cornwall Hospitals the LOS for the three sites is: 
Table 54. Number and Mean Length of Stay with Allogeneic Transfusion/No Reinfusion; Excluding $H R G H B 12 C$

\begin{tabular}{|c|c|c|c|c|c|c|c|c|}
\hline \multirow[t]{2}{*}{$\begin{array}{c}\text { Hospital: } \\
\text { URRG }\end{array}$} & \multicolumn{2}{|c|}{$\begin{array}{c}\text { South } \\
\text { Manchester }\end{array}$} & \multicolumn{2}{|c|}{ Royal Cornwall } & \multicolumn{2}{|c|}{$\begin{array}{c}\text { Spec Orth } \\
\text { Centre }\end{array}$} & \multicolumn{2}{|c|}{ Total } \\
\hline & $\mathrm{n}$ & $\begin{array}{c}\text { Mean } \\
\text { LOS }\end{array}$ & $\mathrm{n}$ & $\begin{array}{c}\text { Mean } \\
\text { LOS }\end{array}$ & $\mathrm{n}$ & $\begin{array}{c}\text { Mean } \\
\text { LOS }\end{array}$ & $\mathrm{n}$ & $\begin{array}{c}\text { Mean } \\
\text { LOS }\end{array}$ \\
\hline HB12B & 11 & 7.6 & 7 & 7.7 & 18 & 6.0 & 36 & 6.8 \\
\hline Other & 2 & 10.0 & 1 & 9.0 & 5 & 6.4 & 8 & 7.6 \\
\hline Total & 13 & 8.0 & 8 & 7.9 & 23 & 6.1 & 44 & 7.0 \\
\hline
\end{tabular}

There is therefore negligible difference between the mean LOS for those patients who received an allogeneic transfusion at South Manchester and those at the Royal Cornwall Hospitals. The numbers of patients are relatively small, but these patients required additional procedures (as indicated by the HRG category) that therefore contributed to LOS.

Figure 23 below shows that, where an allogeneic transfusion is administered at the Royal Cornwall Hospital, over $90 \%$ of the patients who have received an allogeneic blood transfusion were permitted to have their $\mathrm{Hb}$ level fall to below $80 \mathrm{~g} / \mathrm{l}$. The corresponding figure for the other two hospitals was less than $50 \%$. The implication is therefore that the Royal Cornwall Hospital operates a more restricted allogeneic transfusion regime with the decision to undertake an allogeneic transfusion based on a lower 'transfusion trigger' $\mathrm{Hb}$ level. This is consistent with the higher standard deviation in the differences between the mean pre-and post-operative $\mathrm{Hb}$ levels in para 6.2. As an indication, the highest post-operative $\mathrm{Hb}$ readings were $105 \mathrm{~g} / \mathrm{l}$ for South Manchester, $104 \mathrm{~g} / \mathrm{l}$ for the SOC and $82 \mathrm{~g} / 1$ for the Royal Cornwall Hospitals when an allogeneic transfusion was undertaken. 
Figure 23. Post-Operative Hb Levels with an Allogeneic Transfusion

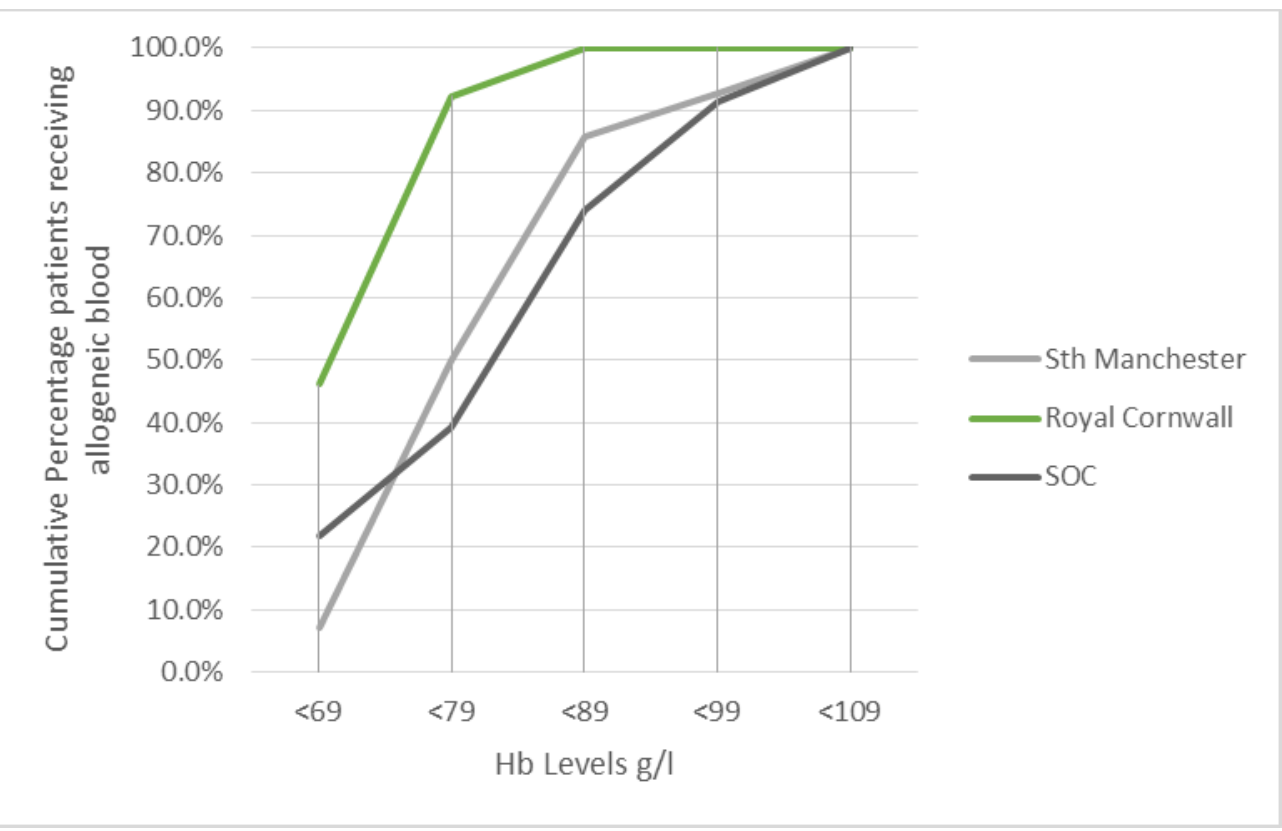

An independent samples t-test was undertaken to compare the post-operative $\mathrm{Hb}$ levels for patients who did or did not have an allogeneic blood transfusion at each site. There was no significant difference in mean post-operative $\mathrm{Hb}$ levels for South Manchester $(\mathrm{p}=.27)$ or the SOC $(\mathrm{p}=.60)$ however the difference in the Royal Cornwall Hospitals was significant $(\mathrm{p}=.02)$. This is consistent with a potentially more subjective approach and a greater tolerance to allowing the post-operative $\mathrm{Hb}$ level to fall lower at the Royal Cornwall Hospitals.

The analysis was extended to quantify the numbers of patients transfused with $\mathrm{Hb}$ levels below $90 \mathrm{~g} / 1$. This is shown in table 55 below. This extracts the data relating to patients with a post-operative $\mathrm{Hb}$ reading of $<90 \mathrm{~g} / \mathrm{l}$, which is approximately the highest $\mathrm{Hb}$ rate at the Royal Cornwall Hospitals where a patient receives an allogeneic transfusion.

Table 55. Allogeneic Transfusions Undertaken on Patients with Post-Operative Level <90 g/l

\begin{tabular}{|c|r|r|r|r|}
\hline $\begin{array}{c}\text { Indicator } \\
\text { /Hospital }\end{array}$ & $\begin{array}{c}\text { Number } \\
\text { of } \\
\text { Patients }\end{array}$ & $\begin{array}{c}\text { Proportion } \\
\text { of Total } \\
\text { Patients }\end{array}$ & $\begin{array}{c}\text { Number } \\
\text { Transfused }\end{array}$ & $\begin{array}{c}\text { \% } \\
\text { Transfusion } \\
\text { Rate on < 90 } \\
\text { g/l patients }\end{array}$ \\
\hline South Manchester & 25 & $16.9 \%$ & 12 & $48.0 \%$ \\
\hline Royal Cornwall Hospitals & 40 & $18.8 \%$ & 13 & $32.5 \%$ \\
\hline With reinfusion & 20 & $9.3 \%$ & 5 & $25.0 \%$ \\
\hline Without reinfusion & 20 & $9.3 \%$ & 8 & $40.0 \%$ \\
\hline Spec Orth Centre & 33 & $24.0 \%$ & 17 & $51.5 \%$ \\
\hline Total & $\mathbf{9 8}$ & $\mathbf{1 9 . 7 \%}$ & $\mathbf{4 2}$ & $\mathbf{4 2 . 9 \%}$ \\
\hline
\end{tabular}


The Royal Cornwall Hospitals 'without reinfusion' transfusion rate is still lower than South Manchester or the SOC. This implies that the restrictive transfusion practice in place at the Royal Cornwall Hospitals is more effective at avoiding allogeneic transfusions than the other two sites even without the benefits of cell salvage. The numbers are low, but cell salvage appears to therefore have only a small impact on avoiding allogeneic blood transfusions and other blood avoidance strategies are having a more beneficial impact at the Royal Cornwall Hospitals than the other two sites.

As noted previously the LOS varies markedly between the three hospitals. The two graphs below summarise the LOS over the HRG noting the significant difference at South Manchester highlighted previously.

Figure 24. Mean Length of Stay Without Allogeneic Transfusion

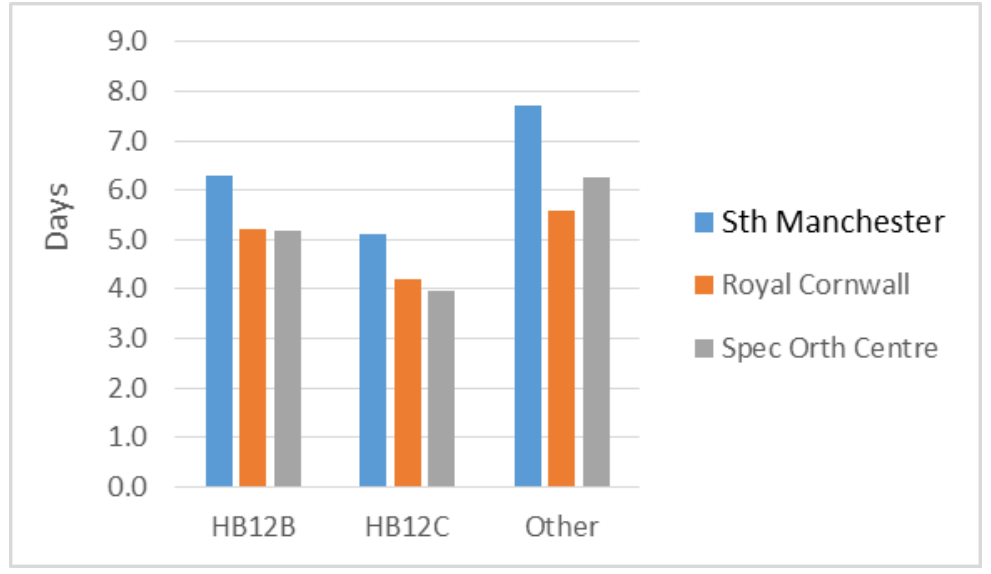

Figure 25. Mean Length of Stay with Allogeneic Transfusion

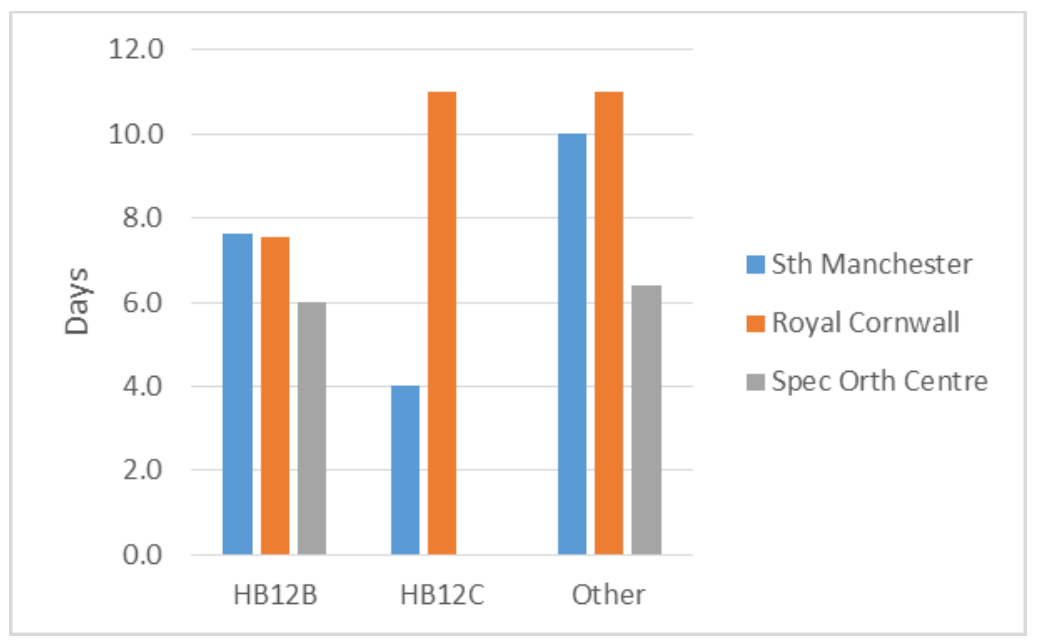


Figures 24 and 25, with table 56 below, highlight the implied relationship between the LOS and whether an allogeneic blood transfusion was administered. The position is however distorted by the number of transfusions being so low in the HB12C HRG category. Approximately $68 \%$ of all the operations relate to the HB12B category (table 31, page 140). Analysing the transfusion rates by HRG will therefore minimise the averaging effect of the low transfusion rate in the 110 operations in the HB12C category.

Table 56. Transfusion Rates Excluding HRG HB12C

\begin{tabular}{|c|c|c|c|c|c|}
\hline $\begin{array}{l}\text { Hospital: } \\
\backslash \text { Transfusion } \\
\text { Rate } \\
\end{array}$ & $\begin{array}{c}\text { South } \\
\text { Manchester }\end{array}$ & $\begin{array}{c}\text { Royal } \\
\text { Cornwall } \\
\end{array}$ & $\begin{array}{c}\text { Spec Orth } \\
\text { Centre }\end{array}$ & Total & $\mathbf{N}$ \\
\hline HB12B & $10.2 \%$ & $8.0 \%$ & $18.9 \%$ & $11.8 \%$ & 340 \\
\hline Other & $15.4 \%$ & $4.5 \%$ & $38.5 \%$ & $16.7 \%$ & 48 \\
\hline Total & $10.7 \%$ & $7.5 \%$ & $21.3 \%$ & $12.4 \%$ & 388 \\
\hline
\end{tabular}

The most frequently occurring HRG in the 'other' category is the HB12A that includes major comorbidities and complications. The transfusion rate is markedly lower for this group at the Royal Cornwall Hospitals compared to the SOC. The 'other' category can comprise higher or lower levels of invasive surgery. The proportions of patients within each HRG category is consistent across the three sites. This was undertaken by grouping the relatively few patients who were not classed in the HB12B and HB12C. 18 patients fell within the HB11A to HB11C category; these patients have more complications and hence attract a higher tariff funding. The Royal Cornwall Hospitals treated 10 of these patients against three in South Manchester and five at the SOC. This level of activity is too small to analyse separately but implies that, using the HRG evidence available, the SOC is not treating a higher proportion of patients who have additional complications and comorbidities than the other two sites. This again points to dispelling one of the possible reasons behind the SOC's higher allogeneic transfusion rate.

The HB12C HRG was then reanalysed, excluding patients who were transfused and re-infused at the Royal Cornwall Hospitals. The mean length of stay (table 57 below) is still markedly higher at South Manchester. It can be said, with certainty, that there are additional factors affecting the longer length of stay at South Manchester. These factors obviously do not include the impact of allogeneic blood transfusions or cell salvage at the Royal Cornwall Hospitals. 
Table 57. HRG HB12C Length of Stay Excluding Allogeneic Transfusions and Excluding Reinfused Patients at Royal Cornwall Hospitals

\begin{tabular}{|l|r|r|r|r|}
\hline \multicolumn{1}{|c|}{$\begin{array}{c}\text { Hospital: } \\
\backslash \text { LOS }\end{array}$} & \multicolumn{1}{c|}{$\begin{array}{c}\text { South } \\
\text { Manchester }\end{array}$} & \multicolumn{1}{c|}{$\begin{array}{c}\text { Royal } \\
\text { Cornwall }\end{array}$} & \multicolumn{1}{c|}{$\begin{array}{c}\text { Spec Orth } \\
\text { Centre }\end{array}$} & \multicolumn{2}{c|}{ Total } \\
\hline Number & 26 & 28 & 29 & 83 \\
\hline $\begin{array}{l}\text { Length of Stay } \\
\text { (days) }\end{array}$ & 5.1 & 4.3 & 4.0 & 4.4 \\
\hline
\end{tabular}

Though the overall age and gender distributions of the patients at the three sites are not significantly different, the transfusion rates by gender reveal a consistently marked difference.

Table 58. Transfusion Rates by Age and Gender

\begin{tabular}{|l|r|r|r|r|r|r|r|r|r|}
\hline \multicolumn{1}{|c}{$\begin{array}{c}\text { Indicator } \\
\text { /Hospital }\end{array}$} & $\begin{array}{c}\text { Mean } \\
\text { Age } \\
\text { Male }\end{array}$ & $\begin{array}{c}\text { Males } \\
\text { n }\end{array}$ & $\begin{array}{c}\text { Txn } \\
\text { Rate } \\
\text { Male }\end{array}$ & $\begin{array}{c}\text { Mean } \\
\text { Age } \\
\text { Female }\end{array}$ & $\begin{array}{c}\text { Females } \\
\text { n }\end{array}$ & $\begin{array}{c}\text { Txn } \\
\text { Rate } \\
\text { Female }\end{array}$ & $\begin{array}{c}\text { Av } \\
\text { Age } \\
\text { Overall }\end{array}$ & $\begin{array}{c}\text { Total } \\
\text { n }\end{array}$ & $\begin{array}{c}\text { Txn } \\
\text { Rate } \\
\text { Overall }\end{array}$ \\
\hline $\begin{array}{l}\text { South } \\
\text { Manchester }\end{array}$ & 78.5 & 2 & $3.1 \%$ & 74.4 & 12 & $14.5 \%$ & 75.0 & 14 & $9.5 \%$ \\
\hline $\begin{array}{l}\text { Royal } \\
\text { Cornwall } \\
\text { Hospitals }\end{array}$ & 44.0 & 1 & $1.2 \%$ & 75.1 & 12 & $9.2 \%$ & 72.7 & 13 & $6.1 \%$ \\
\hline $\begin{array}{l}\text { Spec Orth } \\
\text { Centre }\end{array}$ & 75.8 & 5 & $9.3 \%$ & 73.0 & 18 & $21.7 \%$ & 73.6 & 23 & $16.8 \%$ \\
\hline Total & $\mathbf{7 2 . 5}$ & $\mathbf{8}$ & $\mathbf{4 . 0 \%}$ & $\mathbf{7 4 . 0}$ & $\mathbf{4 2}$ & $\mathbf{1 4 . 1 \%}$ & $\mathbf{7 3 . 8}$ & $\mathbf{5 0}$ & $\mathbf{1 0 . 0 \%}$ \\
\hline
\end{tabular}

The proportion of males who have had an allogeneic blood transfusion is very low. Little or no conclusions could be drawn on whether cell salvage and a reinfusion had an impact on the sole male patient at the Royal Cornwall Hospitals (patient R148 who was in hospital for 11 days and was identified to the lower HRG classification of $\mathrm{HB} 12 \mathrm{C})$. The other two centres' allogeneic transfusion rates were also significantly lower in the male category. The question could therefore be asked that, given there is low likelihood of an allogeneic transfusion, should the Royal Cornwall Hospitals salvage male total hip replacement patients?

The reinfusion rate by gender was extracted. Out of the 180 patients salvaged $68 \%$ of males were reinfused against $52 \%$ of females being reinfused. Given males have a lower likelihood of requiring an allogeneic transfusion it logically follows that their blood is more suitable for reinfusing (see para 1.13 for the 'smoothie' interpretation). A Chi-square test for independence (with Yates' continuity correction) indicated that there was a significant association between gender and reinfusion $(p=.046)$.

Patient Blood Management, PBM, initiatives recommend the administration of allogeneic blood in separate single units with an assessment of the patient's condition 
and $\mathrm{Hb}$ levels before a second or subsequent allogeneic unit is administered. This has not been recorded in the data gathered. This omission may have had an impact on the overall allogeneic blood usage if this more restrictive procedure was adopted. The breakdown of the 50 patients who had an allogeneic transfusion is shown in table 59 below:

Table 59. Analysis of Number of Units Transfused

\begin{tabular}{|c|c|c|c|c|c|}
\hline $\begin{array}{l}\text { Indicator } \\
\text { UHospital }\end{array}$ & $\begin{array}{l}\text { Patients } \\
\text { Having } 1 \text { Unit } \\
\text { Transfused }\end{array}$ & $\begin{array}{l}\text { Patients } \\
\text { Having } 2 \\
\text { Units } \\
\text { Transfused }\end{array}$ & $\begin{array}{l}\text { Patients } \\
\text { Having >2 } \\
\text { Units } \\
\text { Transfused }\end{array}$ & $\begin{array}{l}\text { Total Units } \\
\text { Transfused }\end{array}$ & $\begin{array}{c}\text { Total } \\
\text { Patients }\end{array}$ \\
\hline South Manchester & 1 & 13 & 0 & 27 & 14 \\
\hline $\begin{array}{l}\text { Royal Cornwall } \\
\text { Hospitals }\end{array}$ & 1 & 11 & 1 & 26 & 13 \\
\hline Spec Orth Centre & 3 & 18 & 2 & 47 & 23 \\
\hline Total & 5 & 42 & 3 & 100 & 50 \\
\hline
\end{tabular}

The indication from table 59 is that the PBM assertion of a 'habitual' level of two units being transfused happens regularly. The 2014 National PBM Report recommended to only transfuse one allogeneic unit at a time to non-bleeding patients. Following this transfusion, the patient would be clinically reassessed to determine whether an additional unit would be required. It is likely that a number of the units were administered together but this cannot be verified.

The split of intra-operative and post-operative allogeneic blood transfusions is not available. As highlighted in para $1.960 \%$ of allogeneic blood transfusions are administered post-operatively (Thomas et al (2005)). Intra-operative allogeneic blood transfusions are mainly administered where there is significant blood loss. For table 59 above it is therefore reasonable to expect that significant blood loss has happened to only three patients (one patient at the Royal Cornwall Hospitals and two patients at the SOC each received three allogeneic units). The vast majority of patients were therefore highly unlikely to have required emergency allogeneic blood transfusions. The decision to administer an allogeneic transfusion was therefore one of judgement by the clinician on the ward and not in an emergency setting. 


\subsection{Financial Impact of Cell Salvage at Royal Cornwall Hospitals NHS Trust}

Cell salvage has been utilised since the late 1990's at the Royal Cornwall Hospitals Trust and currently the majority of primary hip operations have shed blood salvaged. During the analysis period (late 2010) this was not the case with 33 patients out of the 213 patients $(15.4 \%)$ not salvaged, primarily due to lack of suitably trained staff being available. These patients were identified separately, and the analysis of cell salvage results can be undertaken on the patients that were actually salvaged. Two types of cell salvage machine were utilised at the Trust for intraoperative cell salvage and post-operative cell salvage. The machines can only be used for one patient at a time and either type is suitable for salvaging a primary hip operation. The available machines at the time were:

- Sorin Electa-Intraoperative cell salvage.

- Haemonetics OrthoPat-Post-operative cell salvage.

The Trust's orthopaedic service is delivered from two centres, the Royal Cornwall Hospital in Truro and St Michael's Hospital, near St Erth 18 miles further to the south west of Truro. The breakdown of the activity is shown in table 60 below.

Table 60. Operations by Site and Salvage Machine

\begin{tabular}{|c|c|c|c|}
\hline $\begin{array}{l}\text { Hospital: } \\
\text { Machine Type }\end{array}$ & $\begin{array}{c}\text { Royal Cornwall } \\
\text { Hospital }\end{array}$ & $\begin{array}{c}\text { St Michael's } \\
\text { Hospital }\end{array}$ & Total \\
\hline Electa & 23 & 53 & 76 \\
\hline OrthoPat & 29 & 75 & 104 \\
\hline None & 16 & 17 & 33 \\
\hline Total & 68 & 145 & 213 \\
\hline
\end{tabular}

Tables 61 and 62 further analyse the cell salvage activity by HRG/salvage machine utilisation and gender

Table 61. Number of Royal Cornwall Patients' Data Collected

\begin{tabular}{|l|r|r|r|r|}
\hline $\begin{array}{l}\text { Machine Type: } \\
\text { lHRG }\end{array}$ & Electa & \multicolumn{1}{c|}{ OrthoPat } & $\begin{array}{c}\text { Not } \\
\text { Salvaged }\end{array}$ & \multicolumn{1}{l|}{ Total } \\
\hline HB12B & 41 & 70 & 26 & 137 \\
\hline HB12C & 25 & 23 & 6 & 54 \\
\hline Other & 10 & 11 & 1 & 22 \\
\hline Total & 76 & 104 & 33 & 213 \\
\hline Male & 25 & 41 & 16 & 82 \\
\hline Female & 51 & 63 & 17 & 131 \\
\hline Total & 76 & 104 & 33 & 213 \\
\hline
\end{tabular}


To calculate the direct costs of the salvage operations the 33 patients who were not salvaged noted in table 61 above can be excluded and the comparison made between the patients who were salvaged, reinfused (where sufficient blood was recovered) and, where occurring, an allogeneic transfusion was administered, and the number of units given.

The Electa and OrthoPat activity can be sub-divided into those patients salvaged and those where the salvaged blood was subsequently reinfused. This is shown in table 62 below.

Table 62. Number of Royal Cornwall Patients Reinfused after Being Salvaged

\begin{tabular}{|l|r|r|r|}
\hline $\begin{array}{l}\text { Machine Type: } \\
\text { UHRG }\end{array}$ & Electa & OrthoPat & \multicolumn{1}{c|}{ Total } \\
\hline HB12B & 17 & 47 & 64 \\
\hline HB12C & 8 & 18 & 26 \\
\hline Other & 4 & 10 & 14 \\
\hline Total & 29 & 75 & 104 \\
\hline Proportion Reinfused & $38.2 \%$ & $72.1 \%$ & $57.8 \%$ \\
\hline
\end{tabular}

The rate of Electa salvaging is lower. This is due to the Electa having a 'collect first' reinfusion option where, if the salvaged blood is deemed not suitable for reinfusion (see para 4.7), then the salvaging can be discontinued and the costs of some of the consumables avoided. This option is not available with the OrthoPat machine and there is therefore a tendency to continue salvaging as all the costs have already been incurred.

With both types of machine, the key priority for their use is to, as far as possible, avoid the need to utilise allogeneic blood. Table 64 below works up the direct costs associated with utilising the two types of cell salvage machines. The costs are based on actual supplier charges with estimates for the electricity usage. Maintenance expenditure, approximately $£ 1,000$ per machine, are estimated based on the proportion of primary total hip replacement operations as a ratio of the total orthopaedic operations. The calculation deriving a maintenance cost of $£ 1,260$ ( $£ 126$ $\mathrm{x} 10$ machines) is shown in Table 63 below: 
Table 63. Extraction of Primary Hip Element of Cell Salvage Costs

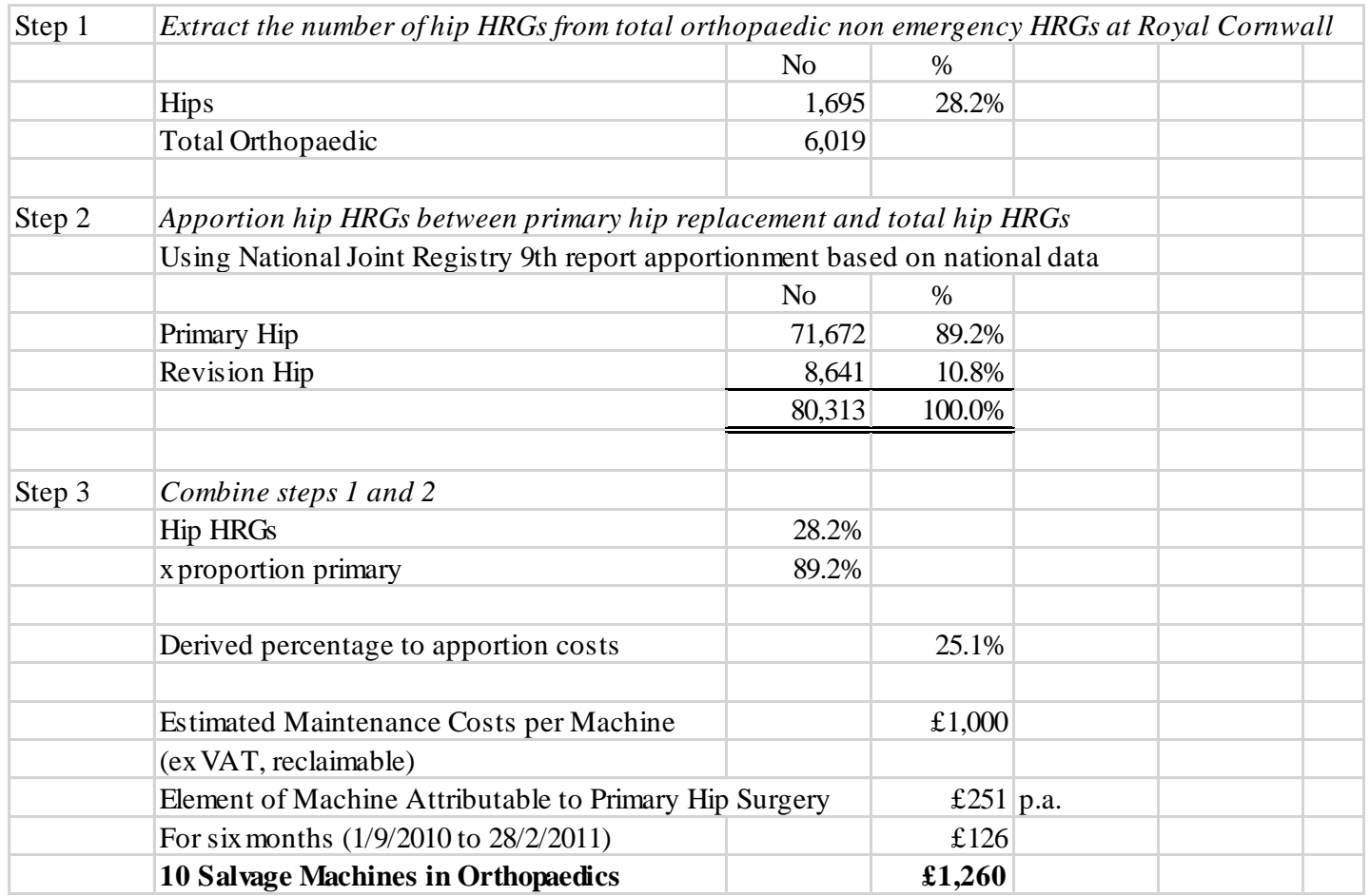

The data can identify the number of allogeneic blood transfusions by machine type. Utilising the $£ 122$ charge from NHSBT will generate a total blood (allogeneic and salvaged) cost for each machine type.

Table 64.Total Allogeneic and Salvaged Blood Costs Including VAT and Transfer Prices

\begin{tabular}{|c|c|c|c|c|c|}
\hline & Electa & OrthoPat & $\begin{array}{c}\text { No } \\
\text { Salvage }\end{array}$ & Total & Basis of Cost \\
\hline No of Patients: & 76 & 104 & 33 & 213 & Table 60 \\
\hline Element: & $£$ & $£$ & $£$ & $£$ & \\
\hline Collection & 1,730 & - & - & 1,730 & Supplier charge inc discounts \\
\hline Processing & 1,297 & - & - & 1,297 & $\begin{array}{l}\text { Supplier charge inc discounts- } \\
\text { note reinfusion elements only }\end{array}$ \\
\hline Combined Kit & - & 16,120 & - & 16,120 & Supplier charge inc discounts \\
\hline OrthoPAT Lines & - & 1,546 & - & 1,546 & Supplier charge inc discounts \\
\hline Heparin and Saline & 1,930 & 2,642 & - & 4,572 & NHS framework charges \\
\hline Electricity & 11 & 24 & - & 35 & $\begin{array}{l}0.8 \mathrm{KwH} .2 .5 \text { hrs Electa, } 4 \mathrm{hrs} \\
\text { OrthoPat } 7.03 \mathrm{p} \text { per KwH inc } \\
\text { climate change levy }\end{array}$ \\
\hline Maintenance & 532 & 728 & - & 1,260 & $\begin{array}{l}\text { From table } 63 \text {, apportioned in } \\
\text { ratio of table } 60 \text { (ex vat) }\end{array}$ \\
\hline Depreciation & 798 & 1,092 & & 1,890 & Table69@ six months \\
\hline Operating Cost & 6,298 & 22,152 & & 28,450 & \\
\hline $\begin{array}{l}\text { Allogeneic Units } \\
\text { Utilised }\end{array}$ & 11 & 9 & 6 & 26 & Table 67 \\
\hline $\begin{array}{l}\text { Allogeneic Blood Cost } \\
£ 122 \text { per unit }\end{array}$ & 1,342 & 1,098 & 732 & 3,172 & $\begin{array}{l}\text { Table } 67 \text { NHSBT charge } \\
\text { including transfer prices }\end{array}$ \\
\hline
\end{tabular}




\begin{tabular}{|c|c|c|c|c|c|}
\hline & Electa & OrthoPat & $\begin{array}{c}\text { No } \\
\text { Salvage }\end{array}$ & Total & Basis of Cost \\
\hline $\begin{array}{l}\text { Total Allogeneic } \\
\text { Blood/Cell Salvage } \\
\text { Costs }\end{array}$ & 7,640 & 23,250 & 732 & 31,622 & \\
\hline $\begin{array}{l}\text { Mean Blood Cost Per } \\
\text { Patient }\end{array}$ & $£ 101$ & $£ 224$ & $£ 22$ & $£ 148$ & $\begin{array}{l}\text { Total cost divided by number } \\
\text { of operations }\end{array}$ \\
\hline $\begin{array}{l}\text { Mean Cell Salvage } \\
\text { Cost Per Operation }\end{array}$ & $£ 83$ & $£ 213$ & & $£ 134$ & $\begin{array}{l}\text { Operating cost divided by } \\
\text { number of operations }\end{array}$ \\
\hline
\end{tabular}

The unit costs were derived from a combination of supplier charges and estimates for the electricity and the maintenance costs. These are shown in table 65 below:

Table 65.Running Cost Estimates for Cell Salvage Machines Utilised for Primary Total Hip Replacement Surgery

\begin{tabular}{|c|c|c|c|}
\hline & \multicolumn{2}{|c|}{ Unit Costs } & Basis of Calculation \\
\hline & Electa & OrthoPat & \\
\hline & $£$ & $£$ & \\
\hline Collection Reservoir & 22.76 & & Supplier charges including discounts over total \\
\hline Processing Kit & 44.72 & 155.00 & range of activity for other procedures and \\
\hline Suction Line & & 8.50 & specialties \\
\hline Post-Op Line & & 6.37 & \\
\hline Heparin & 21.20 & 21.20 & NHS framework charge \\
\hline Saline & 4.20 & 4.20 & NHS framework charge \\
\hline Electricity & 0.17 & 0.28 & $\begin{array}{l}0.8 \mathrm{KwH} \times 7.03 \mathrm{p} \text { per KwH @ } 2.5 \text { hours (Electa) and } \\
4 \text { hours (OrthoPat) }\end{array}$ \\
\hline Maintenance & $£ 7$ & $£ 7$ & $\begin{array}{l}\text { Used HRGs to apportion c. } £ 1,000 \text { per machine per } \\
\text { annum over usage on primary total hip } \\
\text { replacements. }\end{array}$ \\
\hline
\end{tabular}

Note: No totalling due to Electa processing kits being dependent on adequate level of shed blood collected. VAT included, where not reclaimable

Though average costs have been criticised (paras 1.18 and 2.3) they can provide an indicator of where the calculated blood/cell salvage costs are distributed. Table 66 below apportions the $£ 31,622$ ( $£ 28,450$ cell salvage cost plus $£ 3,172$ allogeneic blood cost) over the age/gender groups and generates an average blood cost for each group.

Table 66. Average Blood Cost by Patient/Gender Group

\begin{tabular}{|l|r|r|r|r|}
\hline & \multicolumn{1}{|c|}{ Electa } & \multicolumn{1}{|c|}{ OrthoPat } & \multicolumn{1}{|c|}{ No Salvage } & \multicolumn{1}{|c|}{ Total } \\
\hline Numbers of Patients: & & & 7 & 32 \\
\hline Male under 65 & 10 & 26 & 9 & 50 \\
\hline Male over 65 & 15 & 18 & 4 & 45 \\
\hline Female under 65 & 23 & 45 & 13 & 86 \\
\hline Female over 65 & 28 & 104 & 33 & 213 \\
\hline & 76 & & & \\
\hline $\begin{array}{l}\text { Average Cost Salvage } \\
\text { only }\end{array}$ & & & - & $£ 4,024$ \\
\hline Male under 65 & $£ 829$ & $£ 3,195$ & - & $£ 6,781$ \\
\hline Male over 65 & $£ 1,243$ & $£ 5,538$ & & \\
\hline
\end{tabular}




\begin{tabular}{|l|r|r|r|r|}
\hline & \multicolumn{1}{|c|}{ Electa } & \multicolumn{1}{c|}{ OrthoPat } & No Salvage & \multicolumn{1}{c|}{ Total } \\
\hline Female under 65 & $£ 1,906$ & $£ 3,834$ & - & $£ 5,740$ \\
\hline Female over 65 & $£ 2,320$ & $£ 9,585$ & - & $£ 11,905$ \\
\hline \multicolumn{1}{|c|}{ Sub total } & $£ 6,298$ & $£ 22,152$ & - & $£ 28,450$ \\
\hline Average Salvage Cost & $£ 83$ & $£ 213$ & - & $£ 158$ \\
\hline $\begin{array}{l}\text { Average Cost Salvage } \\
\text { plus Allogeneic Blood }\end{array}$ & & & & \\
\hline Male under 65 & $£ 951$ & $£ 3,195$ & - & $£ 4,146$ \\
\hline Male over 65 & $£ 2,150$ & $£ 5,538$ & - & $£ 6,781$ \\
\hline Female under 65 & $£ 3,296$ & $£ 10,683$ & - & $£ 5,984$ \\
\hline Female over 65 & $£ 7,640$ & $£ 23,250$ & $£ 732$ & $£ 14,711$ \\
\hline Total Blood Costs & & & $£ 31,622$ \\
\hline
\end{tabular}

Crudely the average cost of salvaging a patient is $£ 28,450 / 180$ which is c. $£ 158$ per patient (broken down over $£ 83$ for a patient being salvaged via an Electa machine against $£ 213$ per patient utilising the OrthoPat). The unit cell salvage operating cost (£158) divided by the $£ 122$ charge for an allogeneic unit implies, on average, 1.3 units of allogeneic blood need to be avoided in each operation. Given the transfusion rate is only $6.1 \%$ the implication is that cell salvage is a very costly way of avoiding a small number of allogeneic transfusions.

Table 67 below derives the simple average costs of blood (both salvaged and allogeneic) per operation for the three Trusts being considered. It subdivides the Royal Cornwall Hospital patients into those that were salvaged and those that were not.

Table 67. Comparison of Average Blood Costs per Operation $(n=498)$

\begin{tabular}{|c|c|c|c|c|}
\hline & $\begin{array}{c}\text { South } \\
\text { Manchester }\end{array}$ & $\begin{array}{c}\text { Royal } \\
\text { Cornwall } \\
\text { without Cell } \\
\text { Salvage }\end{array}$ & $\begin{array}{c}\text { Spec } \\
\text { Orthopaedic } \\
\text { Centre }\end{array}$ & $\begin{array}{c}\text { Royal } \\
\text { Cornwall } \\
\text { with Cell } \\
\text { Salvage }\end{array}$ \\
\hline $\begin{array}{l}\text { Number of Allogeneic } \\
\text { Units }\end{array}$ & 27 & 6 & 47 & 20 \\
\hline $\begin{array}{l}\text { Allogeneic Blood Cost } \\
\text { (£122 per unit) }\end{array}$ & $£ 3,294$ & $£ 732$ & $£ 5,734$ & $£ 2,440$ \\
\hline $\begin{array}{l}\text { Cell Salvage Cost (table } \\
\text { 64) }\end{array}$ & - & - & - & $£ 28,450$ \\
\hline Sub Total & $£ 3,294$ & $£ 732$ & $£ 5,734$ & $£ 30,890$ \\
\hline Number of Operations & 148 & 33 & 137 & 180 \\
\hline $\begin{array}{l}\text { Cost of allogeneic /salvaged } \\
\text { blood per patient }\end{array}$ & $£ 22.25$ & $£ 22.18$ & $£ 41.85$ & $£ 171.61$ \\
\hline $\begin{array}{r}\text { Allogeneic Transfusion } \\
\text { Rate }\end{array}$ & $9.5 \%$ & $9.1 \%$ & $16.8 \%$ & $5.6 \%$ \\
\hline
\end{tabular}


From a financial perspective, the Royal Cornwall Hospital cell salvage programme results in a c. $£ 149$ higher average blood cost (allogeneic blood plus salvaged blood costs) than South Manchester (£171.61 - £22.25). There are some differences in the pre-operative $\mathrm{Hb}$ levels of patients presenting for operation (para 6.3); the outputs are similar, so the focus should be on the benefits of cell salvage. This will be discussed in chapter 7. Additionally, the higher transfusion rate at the Specialist Orthopaedic Centre almost doubles the allogeneic blood costs but again this cost is very small compared to the overall Royal Cornwall Hospital combined blood costs. Arguably the costs of the operation of cell salvage are understated given factors such as training costs and the capital costs of the cell salvage machines are not included in the comparison. These would all contribute to a higher overhead cost; however, these costs are mainly sunk costs i.e. the costs have already been incurred and therefore not part of ongoing decision making.

The key challenge is attempting to isolate the contribution made by cell salvage. This was highlighted in para 1.13. Based on the costs in table 67 the isolated cell salvage costs seem prohibitive in the pursuit of trying to avoid a potentially small volume of allogeneic blood.

Further analysis was undertaken following the publication of the article by Dusik et al (2014) (para 3.3) to generate a comparison between the two types of machines used. An extract is shown in table 68 below where the data relating to five patients who received an allogeneic transfusion was extracted.

Table 68. Summary of Allogeneic Transfused Patients with Cell Salvage/Without Reinfusions

\begin{tabular}{|c|c|c|c|c|c|r|r|c|}
\hline & \multicolumn{5}{|c|}{ Electa } & \multicolumn{4}{c|}{ OrthoPat } \\
\hline & $\begin{array}{c}\text { Number } \\
\text { of } \\
\text { Patients }\end{array}$ & $\begin{array}{c}\text { Mean } \\
\text { Age }\end{array}$ & $\begin{array}{c}\text { Mean } \\
\text { Average of } \\
\text { Pre_Op_Hb }\end{array}$ & $\begin{array}{c}\text { Lowest } \\
\text { Post } \\
\text { Op Hb }\end{array}$ & $\begin{array}{c}\text { Number } \\
\text { of } \\
\text { Patients }\end{array}$ & $\begin{array}{c}\text { Mean } \\
\text { Age }\end{array}$ & $\begin{array}{c}\text { Average of } \\
\text { Pre_Op_Hb }\end{array}$ & $\begin{array}{c}\text { Lowest } \\
\text { Post } \\
\text { Op Hb }\end{array}$ \\
\hline HB12B & 4 & 77.5 & 132.8 & 75.0 & 1 & 78.0 & 123.0 & 60.0 \\
\hline
\end{tabular}

The patients, all five of whom were female, were sufficiently prepared for surgery; all having pre-operative $\mathrm{Hb}$ levels over the WHO guidelines of $120 \mathrm{~g} / \mathrm{l}$. The allogeneic transfusion would have been administered in response to the postoperative $\mathrm{Hb}$ reading being low. The decision not to reinfuse would have been taken by reference to clinical judgement for the Electa patients and it would be likely that 
the blood volume collected was too small for the OrthoPat patient to bother reinfusing. This approach will be discussed further in the next chapter but, statistically, the sample sizes are too small to facilitate a comparison between the two types of cell salvage machine without reinfusions.

\subsection{Comparison of Costs of Salvaging Male Patients}

As highlighted in table 68 only 1 male patient received an allogeneic transfusion. Approximately $£ 10,900(£ 4,146+£ 6,781)$ was incurred in salvaging male patients. A simple breakeven analysis indicates that c. 89 allogeneic units $(£ 10,900 / £ 122$ per allogeneic unit) would need to be avoided to cover the costs of operating cell salvage on male patients. Given there are 82 male patients this logic would assume that, on average, salvaging a male patient would always avoid an allogeneic blood transfusion. The relatively low rates of male allogeneic blood transfusions at both South Manchester and the Specialist Orthopaedic Centre, obviously without utilising cell salvage, would imply that 89 allogeneic units being avoided is not realistic.

\subsection{Treatment of Depreciation and Opportunity Cost}

Para 2.7 highlighted that the treatment of capital expenditure is similar from both a financial and economic perspective. The main conceptual differences in this analysis are that VAT will be included in the calculations in a financial analysis with this being excluded in the economic approach. Additionally, an economic approach would require the calculations to be discounted to reflect the opportunity cost of investing in the resource. The Treasury discount rate of $3.5 \%$ was used in the calculations in table 69 below. 
Table 69. Comparison of Discounted Capital Costs

\begin{tabular}{|c|c|c|c|c|c|c|c|c|c|c|}
\hline \multicolumn{11}{|l|}{ Economic Approach } \\
\hline Acquisition cost (10 machines) & & $£ 125,000$ & ex VAT & & & & & & & \\
\hline \multicolumn{11}{|l|}{ zero residual value } \\
\hline Year: & 1 & 2 & 3 & 4 & 5 & 6 & 7 & 8 & 9 & 10 \\
\hline Depreciation & 12,500 & 12,500 & 12,500 & 12,500 & 12,500 & 12,500 & 12,500 & 12,500 & 12,500 & 12,500 \\
\hline Undepreciated balance & 125,000 & 112,500 & 100,000 & 87,500 & 75,000 & 62,500 & 50,000 & 37,500 & 25,000 & 12,500 \\
\hline Opportunity cost $(3.5 \%)$ & 4,375 & 3,938 & 3,500 & 3,063 & 2,625 & 2,188 & 1,750 & 1,313 & 875 & 438 \\
\hline Dep + opp cost & 16,875 & 16,438 & 16,000 & 15,563 & 15,125 & 14,688 & 14,250 & 13,813 & 13,375 & 12,938 \\
\hline Discount factor & 0.966 & 0.934 & 0.902 & 0.871 & 0.842 & 0.814 & 0.786 & 0.759 & 0.734 & 0.709 \\
\hline Present Value & 16,304 & 15,345 & 14,431 & 13,562 & 12,735 & 11,948 & 11,200 & 10,489 & 9,814 & 9,172 \\
\hline Total NPV & 125,000 & & & & & & & & & \\
\hline \multicolumn{4}{|c|}{ Equivalent Annual Cost (EAC) factor $3.5 \%$ over 10 years $=$} & 8.3166 & & & & & & \\
\hline & & \multicolumn{2}{|c|}{ EAC per year } & $£ 15,030$ & & & & & & \\
\hline \multicolumn{4}{|c|}{ At $25.1 \%$ for primary total hip replacement operations $=$} & $£ 3,777$ & & & & & & \\
\hline & & & & & & & & & & \\
\hline \multicolumn{11}{|l|}{ Financial Approach } \\
\hline Acquisition cost (10 machines) & & $£ 150,000$ & inc VAT & & & & & & & \\
\hline Year: & 1 & 2 & 3 & 4 & 5 & 6 & 7 & 8 & 9 & 10 \\
\hline Depreciation & 15,000 & 15,000 & 15,000 & 15,000 & 15,000 & 15,000 & 15,000 & 15,000 & 15,000 & 15,000 \\
\hline Undepreciated balance & 135,000 & 120,000 & 105,000 & 90,000 & 75,000 & 60,000 & 45,000 & 30,000 & 15,000 & 0 \\
\hline \multicolumn{4}{|c|}{ At $25.1 \%$ for primary total hip replacement operations $=$} & $£ 3,770$ & & & & & & \\
\hline
\end{tabular}

There appears to be little difference between the derived costs from both approaches however this is mainly a product of the differing treatment of VAT. It is assumed there will be no residual value following the disposal of the machines after a ten-year period. From both perspectives, however, the analysis has extracted a $25.1 \%$ apportionment of the machine costs for primary total hip replacement calculations. This is not realistic as the individual machines are utilised across all the specialties and these fixed costs will still be borne by the hospital over the lifetime of the equipment. These costs are not therefore divisible in order to apportion to a particular operation or specialty. The corresponding differences utilising a discount factor of $3 \%$ and $4 \%$ give differences ranging from $-£ 87$ to $+£ 103$ respectively. These differences are not material and the capital costs of the cell salvage equipment would not therefore influence the overall comparison between the financial and economic costs in order to answer the research question.

\subsection{Costs and Income at NHS Blood and Transplant}

The overall operation of NHSBT in 2010/11 cost approximately $£ 420 \mathrm{~m}$. NHSBT’s role includes the provision of blood and specialist haematological products along with operating the UK wide organ donation and transplant service. Table 70 below summarises the position extracted from the 2010/11 published audited accounts: 
Table 70. NHSBT Income \& Expenditure from Published 2010/11 Audited Accounts

\begin{tabular}{|c|c|c|c|}
\hline & $\begin{array}{c}\text { Sales } \\
\text { Income } \\
\text { fm } \\
\end{array}$ & $\begin{array}{c}\text { Revenue } \\
\text { Grant in } \\
\text { Aid fm }\end{array}$ & $\begin{array}{c}\text { Total } \\
\mathbf{f m}\end{array}$ \\
\hline \multicolumn{4}{|l|}{ Income: } \\
\hline Blood Components & 304 & 4 & 308 \\
\hline Specialist Services & 45 & 4 & 49 \\
\hline Organ Donation \& Transplant & 7 & 55 & 62 \\
\hline Group Services & 12 & 3 & 15 \\
\hline Total Income & 368 & 66 & 434 \\
\hline Total Expenditure & & & 420 \\
\hline 2010/11 Operating Surplus & & & 14 \\
\hline
\end{tabular}

Source: Analysis of 2010/11 NHSBT Annual Report and Accounts

Red cell issues are responsible for $£ 224 \mathrm{~m}$ of the $£ 304 \mathrm{~m}$ of income from the sale of blood components $(1,838,000$ units issued at $£ 122$ per unit). Platelet issues account for c. $£ 55 \mathrm{~m}$ with the remainder being specialist component products and other services provided. Red cell issues therefore account for c. $74 \%$ of all blood component income.

NHSBT utilises an activity-based costing $(\mathrm{ABC})$ system to report on its costs (para 5.8). There are discrete cost drivers and a suitably aligned general ledger coding structure to capture NHSBT costs to categories. Table 71 below summarises the breakdown of the costs incurred by NHSBT.

Table 71. Analysis of the Cost Breakdown of an Allogeneic Unit of Blood

\begin{tabular}{|l|r|l|}
\hline ABC Cost Element & \multicolumn{1}{|l|}{$\begin{array}{l}\text { Unit } \\
\text { Price } \mathfrak{E}\end{array}$} & Examples \\
\hline Source Donors & 11 & $\begin{array}{l}\text { Marketing/Advertising; recruitment \& retention costs, } \\
\text { database management }\end{array}$ \\
\hline $\begin{array}{l}\text { Blood Collection-fixed } \\
\text { elements }\end{array}$ & 30 & $\begin{array}{l}\text { Costs include staff, equipment, location hire, team base } \\
\text { costs, medical, transport }\end{array}$ \\
\hline $\begin{array}{l}\text { Blood Collection-variable } \\
\text { elements }\end{array}$ & 18 & Blood collection bags, test kits and other consumable costs \\
\hline Processing & 12 & Costs of separating whole blood into constituent elements \\
\hline Testing & 14 & Testing for specific disease types \\
\hline $\begin{array}{l}\text { Order Processing, Storage and } \\
\text { Dispatch }\end{array}$ & 6 & Receipt of orders from hospitals, picking and packing \\
\hline Distribution & 4 & Delivery to customers \\
\hline Sub Total-Allocated Costs & 95 & \\
\hline Current Cost/Transfer Price & $\mathbf{1 2 2}$ & \\
\hline Contribution to Overheads & $\mathbf{2 7}$ & $\begin{array}{l}\text { Finance, Payroll, HR, Public Affairs, Chief Executive, IT, } \\
\text { Customer Services, Estates (including building depreciation) }\end{array}$ \\
\hline
\end{tabular}

Source: Information provided by NHSBT Finance Nov 2012; extract from Board paper 
A key feature of the table is the relatively low level of variable costs (£18). The balance, $£ 104$, in the short to medium term is relatively fixed. For example, the NHSBT estate is either owned or is utilised under a long-term lease. To remove these costs from the NHSBT cost base requires complex long-term negotiations to dispose of the estate. Both the Southampton and Oxford buildings were re-profiled when the majority of services were transferred out with the respective local hospital taking over the estate. Over the past 10 years NHSBT has steadily consolidated its operations on fewer sites and centralised its blood processing and testing services in Bristol, Manchester and Colindale in North London.

The above cost profile can be contrasted with the cost profile of cell salvage at the hospital level where costs of consumables and allogeneic blood are viewed as variable costs. This can be viewed as a variation on the theme of 'goal congruence' that Horngren et al (2015) describe as where "individuals and groups work towards achieving the organisation's goals". There are different views on what the 'organisation' is comprised of. This could be interpreted as the overall NHS allogeneic blood usage down to the individual hospital department that receives an internal charge for allogeneic blood use. In the short term these goals will vary from a financial perspective (table 8 para 2.2) however, over time and, with an annual review of the blood charge (effectively the transfer price, para 1.23), the aim of achieving an optimal volume of allogeneic blood to be collected by NHSBT can be developed.

\subsection{Summary of Financial Analysis}

The above analysis is based on a financial analysis of the costs and income associated within the relevant 'business units' in the NHS. It follows the similar pattern of most previous studies. The costs include:

- Transfer payments, such as VAT and employers' national insurance contributions.

- The internal transfer payment of $£ 122$ per unit of allogeneic blood, which also includes elements of VAT and employers' national insurance.

- Elements such as depreciation of the NHSBT properties and equipment are also included in the $£ 122$ charge. 
The analysis uses basic average (unit) costs to make a comparison. Horngren et al (2015) advise to use average costs "cautiously". Given a unit of allogeneic blood is a homogenous product it is accepted through the NHS that the one national charge of $£ 122$ (reviewed annually) is a fair reflection of the aggregated costs across NHSBT. For the cell salvage costs the majority of these are based on actual prices (including VAT). These prices were unchanged through the base period in financial year 2010/11. Costs of cell salvage consumables and allogeneic blood costs are viewed as variable costs at hospital level whereas, at NHSBT, most costs are viewed as fixed in the short term.

The next section will review the associated societal (also referred to as 'social cost') costs from an economic, rather than financial, angle.

\subsection{Development of Donor/Societal Costs Associated with Blood Donation}

The questionnaire (para 5.8 on page 135) was, in part, designed to estimate the costs incurred by the donor attending a donation session, in order to obtain a holistic view of the costs associated with a transfusion. The assertion was that, all other things being equal, an expansion in cell salvage would therefore reduce the demand for allogeneic blood and therefore make more time available for a donor to do something other than give blood. The questions/responses are shown in appendix 8 with a summary of the main conclusions grouped below; where relevant a comparison is made against the Varney \& Guest (2003) findings:

Donors' altruistic views (questions 1-5). The answers to these series of questions was very positive and attracted the highest response rates. The number of respondents was high, and the level of altruistic views was apparent through the responses. Question 4 highlighted that over $88 \%$ of donors would "definitely" give blood in the future and question 5 elicited that over $90 \%$ of respondents felt "giving blood is very important to me". Comments from NHSBT staff noted that many donors made the point at donation sessions that giving blood was part of their civic duty. This was consistent with the claim in the Economist (para 1.8) that "Blood donors are stalwarts of the voluntary sector". 
Donors' travel (questions 6-8). Travel time was virtually unchanged from the 2003 findings for donors with a high (53\%) rate of single car occupancy journeys to/from the donation session.

Employment/Earnings/Leisure (questions 9-12). 63\% of donors were in paid employment with only a low proportion of donors having pay deducted from their employer for taking time off to give blood. Given the increased opening times and pre-booking availability of donation at sessions it is also more likely that donors will give blood in their leisure time than requiring time off work.

Actual Donor Costs Incurred (question 13). Donors highlighted the costs of parking and travel to/from the donation session. The cost of fuel, especially, was flagged by a high proportion (36\%) of the respondents. 
Table 72. Comparison of 2003 and 2013 Questionnaire Results

\begin{tabular}{|c|c|c|}
\hline Issue & $\begin{array}{c}2003 \text { Varney \& Guest } \\
\text { Study }\end{array}$ & 2013 Questionnaire \\
\hline $\begin{array}{l}\text { Length of time to donate } \\
\text { (excludes travel time) }\end{array}$ & $\begin{array}{l}55 \text { mins (derived from } \\
\text { study) }\end{array}$ & 60 mins \\
\hline Lost Leisure time (000's hours) & 3,001 & 1,274 \\
\hline \multicolumn{3}{|l|}{ Altruistic Questions: } \\
\hline $\begin{array}{l}\text { Attendance and views on blood } \\
\text { donation }\end{array}$ & $\mathrm{n} / \mathrm{a}$ & $\begin{array}{l}\text { Highly satisfied 'customers' } \\
\text { and a feeling of making an } \\
\text { active contribution to } \\
\text { society }\end{array}$ \\
\hline \multicolumn{3}{|l|}{ Travel Questions: } \\
\hline Journey length by car (return) & 5.6 miles & $\begin{array}{l}\text { Calculation based on } 20 \\
\text { mph for } 10 \text { mins }=6.7 \text { miles }\end{array}$ \\
\hline $\begin{array}{l}\text { Mode of travel-Driving single } \\
\text { occupancy or car share }\end{array}$ & $52 \%$ & $53 \%$ \\
\hline $\mathrm{CO} 2$ emissions from cars? & Not calculated & c. 2,500 tonnes $\mathrm{CO} 2$ \\
\hline Other travel costs estimated? & Yes & Yes \\
\hline \multicolumn{3}{|l|}{$\begin{array}{l}\text { Employment/Earnings and } \\
\text { Leisure Questions }\end{array}$} \\
\hline Loss of Earnings? & $1 \%$ lost & $3.2 \%$ lost (Q13) \\
\hline Salary & $\begin{array}{l}\text { Donors asked which } \\
\text { salary bracket they fell } \\
\text { within. }\end{array}$ & $\begin{array}{l}\text { Used ONS final } 2013 \\
\text { median earnings } £ 11.59 \text { per } \\
\text { hour. }\end{array}$ \\
\hline Child care costs? & 0 & Negligible \\
\hline Percent in paid employment & $75 \%$ & $63 \%$ \\
\hline Percent lost productive time & $14 \%$ & $\begin{array}{l}(100 \%-49.5 \% \text { Q11 working }) \\
\mathrm{x} 69 \%(\mathrm{Q} 12)=34.8 \% \text { in } \\
\text { work and work time not } \\
\text { made time up }\end{array}$ \\
\hline Donors' costs & $\mathrm{n} / \mathrm{a}$ & $\begin{array}{llll}\begin{array}{l}\text { Average of } \\
\text { donation }\end{array} & £ 0.62 \text { per } \\
\end{array}$ \\
\hline
\end{tabular}

Table 72 above notes more similarities than differences. Varney and Guest's (2003) study was UK based for all blood components rather than the England and North Wales survey base of allogeneic blood donors for the 2013 questionnaire. Against a significantly higher level of donor collections the leisure time calculation is therefore not a valid comparison.

The only other noticeable difference is in the lost productive time estimate. This recalculation was based on an assessment of the responses to questions 11 and 12 . This difference may be reflective of an increased awareness of blood donations. High profile TV advertisements and more marketing compared to 2003 may influence the discussions on altruism and corporate social responsibility within employer groups, therefore allowing a more flexible employment policy. An article in the Health Service Journal (4 December 2006) quoted an NHS Networks poll that indicated $45 \%$ of NHS staff donated blood regularly. NHSBT do not keep records on donors' occupations or employers. This poll may point to the NHS being a large supplier of 
blood donors given the enthusiasm of NHS staff to give blood. A substantial proportion of the lost productivity costs may therefore be NHS staff related.

The detailed workings are shown in table 73 below. They are utilised primarily to generate estimates of donor transport costs and estimates of lost production and earnings and are based on the median hourly earnings paid in 2011. 
Table 73. Derivation of Donor Costs and Estimates of Lost Earnings and Production

Median Earnings ONS 2011 final results 2011

Website accessed on 4 April 2018

Percent of donors in paid employment

Pay deducted by employer $\mathrm{Y}$ ?

Pay deducted by employer $\mathrm{N}$ ?

N/A because in own time

Percent working having to make up time $\mathrm{Y}$ ?

Percent working having to make up time N?

$81 / 1161$ noted parking costs

172/1161 noted fuel costs

$£ 12.62$ per hour

Lost pay-use actual noted

Median journey duration (mins)

Driving

Car shared with other donor

Walk/Bike

Other

Driving MPH

Average emissions per $\mathrm{km} / \mathrm{Kg}$

No of Donations Collected

No of Units issued

Leisure time-1.33 hour per donation

How many drove?

Cost of fuel:

$20 \mathrm{mph}$ at 10 minutes each way

At 10 miles to litre of fuel $(45 \mathrm{mpg}$ )

@£1.30 per litre

Total fuel cost to donor

Less 60\% tax, excise duty and VAT

Cost of parking:

Less VAT on parking

Other public transport @ £2 for return

Total Donor Transport Cost

\begin{tabular}{|l|l|}
\hline \\
\hline \\
\hline
\end{tabular}

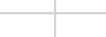

63.3\% Q9

2.6\% Q 11 Adjusted proportions

$49.5 \%$ Q $11 \quad$ See working

$47.9 \%$ Q 11

$31.0 \%$ Q 12

$69.0 \%$ Q 12

$7.0 \%$ Q 13

$14.8 \%$ Q 13

$3.20 \%$ Q 13

10

Each way so 20 mins or 0.33 of hour

$52.9 \%$ Q8

$9.6 \%$ Q8

$31.3 \%$ Q8

$6.2 \% \mathrm{Q} 8$

20

0.2

$1,933,854$

$1,838,000$

$1,231,979$ hours

$2010 / 11$ issues

Assume paid for own fuel, potential wear and tear on car not included

1,023,009 Drivers $\mathrm{x}$ donations

\subsection{7 miles}

0.67 litres

$£ 0.87$ per donor

$£ 886,608 \mathrm{NB}$ excise duty and VAT revenue flows back to government

$-£ 531,965 \quad £ 531,965$

$£ 71,373$ No of drivers x 7\% @ £1/hour parking cost, ex VAT, Q13

$£ 11,895 \quad £ 11,895$

$£ 653,918$

$£ 1,197,778$ total of fuel parking and other pub trans (gross)

Emissions convert miles to $\mathrm{km}$

Emissions tonnes $\mathrm{CO} 2$

$11,366,787$ Used 1.67 2,273

Lost earnings @ 1.33 hours

Lost production@1.33 hours

Total opportunity cost of lost prodn/earnings

Total Cost

$£ 657,316$

(
Divide by no of donations =

$£ 0.62$

\begin{tabular}{l|l|l}
$£ 14,173,366$ & Percent in paid empl x not having to make up lost time (69\%)
\end{tabular}

$£ 14,830,682$

Per unit of allogeneic blood issued

Ties to table 74

$£ 15,484,600$

$£ 8.42$ extax

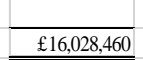

Both with and ex tax are relevant

Varney \& Guest (2003), pg 212. Total Donor Cost

Direct

Indirect

Red Cell element

"NBS" element 84\%

infl $2.5 \%$ p.a. from 2001 base period

Donation ratio

Donations Collected

Unit cost

Percentage increase

Tax on Fuel 60\% (VAT and excise duty)

Tax on parking (VAT)
$£$

$8,121,947$

$7,196,597$

$15,318,544$

$12,734,693$

$10,697,142$ pg 208 of V\&G

1.280

$£ 13,693,247$

2001/02 2010/11

$\begin{array}{ll}2,357,568 & 1,838,000\end{array}$

$£ 5.81 \quad £ 8.42$

$45.0 \%$

$£ 531,965$

$£ 11,895$

$£ 543,860$ /no of donations $2 \mathrm{~m}=$

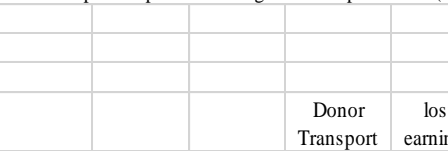

\begin{tabular}{|l|l|l|l} 
Transport & earnings & Total & Bal (check) \\
\hline
\end{tabular}

$£ 8.72$ inc tax Donor cost element inc tax

Donor cost element ex tax

\begin{tabular}{|l|l|l|}
\hline$£ 0.36$ & $£ 1.01$ & $£ 7.71$ \\
\hline$£ 0.36$ & $£ 0.71$ & $£ 7.71$ \\
\hline
\end{tabular}

$£ 0.36$

Cost prop 2003 study

\begin{tabular}{|l|l|l|}
\hline Red cells & 69 & $83.1 \%$ \\
\hline
\end{tabular}

$\begin{array}{llll}\text { Other } & 14 & 16.9 \%\end{array}$

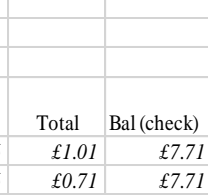

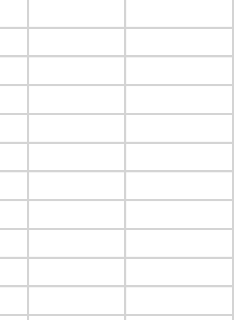


The total costs incurred by the donor and the derived societal costs are summarised in table 74 below:

Table 74. Estimated Total Donor/Societal Cost of a Unit of Allogeneic Blood Including Transfer Prices

\begin{tabular}{|l|r|r|}
\hline Category & \multicolumn{1}{|c|}{$\mathfrak{\prime}^{\prime} \mathbf{1 0 0}$} & \multicolumn{1}{c|}{ Unit $\mathfrak{}$} \\
\hline Donor transport (inc taxes) & 1,198 & 0.65 \\
\hline Societal Costs: & & \\
\hline Lost earnings (1.33 hours) & 657 & 0.36 \\
\hline Lost production (1.33 hours) & 14,173 & 7.71 \\
\hline Total & $\mathbf{1 6 , 0 2 8}$ & $\mathbf{8 . 7 2}$ \\
\hline Number of units issued (2010/11) & $1.838 \mathrm{~m}$ & \\
\hline Total Donor/Societal Cost per Unit Issued (inc VAT) & $\mathbf{£ 8 . 7 2}$ & \\
\hline
\end{tabular}

Note costs based on allogeneic units collected, total cost based on issues

The main aim of this analysis was to estimate avoidable costs relating to the donor in the event of a downturn in demand for allogeneic blood due to an expansion in cell salvage. It is beyond the scope of the thesis to assess whether the donor derives more benefit from his/her perceived altruistic action or freeing up a few pounds and an hour's leisure time every four to six months. The c. $£ 8.72$ unit cost figure is obviously an estimate, based on averages, but implies that a proportion of donor costs would be avoided if the demand for allogeneic blood were to decrease through an expansion in cell salvage.

A pertinent discussion point was that the calculations estimated the revenue to HMRC from the combined VAT and vehicle excise duty (VED) was approximately $£ 544 \mathrm{k}$. Though this is only a miniscule amount of tax revenue the principle that altruistic donors must pay additional tax to complete their donation seems hard to justify. The indicative VAT revenue on fuel/car parking for each blood donation is therefore estimated to be in the region of $28 \mathrm{p}$.

On a related note, the estimated vehicle emissions for donors driving to/from sessions were calculated at approximately 2,350 tonnes of $\mathrm{CO} 2$. These environmental costs may be unavoidable but again, would fall if there were an expansion in cell salvage use and a fall in the demand for allogeneic blood deeming fewer donor related journeys.

The calculated loss of leisure time has been assumed to be freely donated so the individual will derive benefit from their altruistic 'gift' and this is consistent with the 
high positive responses to question 3. This issue is beyond the scope of the thesis, but it can be argued that the donors are more than willing to incur costs as they derive more benefit from their altruism than the income lost.

Table 67 can therefore be restated to incorporate the donor costs in table 75 below:

Table 75. Derived Cost of Blood per Patient (Including Donor Costs and Transfer Prices)

\begin{tabular}{|c|c|c|c|c|}
\hline $\begin{array}{c}\text { Hospital } \\
\text { ICategory } \\
\end{array}$ & $\begin{array}{c}\text { South } \\
\text { Manchester }\end{array}$ & $\begin{array}{c}\text { Royal } \\
\text { Cornwall } \\
\text { without Cell } \\
\text { Salvage } \\
\end{array}$ & $\begin{array}{c}\text { Spec } \\
\text { Orthopaedic } \\
\text { Centre } \\
\end{array}$ & $\begin{array}{c}\text { Royal } \\
\text { Cornwall } \\
\text { with Cell } \\
\text { Salvage } \\
\end{array}$ \\
\hline No of Allogeneic Units & 27 & 6 & 47 & 20 \\
\hline Allogeneic Blood Costs (£122/unit) & 3,294 & 732 & 5,734 & 2,440 \\
\hline Cell Salvage Cost & - & - & - & 28,450 \\
\hline $\begin{array}{l}\text { Donor Costs ( } £ 0.65+£ 0.36 \text { per unit) } \mathrm{x} \\
\text { allogeneic units }\end{array}$ & 27 & 6 & 47 & 20 \\
\hline $\begin{array}{l}\text { Lost Production Costs }(£ 7.71) \mathrm{x} \\
\text { allogeneic units }\end{array}$ & 208 & 46 & 362 & 154 \\
\hline Total Derived Cost & $£ 3,529$ & $£ 784$ & $£ 6,143$ & $£ 31,064$ \\
\hline Total Patients & 148 & 33 & 137 & 180 \\
\hline Unit Blood Cost per Operation & $£ 23.84$ & $£ 23.76$ & $£ 44.84$ & $£ 172.57$ \\
\hline
\end{tabular}

The Royal Cornwall Hospitals therefore generates the lowest allogeneic blood cost when not using cell salvage. This is no surprise, given the lowest allogeneic transfusion rate. There is, however, a significant increase in the unit costs when cell salvage is utilised. The above costs all include the transfer prices. A financial analysis of blood costs would primarily be the cost of allogeneic blood utilised (plus cell salvage costs at the Royal Cornwall) divided by the number of patients treated. Given the donor/societal costs are also unit costs the same relative difference is maintained. South Manchester and the Royal Cornwall non-salvaged patients have the lowest unit cost given their low allogeneic transfusion rate. The 180 Royal Cornwall patients who are salvaged have the highest unit costs. The argument would be that this additional cost would offset the cost of allogeneic blood usage however the unit costs do not support this argument given the relatively low allogeneic blood transfusion rates at the other two sites.

\subsection{Extraction of Transfer Prices}

Table 75 above includes the transfer prices; most notably the $£ 122$ charge for an allogeneic unit. An economic analysis approach would calculate the cost of the allogeneic blood/cell salvage from an NHS wide perspective. The key element would 
be to extract the transfer price elements from the overall $£ 122$ transfer price. This was undertaken by reference to the 2010/11 NHSBT published audited accounts.

Table 76. Adjusted costs for the Provision of Blood Components-NHSBT Annual Accounts 2010/11

\begin{tabular}{|c|c|c|c|c|c|c|}
\hline & $£^{\prime} 000$ & $£^{\prime} 000$ & & $\begin{array}{l}\text { Transfer } \\
\text { Payment? }\end{array}$ & $\begin{array}{l}\text { Direct } \\
\text { Alloc }\end{array}$ & $\begin{array}{l}\text { NI/Pension/ } \\
\text { VAT Adjust }\end{array}$ \\
\hline \multicolumn{7}{|l|}{ Note 3.1 Salaries \& Wages: } \\
\hline Permanent & 171,275 & & & $\mathrm{~N}$ & & \\
\hline NI & 11,415 & & & Y & & $-11,415$ \\
\hline \multirow[t]{2}{*}{ Pension } & 19,531 & & & Y & & $-19,531$ \\
\hline & & 202,221 & & & & \\
\hline Note 3.2 Other Adminis trative Expenses & & & & With VAT? & & \\
\hline Other staff related costs & 14,747 & & & $\mathrm{~N}$ & & 0 \\
\hline Consumable supplies & 68,776 & & & Y & & $-11,463$ \\
\hline Maint of buildings plant \& equipment & 16,705 & & & $\mathrm{~N}$ & & 0 \\
\hline Rent \& rates & 11,506 & & & $\mathrm{~N}$ & & 0 \\
\hline Transport Costs & 10,061 & & & $\mathrm{~N}$ & & 0 \\
\hline External contractors & 14,916 & & & $\mathrm{~N}$ & & 0 \\
\hline Purchase and lease of equipment $\&$ furniture & 3,914 & & & Y & & -652 \\
\hline Utilities \& telecommunications & 7,842 & & & Y & & $-1,307$ \\
\hline Media advertising & 2,597 & & & $\mathrm{~N}$ & & 0 \\
\hline ODT scheme payments & 29,241 & & & & to ODT & 0 \\
\hline Professional fees & 7,821 & & & $\mathrm{~N}$ & & 0 \\
\hline Capital charges & 18,765 & & & & Separate & 0 \\
\hline Capital non cash & 3,085 & & & & & 0 \\
\hline Auditors' remuneration & 120 & & & $\mathrm{~N}$ & & 0 \\
\hline \multirow[t]{2}{*}{ Miscellaneous } & 8,510 & & & $\mathrm{Y}$ & & $-1,418$ \\
\hline & & 218,606 & & & & \\
\hline Total & & 420,827 & & & & \\
\hline Less Capital Charges & & $-18,765$ & & & & \\
\hline \multirow[t]{2}{*}{ Ties to Staff Costs and Other Admin Exps note 2 page 49} & & 402,062 & & & & \\
\hline & Total & $\begin{array}{c}\text { Blood } \\
\text { Compone } \\
\text { nts }\end{array}$ & $\begin{array}{l}\text { Spec } \\
\text { Servs }\end{array}$ & ODT & Group & \\
\hline Total from above, already split out in a/cs (para 2 of a/cs) & 402,062 & 198,672 & 37,775 & 52,966 & 112,649 & \\
\hline Less direct to ODT & $-29,241$ & & & $-29,241$ & & \\
\hline Apportion Group costs & 0 & 77,330 & 14,703 & 20,616 & $-112,649$ & \\
\hline Sub total & 372,821 & 276,002 & 52,478 & 44,341 & 0 & \\
\hline Cap Charges & 0 & & & & & \\
\hline NI & $-11,415$ & $-8,451$ & $-1,607$ & $-1,358$ & 0 & \\
\hline Pension & $-19,531$ & $-14,459$ & $-2,749$ & $-2,323$ & 0 & \\
\hline Consumable supplies & $-11,463$ & $-8,486$ & $-1,613$ & $-1,363$ & 0 & \\
\hline Purchase and lease of equipment $\&$ furniture & -652 & -483 & -92 & -78 & 0 & \\
\hline Utilities \& telecommunications & $-1,307$ & -968 & -184 & -155 & 0 & \\
\hline Miscellaneous & $-1,418$ & $-1,050$ & -200 & -169 & 0 & \\
\hline Costs less transfer payments & 327,035 & 242,106 & 46,033 & 38,896 & 0 & \\
\hline Blood Components Costs less transfer payments & & 242,106 & & & & \\
\hline \multirow[t]{2}{*}{ Red cells a/c for $£ 224 \mathrm{~m} / £ 304 \mathrm{~m}$ sales $=$} & & $73.7 \%$ & & \multicolumn{3}{|c|}{$£ 224 \mathrm{~m}$ is $£ 122 \times 1,838,000$ units } \\
\hline & & $£^{\prime} 000$ & & & & \\
\hline Net costs of providing red cells & & 178,394 & & & & \\
\hline \multicolumn{2}{|l|}{$2010 / 11$ Unit Cost-Divide by number of red cells is sued $(1,838 \mathrm{k})$} & $£ 97.06$ & & & & \\
\hline
\end{tabular}


Para 2.8 noted that VAT and other transfer payments would be included in the main calculations in a financial analysis. This decision was primarily based on discussions with hospitals who readily recognised the $£ 122$ figure for the charge for a unit of allogeneic blood from NHSBT and virtually all published studies ignored the issue of transfer payments. The majority of non-pay expenditure incurred by NHS organisations includes VAT. The provision of healthcare is an exempt supply in VAT accounting and the NHS can only report transactions exclusive of VAT in specific circumstances. These transactions mainly fall into the 'contracted out services' category and include the provision of external services e.g. professional advice and training. Table 76 recalculates the costs associated with allogeneic blood at NHSBT in $2010 / 11$ by extracting the transfer payments. The notes accompanying the audited accounts were used as the start point and adjustments made. The revised cost of a unit of allogeneic blood was thus estimated at c. £97. Approximately $20 \%$ of the $£ 122$ charge therefore related to calculated transfer payments. This is not surprising given the high proportion of staffing costs and the associated national insurance and pension payments made to HM Revenue and Customs (HMRC) and the Department for Work and Pensions (DWP).

An adjustment to extract the VAT element in the cell salvage costs is required. This is shown in table 77 below.

Table 77. Extraction of VAT from Cell Salvage Costs

\begin{tabular}{|l|r|r|r|}
\hline & Electa & \multicolumn{1}{c|}{ OrthoPat } & \multicolumn{1}{c|}{ Total } \\
\hline & \multicolumn{1}{|c|}{$£$} & \multicolumn{1}{c|}{$£$} & \multicolumn{1}{c|}{$£$} \\
\hline Operating Costs (table 64 above) & 6,298 & 22,152 & 28,450 \\
\hline Less Maintenance (ex VAT as reclaimable) & 532 & 728 & 1,260 \\
\hline \multicolumn{1}{|c|}{ Sub Total } & 5,766 & 21,424 & 27,190 \\
\hline Less VAT & 961 & 3,571 & 4,532 \\
\hline Net Position ex VAT & 4,805 & 17,853 & 22,658 \\
\hline Add back Maintenance & 532 & 728 & 1,260 \\
\hline Total Cell Salvage Costs ex VAT & $\mathbf{5 , 3 3 7}$ & $\mathbf{1 8 , 5 8 1}$ & $\mathbf{2 3 , 9 1 8}$ \\
\hline
\end{tabular}

The derived unit cost of blood per patient, excluding transfer prices, can now therefore be restated in table 78 below: 
Table 78. Derived Unit Cost of Blood per Patient (Excluding Transfer Prices)

\begin{tabular}{|c|c|c|c|c|}
\hline $\begin{array}{c}\text { Hospital } \\
\text { |Category } \\
\end{array}$ & $\begin{array}{c}\text { South } \\
\text { Manchester }\end{array}$ & $\begin{array}{c}\text { Royal } \\
\text { Cornwall } \\
\text { without Cell } \\
\text { Salvage } \\
\end{array}$ & $\begin{array}{c}\text { Spec } \\
\text { Orthopaedic } \\
\text { Centre } \\
\end{array}$ & $\begin{array}{c}\text { Royal } \\
\text { Cornwall } \\
\text { with Cell } \\
\text { Salvage } \\
\end{array}$ \\
\hline No of Allogeneic Units & 27 & 6 & 47 & 20 \\
\hline Allogeneic Blood Costs (£97/unit) & 2,619 & 582 & 4,559 & 1,940 \\
\hline Cell Salvage Cost (table 77) & - & - & - & 23,918 \\
\hline $\begin{array}{l}\text { Donor Cost (transport and earnings } \\
£ 0.36+£ 0.33=£(0.69) \times \text { allogeneic } \\
\text { units }\end{array}$ & 19 & 4 & 32 & 14 \\
\hline Social Cost (£7.08) x allogeneic units & 191 & 42 & 333 & 141 \\
\hline Total Derived Cost & $£ 2,829$ & $£ 628$ & $£ 4,924$ & $£ 26,013$ \\
\hline Total Patients & 148 & 33 & 137 & 180 \\
\hline Unit Blood Cost per Operation & $£ 19.11$ & $£ 19.03$ & $£ 35.94$ & $£ 144.52$ \\
\hline
\end{tabular}

The same trend is exhibited as in table 75 above where there is a miniscule difference in the unit allogeneic blood costs between the non-salvaged Royal Cornwall patients and South Manchester. The other two categories are both consistently higher as with the financial analysis in table 75.

\subsection{Summary of Chapter 6}

This chapter has analysed the detailed HRG patient statistics and concluded that there is little evidence to indicate that the three sample groups of patients are significantly different in their composition. The only significant difference is the higher rate of anaemic patients presenting for surgery at South Manchester. This will impact on the LOS. The evidence therefore facilitates a direct comparison between approaches to allogeneic blood management.

Approaching the costs from both a financial and economic analysis therefore concludes that the utilisation of cell salvage significantly adds to the total blood costs and hence the unit costs per patient undergoing primary total hip replacement surgery.

The initial findings are shown in table 79 below:

Table 79. Initial Findings from Analysis

\begin{tabular}{|r|l|l|}
\hline \multicolumn{1}{|l|}{ Ref } & \multicolumn{1}{|c|}{ Finding } & \multicolumn{1}{c|}{ Evidence } \\
\hline 1 & Patients are equally 'prepped'. & $\begin{array}{l}\text { No significant difference in pre-operative Hb levels } \\
\text { (ANOVA) though South Manchester has a } \\
\text { significantly higher rate of WHO defined anaemic } \\
\text { patients (Chi square) }\end{array}$ \\
\hline 2 & Homogeneous set of patients. & $\begin{array}{l}\text { Age and gender distributions are not significantly } \\
\text { different (Chi square and ANOVA). }\end{array}$ \\
\hline
\end{tabular}




\begin{tabular}{|c|c|c|}
\hline Ref & Finding & Evidence \\
\hline 3 & $\begin{array}{l}\text { Patients present and are treated with } \\
\text { similar levels of intervention. }\end{array}$ & HRG distribution is similar (Chi square). \\
\hline 4 & $\begin{array}{l}\text { Immediate post-operative recoveries } \\
\text { are similar. }\end{array}$ & $\begin{array}{l}\text { No significant difference in post-operative Hb levels } \\
\text { (ANOVA). }\end{array}$ \\
\hline 5 & $\begin{array}{l}\text { Mean LOS significantly higher at } \\
\text { South Manchester with or without } \\
\text { allogeneic transfusion. }\end{array}$ & ANOVA analysis and regression. \\
\hline 6 & $\begin{array}{l}\text { LOS is unlikely to be influenced by } \\
\text { an allogeneic blood transfusion. } \\
\text { Hence a cost benefit analysis can be } \\
\text { excluded from the discussion (para } \\
\text { 6.5) and a cost minimisation approach } \\
\text { adopted. }\end{array}$ & $\begin{array}{l}\text { ANOVA analysis and regression. Cross reference to } \\
\text { paras } 2.3 \text { and } 2.4 \text {. }\end{array}$ \\
\hline 7 & $\begin{array}{l}\text { Royal Cornwall Hospitals adopt a } \\
\text { more restrictive allogeneic } \\
\text { transfusion regime. }\end{array}$ & $\begin{array}{l}\text { Comparison of 'Transfusion trigger' points and test } \\
\text { on post-operative } \mathrm{Hb} \text { levels to compare with other } \\
\text { two sites. }\end{array}$ \\
\hline 8 & $\begin{array}{l}\text { Royal Cornwall Hospitals salvaged c. } \\
85 \% \text { of patients-reinfusion rates vary } \\
\text { significantly depending on machine. }\end{array}$ & $\begin{array}{l}\text { Can access the relevant data by patient by machine } \\
\text { utilised. }\end{array}$ \\
\hline 9 & $\begin{array}{l}\text { Significant differences in costs } \\
\text { associated with consumables for } \\
\text { OrthoPat and Electa. }\end{array}$ & $\begin{array}{l}\text { Received prices from Royal Cornwall Hospitals } \\
\text { Transfusion Coordinator. Utilising with activity will } \\
\text { generate the costs. }\end{array}$ \\
\hline 10 & $\begin{array}{l}\text { No significant difference between } \\
\text { patients at } \mathrm{RCH} \text { that were or were not } \\
\text { salvaged. }\end{array}$ & $\begin{array}{l}\mathrm{t} \text { test on pre-and post-operative } \mathrm{Hb} \text { levels, age, } \\
\text { gender and HRG comparisons. }\end{array}$ \\
\hline 11 & $\begin{array}{l}\text { Overall blood costs are significantly } \\
\text { higher when utilising cell salvage. }\end{array}$ & $\begin{array}{l}\text { Aggregating actual costs and derived donor /societal } \\
\text { costs. Consistent difference from both a financial } \\
\text { and economic methodology. }\end{array}$ \\
\hline 12 & $\begin{array}{l}\text { Virtually all NHSBT costs are fixed } \\
\text { in the short term. }\end{array}$ & $\begin{array}{l}\text { Received and discussed information with Planning } \\
\text { \& Management Accountant at NHSBT. }\end{array}$ \\
\hline 13 & $\begin{array}{l}\text { Societal costs are relatively small } \\
\text { compared to the costs of operating } \\
\text { cell salvage. }\end{array}$ & Derived an average indicative cost. \\
\hline
\end{tabular}

When comparing overall allogeneic and salvaged blood use the indications are that the hospital-based costs are higher when cell salvage is utilised than when allogeneic blood is used to maintain or increase $\mathrm{Hb}$ levels. This is evidenced by the relatively small difference in the allogeneic transfusion rate between the Royal Cornwall Hospitals and South Manchester. Length of stay does not appear to be affected by allogeneic transfusions as the length of stay is significantly longer at South Manchester even when comparing operations where no allogeneic transfusion was administered and there were no discernible differences between the cohorts of patients.

The summary statistics for the pre-operative $\mathrm{Hb}$ levels indicate that there is a wider variation of $\mathrm{Hb}$ levels at South Manchester than at the other two sites. This is highlighted by the significantly higher proportion of patients who present with $\mathrm{Hb}$ 
levels below the WHO threshold. It is likely that this has contributed to the longer length of stay and the higher allogeneic transfusion rate.

It was confirmed that costs at NHS Blood and Transplant were stable over the period; the transfer price of $£ 122$ was static and was subsequently being lowered to $£ 120$ for $2015 / 16$. It is currently (2018/19) back to c. £122. Red cell sales income accounted for c. $70 \%$ of all blood related income for NHS Blood and Transplant in 2010/11. A fall in allogeneic blood usage would have a significant impact on NHS Blood and Transplant's financial position given the high level of fixed costs.

The donor cost methodology/calculation is subjective. Most of the results are consistent with Varney and Guest's (2003) study and are indicative of the costs a blood donor would incur. An overall headline summary of the cost comparison is shown in table 80 below.

Table 80. Mean Blood Costs by Site

\begin{tabular}{|l|r|r|r|c|}
\hline \multicolumn{1}{|c|}{$\begin{array}{c}\text { Hospital } \\
\text { Category }\end{array}$} & $\begin{array}{c}\text { South } \\
\text { Manchester }\end{array}$ & $\begin{array}{c}\text { Royal } \\
\text { Cornwall } \\
\text { without Cell } \\
\text { Salvage }\end{array}$ & $\begin{array}{c}\text { Spec } \\
\text { Orthopaedic } \\
\text { Centre }\end{array}$ & $\begin{array}{c}\text { Royal } \\
\text { Cornwall } \\
\text { with Cell } \\
\text { Salvage }\end{array}$ \\
\hline $\begin{array}{l}\text { Unit Blood Cost per Operation (table } \\
\text { 67) Including Transfer Payments }\end{array}$ & $£ 22.25$ & $£ 22.18$ & $£ 41.85$ & $£ 171.61$ \\
\hline $\begin{array}{l}\text { Unit Blood Cost per Operation (table } \\
\text { 78) Excluding Transfer Payments }\end{array}$ & $£ 19.11$ & $£ 19.03$ & $£ 35.94$ & $£ 144.52$ \\
\hline
\end{tabular}

The overall conclusion from the results is that adopting cell salvage is significantly more expensive than relying on allogeneic blood transfusions. South Manchester, however, exhibits a significantly longer patient length of stay for the selected data in primary total hip replacement surgery than the other two sites. On the results in this chapter the indications are that there are other, non-blood related, factors that impact on length of stay given the length of stay is higher when there are no allogeneic transfusions utilised. Additionally, the Specialist Orthopaedic Centre's allogeneic blood usage is higher with the length of stay being approximately the same for the Royal Cornwall Hospitals. Adopting the dual approach of calculating both the financial costs and the economic costs allows the discussions to develop in both arenas. The accountants at NHSBT and the hospitals can compare blood/salvage usage against activity whereas the economic appraisal can focus on the opportunity costs of utilising both allogeneic blood and cell salvage; adopting a cost 
minimisation approach. Table 80 above, though using unit costs, is indicative of the same trends exhibited by either approach.

These interrelationships will be discussed in chapter 7 . 


\section{Chapter 7. Discussion}

\subsection{Introduction}

This chapter will revisit the objectives of the thesis set out in chapter 3 and determine whether the results presented in chapter 6 can provide sufficient reassurance that the research question can be answered. The three elements of the objectives noted in para 3.3 were:

- Establish the homogeneity of the patient cohorts selected in order to minimise allegations of bias and compare patient data between sites that use and do not use cell salvage. This will support a valid comparison between the three sites.

- Evaluate the cost impacts of cell salvage against using allogeneic blood from both a financial and an economic perspective;

- Investigate other possible factors that may impact on comparison across sites such as preparation for surgery and length of stay.

As noted previously the discussions on whether cell salvage can reduce overall healthcare costs in primary total hip replacement surgery have been inconclusive. The researcher has been aware that the focus on blood conservation has evolved into international Patient Blood Management (PBM) initiatives with cell salvage being an element within the initiatives. The schematic in para 5.5 (figure 13) highlights that cell salvage is one of the few initiatives being utilised both intra-operatively and post-operatively within the PBM framework. PBM is currently being rolled out across the four home nations and extensively publicised worldwide so any conclusions from this study can be incorporated into the wider debate.

The elements above will be dealt with in turn and a number of limitations in the study will be noted that will require further investigation.

\subsection{Objective One: Establish Patient Homogeneity and Compare Data}

This section will cover a number of elements: 


\section{Pre-Operative Haemoglobin Levels}

It should be stressed that the researcher has focused on elective, rather than emergency, primary hip replacement surgery. This was deliberate in order to ensure the hospitals were able to prepare the patient for surgery. By its very nature emergency surgery requires a different set of treatments and invariably the patient is not optimised prior to surgery. This would make comparisons and interpretations on e.g. requirements for allogeneic blood usage, highly subjective.

The mean $\mathrm{Hb}$ level across the three sites was virtually the same. The standard deviation was higher at South Manchester and figure 17 (boxplot on page 145) indicated a wider range of $\mathrm{Hb}$ readings. There was a much higher proportion of patients presenting at South Manchester below the WHO Hb criteria (males $<130 \mathrm{~g} / 1$, females $<120 \mathrm{~g} / \mathrm{l})$. This trend was not immediately apparent. Para 5.7 noted clinicians asserting that cell salvage can mask inefficiencies in patient preparation however this was not the case with the Royal Cornwall Hospitals having the lowest proportion of patients $(9.3 \%)$ presenting with $\mathrm{Hb}$ readings below the WHO threshold. The corresponding readings at the SOC and South Manchester were 10.9\% and $22.2 \%$ (table 37) respectively. The significantly higher rate at South Manchester may be a contributor to the higher transfusion rate compared to the Royal Cornwall Hospitals. This rate difference was not identified as a significant contributor to the longer length of stay at South Manchester in the regression analysis (para 6.5).

The sample size was too small to determine the contribution of cell salvage in minimising the allogeneic transfusion rate for the 9.3\% (23) of the Royal Cornwall Hospitals patients presenting who were below the WHO threshold. The likelihood is, however, that the comparatively lower anaemia rate at the Royal Cornwall Hospitals would contribute towards achieving a lower allogeneic transfusion rate. Cell salvage at the Royal Cornwall Hospitals may therefore appear to be more effective compared to South Manchester by the proxy of a more effective pre-operative assessment programme. It could be asserted that cell salvage is contributing less to the avoidance of an allogeneic transfusion at the Royal Cornwall Hospitals than thought since c. $90 \%$ of the patients have pre-operative iron levels capable of adequately supporting the surgery. This is compared to c. $78 \%$ of South Manchester patients (figure 23). 
Various articles e.g. Phillips S et al (2006) and Spahn (2010) in the literature review stressed the causational link between lower pre-operative readings and a higher likelihood of a requirement for an allogeneic transfusion. The researcher drew similar conclusions; Spahn (2010) recommended "high impact prospective studies" to be undertaken however the similar issue in para 1.4 is pertinent in that it is difficult from an ethical perspective to withdraw other allogeneic blood avoidance techniques to just focus on testing one. A recent study, Guzel et al (2017), segregated a cohort of patients to receive tranexamic acid or post-operative cell salvage on knee replacement surgery. The authors concluded that tranexamic acid was more cost effective than post-operative cell salvage. The study was relatively small scale (50 patients in each cohort) and the lesser used post-operative cell salvage is significantly more expensive than intra-operative cell salvage anyway. The study does, however, point to the ethical perspectives now being stretched to enhance the discussions.

An overall comparison of WHO pre-operative anaemia rates against overall transfusion rates is shown in table 81 below.

Table 81. Comparison of Transfusion Rate to WHO Defined Anaemia Rate

\begin{tabular}{|c|r|r|r|r|}
\hline $\begin{array}{c}\text { Hospital: } \\
\text { IRate }\end{array}$ & $\begin{array}{c}\text { South } \\
\text { Manchester }\end{array}$ & $\begin{array}{c}\text { Royal } \\
\text { Cornwall }\end{array}$ & $\begin{array}{c}\text { Spec Orth } \\
\text { Centre }\end{array}$ & $\begin{array}{c}\text { Mean } \\
\text { Overall }\end{array}$ \\
\hline \% Patients Defined as Anaemic (WHO) & $22.2 \%$ & $9.3 \%$ & $10.9 \%$ & $14.5 \%$ \\
\hline Allogeneic Blood Transfusion Rate & $9.5 \%$ & $6.1 \%$ & $16.8 \%$ & $10.0 \%$ \\
\hline
\end{tabular}

A simple assertion would be that, if South Manchester could decrease the rate of anaemic patients presenting for surgery, then, all other things being equal, less allogeneic blood would be required. Whether or not this rate would decrease to the Royal Cornwall's allogeneic blood transfusion rate is a moot point. The researcher has shared this information with the three sites and has been reassured that the preoperative anaemia rate has improved at South Manchester with a corresponding fall in the allogeneic blood transfusion rate.

It is interesting to note that the regression analysis on length of stay (LOS) does not highlight the South Manchester's higher WHO classed anaemia rate as being a contributor to the increased LOS at South Manchester (para 6.5).

Each of the sites' subsequent approach to the challenges of minimising pre-operative anaemia were encouraging. The data analysed was from 2010/11 and could be 
perceived as being out of date (e.g. the researcher criticised Tawfick et al (2008) where the data collection period spanned nine years) however the principle remains that there is a higher probability of an allogeneic blood transfusion being required when pre-operative $\mathrm{Hb}$ levels are lower. Additionally, the data from the three sites was extracted over a relatively short time period thereby minimising any likelihood of staff changes or developments in health technologies being utilised. The detailed results were shared and discussed with the leads in the three hospitals in 2014/15; the leads confirmed that the information had been shared with their respective anaemia leads to support further initiatives to managing pre-operative anaemia.

A number of authors assert that the pre-operative $\mathrm{Hb}$ level is a reliable indicator of how well the patient is prepared for the operation (Spahn (2010) above, Waters (2010b)). A more recent conference poster (Rajkumar et al (2015)) highlighted the proportion of patients presenting for primary hip replacement surgery at Guy's Hospital with a Hb level of $<120 \mathrm{~g} / \mathrm{l}$ falling from $19 \%$ in 2007 to $5 \%$ in 2014 with a concomitant fall in the allogeneic transfusion rate from 13\% in 2007 to $0 \%$ in 2014. As noted previously, the pre-operative $\mathrm{Hb}$ level significantly influences whether an allogeneic transfusion is administered during or after elective surgery. It is likely that the pre-operative $\mathrm{Hb}$ level is therefore an indicator of the assiduous application of other best practice pre-operative techniques e.g. the supply of pre-operative nutrients or 'pre-habilitation' advice at the patient's assessment appointment (para 1.19). A wider study would clarify this point.

Preparedness for surgery can vary with factors such as a patient's age, personal circumstances or comorbidities. Any significant comorbidity would, however, impact on the patient's HRG coding. The $\mathrm{Hb}$ analysis therefore points to the Royal Cornwall Hospitals and the SOC's patient preparation being potentially more comprehensive than South Manchester after other factors potentially contributing to the variation being ruled out.

\section{Patient and Condition Homogeneity}

As highlighted in para 6.15 (table 79 , ref 2) the age and gender of the patients at the three sites are consistent. This gives a significant level of reassurance over the homogeneity of the patients presenting. Most studies identify these two categories in their analysis. There is the assertion that some studies may differ as they may have, 
on average, younger patients or a higher proportion of male patients. A single site study may therefore have an unintended level of bias if the data selected in these categories is significantly different from the population's overall characteristics. Homogeneity in this three-site study would therefore minimise the possibility of patient age and condition bias.

This study was novel in that it utilised Healthcare Resource Groups (HRGs) to compare the severity of the total hip replacement operations. The widely-held view would be that the more severe the operation, requiring additional procedures, the more likely an allogeneic blood transfusion would be required. The uniformity of the HRG breakdown gave a level of confidence that the operations were of a similar intensity and level of invasiveness. An initial assertion from a member of the SOC staff was that, as a specialised centre, the higher allogeneic transfusion rate may have reflected surgery undertaken on more severe cases. The HRG coding results refuted this assertion, highlighting the similarity in the profiles of operations at the SOC to the other two sites. Adoption of the HRG coding therefore added a level of reassurance that is not included in any other study regarding allogeneic transfusion rates and cell salvage. It also provides an additional level of objectivity. Following discharge, the hospital clinical coders summarise the care provided to the patient by reference to the ICD-10 and OPCS-4 procedural classification codes. The NHS 'grouper' software (para 1.24) generates the HRG code from this information. This retrospective coding and assignment of the HRG classification is therefore undertaken independently of the staff associated with the allogeneic blood transfusions; thereby minimising the potential allegations of DRG/HRG 'creep'. The researcher received the HRG codes directly from the relevant Trust information department thereby adding an additional level of independence.

The HRG coding prompted further discussions with clinicians, few of whom had even heard of the term 'HRG' but appreciated the additional level of granularity. The researcher noted the conclusion of Jaben et al (2010) who studied long term survival rates following surgery when an allogeneic transfusion was required. The study utilised the Charlson comorbidity index to measure and classify the severity of the comorbidities. More recent US studies e.g. Frank et al (2014) have commenced the introduction of Diagnosis Related Groups (DRGs) into comparisons of allogeneic blood usage. These are the US equivalent of HRGs. Being able to incorporate this 
additional level of information would help to minimise the potential allegations of bias and allow more objective comparisons. There are currently no published comparative studies on allogeneic blood usage utilising HRGs in the UK. By not adopting this additional check on the severity of the operation other studies run the risk of potential allegations of bias in their results.

The pre-operative results showed the patients' age, gender and pre-operative conditions (HRG profile) were homogeneous. Prior to delving deeper, a general overall reassurance is implied that these three factors would not influence any differences in the post-operative comparisons. Table 37 (page 146) highlights the higher proportion of South Manchester patients who are presenting as anaemic as defined by the WHO limits. This issue is likely to be significant and may influence the LOS, impacting on patients who were not adequately 'prepped' for surgery.

\section{Post-Operative Results}

Para 6.4.1. (Page 148) noted that the mean post-operative Hb levels are relatively uniform across the three sites and table 44 (page 151) compared the mean postoperative falls. With there being so little difference in the post-operative Hb levels it can be safely assumed that most operations have been successfully completed.

Figure 23 (page 163) highlighted the significant disparity in the post-operative transfusion rates. The challenge has been to isolate the impact of cell salvage at the Royal Cornwall Hospitals rather than the impact of other blood avoidance techniques. The first key aspect is the allogeneic transfusion rates. The percentages are 'diluted' by a negligible number of allogeneic transfusions in the HB12C category across all three sites. This adds reassurance to the assertion in chapters 1 and 4 that previous studies were not deriving the effective allogeneic transfusion rate since they were using the generic category 'total hip replacement'. By excluding the HRG HB12C the Royal Cornwall Hospitals' adjusted allogeneic transfusion rate is 7.5\% against $10.7 \%$ for South Manchester and $21.3 \%$ for the SOC (table 56 page 165). Overall one could assert that, given the overall length of stay was 4.9 days for both the Royal Cornwall Hospitals and the SOC against 6.2 days for South Manchester, the Royal Cornwall Hospitals were therefore deriving a successful outcome from their cell salvage programme (table 46 page 154). This assertion is however, simplistic. 
A key contributor is the restrictive allogeneic transfusion practice that the Royal Cornwall Hospitals adopts. This may not be as formal as an assessment of "computerized physician order entry" as described by Goodnough et al (2014) but figure 23 shows that Royal Cornwall Hospitals staff are prepared to let the patients' $\mathrm{Hb}$ levels drop significantly lower before administering an allogeneic transfusion. Goodnough et al (2014) set their hospital transfusion trigger at $70 \mathrm{~g} / 1$ (at the lower end of the $\mathrm{AABB}$ recommended scale). This did not differentiate between genders and there was a slight decrease $(52.7 \%$ to $49.9 \%$ over the five-year study) in the proportion of females who generally tolerate a lower $\mathrm{Hb}$ level before being considered anaemic under the WHO categories. Figure 23 indicates that only the Royal Cornwall Hospitals come near the AABB transfusion trigger (para 4.7 and appendix 4).

There is little difference in the post-operative $\mathrm{Hb}$ levels for patients at South Manchester and the non-reinfused patients at the Royal Cornwall Hospitals (table 34). This reinforces the assertion that there is very little difference in the procedures required within the operation and that it is the extraneous factors of the weekend impacts that are contributing to the longer LOS for the South Manchester patients who did not receive an allogeneic transfusion. It is possible (though not verifiable) that the condition of the South Manchester patients who had allogeneic transfusions were regarded as more serious within the parameters of each of the HRG code and required more post-operative input.

Overall the post-operative analysis indicates:

- The Royal Cornwall Hospitals practice a significantly more restrictive transfusion regime. Four of the five patients who were salvaged and also received an allogeneic transfusion, had post-operative $\mathrm{Hb}$ readings below 67 $\mathrm{g} / \mathrm{l}$. The remaining patient had a reading of 71 . The implication is that the allogeneic transfusions were a 'last resort' after all other procedures had been utilised. This factor therefore contributes towards the lower allogeneic transfusion rate.

- The differences in length of stay are likely to be the product of factors not associated with a patient having an allogeneic blood transfusion. Given the number of allogeneic transfused patients is relatively small it would be 
necessary to obtain activity relating to a longer period to fully investigate and substantiate this assertion. The SOC length of stay is significantly lower for the patients who have an allogeneic transfusion than the other two sites. This may be that there are more experienced orthopaedic staff who can rehabilitate older, less responsive patients than the other two sites. This assertion, again, would benefit from a fresh study.

\subsection{Objective Two: Evaluation of Cost Impacts and Assessment of the Cost Effectiveness of Cell Salvage}

As highlighted in para 6.13 the majority of costs associated with allogeneic blood transfusions comprise the charge from NHSBT for the allogeneic blood and the cell salvage related costs. All other costs are viewed as being constant (e.g. cross matching, utilisation of tranexamic acid) and would be incurred regardless of whether a patient had an allogeneic transaction, cell salvage or no blood requirements at all. This would include the cost of the operation of the blood bank (para 2.2).

This study has benefited from the Royal Cornwall Hospitals holding patient information on two types of cell salvage machine, separate information on patients who were not salvaged and also information relating to patients being salvaged but not being reinfused. This has allowed multiple comparisons, not usually adopted in studies. The main aspects are:

7.3.1 This study is not as detailed as some other published studies (e.g. Waters et al (2007), NICE NG24 Guideline (2015)). This thesis has a wider focus; utilising cell salvage against an allogeneic blood transfusion without cell salvage. A further difference is that both quoted studies include an allowance for additional staff time to operate the machine. At the Royal Cornwall Hospitals, additional staff time in theatre is not required when utilising cell salvage. Staff are trained to operate the machines within their existing duties. The NICE guidance includes an additional 3.5 hours of nursing time when cell salvage is utilised. The researcher has additionally seen hip replacement surgery undertaken in Swansea and Pittsburgh where only a surgeon and one nurse or ODP were involved in the surgery. This requirement will be different for e.g. a complex cardiac operation, but it is likely the NICE (2015) staffing costs of cell salvage are overstated. 
7.3.2 The cell salvage costs derived in chapter 6 utilise a significantly different comparison methodology from those utilised in previous studies. Other studies (e.g. Rao et al (2012)) include a notional element from the allogeneic blood not required but South Manchester has shown that the low allogeneic blood transfusion rate can be achieved without the need for cell salvage. Hence the notional cost savings of cell salvage are irrelevant. The factors that influence South Manchester's longer LOS appear to be independent of allogeneic blood transfusions. The cost of the additional LOS compared to the Royal Cornwall Hospitals or the SOC is not therefore likely to be an impact of the higher allogeneic blood transfusion rate.

7.3.3 Patients at the Royal Cornwall Hospitals tolerate greater falls in post-operative $\mathrm{Hb}$ levels than the other two sites. This would have the effect of reducing the requests for allogeneic blood and would contribute towards the lower allogeneic transfusion rate. Given this policy runs concurrently with other strategies within the cell salvage programme it is impossible to segregate the impacts of the separate strategies on allogeneic blood usage.

7.3.4 The impact of a shorter LOS on costs, in the short term, would be limited to the release of some marginal costs avoided. These would mainly relate to the cost of accommodation and patient meals. There is a wide expectancy that cost savings in reducing LOS will be higher. The Clinical Services Journal (January 2012), in an article on improvement on pre-operative $\mathrm{Hb}$ management in hip and knee replacement, stated "The average length of stay, which costs around $£ 300$ per day has fallen from 7.5 days to 6.5 days for hips..". The intimation in this sentence is that significant savings could be achieved. In the short term this will not be the case given the majority of costs are fixed. Other articles e.g. Dixon et al (2005) and Freedman et al (2008) also imply fixed costs would be released quickly in comparisons on avoiding allogeneic blood transfusions. Para 6.5 (regression analysis) noted that there is unlikely to be any significant causational relationship between cell salvage and LOS, once other factors have been considered. Any resultant savings would therefore be minimal.

It is likely that South Manchester could also improve on its low allogeneic transfusion rate if the rate of anaemia was nearer the rate of the other two sites. This however cannot be quantified and would benefit from more recent analysis. 
7.3.5 Impact of Weekend Working. The cost impact of this area would need to be considered primarily in the context of the costs of length of stay. More weekend therapy support working would be likely to attract premium payments for staff in the short to medium term. This should contribute towards savings in the lower length of stay but only after an initial rise in overall costs as the new system would take time to establish. The evidence from this comparative study indicates that an allogeneic blood transfusion has little or no impact on LOS. As such no costs of LOS have been incorporated in this study.

7.3.6 The early analysis and articles generally noted higher allogeneic transfusion rates in operations. Introduction of cell salvage systems would therefore be more likely to generate a greater fall in the rate of allogeneic blood usage. Cell salvage would therefore appear successful in decreasing the allogeneic transfusion rate however it was an expensive method to avoid a blood transfusion. In the English NHS, the price of a unit of red cells has been at a maximum of $£ 140$ (figure 10, page 42 ) in 2008/09. The relatively high cost of the consumables for the OrthoPat machine (c. $£ 170$ per operation from a financial perspective, table 64) was offset by the high red cell price and high allogeneic blood volumes thereby allowing a surplus to be maintained. In reality, there were a number of patient blood management (PBM) techniques much cheaper than cell salvage that would, when utilised, bring down the blood usage and hence costs. The researcher discussed this issue with the teams in Pittsburgh and Swansea in 2014 and 2015. Independently both organisations had taken the decision to run down and phase out their use of the OrthoPat cell saver. Dr Jon Waters at Pittsburgh confirmed that the allogeneic transfusion rate at Pittsburgh for total hip replacement operations had fallen from $27.4 \%$ in 2009 to $19.5 \%$ in 2014 and in October 2016 noted the rate was running at around $9.0 \%$. This rate was achieved by focusing on PBM techniques, at the same time as withdrawing both intra and post-operative cell salvage from most total hip replacement patients. The Cell Salvage Coordinator for the Welsh Blood Service also confirmed that, since 2015, no hospital in Wales uses post-operative cell salvage. Dr Waters' comments are especially relevant as the savings in blood avoidance are significantly higher when there is a high allogeneic transfusion. Decreasing the allogeneic rate via PBM methods and, at the same time, phasing out cell salvage will obviously enhance the continuing fall in overall blood related costs. 
7.3.7 As highlighted in the literature review there have been few discussions relating to the cost of the donation process and the time taken to make the donation. Whatever blood avoidance technique is adopted there will be a corresponding decrease in the volume of allogeneic blood required. NHSBT's variable costs are c. $£ 18$ per unit of allogeneic blood (table 71). A crude analysis (table 74 page 183) calculates the donor/societal cost at $£ 8.72$ per unit. As the $£ 122$ charge for an allogeneic unit is a transfer price from one NHS organisation to another this element can be excluded. The 'saving' of avoiding an allogeneic unit is therefore $£ 26.72$ ( $£ 18$ $+£ 8.72$ ). Comparing this to the c. $£ 83$ cost of operating cell salvage per operation for the Electa salvage machine at the Royal Cornwall Hospitals (table 64 page 171) implies a shortfall of c. $£ 55$ per operation ( $£ 83$ - $£ 26.72)$. The corresponding shortfall for the OrthoPat cell saver ( $£ 213$ per operation) would be c. $£ 186$. Using cell salvage therefore points to a significant loss and, from a cash perspective, it would be arguably cheaper to use allogeneic blood.

7.3.8 Para 1.7 noted the disadvantages of allogeneic blood transfusions. Donors themselves perceive that their donation is the 'gift of life' (para 1.8) and Q5 of the donor survey highlighted that $90 \%$ felt "giving blood is important to me". It could be argued that this "feel good factor" may be partially diminished if donors were aware that, potentially, their donation could be replaced by potentially more expensive blood avoiding initiatives such as cell salvage. Para 1.10 highlights the challenges on recruitment and retention of blood donors. Regular donors may balk at the idea that each donation does not save a person's life, or their donation could be perceived as not being required by being replaced by a recycling machine.

7.3.9 Costs at NHSBT (or any other blood collection organisation) rarely figure in the wider discussions. Davies et al (2006) noted the impact of the fall in demand for allogeneic blood in 2002/2003 and highlighted the impact on NHSBT's fixed costs stating: "the average cost of fixed overheads per unit of blood will increase". Davies et al (2006) implied this would put upward pressure on the allogeneic blood price, assuming that NHSBT would need to cover all these costs. In hindsight, this assumption did not consider the reaction by NHSBT to 'downsize' and remove fixed costs to reflect the lower level of activity. As noted in para 1.23 the transfer price of a 
unit of allogeneic blood will be adjusted to reflect changing costs as annually agreed with the National Commissioning Group for Blood.

7.3.10 Maintenance costs were calculated in table 63 (page 170). This was calculated at $25.1 \%$ of the total annual cell salvage maintenance cost of $£ 10,000$. This percentage was based on the apportionments of primary total hip replacement operations as a percentage of all orthopaedic operations (28.2\%). The national split of primary to secondary total hip replacement surgery was then utilised $(89.2 \%)$ to derive a proportion of primary total hip replacements. This derived estimate was required as the detailed data had been archived. There is no reason to think that the Royal Cornwall Hospitals resident profile is significantly different from the national average however there is a possibility that this percentage may be slightly understated. Any difference, however, is not likely to impact on the relative costs of the two types of cell salvage machines in use.

7.3.11 The researcher had various 'off the record' discussions with blood bank managers and clinicians regarding the cost of a unit of allogeneic blood and volumes utilised in hospitals. The discussions elicited that a number of blood bank/haematology departments noted the lower volumes of allogeneic blood could be offered up annually as part of a savings programme within their respective hospital trust. The relative ease of decreasing the volumes of allogeneic blood with the relatively basic financial monitoring systems helped to avoid scrutiny within the hospital's annual budgeting discussions.

7.3.12 All the above comments are equally relevant irrespective of whether a financial or economic costing approach was undertaken. It was viewed that the calculation of the wider societal cost was justifiable since few studies considered these costs when calculating the financial impact of avoiding allogeneic blood transfusions. In particular; question 12 of the donor questionnaire asked if the donor had to make up work time spent donating. $69 \%$ of respondents stated they did not have to. This proportion was used to generate a cost of 'lost production' in the economy through blood donation. In hindsight, this figure is only a snapshot. The researcher can personally confirm that city centre pre-booked donations can be undertaken very quickly and his current employer encourages staff to donate where possible. A further questionnaire to research the employment background and 
location (this data is not currently collected) of the employers would give some corroboration of this split. The average cost per unit relating to the donor/societal cost was calculated at $£ 8.42$ (table 73 ), when taxes are excluded. This is relatively small compared to the hospital-based costs. An associated issue is the 'windfall' of additional tax revenues (excise duty and VAT) that relates to the journey to/from the donor centre by the donors. This is estimated at c. $£ 0.55 \mathrm{~m}$ on $2 \mathrm{~m}$ donations p.a. To the best of the researcher's knowledge this tax revenue has not been discussed or publicised. An additional cost is the associated $\mathrm{CO} 2$ emissions that were calculated at 2,351 tonnes relating to the donor's journey to/from the donation centre.

7.3.13 Drummond et al (2015) developed a checklist to assess economic evaluations. Table 82 below summarises the questions with responses and notes any parallels/contradictions between financial and economic evaluations.

Table 82. Drummond et al (2015) Economic Evaluation Checklist

\begin{tabular}{|c|c|c|}
\hline Question & Response & $\begin{array}{c}\text { Para } \\
\text { Ref(s) }\end{array}$ \\
\hline $\begin{array}{l}\text { 1. Was a well-defined } \\
\text { question posed in answerable } \\
\text { form? }\end{array}$ & $\begin{array}{l}\text { The research question sought to evaluate whether cell } \\
\text { salvage was an appropriate technique to decrease } \\
\text { allogeneic blood costs. It examined costs associated with } \\
\text { allogeneic and salvaged blood and associated activity } \\
\text { over a similar time frame in three sites covering one } \\
\text { procedure; one of the sites used cell salvage. }\end{array}$ & 3.3 \\
\hline $\begin{array}{l}\text { 2. Was a comprehensive } \\
\text { description of the competing } \\
\text { alternatives given? (i.e. can } \\
\text { you tell who did what to } \\
\text { whom, where and how } \\
\text { often?) }\end{array}$ & $\begin{array}{l}\text { The choice was utilising allogeneic blood transfusions in } \\
\text { two of the hospitals } v \text { an alternative combination of cell } \\
\text { salvage/allogeneic blood transfusion in one hospital. In all } \\
\text { three hospitals it was stated that there was an assiduous } \\
\text { blood management programme in place in line with the } \\
\text { 'Better Blood Transfusion' initiatives. }\end{array}$ & 5.2 \\
\hline $\begin{array}{l}\text { 3. Was the effectiveness of } \\
\text { the programmes or services } \\
\text { established? }\end{array}$ & $\begin{array}{l}\text { The study utilised information from a consecutive series } \\
\text { of primary total hip replacement patients from late } 2010 \\
\text { to early 2011. Key datasets were utilised, based on } \\
\text { previous studies and discussions with clinicians. HRG } \\
\text { information was extracted separately by the relevant } \\
\text { hospital information department. Patients with a length of } \\
\text { stay > } 14 \text { days were excluded as there may have been } \\
\text { significant associated comorbidities or other reasons for } \\
\text { delaying discharge. }\end{array}$ & $\begin{array}{l}6.2 \\
\text { to } \\
6.7\end{array}$ \\
\hline $\begin{array}{l}\text { 4. Were all the important and } \\
\text { relevant costs and } \\
\text { consequences for each } \\
\text { alternative identified? }\end{array}$ & $\begin{array}{l}\text { Key relevant costs relating to allogeneic blood and cell } \\
\text { salvage usage from both a financial and economic } \\
\text { perspective were identified. }\end{array}$ & 6.8 \\
\hline $\begin{array}{l}\text { 5. Were unit costs and } \\
\text { consequences measured } \\
\text { accurately in appropriate } \\
\text { physical units prior to } \\
\text { valuation? }\end{array}$ & $\begin{array}{l}\text { Operating costs of cell salvage were identified and } \\
\text { information on number of operations utilising cell salvage } \\
\text { and units of allogeneic blood transfused supported the } \\
\text { calculation of unit costs. Some shortcomings/limitations } \\
\text { were identified. }\end{array}$ & 6.8 \\
\hline
\end{tabular}




\begin{tabular}{|c|c|c|}
\hline Question & $\begin{array}{c}\text { Response } \\
\end{array}$ & $\begin{array}{c}\text { Para } \\
\operatorname{Ref}(\mathbf{s})\end{array}$ \\
\hline $\begin{array}{lrr}6 . \quad \text { Were } & \text { costs } & \text { and } \\
\text { consequences } & & \text { valued } \\
\text { credibly? } & & \end{array}$ & $\begin{array}{l}\text { Costs of providing allogeneic blood from NHSBT needed } \\
\text { manipulation to isolate further detail. Transfer prices were } \\
\text { extracted from the NHSBT charge by reference to the } \\
\text { NHSBT audited accounts and an estimate for VAT was } \\
\text { extracted from cell salvage operating costs. These were } \\
\text { mainly from agreed supplier prices. Running costs were } \\
\text { calculated by utilising estimated energy usage and price } \\
\text { of KwH. } \\
\text { Extraction of the transfer prices allowed analysis from } \\
\text { both a financial and economic perspective. }\end{array}$ & 6.14 \\
\hline $\begin{array}{lll}\text { 7. Were costs } & \text { and } \\
\text { consequences adjusted } & \text { for } \\
\text { differential timing? } & \end{array}$ & $\begin{array}{l}\text { Not directly applicable. All activity information collected } \\
\text { was within a six-month time frame, so no discounting } \\
\text { required. Equivalent annualised costs were utilised for } \\
\text { depreciation of equipment, these costs were not materially } \\
\text { different between a financial and economic approach. }\end{array}$ & 6.10 \\
\hline $\begin{array}{l}\text { 8. Was an incremental } \\
\text { analysis of costs and } \\
\text { consequence of alternatives } \\
\text { performed? }\end{array}$ & $\begin{array}{l}\text { Extensive statistical analysis to establish homogeneity of } \\
\text { patient characteristics and treatment was utilised. Basic } \\
\text { sensitivity analysis to check the alternative of cell salvage } \\
\text { costs } \mathrm{v} \text { allogeneic blood costs and units utilised was } \\
\text { undertaken. An incremental analysis of costs was not } \\
\text { explicitly calculated given the significant difference in } \\
\text { costs between salvaged and allogeneic blood. }\end{array}$ & $\begin{array}{l}6.3 \\
6.4 \\
6.15\end{array}$ \\
\hline $\begin{array}{l}\text { 9. Was uncertainty in the } \\
\text { estimates of costs and } \\
\text { consequences adequately } \\
\text { characterized? }\end{array}$ & $\begin{array}{l}\text { The information from NHSBT breaking down the unit } \\
\text { cost/price of } £ 122 \text { has to be taken on face value and } \\
\text { cannot be verified as this breakdown is relatively } \\
\text { confidential and would need to be reworked. This price } \\
\text { has remained relatively static since } 2010 \text {. A reconciliation } \\
\text { to the published, audited, accounts for } 2010 / 11 \text { was } \\
\text { undertaken to generate reassurance } \\
\text { It is likely, given the continuing redundancy programme, } \\
\text { downsizing of the estate stock etc, that fixed costs are } \\
\text { being removed, implying the profile of costs are } \\
\text { changing. In real terms there has therefore been a price } \\
\text { decrease. }\end{array}$ & $\begin{array}{l}1.23 \\
2.2\end{array}$ \\
\hline $\begin{array}{l}\text { 10. Did the presentation and } \\
\text { discussion of study results } \\
\text { include all issues of concern } \\
\text { to users? }\end{array}$ & $\begin{array}{l}\text { Conclusions were based on the assessment that this was a } \\
\text { cost minimisation analysis. They were compared to the } \\
\text { conclusions of other studies in the literature review and } \\
\text { information on other sites' transfusion rates. } \\
\text { It is not clear if any of the patients were Jehovah's } \\
\text { Witnesses who explicitly rejected an allogeneic blood } \\
\text { transfusion regardless of the clinical judgement. Given } \\
\text { there are an estimated } 138,000 \mathrm{JW} \text { followers in UK } \\
(0.21 \% \text { of population-JW website accessed } 4 \text { March } \\
2018) \text { it is likely that only } 1 \text { out of the } 498 \text { patients was a } \\
\text { JW patient. } \\
\text { Issues relating to LOS were addressed, however one } \\
\text { cannot say with absolute certainty that cell salvage has } \\
\text { avoided allogeneic transfusions at RCH } \\
\text { The conclusions are likely to be relevant to other } \\
\text { orthopaedic procedures (especially total knee replacement } \\
\text { surgery) but not Cardiac procedures where the blood loss } \\
\text { is generally higher and only intra-operative cell salvage is } \\
\text { applicable. } \\
\text { It is therefore recommended that a similar model is } \\
\text { adopted to study Cardiac patients. }\end{array}$ & $\begin{array}{l}6.5 \\
\& \\
7.5\end{array}$ \\
\hline
\end{tabular}


A summary of all the associated costs is reproduced from table 80 and shown in table 83 below:

Table 83. Unit Blood Costs for Primary Total Hip Replacement Surgery by Site by Operation

\begin{tabular}{|l|r|l|l|l|}
\hline $\begin{array}{l}\text { Hospital } \\
\text { Vategory }\end{array}$ & $\begin{array}{l}\text { South } \\
\text { Manchester }\end{array}$ & $\begin{array}{l}\text { Royal } \\
\text { Cornwall } \\
\text { without Cell } \\
\text { Salvage }\end{array}$ & $\begin{array}{l}\text { Spec } \\
\text { Orthopaedic } \\
\text { Centre }\end{array}$ & $\begin{array}{l}\text { Royal } \\
\text { Cornwall } \\
\text { with Cell } \\
\text { Salvage }\end{array}$ \\
\hline $\begin{array}{l}\text { Unit Blood Cost per Operation } \\
\text { Financial Analysis Method }\end{array}$ & $£ 22.25$ & $£ 22.18$ & $£ 41.85$ & $£ 171.61$ \\
\hline $\begin{array}{l}\text { Unit Blood Cost per Operation } \\
\text { Cost Minimisation Method }\end{array}$ & $£ 19.11$ & $£ 19.03$ & $£ 35.94$ & $£ 144.52$ \\
\hline
\end{tabular}

From both a financial and economic assessment cell salvage is still showing that it is not cost effective in primary total hip replacement surgery. The costs of cell salvage consumables are increasing the overall blood costs considerably. Against an existing low allogeneic transfusion rate (without reinfusions or allogeneic transfusions) at the Royal Cornwall Hospitals, the allogeneic transfusion rate is unlikely to drop much lower; therefore, the use of cell salvage in primary total hip replacement surgery would only generate marginal savings. Cell salvage cannot therefore be viewed as cost effective in primary total hip replacement surgery. It is also likely that Patient Blood Management initiatives have lowered the 'baseline' allogeneic transfusion rate at South Manchester with the potential to decrease this for the SOC.

\subsection{Objective Three: Investigate Other Issues}

To the best of the researcher's knowledge no study has been undertaken to gauge the views of blood donors regarding cell salvage or other blood avoiding techniques. It may be that donors feel their time is precious and, if some donations could be replaced by a machine, then the donor would not need to donate as often. This may alter the donor's view point to one that believes allogeneic blood is only required to replace more expensive cell salvage rather than focusing on the 'life-saving' capabilities. The contrasting view would be that active donors need to be retained to meet potential increases in demand. This potential conflict would be best discussed away from the media. 
The advent of on line bookings and larger venues can make the matching of donor supply to blood demand more effective. This is likely to encourage younger donors (including the 'Class of 96', para 1.10) to attend more frequently. There will obviously be an additional cost associated with this.

\section{Manufacturer's Claims}

The investor discussions with the manufacturer Haemonetics in para 1.9 pointed to a decrease in usage and hence demand for the OrthoPat post-operative cell salvage machine and the associated consumables (disposables). The reference to costs of allogeneic blood in the OrthoPat brochure is shown in appendix 1 and can still (5 April 2018) be viewed on the Haemonetics website. The brochure still quotes that a unit of blood costs "more than $\$ 1,400$ ". The reference is to an article by Dr Aryeh Shander (Shander et al (2007)). Dr Shander was one of the authors of the "threepillar approach" (para 5.5), that was the foundation for the Patient Blood Management (PBM) initiative. The three-pillar approach explicitly recommended post-operative cell salvage and this recommendation was echoed in the UK PBM guidance issued in June 2014. There would obviously be differences in the exchange rate and relative purchasing power differences, but $\$ 1,400$ would equate to a UK unit of allogeneic blood costing over $£ 1,000$. This is not realistic. Additionally, in 2009 UPMC at Pittsburgh were paying c. $\$ 300$ per unit of allogeneic blood. The indications are that the costings supporting the OrthoPat cell salvage machine are substantially overstated irrespective of whether these have been derived from a financial or economic approach.

\section{Length of Stay}

The longer LOS in South Manchester is likely to be associated with a number of key factors:

- A higher incidence of pre-operative anaemia; highlighted by the higher proportion of patients below the WHO anaemia criteria (para 6.3).

- The day of the week scheduled for primary total hip replacement surgery with recovery coinciding with the level of lower therapy support being available. This can prolong the overall recovery time for the patient and therefore impact on the time to discharge. 
- The low number of discharges that actually occur on a weekend.

The severity of the operation/comorbidities and the patients' age have not been identified as contributors in the statistical analysis as these are not significantly different from the other two sites. The impact on the difference in LOS at South Manchester was estimated by regression with the R square value of 36.3\% (para 6.5). This points to additional factors influencing the difference. However, the operating day should not be considered in isolation. As highlighted in table 47, operations undertaken on a Tuesday/Wednesday imply a correlation with a longer length of stay at South Manchester than the other two centres.

The day of the week of surgery is therefore likely to be significant. $61 \%$ of patients at South Manchester have their operation on a Wednesday. These patients should be commencing their recovery programme with the therapy support commencing by the Friday. This is likely to be interrupted with little therapy support available on the weekend.

Munoz et al (2012) highlighted that the line of causation was that if the patient's $\mathrm{Hb}$ level was low this would slow the recovery. An allogeneic transfusion would therefore be required to increase the Hb level. Munoz et al (2012) noted the LOS for patients who had an allogeneic transfusion was a day longer. It was highlighted in the literature review that there was a (potentially unintended) view that the absence of an allogeneic transfusion was the reason for a lower LOS. The SOC has indicated this is not the case since their LOS is similar to the Royal Cornwall Hospitals. The allogeneic transfusion is likely to be an indicator that the patient needs further support in his/her comparatively slower recovery, not a cause of the increased LOS.

The indication is therefore that the LOS is, in part, a function of the day of the week of the surgery coinciding with the associated availability of therapy support. Additionally, the rate of discharge on the weekend is significantly lower at South Manchester than the other two sites. This may point to a lower number of staff available at the weekend to manage the discharge process.

There may be capacity (both space and clinical resource) issues in moving the theatre lists to another day. It seems, however, that if there was a shift towards the end of the week then the patients' recovery would still be likely to fall foul of the lack of 
therapy support on the weekend. Moving to a seven-day working week at South Manchester would circumvent the 'weekend effect' permitting more weekend therapy support for patients who had their operations later in the week and allowing more weekend discharges. More weekend therapy support is now in place at South Manchester and it would be useful to rework the analysis with more recent activity to verify this impact is now minimised and LOS has fallen.

\section{Variation in Severity of Cases and Comorbidities}

Discussions with the SOC staff pointed to their higher transfusion rate relating to more operations being undertaken at the higher end of the HB12B range with potentially more comorbidities and complications. This is a possible explanation, given that the centre deals with more specialist orthopaedic patients but there has been a significant time elapsed since the data was extracted all the information has been archived. It would take a lot of time and resource to drill down the old data beyond HRG level. As noted earlier the HRG analysis is already more detailed than any previous study on primary hip replacement surgery. It was also noted that the LOS was not significantly different between the Royal Cornwall Hospital and the Specialist Orthopaedic Centre where patients did not have an allogeneic transfusion. Arguably, the patients may have had similar comorbidities giving a similar LOS or, however, the Specialist Orthopaedic Centre patients could have had more comorbidities but the potentially more specialist service ensured a relatively quick recovery. This issue is highly subjective with no further evidence available to make a judgement.

Table 57 (page 166) compared the least invasive HRG (HB12C) activity in the three sites where no allogeneic transfusions or Royal Cornwall Hospitals reinfusions was administered. The LOS is still significantly longer at South Manchester. The longer LOS cannot therefore be an issue relating to allogeneic transfusions or the utilising of cell salvage for these patients.

The older a patient the generally longer s/he will take to recover from surgery and the effects of the anaesthetic. Given both the mean and standard deviation of patients' ages are similar then the patients' age should not be a distorting factor to LOS in this analysis. 
Overall, adopting an approach to focus on comparative data relating to patients who did not have an allogeneic transfusion/reinfusion has established a baseline of patient data where it can be said $100 \%$ certainty that this data is not affected by cell salvage or allogeneic blood transfusions because these transfusions did not occur. The most striking aspects are that the LOS remained significantly longer in South Manchester and that there is a significantly higher proportion of patients presenting as anaemic. These patients are likely to take longer in their recovery and may therefore have an impact on lengthening the LOS.

Allied to the HRG discussion is the view that cell salvage should be more targeted. All patients may not need salvaging. It is highly unlikely that a patient retrospectively identified as a $\mathrm{HB} 12 \mathrm{C}$ HRG will require an allogeneic transfusion (table 53 page 161) therefore it would not be cost effective to aim to salvage all patients at the Royal Cornwall Hospitals. Likewise, with age and gender (table 34 page 142), where only one male across the three sites under the age of 65 required an allogeneic transfusion. This would be the case from both a financial and an economic perspective. Tio et al (2016) point to the need to identify which patients to salvage. The challenging aspect is therefore to predict which patients are at a higher risk of requiring an allogeneic transfusion. The Royal Cornwall Hospitals are arguably salvaging too many patients and the overall costs of operating cell salvage would obviously be reduced if cell salvage utilisation was lower. Tio et al (2016) calculate, for total knee replacement surgery, post-operative cell salvage would be required in seven patients to avoid one allogeneic unit. The cell salvage cost would therefore be more than ten times the cost of one allogeneic unit.

\subsection{Limitations}

As noted previously the hospital systems do not have the level of sophistication to easily extract information relating to when the patients' $\mathrm{Hb}$ readings were taken and when the allogenic donations were administered. As such, the summary information is limited to the number of allogeneic donations, if any, per patient and the lowest post-operative $\mathrm{Hb}$ level taken. It is highly likely that most of the allogeneic units were administered post-operatively. There is a level of reassurance that, if there was a significant post-operative blood loss, any associated co-morbidity would result in a higher resource HRG code being allocated. Similarly, there is a chance that the 
patient's post-operative $\mathrm{Hb}$ level was even lower than that recorded. If this happened it is likely that the patient was recovering more slowly and would have been attended to by a clinician. In these cases, an allogeneic blood transfusion may have been administered following an additional $\mathrm{Hb}$ reading being taken.

Though the sample sizes were relatively large the HRG analysis needed to be grouped in order that non-parametric analysis did not violate the key assumptions on numbers of samples. The grouping 'tight HRG' was an amalgam of all HRG codes not classed as HB12B or HB12C. This accounted for c. $9.6 \%$ of the 498 patient records. This group included both less and greater ' $\mathrm{CC}$ ' requirements hence the data could potentially distort the conclusions. Table 84 breaks down the activity by HRG. The Royal Cornwall Hospital has the highest proportion of the HB11 series of major HRGs (4.7\% against 2.0\% at South Manchester and 3.6\% at the SOC); thus, there is little chance this issue affects any conclusions on the allogeneic transfusion rate.

Table 84. Breakdown of HRGs by Site and Extraction of Major HRGs (HB11 Series)

\begin{tabular}{|l|r|l|l|r|}
\hline Row Labels & Manchester & $\begin{array}{l}\text { Royal } \\
\text { Cornwall }\end{array}$ & $\begin{array}{l}\text { Spec Orth } \\
\text { Centre }\end{array}$ & Total \\
\hline HB11A & 1 & 1 & - & 2 \\
\hline HB11B & 2 & 6 & 4 & 12 \\
\hline HB11C & - & 3 & 1 & 4 \\
\hline HB12A & 8 & 12 & 8 & 28 \\
\hline HB12B & 108 & 137 & 95 & 340 \\
\hline HB12C & 27 & 54 & 29 & 110 \\
\hline HB13Z & 2 & - & - & 2 \\
\hline Total & 148 & 213 & 137 & 498 \\
\hline $\begin{array}{l}\text { Major HRG } \\
\text { (HB11s) } \%\end{array}$ & & & & \\
\end{tabular}

The development of tranexamic acid was highlighted in para 1.9. During the period when the data for this thesis was collected (2010/2011) tranexamic acid was becoming widely used in surgery across the NHS. At the time, most dosages would be dispensed orally immediately prior to surgery. The means of application has since progressed and both intravenous and a local wound spray application has been developed. Confirmation was received from the three sites that tranexamic acid was administered to all patients however this was not formally verified in the information provided to the researcher. As such there is a risk that some patients may have not 
actually received a dosage of tranexamic acid, thereby potentially distorting the results.

The socio-economic background of the patients was not considered in the study. Generally, the more affluent and higher educated people lead a healthier lifestyle, including a healthy diet and exercise. It would therefore be more likely for patients in higher socio-economic groups to ensure they listened to the advice in the preoperative assessments.

Quality of surgery could potentially be a factor in influencing the requirement for an allogeneic blood transfusion leaving the researcher's assertions open to criticism. Generally, one would expect the quality of surgery to be of a high standard. Primary total hip replacement surgery is a routine procedure and hospital quality control procedures would indicate deviations from the expected outcome. The researcher discussed this with the three sites and had not been made aware of any issues in quality.

Similarly, the quality and level of post-operative therapy support may vary across sites. This has not been measured or clarified and therefore could impact on the patient's recovery. Given the relevant institute professional standards for physiotherapists and occupational therapists, the overall impact of any variation is unlikely. What may be more likely in international comparisons are that the amount, day and timing of therapy support (Husted et al (2008)) may cause variations.

The length of stay issues should not be taken in isolation for primary total hip replacement surgery. It may also be that other procedures exhibit a significantly shorter LOS at South Manchester than the Royal Cornwall Hospital because their recovery does not straddle a weekend. The indication in the statistics is that the LOS is likely to be a function of the day of the week of surgery for primary total hip replacement surgery only and not as a view of all specialties across the sites.

The analysis also does not consider readmissions due to the operation not being successful. The National Joint Registry 10 ${ }^{\text {th }}$ Annual Report (2013) estimated a national readmission rate of $7.6 \%$ for primary total hip replacement operations using PROMS (Patient Reported Outcome Measures) data. The significant areas of postoperative problems/complications highlighted in the report relate to wound problems 
including bleeding, urinary problems and allergic reactions to drugs. It is reasonable to therefore assume that allogeneic blood/cell salvage has not had any significant adverse impact on the surgery thereby necessitating a readmission.

Capital costs of cell salvage machines are estimated in the calculations. The acquisition cost of the capital items is 'sunk' and Horngren (1997) defines these as "Past costs that are unavoidable because they cannot be changed no matter what action is taken". From an economic perspective Nechyba (2011) defines a sunk cost as "an expense that is unaffected by the economic choice at hand". The choice to salvage is therefore not based on the capital cost of the acquired equipment. Depreciation and the opportunity cost relating to the cell salvage equipment was calculated in para 6.10. From both a financial and an economic perspective the amounts were immaterial, given the long forecast life of the equipment. These calculated costs were also notional given the equipment had been acquired and replaced on a piecemeal basis over the years. They may be more relevant if a decision was taken to buy a new machine; in which case the calculations could be used to support a 'make $\mathrm{v}$ buy' decision. This approach is also consistent with Horngren's 'concept of relevance' where managers focus on future expected results (para 2.2).

The transfer prices adjustment for the cost of an allogeneic blood unit was based on the annual published accounts for 2010/11 and was obviously an estimate. A more accurate calculation could have been derived using the NHSBT capital asset management system however this information was not available to the researcher. A crude estimate of the unit capital cost within the $£ 122$ price of an allogeneic unit would be to take $73.7 \%$ of the depreciation element of $£ 13,892 \mathrm{k}$ (table 85 below) and divide by the $1,838 \mathrm{k}$ units of blood issued. The resultant estimate is therefore $\mathrm{c}$. $£ 5.57$ per allogeneic unit.

The associated maintenance and depreciation costs of the cell salvage machines were based on a mix of national and local activity. The machines were classed as a 'grouped asset' and, at the time, the depreciation costs were not charged out to the relevant cost centres in the Royal Cornwall Hospitals. The machines were acquired over different dates and an acquisition cost of $£ 15,000$ (including VAT) was assumed, based on the approximate list prices at the time. It is likely that these costs were 
over-estimated however they were not deemed to have skewed the overall cost comparison. The total amount of costs involved were not material (figure 26).

The depreciation and the transfer price for a unit of allogeneic blood were extracted from the summary of the 2010/11 audited accounts from NHS Blood and Transplant (para 6.14). The various taxation elements extracted were based on apportionments along with an overall apportionment of the NHSBT 'Group Costs'; these are primarily overhead costs. Complex areas such as NHS VAT accounting for contracted out services were estimated on the balances in the reported categories in the accounts. An actual assessment based on the detailed analysis of VAT returns was unavailable. In order to check the overall reasonableness of the derivation of the economic cost of an allogeneic unit of blood (table 76) the NHSBT depreciation element (reported as "capital charges" in the accounts) was added back into the calculations and apportioned on the basis of expenditure over the three management units. The elements of the transfer payments were also added back. Table 85 below estimates a total cost of $£ 130$ per unit. This is close to the $£ 122$ actual charge provided independently by the NHSBT Finance Department implying a level of accuracy of the methodology to derive the economic cost of an allogeneic unit from the limited published information available. A much more accurate calculation could be derived from having full access to NHSBT's reporting systems however this access was not available.

Table 85. Reworked NHSBT 2010/11 Annual Accounts Totals to Verify Internal Market Price of An Allogeneic Unit

\begin{tabular}{|c|c|c|c|c|}
\hline & Total & $\begin{array}{c}\text { Blood } \\
\text { Compone } \\
\text { nts }\end{array}$ & $\begin{array}{l}\text { Spec } \\
\text { Servs }\end{array}$ & ODT \\
\hline & $£^{\prime} 000$ & $£^{\prime} 000$ & $£^{\prime} 000$ & $£^{\prime} 000$ \\
\hline Overall Expenditure less Capital Charges & 372,821 & 276,002 & 52,478 & 44,341 \\
\hline Apportion depreciation & 18,765 & 13,892 & 2,641 & 2,232 \\
\hline Add back transfer payments & 45,786 & 33,896 & 6,445 & 5,446 \\
\hline Sub total & 437,372 & 323,789 & 61,565 & 52,018 \\
\hline At $73.7 \%$ to reflect red cell element & & 238,633 & & \\
\hline Divide by $1,838,000$ units is sued & & $£ 130$ & & \\
\hline
\end{tabular}

The overhead apportionment methodology was very basic in the extraction of an estimate of the economic costs from the published accounts. Additionally, there was a reluctance to share the information by former colleagues at NHSBT on the detail behind the breakdown of the $£ 122$ into the related activities. The implication is, 
however, that the derived figures are reasonably verifiable against the published accounts totals. These are audited and therefore give an additional level of reassurance of independent verification.

Further apportionments were required to estimate the maintenance costs and depreciation for the cell salvage machines. These were based on an overall split of the orthopaedic HRGs.

A further limitation in this analysis is the calculations to derive the costs associated with the allogeneic blood donor. As highlighted in the literature review these costs are generally ignored. The donor survey indicated lost production time to donate was significant primarily because the majority of employers did not deduct pay for donors who donated in work time nor did they insist on the donors making up the lost time. The calculation is relatively subjective, based on Office for National Statistics median earnings 2011 final results, and this area would therefore benefit from an updated study. In hindsight one of the survey questions (Q 11) could have been made clearer but the overall estimate enabled a new complexion to be added into the discussion and allowed an overall cost of blood usage in operations to be calculated.

The comparative prices of units of red cells, charged by NHSBT, are effectively averages. It was noted in para 6.12 that Horngren et al (2015) advises these average costs are treated "cautiously". Given, however, that NHSBT is effectively reactive to activity decreases and needs to maintain a presence across England to supply hospitals the average costs are therefore useful as an indicative tool. Other forms of costing from a financial perspective may not be appropriate given the price of an allogeneic unit of blood is fixed over a time period and most consumables' costs are also at negotiated fixed rates over a particular activity range.

Most costs associated with cell salvage will therefore be similar between hospital trusts. There may be some variation in the local agreements struck with suppliers. These were viewed as more competitive than the NHS national framework prices. A comparison of costs between hospitals utilising cell salvage would be possible subject to any confidentiality clauses on prices imposed by the manufacturers. 
Arguably the most significant limitation of this study is that since there is no significant difference between those patients salvaged and not salvaged (para 6.6 page 160) at the Royal Cornwall Hospitals the researcher cannot be certain that reinfusing has avoided an allogeneic transfusion. The numbers of patients receiving an allogeneic transfusion was too low to undertake a statistical comparison. The potential allegations of bias would arise if patients were pre-selected to undergo or not have, cell salvage. The more restrictive blood management techniques (para 6.7 page 163) adopted by the Royal Cornwall Hospitals imply a lower likelihood of a patient receiving an allogeneic transfusion. The implication is therefore that allogeneic transfusion rate differences between the sites are influenced by various factors and cannot be fully explained by using, or not using, cell salvage.

\subsection{Reflection and Assessment of Position at June 2018}

Allogeneic blood usage has continued to fall year on year. It is highly likely that the fall is due to less allogeneic blood being required in the surgical environment. The impact of the three Better Blood Transfusion initiatives (para 1.11 page 18) has prompted a reassessment of allogeneic blood requirements. This laid the foundation to the international Patient Blood Management (PBM) approach from 2014. Cell salvage was promoted as a means of supporting the avoidance of an allogeneic blood transfusion but its costs, both from a financial and economic viewpoint (para 6.15) seem prohibitive compared to a course of iron tablets (less than £1) or a dose of tranexamic acid (c £1-£2 per ampoule) prior to surgery. These options can significantly reduce the allogeneic transfusion rate.

The researcher found universal acceptance that a lower allogeneic transfusion rate was more favourable for the patient. He would have liked to pursue the difference in viewpoint with the Bavarian/German Blood Service (para 1.15 page 26) however this was beyond the scope of the thesis and may be revisited in the future in the event of any collaborative work arising with NHSBT.

Similarly, seeking explanations for the differing length of stay in response to various articles in the literature review was challenging. Previous studies did not undertake detailed work on developing a 'background count' where information on nontransfused patients was compared. The researcher was pleased that he had devoted a 
lot of time to this area. Given the length of stay was significantly longer at South Manchester for patients who did not have an allogeneic transfusion the researcher could say with confidence that the longer average length of stay was not a factor of allogeneic transfusions but of other issues such as the availability of staff on a weekend to provide therapy support and patient discharge procedures. Noting that the majority of total hip replacement patients have their operation at South Manchester on a Wednesday exacerbates the issue as patients should have been on their way to recovery by the weekend however the staff availability was a limiting factor. The researcher was satisfied that he was able to independently highlight this issue allowing South Manchester to go some way to addressing this challenge.

The focus of the economic appraisal was finalised as a cost minimisation analysis. Cost benefit analysis was considered but was excluded (point 6, table 79, page 188) as the length of stay was not deemed to be a factor of having an allogeneic blood transfusion. As noted in para 2.4 the 'output' of the study is a successful primary total hip replacement operation and the focus is therefore on the 'input' of the management of blood (either allogeneic, salvaged or avoided totally).

The researcher has had follow up discussions with the Royal Cornwall Hospitals and has shared his activity information with the cell salvage lead. As at April 2018 the Royal Cornwall Hospitals do not now use post-operative cell salvage (the OrthoPat machine) on the grounds of the cost of consumables and inflexibility since there is no 'collect first' option. The researcher's average cost comparison (para 6.8 page 172) supported the Royal Cornwall Hospitals in reaching this decision.

The OrthoPat Advance (para 1.9, page 13) has still not come on the market and, in 2017, the US manufacturers, Haemonetics, closed down their manufacturing and distribution plant near Glasgow. 270 jobs were shed, and the work was transferred to Malaysia. An additional plant was also closed in Italy. These closures are consistent with the lower demand for both blood donation and cell salvage equipment across Europe.

The Royal Cornwall Hospitals are also now more selective on the patients they salvage. This decision was again based, in part, on the researcher's findings. The cell salvage lead has also expanded his role to lead the Trust's anaemia service, 
acknowledging the significant interrelationships between the two elements of blood management.

The Association of Anaesthetists of Great Britain and Ireland (AAGBI) guidelines still recommend intraoperative and post-operative cell salvage be "considered", prior to orthopaedic surgery. In reality, it would be difficult for the AAGBI to specifically recommend adoption or non-adoption of cell salvage in specific applications e.g. primary total hip replacement surgery, given each patient will have different characteristics. The Royal Cornwall Hospitals approach therefore remains consistent with the guideline.

Technology is also developing in areas such as wound closure technology with products being utilised to stem bleeding more quickly and hence reduce blood loss. Widespread use would be likely to decrease the demand for allogeneic blood. These technologies are currently still being developed but will be likely to add to the debate on potentially reducing the impact of cell salvage.

In April 2018 the researcher had a discussion with the Chief Nurse at NHSBT. She highlighted that allogeneic transfusion rates are continuing to fall and are likely to have been a combination of all the blood avoidance methods in PBM. She confirmed that cell salvage is still promoted by the UK Cell Salvage Action Group (para 1.15 page 25), but their utilisation studies and anecdotal evidence indicate activity is still at approximately the same rate across the UK as 2011.

The National Comparative Audit of Blood Transfusion 2016 Repeat Audit was developed by NHSBT in conjunction with the Royal College of Surgeons and the Faculty of Intensive Care Medicine. It gathered information on the impact of Patient Blood Management on transfusion rates across 156 hospital sites in the UK and Ireland. The data is still being analysed as part of a wider study, reporting in 2019 (the "AFFINITIE" Programme), however the interim conclusions to the report highlight that:

- Hospital Transfusion Committees (HTCs) should ensure the use of tranexamic acid is the "standard of care for surgical patients expected to have moderate or more significant blood loss". 
- "The HTC should identify the need for intra-operative cell salvage and resource appropriately; this would normally be used in relevant high blood loss procedures".

These conclusions support the researcher's view that the impact of tranexamic acid is a crucial part of the portfolio of blood avoidance techniques. The report is not as enthusiastic on cell salvage and leaves the door open for local interpretation on the need for cell salvage; being consistent with the AAGBI recommendations above.

In terms of costs, cell salvage is at the highest end of the cost spectrum of allogeneic blood avoidance methods and, as noted above, iron tablets and tranexamic acid are much cheaper methods of avoiding an allogeneic transfusion. The future requirement for cell salvage in surgery is therefore likely to be in the more complex cases that involve a higher blood loss and associated steeper fall in $\mathrm{Hb}$ levels. These cases are more likely to be within Cardiac surgery. These cases may, in turn, be more likely to be in an emergency setting where obviously the pre-operative $\mathrm{Hb}$ levels have not been managed and the programme of preparatory iron tablets cannot be introduced prior to surgery.

The utilisation of the HRG coding added a new dimension to the comparison and gave additional reassurance that the patients conditions were similar across the three sites. What was surprising was that this comparative analysis had not been undertaken previously. In part, it seems to be due to lack of knowledge by clinicians over the HRG process. Most of the studies in cell salvage are written by clinicians. Their 'currency' is the operation and view a total hip replacement operation as being the unit of measurement. In discussions most clinicians had not heard of the term 'HRG'. It is reassuring to see that the Royal Cornwall Hospitals systems can now generate monthly reports that analyse blood transfusions by HRG. Arguably the researcher could assert that this thesis adds an element of doubt to previous published studies that do not have this additional homogeneity check. It is refreshing that US studies have commenced work in this area (Frank et al (2014)).

On reflection, the researcher made significant headway in reaching a baseline; allowing a 'background count' across the three sites to isolate any anomalies. It is likely that the gap between the transfusion rates at South Manchester and the Royal Cornwall Hospitals would be narrower if the pre-operative $\mathrm{Hb}$ levels at South 
Manchester were addressed. All other things being equal; the narrower the apparent gap in allogeneic transfusion rates the weaker the assertion that cell salvage is delivering benefits. It is, frustratingly, this gap in allogeneic transfusion rates that the researcher cannot fully explain. A repeat study focusing on patients solely within the WHO $\mathrm{Hb}$ levels may eliminate the impact of pre-operative $\mathrm{Hb}$ disparities but leave the study open to allegations of bias in the cohort for selection.

\subsection{Summary of Chapter 7}

This thesis has segregated the activity into a number of distinct clusters (e.g. HRG, patients with/without cell salvage and reinfusions with/without transfusions etc) in order to achieve a baseline comparison of patients within three sites who did not have an allogeneic blood transfusion or utilise reinfused blood. The strong indications are that the Royal Cornwall Hospitals can manage to maintain a lower allogeneic transfusion rate without the requirement to salvage primary total hip replacement patients.

The study has ensured the relevant costs are identifiable and quantifiable from both a financial and economic approach. These costs vary significantly but both sets are consistent with the view that cell salvage in primary total hip replacement surgery will not support a reduction in overall blood costs (allogeneic or salvaged).

Given the relatively long duration to complete this study the recent discussions with the Royal Cornwall Hospitals and NHSBT bear out the researcher's thoughts that cell salvage cannot be utilised in isolation. The continuing fall in the overall allogeneic blood usage is unlikely to be a product of cell salvage given national cell salvage activity has been relatively unchanged since 2011. It is therefore much more likely that the low cost and high impact recommendations from the 2014 Patient Blood Management guidance are having this effect. These include pre-operative $\mathrm{Hb}$ management, tranexamic acid and changes in administration of allogeneic blood to avoid administrating two allogeneic units at the same time.

The researcher approached the study from a different angle than most other studies; using HRG coding and, initially, comparing data from patients who did not have an allogeneic transfusion or had salvaged blood reinfused. This approach gives more 
confidence that the costs can be readily compared from both a financial and economic viewpoint. 


\section{Chapter 8. Conclusions}

\subsection{Introduction}

This chapter summarises the research work and confirms whether, in the researcher's view, the research question has been answered.

Is cell salvage an appropriate method of blood conservation to support the reduction in costs associated with the collection and utilisation of allogeneic blood?

\subsection{Response to the Research Question}

A short answer to the research question would be that cell salvage is currently not an appropriate method to support the reduction in costs associated with the collection and utilisation of allogeneic blood in primary total hip replacement surgery. This conclusion is the same from both a financial and an economic approach.

The main reason for coming to this conclusion is that only a small percentage of successful primary total hip replacement operations now require an allogeneic blood transfusion. This is due a combination of factors associated with the development of best practice in managing the use and application of allogeneic blood along with less invasive surgery causing lower blood loss. Cell salvage is one of an array of allogeneic blood avoidance techniques but is much more expensive than ensuring a patient is adequately prepared for surgery; this can be as simple as prescribing a course of iron tablets for the patient to take after the pre-operative assessment and prior to surgery. Additionally, clinicians now widely use antifibrinolytic drugs such as tranexamic acid that prevent blood clots breaking down and hence slow down blood loss. If these procedures are adopted the impact of cell salvage in primary total hip replacement surgery is marginal and the cell salvage costs compared to the costs of allogeneic blood avoided are prohibitive. This conclusion has been reached by initially comparing the costs associated with the NHS internal market for blood with cell salvage costs from both a financial and economic analysis. In both comparisons cell salvage was deemed more expensive and hence not cost effective. 
The internal market for allogeneic blood and the associated high price is likely to have stimulated interest in alternatives to allogeneic blood such as cell salvage. The relative price of allogeneic blood is continuing to falling in real terms due to the continual fall in the demand for the product. This fall in demand has continued from 2000 to the present. As the real term cost of utilizing allogeneic blood is falling (para 1.23) the perceived 'savings' at hospital level by using cell salvage to avoid an allogeneic transfusion will also fall.

The approach to the study was significantly different to traditional studies reviewed in chapter four, in that the study was able to secure a baseline position to compare sites by initially excluding data from patients who received allogeneic blood transfusions or had their own blood recycled. This, along with using HRG data, allowed any differences in patient profile and preparation to be tested. These differences were therefore isolated before the comparison extended to allogeneic transfusions and reinfusions of salvaged blood. The key differences identified were pre-operative $\mathrm{Hb}$ levels and the length of stay.

The use of allogeneic blood was concluded not to have any significant impact on length of stay. Other factors such as availability of weekend therapy staff to support the recovery programme and staff available on the weekend to discharge the patients were considered more influential. It must be stressed that this analysis is not a criticism of South Manchester's scheduling of most orthopaedic surgery on a Wednesday. The other two sites may have corresponding challenges with other specialties. Examining this issue in isolation is therefore unlikely to lead to any significant conclusions. It does, however, point to length of stay being an unnecessary distraction in the discussion on allogeneic blood and cell salvage.

The US term 'transfusion trigger' was still apparent in the data with the Royal Cornwall Hospitals' restrictive transfusion policy contributing towards the lower allogeneic transfusion rate. This, again, is another blood conservation measure working in tandem with cell salvage. The evidence points to these measures running concurrently at the Royal Cornwall Hospitals and their joint impact leads to a lower allogeneic transfusion rate. The difference, however, between the costs of the different measures is significant ranging from around $£ 1$ for a packet of iron tablets to over $£ 200$ (from a financial perspective) for post-operative cell salvage. 
Further studies are therefore recommended to investigate the costs associated with cell salvage in operations with a higher predicted blood loss e.g. in various Cardiac procedures or more specialist elective surgery.

\subsection{Overall Conclusion}

In primary total hip replacement surgery, cell salvage has been found not to be effective in supporting the Patient Blood Management process and reducing costs associated with the collection and utilisation of allogeneic blood. Cheaper and easier to implement methods exist to minimise the potential requirements for an allogeneic blood transfusion and it is recommended that hospitals focus on these methods to minimise their allogeneic blood requirements for this branch of orthopaedic surgery. 


\section{Glossary}

\section{Term}

Alloimmunization

Autologous

Transfusion

Anticoagulant

Antifibrinolytic

Arthroplasty

Cross Matching

Group and Screen

Haematocrit

Haemoglobin $(\mathrm{Hb})$

Haemopoiesis

\section{Definition}

An immune response to foreign bodies in allogeneic blood.

A transfusion involving the patient's own blood. This includes cell salvage as well as forms of pre-deposit blood

A substance that helps prevent blood clotting. This will be mixed in with the shed blood during the recycling process (see figure 6).

Drugs that prevent blood clots breaking down and hence slowing down blood loss.

Replacing or reconstructing a joint in the body.

A check undertaken on a sample of the patient's blood to ensure the best match with allogeneic blood by minimising the level of antibodies. This is focused on the red cells in the blood.

A wider cluster of tests than cross matching to determine the patient's blood group and antibodies.

The volume of red cells in the blood expressed as a percentage of blood volume.

The protein molecule in blood that carries oxygen around the body. This is measured in grams per litre (grams per decilitre is still a common measurement in the US). Generally, the higher the better as this implies oxygen will travel faster around the body and assist recovery.

Where the body generates the production of its own blood and blood components.

The situation where the body is losing blood. 
Heteroscedasticity

SAGM
Where the size of the errors differs across the values of an independent variable. Taking the logarithm lowers the relative difference to a more manageable comparison.

A preservative added to allogeneic blood. 


\section{Bibliography}

Agostini V, Delucia M, Gagliardi S, Gasperoni A, Santarelli R. (2012). Preoperative Use of Erythropoietin as an Alternative to Preoperative Blood Donation Programme in Elective Orthopedic Surgery. Transfusion Alternatives in Transfusion Medicine. 12/2(22), 1295-9022

Allanki S (2009). Transfusion Alternatives in Liver Transplantation: Single Center Study. Vox Sanguinis. 96/(242), 0042-9007

Aluri S., Wrench I.J., Wilson M. (2012). Cell Salvage During Caesarean Section Reduces Perioperative Allogeneic Red Cell Transfusion in Suitable Patients. International Journal of Obstetric Anesthesia 21/(S17). 0959-289X

Ambarkova Vilarova E.; Blagoevska M.; Kocovska E.; Mitrev Z. (2010). Use of Red Cell Savage for Abdominal Aneurysm Repair and Transfusion Requirements. Vox Sanguinis. 99/(420), 0042-9007

American Association of Blood Banks (2014). Patient Blood Management. www.aabb.org/pbm. [Accessed 19 January 2016] American Cancer Society. Blood Transfusion and Donation. https://www.cancer.org/treatment/treatments-and-side-effects/treatment-types/bloodtransfusion-and-donation/how-blood-transfusions-are-done.html. [Accessed 28 Oct 2014]

Amin M, Fergusson D, Wilson K, Tinmouth A, Aziz A, Coyle D, Hebert P (2004). The Societal Unit Cost of Allogenic Red Blood Cells and Red Blood Cell Transfusion in Canada. Transfusion 44(10), 1479-1486

Anderson S; Panizza B (2010). Are Cell Salvage and Autologous Blood Transfusion Safe in Endonasal Surgery? Otolaryngology-Head \& Neck Surgery. 142/3 Suppl $1(0-), 01945998$

Ashworth A; Hanison J; Klein AA (2010). Is Cell Salvage Safe in Transnasal Surgery? Anaesthesia. 65/5(534-535), 00032409

Association of Anaesthetists of Great Britain and Ireland (AAGBI). Cell Salvage Guidelines. www.aagbi.org [Accessed 14 April 2018]

Attaran S.; McIlroy D.; Fabri B.M.; Pullan M.D. (2011). The Use of Cell Salvage in Routine Cardiac Surgery is Ineffective and Not Cost Effective and Should be Reserved for Selected Cases. Interactive Cardiovascular and Thoracic Surgery. 12/5(824-826), 1569-9293;1569-9285

Atwal NS, Bedi G, Lankester BJ, Campbell D, Gargan MF (2008). Management of Blood Loss in Periacetabular Osteotomy. HIP International 18/2(95-100), 11207000

Australian Red Cross Blood Service. Eligibility Criteria. www.donateblood.com.au/eligibility. [Accessed 18 March 2017] Aylin P, Alexandrescu R, Bottle A, Jen M, Mayer E (2013). Day of week of Procedure and 30 Day Mortality for Elective Surgery: Retrospective Analysis of Hospital Episode Statistics. BMJ 2013;346:f2424 
Baker, Robert A., Merry, Alan F. (2012). Cell Salvage Is Beneficial for All Cardiac Surgical Patients: Arguments for and Against. Journal of Extra-Corporeal Technology 44/1(0-), 00221058

Beliaev A.M, Marshall R.J, Gordon M, Smith W, Windsor, J.A. (2011). Clinical benefits and cost-effectiveness of allogeneic red blood cell transfusion in severe symptomatic anaemia. Vox Sanguinis. 103, 18-24

Bellam S, Rose P, Porter M (2014). Service Evaluation of Intraoperative Cell Salvage as Routine for All Caesarean Sections in a Tertiary Hospital. International Journal of Obstetric Anaesthesia 23/S55), 0959-289X

Berrizbeitia LD; Wry P; Fernandez J (2008). Repair of Acute Type A Aortic Dissection Without the Use of Blood Products. Heart \& Lung. 37/4(296-298), 01479563

Berry C (2011). Surgery that's a Cut Above the Rest. Health Service Journal 10 March 2011.

Bess R.S.; Lenke L.G. (2006). Blood Loss Minimisation and Blood Salvage Techniques for Complex Spinal Surgery. Neurosurgery Clinics of North America 17/3(227-234), 1042-3680.

Bhangu, Aneel, Nepogodiev, Dmitri, Doughty, Heidi, Bowley, Douglas M (2013). Intraoperative Cell Salvage in A Combat Support Hospital: A Prospective Proof of Concept Study. Transfusion 53/4(805-810), 00411132.

Bigsby E., Acharya M.R., Ward A.J., Chesser T.J. (2013). The Use of Blood Cell Salvage in Acetabular Fracture Internal Fixation Surgery. Journal of Orthopaedic Trauma 27/10(e230-e233), 0890-5339;1531-2291

Bird C (2006). Cell Salvage. Hospital Doctor /(24-24), 02623145

Blanchette C.M.; Wang P.F.; Joshi A.V.; Asmussen M.; Saunders W.; Kruse P. (2007). Cost and Utilisation of Blood Transfusion Associated with Spinal Surgeries in the United States. European Spine Journal 16/3(353-363), 0940-6719

Bouras I; Mingo O (2010). Should Cell Salvage be Used in Oncological Surgery? British Journal of Hospital Medicine, 71/1(57-57), 17508460

Bowen RE; Gardner S; Scaduto AA; Eagan M; Beckstead J (2010). Efficacy of Intraoperative Cell Salvage Systems in Paediatric Idiopathic Scoliosis Patients Undergoing Posterior Spinal Fusion with Segmental Spinal Instrumentation. Spine, 35/2(246-251), 03622436

Brearton C., Bhalla A., Mallaiah S., Barclay P. (2012). The Economic Benefits of Cell Salvage in Obstetric Haemorrhage. International Journal of Obstetric Anesthesia 21/4(329-333), 0959-289X;1532-3374

British Broadcasting Corporation. Blood Donors "Passing on Hepatitis E". www.bbc.co.uk. [Accessed 28 July 2014]

British Broadcasting Corporation. Blood Donors "Discovery Enables 'Mass Produced Blood'". www.bbc.co.uk. [Accessed 24 March 2017]

British Committee for Standards in Haematology. Predeposit Autologous Blood Donation. www.b-s-h.org.uk/guidelines/guidelines/policies-on-alternatives-toallogeneic-blood-transfusion-predeposit-autologous-blood-donation/. [Accessed 28 Oct 2014]

British Liver Trust. Hepatitis E. https://www.britishlivertrust.org.uk/liverinformation/liver-conditions/hepatitis-e/. [Accessed 13 August 2014] 
Brown C.V.R.; Foulkrod K.H.; Sadler H.T.; Richards E.K.; Biggan D.P.; Czysz C.; (2010). Autologous Blood Transfusion During Emergency Trauma Operations. Archives of Surgery, 145/7(690-694), 0004-0010;1538-3644

Buckley F.; O'Sullivan C.; Wolf B.; Lush C. (2011). Examining the Efficiency of Use of Cell Salvage in Elective Aortic Surgery in a District General Hospital. Transfusion Medicine, 21/(46), 0958-7578

Butchart A.G.; Abdy S. (2011). Are We Using Cell Salvage Enough? TATM, 12/1(26-27), 1295-9022

Bridgens JP; Evans CR; Dobson PM; Hamer AJ (2007). Intraoperative Red-Blood Cell Salvage in Revision Hip Surgery. Journal of Bone \& Joint Surgery, 89A/2(270275)

Campbell, J, Holland, C, Richens, D, Skinner, H (2012). Impact of Cell Salvage During Cardiac Surgery on the Thrombelastomeric Coagulation Profile: A Pilot Study. Perfusion 27/3(221-224), 02676591

Canan C.E., Myers J.A., Owens R.K., Crawford C.H., Djurasovic M., Burke L.O., Bratcher K.R., McCarthy K.J., Carreon L.Y. (2013). Blood Salvage Produces Higher Total Blood Product Costs in Single-Level Lumbar Spine Surgery. Spine 38/8(703708), 0362-2436;1528-1159

Canniff E., McCarthy K.F., Iohom G. (2012). The Use of Cell Salvage During Anaesthesia. European Journal of Anaesthesiology 29/(98), 0265-0215

Carey K., Paul A., MacLaughlin S., Garrido E. (2012). Blood Conservation in Adult Scoliosis Surgery: A Report of The First 15 Months of The New Scottish National Adult Spine Deformity Correction Service. British Journal of Anaesthesia 109/3(478P-479P), 0007-0912

Carless P, Henry D, Moxey A, O’Connell D, Fergusson DA (2004). Cell Salvage for Minimising Perioperative Allogeneic Blood Transfusion (Cochrane Review). The Cochrane Library, 2, 2004

Carless PA, Henry DA, Moxey AJ, O'Connell D, Brown T, Fergusson DA (2010). Cell Salvage for Minimising Perioperative Allogeneic Blood Transfusion. Cochrane Database Syst Rev. 2010; (4): CD001888

Catling S (2007). Blood Conservation Techniques in Obstetrics: A UK Perspective. International Journal of Obstetric Anaesthesia 16/3(241-249), 0959-289X

Catling S (2008). Intraoperative Cell Salvage in Obstetrics. Clinical Risk, 14/1(1417), 13562622

Catling S; Williams S; Freites O; Rees M; Davies C; Hopkins L (2009). Use of a Leucocyte Filter to Remove Tumour Cells from Intra-Operative Cell Salvage Blood. Anaesthesia, 63/12(1332-1338), 00032409

Catling S; Wrench I (2009). Cell Salvage at Caesarean Section: The Need for an Evidence-Based Approach. BJOG, 117/1(122-124), 14700328

Che, J., Tian, M., Ding, G., Huai, Q., Dong, P., Li, Y., Li, S. (2013). Effects Of Cell Salvage On Erythrocyte 2,3-Disphosphoglycerate And G-6- Pd Levels And Phosphatidylserine Expression. International Journal of Laboratory Hematology 35/4(385-392), 17515521 
Chieza J.T.; Sharafudeen S.; Skelton V.; Parry N. (2010). Types of Abnormal Placentation and IOCS: Do They All Benefit? Internat Jnl of Obstetric Anaesthesia, 19/(S34), 0959-289X

Choi, E S, Ahn, W S, Lee, J M, Jeon, J K, Kim, H C, Lim, Y J, Sim, J Y (2013). A Laboratory Study of The Effects of Processing Blood Through a Cell Salvage Device And Leucocyte Depletion Filter on Levels of Pro-Inflammatory Cytokines and Bradykinin.. Anaesthesia 68/12(1259-1265), 00032409

Clement R.C., Kamath A.F., Derman P.B., Garino J.P., Lee G.-C. (2012). Bipolar Sealing in Revision Total Hip Arthroplasty for Infection. Efficacy and Cost Analysis. Journal of Arthroplasty 27/7(1376-1381), 0883-5403;1532-8406

Clinical Services Journal. Improving Hip Fracture Care. January 2012 (46-49). http://content.yudu.com/A1v256/CSJjan12/resources/index.htm?referrerUrl=\&skipFl ashCheck=true [Accessed 11 April 2018]

Colomina M.J., Cassinello C., Diez-Lobo A., Hidalgo F., Aragon S., Duran L. (2013). Implementation of Patient Blood Management Program in Spain: Evaluation Survey. European Journal of Anaesthesiology 30/(97), 0265-0215

Courtemanche K., Elkouri S., Dugas J.-P., Beaudoin N., Bruneau L., Blair J.-F. (2013). Reduction in Allogeneic Blood Products with Routine Use of Autotransfusion in Open Elective Infrarenal Abdominal Aortic Aneurysm Repair. Vascular and Endovascular Surgery 47/8(595-598), 1538-5744;1938-9116

Cowlishaw PJ; Belavy D (2010). Is Cell Salvage Safe in Transnasal Surgery?. Anaesthesia, 65/2(209-209), 00032409

Crotty B (2006). Recycling Blood: Sharing the Benefits of Cell Salvage. Applied Health Economics \& Health Policy 5/1(5-10), 1175-5652

Crotty B, Grainger H (2010). When Blood Turns Green. Healthcare Finance. HFMA September 2010

Daniels G, Bromilow I. (2014). Essential Guide to Blood Groups. Wiley 2014.

Davies L; Brown TJ; Haynes S; Payne K; Elliott RA; McCollum C (2006). Cost Effectiveness of Cell Salvage and Alternative Methods of Minimising Perioperative Allogeneic Blood Transfusion: a Systematic Review and Economic Model. Health Technology Assessment 10/44(0-213), 13665278

DeBois W., Prata J., Elmer B., Liu J., Fominyam E., Salemi A. (2013). Improved Environmental Impact with Diversion Of Perfusion Bypass Circuit to Municipal Solid Waste. Journal of Extra-Corporeal Technology 45/2(143-145), 0022-1058 Department of Health (1998). Better Blood Transfusion. Health Service Circular. HSC 1998/224

Department of Health (2002). Better Blood Transfusion-Appropriate Use of Blood. Health Service Circular. HSC 2002/009

Department of Health (2007). Better Blood Transfusion-Safe and Appropriate Use of Blood. Health Service Circular. HSC 2007/001

Department of Health (2010). Enhanced Recovery Archived Website. http://webarchive.nationalarchives.gov.uk/20130107105354/http:/www.dh.gov.uk/en /Healthcare/Electivecare/Enhancedrecovery/DH_117433. [Accessed 19 October 
Department of Health (2011). National Schedule of Reference Costs 2010/11. www.gov.uk/government/publications/2010-11-reference-costs-publication.

Department of Health (2011). Innovation, Health and Wealth, Accelerating Adoption and Diffusion in the NHS.

http://webarchive.nationalarchives.gov.uk/20130107105354/http:/www.dh.gov.uk/pr od_consum_dh/groups/dh_digitalassets/documents/digitalasset/dh_134597.pdf [Accessed 26 March 2017]

Department of Health. Why a Blood Transfusion is Necessary. www.nhs.uk [Accessed 27 March 2014]

Dhawale AA, Shah SA, Sponseller PD, Bastrom T, Neiss G, Yorgova P, Newton PO, Yaszay B, Abel MF, Shufflebarger H, Gabos PG, Dabney KW, Miller F (2012). Are Antifibrinolytics Helpful in Decreasing Blood Loss And Transfusions During Spinal Fusion Surgery In Children With Cerebral Palsy Scoliosis? Spine 37/9(0-), 03622436

Dixon S, James V, Hind D, Currie CJ. (2005). Economic Analysis of the Implementation of Autologous Transfusion Technologies Throughout England. International Journal of Technology Assessment in Health Care. 21:2 (2005), 234239

Drummond M, Schulpher M, Claxton K, Stoddart G, Torrance G (2015). Methods for the Economic Evaluation of Health Care Programmes. Oxford University Press 2015.

Dunn J.J.; Aning J.J.; Sprott H.H.; McGrath J.S.; Pocock R.D.; Thompson J.F.; Ridler B.M.F.; Daugherty M.O. (2010). Centralisation of Urological Cancer SurgeryIs Cell Salvage Still Effective? TATM, 11/(26-27), 1295-9022

Dusik C.J, Hutchison C, Langelier D (2014). The Merits of Cell Salvage in Arthroplasty: An Overview. Canadian Journal of Surgery 2014, 51(1):61-66

Edelstein S.B.; Shipp C.; Kang J.; Jarosz C.; DeChristopher P.J. (2011). Successful Implementation of a Blood Management Program at an Academic Health Center. Transfusion, 51/(269A), 0041-1132

Effa Heap G (2009). Blood Transfusion: Implications of Treating a Jehovah's Witness Patient. British Journal of Nursing, 18/3(174-177), 09660461

Everts PAM; Knape JTA; Weibrich G; Schonberger JPA; Hoffmann J; Overdevest EP; Box HAM; van Zundert A (2006). Platelet-Rich Plasma and Platelet Gel: A Review. Journal of Extra-Corporeal Technology 38/2(174-187), 00221058

Folkersen L.; Grunnet N.; Jakobsen C.-J. (2009). Transfusion of Shed Mediastinal Blood Reduces the Use of Allogeneic Blood Transfusion Without Increasing Complications. Jnl of Cardiothoracic and Vascular Anaesthesia, 23/3 SUPPL. 1(S2), 1053-0770 
Frank S M. (2011). Who Benefits from Red Blood Salvage?-Utility and Value if Intraoperative Autologous Transfusion. Transfusion, 51/10(2058-2060), 00411132

Frank S, Wick E, Dezen A, Ness P et al (2014). Risk-Adjusted Clinical Outcomes in Patients Enrolled in a Bloodless Program. Transfusion 54(10 0 2): 2668-2677

Freedman J; Luke K; Escobar M; Vernich L; Chiavetta JA (2008). Experience of a Network of Transfusion Coordinators for Blood Conservation (Ontario Transfusion Coordinators [ONTraC]. Transfusion, 48/2(237-250), 00411132

Garratt C., Sharafudeen S., Skelton V., Parry N., Groves P., Fleming I. (2013). Lean Transformation Of Intra-Operative Cell Salvage (Iocs) Practice In A Teaching Hospital Birth Centre: An Audit Of Efficacy And Cost. European Journal of Anaesthesiology 30/(95), 0265-0215

Geoghegan J; Daniels J; Moore P; Thompson P; Khan K; Gülmezoglu A (2009). Cell Salvage at Caesarean Section: the Need for an Evidence-Based Approach. BJOG, 116/6(743-747), 14700328

Ging AL; St. Onge JR; Fitzgerald DC; Collazo LR; Bower LS; Shen I (2008). Bloodless Cardiac Surgery and the Pediatric Patient: a Case Study. Perfusion, 23/2(131-134), 02676591

Golab H.D.; Scohy T.V.; de Jong P.L.; Takkenberg J.J.M.; Bogers A.J.J.C. (2008). Intraoperative Cell Salvage in Infants Undergoing Elective Cardiac Surgery: A Prospective Trial. European Journal of Cardiothoracic Surgery, 34/2(354-359), 1010-7940

Goodnough L, Murphy M. (2014). Do Liberal Blood Transfusions Cause More Harm than Good? British Medical Journal. 2014:349:g6897

Grainger H, Catling S. (2011). Intraoperative Cell Salvage in Obstetrics. Journal of Perioperative Practice, 21/8(264-270), 17504589

Grainger H; Jones J; McGee D (2008). Education, Training and Competency Assessment for Intraoperative Cell Salvage. Jnl of Perioperative Practice, 18/12(536-542), 17504589

Grainger, H., Howell, C., Jones, J. (2013). Update on The UK Cell Salvage Action Group Autologous Transfusion Label. British Journal of Anaesthetic \& Recovery Nursing 14/3/4(51-51), 17426456

Gray M.; Gowrie-Mohan S.; Harvey D. (2009). Six Year Experience Of Intraoperative Red Cell Salvage In One District General Hospital. British Journal of Haematology, 145/(77), 0007-1048

Guzel Y, Gurcan O, Golge U, Dulgerglu T, Metineren H (2017). Topical Tranexamic Acid versus Autotransfusion after Total Knee Arthroplasty. Journal Of Orthopaedic Surgery 2017:24/2, 179-182

Haemonetics. Haemonetics OrthoPat Brochure.

http://www.haemonetics.com/ /media/sharepoint/devices/orthopat/marketing/brochu res/col-pp-000020-us_brochure_orthopat.pdf.pdf. [Accessed 5 April 2018]

Hassan N.; Halanski M.; Wincek J.; Reischman D.; Sanfilippo D.; Rajasekaran S.; Wells C.; Tabert D.; Kurt B.; Mitchell D.; Huntington J.; Cassidy J. (2011). Blood Management in paediatric spinal deformity surgery: review of a 2-year experience. Transfusion, 51/10(2133-2141), 0041-1132;1537-2995 
Healthcare Financial Management Association. Payment by Results in Acute Healthcare. HFMA Briefing. HFMA July 2012

Healthcare Financial Management Association (2013). Introductory Guide to NHS Finance (11th Edition). HFMA Publishing.

Healthcare Financial Management Association (2014). Glossary for NHS Finance and Governance. HFMA Briefing. HFMA September 2014

Her Majesty's Revenue \& Customs (2017). Contracted Out Services. https://www.gov.uk/hmrc-internal-manuals/vat-government-and-publicbodies/vatgpb9700. [Accessed 20 March 2017]

Herd J.M., Joseph J., McGarvey M., Tsimbouri P., Bennett A., Meek R.M.D., Morrison A. (2013). Intra-Operative Cell Salvage In Revision Hip Surgery. Vox Sanguinis 105/(285-286), 0042-9007

HES Development (PROMS) Team (2014). Finalised Patient Reported Outcome Measures (PROMS) in England-April 2012 to March 2013. Health \& Social Care Information Centre (2014).

Hill B (2007). Bloodless Surgery. Hospital Doctor (18-19), 02623145

Holt DW, McMullen B, Ask AM (2009). Ultrafiltration is an Effective Substitute for Cell Centrifugation in Perioperative Blood Management Techniques. Journal of Extra-Corporeal Technology, 41/1(A4), 0022-1058

Horngren CT, Datar S Rajan MV (2015). Cost Accounting-A Managerial Emphasis. Prentice Hall. 15th Edition

Hulatt LJ; Fisher W (2010). Intra-operative Cell Salvage and Sickle Cell Carrier Status. Anaesthesia, 65/6(649-649), 00032409

Hussain S; Clyburn P (2010). Cell Salvage-Induced Hypotension and London Buses. Anaesthesia, 65/7(661-663), 00032409

Husted H, Holm G, Jacobsen S (2008). Predictors of Length of Stay and Patient Satisfaction After Hip and Knee Replacement Surgery: Fast-track Experience in 712 Patients. Acta Orthopaedica 79:2, 168-173

Irish Blood Transfusion Service. Donor information frequently asked questions. www.giveblood.ie/Become_a_Donor. [Accessed 18 March 2017]

Jaben E.A.; Bryant S.C.; Winters J.L. (2010). Long Term Survival After Transfusion Among Olmstead County, MN Residents 1991-2009. Transfusion, 50/(27A), 00411132

Jehovah's Witness Website. What Does the Bible Say About Blood Transfusions?. https://www.jw.org/en/bible-teachings/questions/bible-about-bloodtransfusion/\#?insight[search_id]=dc8bbcbb-742f-4762-ade3fe69e6f4eb5f\&insight[search_result_index]=3. [Accessed 18 January 2016]

Joint United Kingdom (UK) Blood Transfusion and Tissue Transplantation Services Professional Advisory Committee. . www.transfusionguidelines.org.uk. [Accessed 18 March 2017]

Joy PJ, Bennet SJ. (2012). The Appropriateness of Blood Transfusion Following Primary Total Hip Replacement. Annals of the Royal College of Surgeons in England. 2012;94:201-203 
Junkin R., Ziarkowski A. (2012). Impact And Experiences Of Introducing Intraoperative Cell Salvage In A District General Hospital. Anaesthesia. 67/(16), 0003-2409

Kelleher A.; Davidson S.; Gohil M.; Machin M.; Kimberley P.; Hall J.; Tillyer L. (2010). Red Cell Salvage in Cardiac Surgery-The Role of Quality Assurance in Providing Evidence to Support a Change of Cell Saver Device. Jnl of Card and Vasc Anaesthesia, 24/3 SUPPL 1(S38), 1053-0770

Kelleher A; Davidson S; Gohil M; Machin M; Kimberley P; Hall J; Banya W. (2011). A Quality Assurance Programme for Cell Salvage in Cardiac Surgery. Anaesthesia, 66/10(901-906), 00032409

Khan K, Moore P, Wilson M, Hooper R et al (2017). Cell Salvage During Caesarean Section: A Randomised Control Trial. American Journal of Obstetrics \& Gynaecology. 216, 1, S559

Klein A.A.; Nashef S.A.M.; Sharples L.; Bottrill F.; Dyer M.; Armstrong J.; Vuylsteke A. (2008). A Randomised Controlled Trial of Cell Salvage in Routine Cardiac Surgery. Anaesthesia \& Analgesia, 107/5(1487-1495), 0003-2999

Kobelt G (2013). Health Economics: An Introduction to Economic Evaluation. Office of Health Economics. 3rd Edition (2013)

Konstantinou E; Brady J; Soultati, A. (2011). Intraoperative Use of Cell Saver on Patients Undergoing Open Abdominal Aortic Aneurysm Surgical Repair: A Greek Hospital Experience. Jnl of PeriAnaesthesia Nursing, 26/4(225-30), 1089-9472

Kumar N., Chen Y., Nath C., Liu E.H. (2012). What is the Role Of Autologous Blood Transfusion In Major Spine Surgery? American Journal of Orthopedics (Belle Mead 41/6(E89-95), 1934-3418

Lambden P (2015). Treatment for Arthritis. NHS Managers Briefing 31 October 2015. www.nhsmanagers.net. [Accessed 10 November 2015]

Liumbruno GM; Liumbruno C; Rafanelli D (2011). Intraoperative Cell Salvage in Obstetrics: is it a Real Therapeutic Option? Transfusion, 51/10(2244-2256), 00411132

MacIvor D; Nelson J; Triulzi D (2009). Impact of Intraoperative Red Blood Cell Salvage on Transfusion Requirements and Outcomes in Radical Prostatectomy. Transfusion, 49/7(1431-1434), 00411132

Mackenzie M.J.; Yentis S.M.; Sooranna S.; Johnson M.R. (2010). Passage of Amniotic Fluid Through Leucocyte Filters. Internat Jnl of Obstetric Anaesthesia, 19/(S13), 0959-289X

Markovic M.; Davidovic L.; Savic N.; Sindjelic R.; Ille T.; Dragas M. (2009). Intraoperative Cell Salvage versus Allogeneic Transfusion During Abdominal Aortic Surgery: Clinical and Financial Outcomes. Vascular, 17/2(83-92), 1708-5381

McClelland DBL (2007). Handbook of Transfusion Medicine (4th Edition). The Stationery Office. 2007

McKinsey \& Co. NHS Productivity Review 2009. . www.nhshistory.net/mckinsey\%20report.pdf 
Meikle J. Permanent blood donation clinics 'may be more effective than mobile units'. The Guardian Newspaper. 24 May 2013.

Michael AL, Loughenbury PR, Rao AS, Dunsmuir RA, Millner PA (2012). A Survey Of Current Controversies In Scoliosis Surgery In The United Kingdom. Spine 37/18(1573-1578), 03622436

Miller H, Pope T (2016). The Changing Composition of UK Tax Revenues IFS Briefing Note BN182. The Institute for Fiscal Studies.

Mogyorosy Z, Smith P (2005). The Main Methodological Issues in Costing Health Care Services. University of York CHE Paper 7

Monitor (12 May 2014). Service-line management: an approach to hospital management. www.gov.uk/government/collections/service-line-management-anapproach-to-hospital-managment. [Accessed 18 March 2017]

Monitor (October 2015). Helping NHS Providers Improve Productivity in Elective Care. IRRES 15/15

Morris S, Devlin N, Parkin D (2007). Economic Analysis in Health Care. Wiley 2007.

Morris S., Robinson M., Uncles D.R. (2012). An Analysis of The Use Of Routine Cell Salvage For Caesarean Section in a South Coast District General Hospital. Anaesthesia 67/(59), 0003-2409

Munoz M., Ariza D., Campos A., Martin-Montanez E. (2012). Cost-Effectiveness of Postoperative Shed Blood Reinfusion After Major Orthopedic Surgery: An Analysis Of 1093 Consecutive Total Knee Arthroplasties. Transfusion Alternatives in Transfusion Medicine 12/2(24), 1295-9022

Murthy N., Uchil D. (2013). Saving Mothers' Lives-Have We Caught Up With Intraoperative Cell Salvage In Obstetrics?. BJOG: An International Journal of Obstetrics and Gynaecology 20/(31), 1470-0328

Murphy MF, Waters J, Wood E, Yazer M (2013). Transfusing Blood Safely and Appropriately. British Medical Journal 347:29-33

Nathwani R., Price J., Kaur J. (2013). Intra-Operative Cell Salvage Use in a Tertiary Orthopaedic Centre. Anaesthesia. 68/(22), 0003-2409

National Institute for Health and Care Excellence (2015). Implementing the NICE guideline on blood transfusion (NG24). www.nice.org.uk/guidance/ng24. [Accessed 21 January 2016]

National Joint Registry (2013). National Joint Registry Annual Report 2013. www.njrcentre.org.uk/njrcentre/Home/tabid/36/Default.aspx. [Accessed 10 November 2015]

Nechyba TJ (2011). Microeconomics-An Intuitive Approach with Calculus. South Western, Cengage Learning. International Edition (2011)

New Zealand Blood Service. Eligibility Criteria. www.nzblood.co.nz/giveblood/donating. [Accessed 18 March 2017] 
NHS Blood \& Transplant. Annual Report and Accounts 2010/11. The Stationery Office. HC 1236 SG/2011/114 Accessible on http://www.nhsbt.nhs.uk/news-andmedia/review-accounts/

NHS Blood \& Transplant. How the Body Replaces Blood. www.blood.co.uk. [Accessed 28 October 2014]

NHS Blood \& Transplant. The Need for Blood. www.blood.co.uk. [Accessed 28 October 2014]

NHS Blood \& Transplant. The Role of Collaboration in Forecasting Blood Demand. Blood and Transplant Matters. 2013; 40:21-26

NHS Blood \& Transplant. National Comparative Audit of Blood Transfusion-Repeat Audit 2016. http://hospital.blood.co.uk/media/29357/2016-pbm-final.pdf [Accessed 15 May 2018]

NHS England-National Blood Transfusion Committee (NBTC) (2014). Patient Blood Management-An evidence-based approach to patient care (2014). www.transfusionguidelines.org.uk/uk-transfusion-committees/national-bloodtransfusion-committee/patient-blood-management. [Accessed 28 Oct 2014]

NHS Networks Poll (2006). Blood Donor Survey. Health Service Journal 4 December 2006.

None stated (2013). Update On The UK Cell Salvage Action Group Autologous Transfusion Label. British Journal of Anaesthetic \& Recovery Nursing 14/3/4(5252), 17426456

None stated (2012). Grant for Cell Salvage Research During Normal Births. Practising Midwife 15/11(12-12), 14613123

None stated (2012). Improving Quality and Reducing Costs. Clinical Services Journal. Jan 2012 (59-62)

None stated (2003). The Cost of Blood: Multidisciplinary Consensus Conference for a Standard Methodology. Transfusion Medicine Reviews. 19 (1) 66-78.

Oberhofer D., Sakic K., Jankovic S., Tonkovic D., Vrgoc G. (2012). [How to Improve Perioperative Blood Management In Patients Undergoing Total Hip Or Knee Replacement Surgery?] Lijecnicki vjesnik 134/11-12(322-327), 0024-3477

Odak S., Raza A., Shah N., Clayson A. (2013). Clinical Efficacy and Cost Effectiveness Of Intraoperative Cell Salvage In Pelvic Trauma Surgery. Annals of the Royal College of Surgeons of England 95/5(357-360), 0035-8843

Offierski C.M., Gagne S., Bishop C. (2013). Efficacy of Tranexamic Acid for Blood Conservation In Primary Total Joint Arthroplasty. Transfusion Medicine 23/(43), 0958-7578

Olshove (2010). Perfusion Techniques Toward Bloodless Paediatric Open-Heart Surgery. Jnl of Extra Corporeal Technology, 42/2(122-127), 00221058 
Osaro E.; Njemanze C. (2010). Challenges of Meeting the Future Blood Transfusion Requirement in England \& Wales. Autologous Blood Transfusion Could Become an Adjunct to the UK Blood Transfusion Program in the Future. Transfusion Alternatives in Transfusion Medicine, 11/2(72-81), 1295-9022;1778-428X

Ostrowsky J; Henderson M; Hennein H (2006). Autologous Priming Technique to Reduce Blood Transfusion in Pediatric Cardiopulmonary Bypass. Journal of ExtraCorporeal Technology 38/2(154-156), 00221058

Pape A.; Habler O. (2007). Alternatives to Allogeneic Blood Transfusions. Best Practice and Research in Clinical Anaesthesiology 21/2(221-239), 1521-6896

Pathak D.; McDonald A.; Barclay P.; Mallaiah S. (2010). Use of Cell Salvage in Caesarean Section. Internat Jnl of Obstetric Anaesthesia, 19/(S14), 0959-289X

Peacock L., Clark V., Catling S. (2012). Recent Developments in The Obstetric Use Of Cell Salvage. Transfusion Alternatives in Transfusion Medicine 12/3-4(66-71), 1295-9022;1778-428X

Perel P, Ker K, Morales Uribe C, Roberts I (2013). Tranexamic Acid for Reducing Mortality in Emergency and Urgent Surgery. Cochrane Database of Systematic Reviews 2013/1 CD010245.

Pendry K, Manzini P, Wikman A et al (2015). Patient Blood Management in Activities in Seven European University Hospitals Vox Sanguinis 109/(99), 00429007

Phillips S.D.; Maguire D.; Deshpande R.; Muiesan P.; Bowles M.J.; Rela M.; Heaton ND. (2006). A Prospective Study Investigating the Cost Effectiveness of Intraoperative Blood Salvage During Liver Transplantation. Transplantation 81/4(536-540), 0041-1337

Phillips SJ; Chavan R; Porter ML; Kay PR; Hodgkinson JP; Purbach B; Reddick AH; Frayne JM (2006). Does Salvage and Tranexamic Acid Reduce the Need for Blood Transfusion in Revision Hip Surgery. Journal of Bone \& Joint Surgery 88B/9(1141-1142), 0301620X

Portsmore S.; Jarman H.; Jaiganesh T. (2011). Autologous Cell Salvage Within an Emergency Department-A Feasibility Study. Trauma, 13/4(369-370), 1460-4086

Powell E.; Osborn N. (2009). Audit of Autologous and Allogeneic Blood Use in Obstetrics. Internat Jnl of Obstetric Anaesthesia, 18/(S44), 0959-289X

Rahman IA; Hoth T; Doughty H; Bonser RS (2007). Thoraco-Abdominal Aneurysm Repair in a Jehovah's Witness: Maximising Blood Conservation. Perfusion 22/5(363364), 02676591

Rajkumar A, Rossi S, King J, Marlow R et al (2015). Postoperative Red Cell Transfusion in Elective Unilateral Primary Total Hip Replacement: An Audit Cycle Over 8 Years Vox Sanguinis 109/97, 0042-9007

Ralph C; Faulds J; Sullivan I (2010). Cell salvage and leucocyte depletion filters. Anaesthesia, 65/12(1228-1229), 00032409

Rando K, Niemann CU, Taura P, Klinck J, De S (2009). Optimizing Cost Effectiveness in Perioperative Care for Liver Transplantation: A model for Resource Limited Health Economies. Liver Transplantation, 15/(S89), 1527-6465 
Rando K.; Niemann C.U.; Taura P.; Klinck J. (2011). Optimizing Cost Effectiveness in Perioperative Care for Liver Transplantation: A model for Low to MediumIncome Countries. Liver Transplantation, 17/11(1247-1278), 1527-6465;1527-6473

Rao VK, Dyga R, Bartels C, Waters JH (2012). A Cost Study Of Postoperative Cell Salvage In The Setting Of Elective Primary Hip And Knee Arthroplasty. Transfusion 52/8(1750-60), 0041-1132;1537-2995

Raval JS, Nelson JB, Woldemichael E, Triulzi DJ (2012). Intraoperative Cell Salvage In Radical Prostatectomy Does Not Appear To Increase Long-Term Biochemical Recurrence, Metastases, Or Mortality. Transfusion 52/12(2590-2593), 00411132

Roberts H., Carroll C. (2012). Use Of Intraoperative Cell Salvage In Neurosurgery. Transfusion Alternatives in Transfusion Medicine 12/3-4(59-65), 1295-9022;1778$428 \mathrm{X}$

Rollins, Ke, Trim, Nl, Luddington, Rj, Colah, S, Klein, A, Besser, Mw, Nair, Sk (2012). Coagulopathy Associated With Massive Cell Salvage Transfusion Following Aortic Surgery. Perfusion 27/1(30-33), 02676591

Samnaliev M, Tran CM, Sloan SR, Gasior I, Lightdale JR, Brustowicz RM (2013). Economic Evaluation of Cell Salvage in Pediatric Surgery. Paediatric Anaesthesia 23/11(1027-34), 1155-5645;1460-9592

Samnaliev M., Tran C., Gasior I., Sloan S.R., Lightdale J., Brustowicz R. (2012). Cost Analysis of Cell Salvage in Pediatric Surgery. Value in Health 15/4(A75-A76), 1098-3015

Sanders J, Patel S, Cooper J, Berryman J, Farrar D, Mythen M, Montgomery H. (2011). Red Blood Cell Storage is Associated with Length of Stay and Renal Complications After Cardiac Surgery. Transfusion. 2011;51:2286-2294

Savvidou C.; Chatziioannou S.N.; Pilichou A.; Pneumaticos S.G. (2009). Efficacy and Cost-Effectiveness of Cell Saving Blood Autotransfusion in Adult Lumbar Fusion. Transfusion Medicine, 19/4(202-206), 0958-7578;1365-3148

Scannell BP; Loeffler BJ; Bosse MJ; Kellam JF; Sims SH (2009). Efficacy of Intraoperative Red Blood Cell Salvage and Autotransfusion in the Treatment of Acetabular Fractures. Jnl of Orthopaedic Trauma, 23/5(340-345), 08905339

Schill DM (2009). Bloodless Aortic Valve and Ascending Aorta Replacement Surgery Requiring Circulatory Arrest: Two Case Studies. Perfusion, 24/3(203-205), 02676591

Scottish Centre for Regenerative Medicine. Next step in research efforts to culture red blood cells for blood transfusions. http://www.crm.ed.ac.uk/news/next-stepresearch-efforts-culture-red-blood-cells-blood-transfusions. [Accessed $24 \mathrm{March}$ 2016]

Seeking Alpha. Haemonetics Management Discusses Q1 2014 Results. www.seekingalpha.com/article/1580892-haemonetics-management-discusses-q12014-results-earnings-call-transcript. [Accessed 19 August 2014]

Shander A, Hoffman A, Ozawa S, Theusinger O, Gombotz, H, Spahn D (2010). Activity Based Costs of Blood Transfusions in Surgical Patients at Four Hospitals. Transfusion, 504 (753-765). 
Shander A, Javidroozi M (2012). Strategies to Reduce the Use Of Blood Products: A US Perspective. Current Opinion in Anesthesiology 25/1(50-58), 09527907

Shander A, Van Aken H, Colomina M, Gombotz H et al (2012). Patient Blood Management in Europe. Br J Anaesthesia 109(1), 55-68.

Shander A, Hoffman A, Ozawa S, Javidroozi M (2008). The True Cost of Red Blood Cell Transfusion in Surgical Patients. Blood 112:3045.

Shander A, Hoffman A, Gombotz H, Theusinger O, Spahn D (2007). Estimating the Cost of Blood: Past, Present, and Future Directions. Best Practice \& Research Clinical Anaesthesiology. 21, 2, 271-289.

Sharma A, Bani-Hani M, Ridler BMF, Campbell WB, Thompson JF (2010). Intraoperative cell salvage (ICS) is Associated with Lower Mortality than Homologous Blood Transfusion (HBT) in Ruptured abdominal aortic aneurysm (RAAA). Transfusion Alternatives in Transfusion Medicine, 11/(26), 1295-9022

Sharma S; Gunning P (2010). The Need for Intra-Operative Cell Salvage training to reduce the Use of Allogeneic "bank" Blood During Surgery. Is the Routine Adoption of a Competency-Based Assessment in Intra-Operative Cell Salvage Required? Internet Jnl of Anesthesiology, 23/1(0-13), 1092406X

Shaz B, Hillyer C, Waters J (2013). Patient Blood Management-Key for Accountable Care Organizations. JAMA Surg/ 148 (6), June 2013

SHOT. Serious Hazards of Transfusion Annual Report. www.shotuk.org. [Accessed 18 March 2017]

Sinclair KC; Clarke HD; Noble BN (2009). Blood Management in Total Knee Arthroplasty: A Comparison of Techniques. Orthopaedics, 32/1(19-19), 01477447

Singh K.; Kaur A.; Singh A.; Singh R. (2007). Intraoperative Autotransfusion-A Simple and Cost-Effective Method. Journal of Indian Medical Assocn, 105/12(688692+699), 0019-5847

Solomon L., von Rahden R.P., Allorto N.L. (2013). Intraoperative Cell Salvage In South Africa: Feasible, Beneficial And Economical. South African Medical Journal 103/10(754-757), 0256-9574

Son M, Evanko J, Mongero L et al (2014). Utility of Cell Salvage in Women Undergoing Abdominal Myomectomy. American Journal of Obstetrics and Gynaecology 211/1(28.e1-28.e8)

Sorin Group. Sorin Xtra Brochure. www.livanova.sorin.com/products/cardiacsurgery/perfusion/autotransfusion/xtra. [Accessed 18 March 2017]

Spahn DR (2010). Anemia and Patient Blood Management in Hip and Knee Surgery. Anaesthesiology, 113/2(482-495), 00033022

Sreelakshmi T.R.; Eldridge J. (2010). Acute Hypotension Associated with Leucocyte Depletion Filters During Cell Salvaged Blood Transfusion. Anaesthesia, 65/7(742744), 0003-2409;1365-2044

Staber M.; Junkin R.; Watson T. (2009). Blood Transfusions in Orthopaedics and Blood Salvage-A Cost Consideration. Eur Jnl of Anaesthesiology, 26/(85-86), 02650215 
Steffens TG; Kohmoto T; Edwards N; Wolman RL; Holt DW (2008). Effects of Modified Ultrafiltration on Coagulation as Measured by the Thrombolelastograph. Journal of Extra-Corporeal Technology, 40/4(229-233), 00221058

Tan N.L., Corbineau H., Phu B.D., Verhoye J.-P. (2012). Is A Cell Saver Necessary in Off-Pump Coronary Artery Bypass Surgery? Asian Cardiovascular and Thoracic Annals 20/5(539-543), 0218-4923;1816-5370

Tanqueray T; Allam J; Norman B; Cox M (2010). Leucocyte Depletion Filter and a Second Suction Circuit During Intra-Operative Cell Salvage in Obstetrics. Anaesthesia, 65/2(207-207), 00032409

Tawfick W.A.; O'Connor M.; Hynes N.; Sultan S. (2008). Implementation of the Continuous Autotransfusion System (CATS) in Open Abdominal Aortic Aneurysm Repair: An Observational Comparative Cohort Study. Vascular \& Endovascular Surgery, 42/1(32-39), 1538-5744

The Economist. Blood Not Money. www.economist.com/blogs/blighty/2011/02/volunteering_and_profiteering. 16 February 2011 [Accessed 18 March 2017]

Thomas D, Wareham K, Cohen D, Hutchings H (2001). Autologous Blood Transfusion in Total Knee Replacement Surgery. British Journal of Anaesthesia; 86: 669-673.

Thomas D, Thompson J, Ridler B. (2005). A Manual for Blood Conservation. TFM Publishing. 2005:1-13

Thomas D (2012). Surgical and Anaesthetic Management of Anaemia: Pros And Cons of Cell Salvage Devices. Vox Sanguinis 103/(65), 0042-9007

Thurer R.L.; Parce P.; Parrell S.; Popovsky M.A. (2011). How Effective are Educational Programs as Part of a Comprehensive Strategy to Limit Stored Blood Transfusion? Transfusion, 51/(243A), 0041-1132

Thurer R.L.; Parrell S.; Dowling W.J.; Parce P.; Popovsky M.A. (2010). Postoperative Blood Salvage with Cell Washing Reduces Transfusion Requirements for Patients Having Total Knee Replacement Surgery. Transfusion, 50/(183A184A), 0041-1132

Tio M, Sanchez-Etayo G, Berge R et al (2016). Cost Effectiveness of Post-Operative Cell Salvage in Total Knee Arthoplasty. Should We Continue to Recommend its Use Today? Revista Espanola de Anestesiologia y Reanamicio 63, 8, 444-450

Tse EY; Cheung WY; Ng KF; Luk KD (2011). Reducing Perioperative Blood Loss and Allogeneic Blood Transfusion in Patients Undergoing Major Spine Surgery. Journal of Bone and Joint Surgery, 93/13(1268-1277), 00219355

Ubee S.S.; Manikandan R.; Gudimetla A.R.; Singh G (2010). Cost Benefits of Cell Salvage in Radical Cystectomy. Indian Journal of Urology, 26/2(196-199), 0970$1591 ; 1998-3824$

Ubee S; Kumar M; Athmanathan N; Singh G; Vesey S (2011). Intraoperative Red Blood Cell Salvage and Autologous Transfusion During Open Radical Retropubic Prostatectomy: a Cost Benefit Analysis. Annals of RCS of Eng, 93/2(157-61), 0035$8843 ; 1478-7083$ 
US Red Cross. What We Do/Blood Donation. www.redcross.org. [Accessed 28 Oct 2014]

Vamvakas E, Blajchman M (2001). Deleterious Clinical Effects of Transfusion Associated Immunomodulation: Fact or Fiction? Blood, Vol 97, 5, 1180-1195.

Van Hoeven L, Janssen M, Rautmann G (2013). The collection, testing and use of blood and blood components in Europe. European Directorate for the Quality of Medicines \& HealthCare of the Council of Europe (EDQM) https://www.edqm.eu/sites/default/files/the_collection_testing_and_use_of_blood_an d_blood_components_in_europe_2013.pdf [Accessed 26 March 2017]

Varney S, Guest J. The Annual Cost of Blood Transfusions in the UK (2003); Transfusion Medicine, 13, 205-218.

Vassili M. (2010). Intraoperative Blood Salvage. Heart Surgery Forum, 13/(S13), 1098-3511

Venkatachalam KL; Fanning LJ; Willis EA; Beinborn DS; Bradley DJ; Cha Y; Shen W; Asirvatham SJ; Sinak LJ; Packer DL; Munger TM; Santrach PJ; Friedman PA (2008). Use of an Autologous Blood Recovery System During Emergency Pericardiocentesis in the Electrophysiology Laboratory. Jnl of Cardiovascular Electrophysiology, 20/3(280-283), 10453873

Vieira S.D.; Dourado D.A.; Amaral E.V.; Souza L.C.; Buffolo E.; Arrais M.; Carballo M.T.; Berwanger O.; Colella R. (2009). Risk Factors for Increased Blood Transfusion in Patients Submitted to Cardiac Surgery with Intraoperative Autologous Transfusion: A Cohort Study. Transfusion, 49/(166A), 0041-1132

Vincent V., Sharafudeen S., Skelton V.A., Parry N., Groves P., Dasan J.K., Fleming I. (2012). Lean Transformation Of IOCS Practice In A Teaching Hospital Birth Centre; An Audit Of Efficacy And Cost. Anaesthesia 67/(23), 0003-2409

Vonk, Alexander B A, Meesters, Michael I, Garnier, Robert P, Romijn, Johannes W A, van Barneveld, Lerau J M, Heymans, Martijn W, Jansen, Evert K, Boer, Christa (2013). Intraoperative Cell Salvage Is Associated With Reduced Postoperative Blood Loss And Transfusion Requirements In Cardiac Surgery: A Cohort Study.. Transfusion 53/11(2782-2789), 00411132

Wald M. Blood Industry Shrinks as Transfusions Decline. New York Times. 22 August 2014

Waldron S (2010). Hypotension Associated with Leucocyte Depletion Filters Following Cell Salvage in Obstetrics. Anaesthesia, 66/2(133-134), 00032409.

Waldron S.; Chadwick S.; Parkes A.; Kirk P. (2011). A Cost Assessment of Cell Salvage in Obstetrics. Int Jnl of Obstetric Anaesthesia, 20/(S16), 0959-289X

Waldron-Lynch F; Herold KC (2009). Advances in Type 1 Diabetes Therapeutics: Immunomodulation and Beta-Cell Salvage. Endocrinology \& Metabolism Clinics of North America, 38/2(303-317), 08898529 
Waters J.R.; Meier H.H.; Waters J.H. (2007). An Economic Analysis of Costs Associated with Development of a Cell Salvage Program. Anaesthesia \& Analgesia 104/4(869-875), 0003-2999

Waters J; Dyga R; Wisniewski M; Yazer M (2010a). RBC Transfusion Practice in Total Hip Replacement Surgery is Highly Variable. Transfusion, 50/(183A-184A), 0041-1131

Waters J; Dyga R; Wisniewski M; Yazer M (2010b). Transfusion Practice in Orthopedic Surgery. Transfusion, 50/(183A-184A), 0041-1133

Waters JH, Dyga R, Waters JF, Yazer M (2011) The volume of returned red blood cells in a large blood salvage program: where does it all go?. Transfusion: 51:10.

Waters JH, Yazer MH. (2013). Bleeding Causes Harm....Really?. Transfusion. 2013;53:2-4

Wells AW, Mounter PJ, Chapman CE, Stainsby D, Wallis JP (2002). Where does blood go? Prospective observational study of red cell transfusion in north England. British Medical Journal. 2002:325;803-4

Wise A, Clark V (2008). Strategies to Manage Major Obstetric Haemorrhage. Current Opinion in Anesthesiology, 21/3(281-287), 09527907

Wood F, Sangster A. Business Accounting Volume 2. Prentice Hall. 10th Edition (2005)

World Health Organisation. Adopted Resolution 63.12 (2010).

http://www.who.int/medicines/areas/quality_safety/regulation_legislation/icdra/WA1B_quality_safety_BloodProducts.pdf. [Accessed 18 March 2017]

World Health Organisation. Model List of Essential Medicines $19^{\text {th }}$ Edition (2015). http://www.who.int/medicines/publications/essentialmedicines/en/ [Accessed 8 November 2015]

Yarham, G; Clements, A Oliver, M; Morris, C; Cumberland, T; Bryan, M; Jekler, S; Johns, K; Mulholland, J (2011). Evaluating the "Next Generation" of Cell SalvageWill it Make a Difference. Perfusion, 26/4(263-270), 02676591

Yazer MH; Waters JH; Elkin KR; Rohrbaugh ME; Kameneva MV (2008). A Comparison of Hemolysis and Red Cell Mechanical Fragility in Blood Collected with Different Cell Salvage Suction Devices. Transfusion, 48/6(1188-1191), 00411132

Yeung S, Karthikeyan V, Wrench I (2016). Minimal Benefit of Cell Salvage with Estimated Blood Loss of Less Than One Litre at Caesarean Section: A Service Evaluation in a Tertiary Centre. International Journal of Obstetric Anaesthesia 26/S44, 1532-3375 
Appendix 1

Manufacturers' Publicity Information 


\section{OrthoPAT}

The one solution for

orthopedic perioperative

autotransfusion

INTEGRATED DEVICES

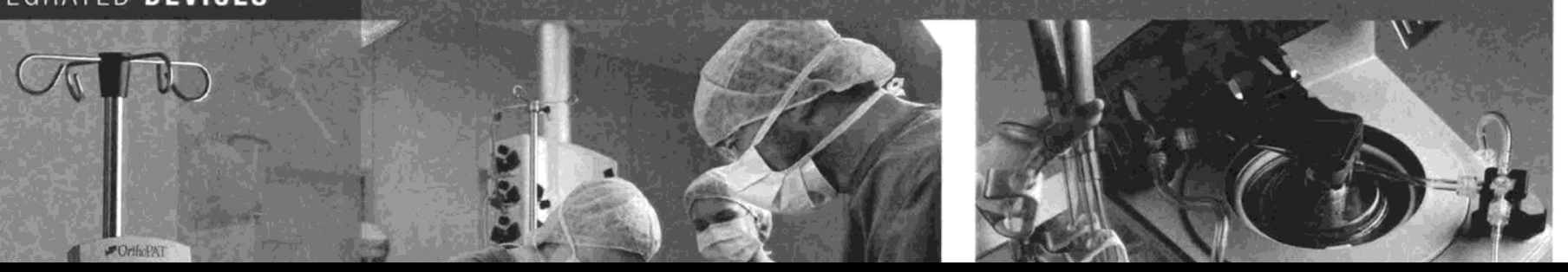




\section{Allogeneic, PAD, and unwashed transfusions: know the risks}




\section{ty SORIN|XTRA。}

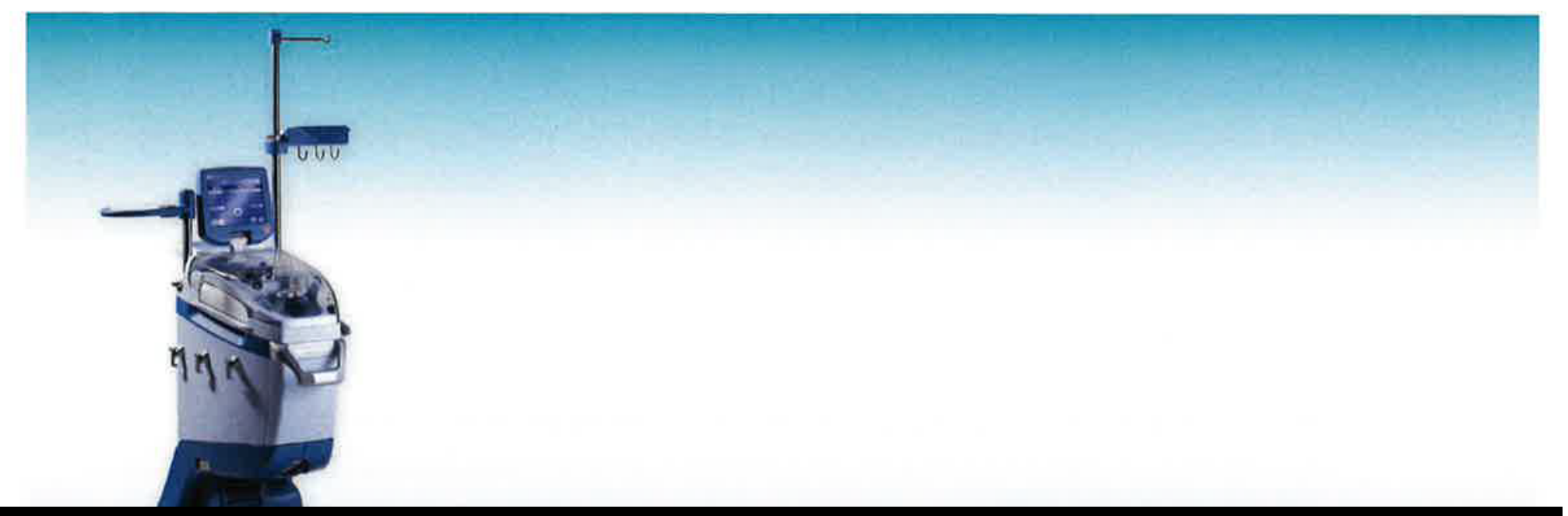




\section{AUTOTRANSFUSION}

\section{A KEY ROLE IN AN EFFECTIVE BLOOD MANAGEMENT STRATEGY}

The risks and costs related to homologous blood transfusion and its constantly decreasing worldwide availability have been widely documented. 


\section{Appendix 2}

Pricing of Allogeneic Unit of Blood 2017/18 Notification 


\title{
NHS \\ Blood and Transplant
}

\author{
NHSBT Board \\ September 2016 \\ NHSBT Pricing Proposals for 2017-18
}

\section{Status - Public}

\section{Executive Summary}

This paper provides a summary of the pricing proposals for NHSBT's blood components and specialist services for 2017-18. Following approval by the Board, these will be discussed with the National Commissioning Group in November 2016 with a view to implementation in 2017-18. Hospitals and the National Blood Transfusion Committee were consulted on these proposals in mid-2016. In overall terms the cost of providing blood to the NHS will decrease by $-1.7 \%$ in $2017 / 18$. Taking Specialist Services into account (and associated demand increases) the total change in cost to the NHS will be $-0.4 \%$.

\section{Action Requested}

The Board is asked to approve the pricing proposals prior to the NCG meeting.

\section{Purpose}

\subsection{Background: red blood cell and platelet demand}

Demand for red cells has declined steadily over the last 5 years, driven by a combination of medical advances such as laparoscopic surgery, pharmacological developments and educational initiatives such as NHSBT's "patient blood management" programme which encourages the safe and appropriate use of blood. Publications in medical journals have also demonstrated that patients can have a better outcome when less blood is used. Despite an increase in the population over 60 years old (i.e. the age group which uses most blood), blood usage continues to decline.

Since the end of $2011 / 12$, NHSBT has seen a $17 \%$ reduction in the demand for blood (vs forecast demand for 2016/17). In the same period, the NHS's expenditure on blood (and hence NHSBT's income) has reduced from $£ 300 \mathrm{~m}$ in $2011 / 12$ to a forecasted $£ 261 \mathrm{~m}$ in $2016 / 17$, while the unit price of red cells has reduced from $£ 125$ to $£ 120$ despite increasing levels of safety and availability. 
Demand for red cells continues to be volatile and is proving challenging to predict, with for example the recent NHS "reset" being seen as a contributory factor to this ongoing uncertainty. The latest figures are suggesting a demand forecast for $2017 / 18$ of $1.461 \mathrm{~m}$ units. This is $4.3 \%$ lower than the plan agreed for this year with the NCG $(1.527 \mathrm{~m}$ units) and lower than the forecast of $1.517 \mathrm{~m}$ units for $2016 / 17$. Demand for platelets is now also declining, for the first time, driven by factors such as the use platelet-sparing drugs in oncology. The platelet demand forecast for $2017 / 18$ is $0.256 \mathrm{~m}$ units compared with a plan of $0.275 \mathrm{~m}$ agreed with the NCG for the current year.

NHSBT has implemented substantial cost reduction programmes (approximately $£ 80 \mathrm{~m}$ since $2011 / 12$ ) and has an ongoing cost improvement plan of $\mathrm{c} £ 16 \mathrm{~m}$ in $2016 / 17$. The cost reductions have included the rationalisation of manufacturing and testing facilities and a reduction in blood collection capacity leading to substantial decreases in headcount. However, NHSBT currently has a need for significant investment to replace an ageing IT infrastructure and to replace the critical operational application underpinning the blood supply chain. The ongoing provision of critical products and services is highly dependent on its successful replacement. The overall cost of this change will be substantial and is estimated to be in the range of $£ 30 \mathrm{~m}-£ 40 \mathrm{~m}$ over 5 years.

The plan for $2017 / 18$ has generated a cost improvement target of $c £ 15 m$, which combines cost pressures (those costs over which NHSBT has no control, e.g. staff grade increment increases; apprenticeship levy; capital charge adjustments etc.), inflation (prospective pay award $1 \%$ and Treasury GDP Deflator 1.8\%) and also the lost contribution to our costs from the demand reductions described above ( $£ 10.0 \mathrm{~m}$ ). Prices for $2017 / 18$ have been set on the basis of planned cost improvements which will address c $£ 9.8 \mathrm{~m}$ of the overall target with the balance being made up from a price increase for red cells to NHS and private hospitals (£3.6m) and platelets $(£ 1.6 \mathrm{~m})$.

The cost improvement plan will be derived from the following:

- Demand reduction and productivity improvements of $£ 3.5 \mathrm{~m}$

- Operational and support function efficiencies of $£ 4.7 \mathrm{~m}$

- Estate Management and Optimisation $£ 1.2 \mathrm{~m}$

- Procurement $£ 0.4 \mathrm{~m}$.

\begin{tabular}{|c|c|c|c|}
\hline Category & Blood (Em's) & SpS (Em's) & Total (Em's) \\
\hline Opening position (closing NCG position 2016/17) & 265.3 & 56.2 & 321.5 \\
\hline 2017/18 Product and Service Demand Impact & -0.1 & 1.8 & 1.7 \\
\hline 2017/18 Cost Reduction Programme & -9.8 & -0.2 & -10.0 \\
\hline 2017/18 Cost Pressures and Developments & 1.9 & 0.4 & 2.3 \\
\hline $\begin{array}{l}2017 / 18 \text { Inflation funding increase (Pay } 1 \% \text {; Non-pay } \\
1.8 \% \text { ) }\end{array}$ & 3.5 & 1.1 & 4.6 \\
\hline Total Impact & -4.5 & 3.1 & -1.4 \\
\hline 2017/18 Revised Position & 260.8 & 59.3 & 320.1 \\
\hline Percentage increase / (decrease) & $-1.7 \%$ & $5.5 \%$ & $-0.4 \%$ \\
\hline
\end{tabular}




\subsection{Pricing: Red Cells}

The proposed cost improvement plan for 2017/18 (c£9.8m) has been extensively reviewed by the Executive Team and represents a balanced approach in the context of the significant organisational challenges facing NHSBT next year, in particular the ongoing level of resource and investment which is currently being focused on core systems. It is in this context that the most realistic approach would be to recommend an increase in the price of blood for 2017/18. It should be noted that a further increase to our prices in $2018 / 19$ can not be ruled out at this stage and would be largely dependent on the level of demand seen.

It is therefore recommended that the price of red blood cells for $2017 / 18$ should increase by $2 \%$ / £2.35 per unit, i.e. an increase from $£ 120$ to $£ 122.35$ per unit. NHSBT is mindful of the difficult financial status of many NHS hospitals, and it should be noted that despite this increase, NHS expenditure on blood will nevertheless reduce by around $1.7 \%$ next year.

\subsection{Provision of Hepatitis E virus (HEV) negative components}

In 2015, SaBTO recommended that HEV negative blood components should be provided for organ and stem cell transplant recipients. NHSBT implemented the change in early 2016. For blood components that were HEV negative as part of their standard manufacture (i.e. neonatal and paediatric packs), the costs were included in the price of red cells. For those units which ordered as HEV negative for adult solid organ or stem cell transplant recipients, an added value charge of $£ 17.18$ per unit was made.

Demand for HEV-negative components is now stabilising. This allows a more accurate picture of the cost of testing, and the added-value charge will be reduced from $£ 17.18$ to $£ 9.37$ for 2017-18. In due course, should SaBTO recommend the universal screening of blood components, NHSBT would need to amend the price to cover the cost of the additional testing.

\subsection{Platelets collected by apheresis}

There are a number of hospitals which only order platelets collected by apheresis. Clinical guidance indicates that apheresis and pooled platelets are functionally equivalent and should be used interchangeably, with the caveat that those recipients born on or after $1^{\text {st }}$ January 1996 should, when available, receive apheresis platelets. We will therefore introduce individual prices for platelets produced by apheresis and for platelets produced by pooling in $2017 / 18$ to reflect the differential cost of manufacture. It is proposed that the price of apheresis-derived platelets will increase be set at $£ 219.30$ compared with $£ 178.19$ for a pooled unit. 


\subsection{Diagnostic and Therapeutic Services Pricing}

Prices will be held flat for all specialist business units in 2017/18, with the exception being Red Cell Reference services, which will increase by $£ 1 \mathrm{~m}(9 \%)$ next year. The additional income will be recovered through an increase to the fixed cost recharge element (a charge made to each hospital to secure the ongoing provision of a national reference service). This service is currently in deficit and will move the service to a balanced income and expenditure position next year. However, the charge per reference referral from hospitals will remain flat.

In line with our strategic aim of continuous growth, DTS will see an increase of $£ 2.2 \mathrm{~m}$ in additional sales activity during 2017/18 of which Tissue and Eye Services will contribute $£ 1.2 \mathrm{~m}$. In overall terms DTS income will rise by $£ 3.1 \mathrm{~m}$ $(5.5 \%)$ and generate an improved contribution of $£ 1.9 \mathrm{~m}$ in $2017 / 18$.

\subsection{Changes to NHSBT Transport Arrangements}

Hospitals are requesting that NHSBT develops its logistics services to reflect changing working patterns, e.g. weekend working. However, the increasing trend for the self-collection of blood by hospitals is significantly impacting our ability to manage the supply chain in an efficient manner and has markedly reduced NHSBT's income from ad hoc delivery charges, which since 2011/12 has now resulted in a reduction to service income of $\mathrm{c} £ 0.8 \mathrm{~m}$ per annum.

NHSBT is therefore recommending a revision to its existing logistics model in $2017 / 18$ which will result in a fixed charge of $£ 11$ per order for the selfcollection of blood by hospitals from NHSBT blood centres. This charge reflects the costs of preparing the order for collection and it is estimated that this will generate additional income of $\mathrm{c} £ 0.7 \mathrm{~m}$, depending on hospitals' future ordering behaviour.

Ad-hoc and blue-light/emergency deliveries are currently charged at £52.15 per order, regardless of distance from the supplying blood centre and will remain unchanged for 2017-18. The future provision and pricing of this service remains under review and we aim to submit further proposals for the commissioning round in 2018/19.

\subsection{Impact on hospitals and customer feedback}

In mid-2016 NHSBT undertook an extensive consultation exercise with hospitals to assess the impact of a range of potential pricing changes. These included the differential pricing of apheresis platelets, differential pricing of rare groups such as $O$ negative red cells and $A$ negative platelets, and changes in transport arrangements. A substantial response was received to the online survey from haematology, finance and operational staff in 116 Trusts. Feedback from the survey was supplemented by face-to-face meetings.

In general, hospitals were not supportive of differential pricing of blood components or in the alternative prices for transport arrangements. One 
particular area of concern was the differential pricing of $O$ negative blood, where the concept of a $50 \%$ increase in price was tested in an attempt to reduce the demand for this rare blood group, which represents $13 \%$ of demand but only $8 \%$ of the donor base. NHS hospitals were particularly vocal in their opposition to the latter proposal (despite a compensatory reduction in the price of other blood groups) and this is not being recommended for 2017/18.

That said, an increase in the price of $O$ negative blood to $£ 180$ per unit for private hospitals will be implemented in late $2016 / 17$, focusing on those which order predominantly $\mathrm{O}$ negative blood, do not have a transfusion laboratory partnership with a local NHS hospital, and often consequently have high wastage levels. Significant Patient Blood Management activity will continue in an attempt to reduce the demand for $\mathrm{O}$ negative blood, and a price rise to NHS hospitals cannot be ruled out in the future if usage patterns do not change.

NHSBT estimates that the impact of the proposed pricing changes on NHS hospitals for $2017 / 18$ is as follows:

\begin{tabular}{|l|r|r|r|}
\hline NHS Trust & $\begin{array}{c}\text { Blood } \\
\text { £k's }\end{array}$ & \multicolumn{1}{c|}{$\begin{array}{c}\text { DTS } \\
£ k^{\prime} \mathbf{s}\end{array}$} & \multicolumn{1}{c|}{$\begin{array}{c}\text { Total } \\
\text { £k's }\end{array}$} \\
\hline Large Trusts (blood usage $>£ 3 m$ per annum) & -73 & 51 & -22 \\
\hline Medium Trusts (blood usage $£ 1-3 m$ per annum) & -32 & 10 & -22 \\
\hline Small Trusts (blood usage $<£ 1 m$ per annum) & -7 & 4 & -3 \\
\hline All Trusts & -25 & 13 & -12 \\
\hline
\end{tabular}

\title{
4.8 Summary
}

Currently, NHSBT faces a difficult financial situation, with declining demand, substantial cost reduction programmes and a parallel need for investment in core systems. For this reason, an increase in the price of red cells is being recommended although the overall cost of blood to the NHS will continue to decline. NHSBT is also recommending the introduction of separate prices for pooled and apheresis platelets (reflecting the different cost of production) and the introduction of a "self-collect" charge. An increase in the price of O negative red cells and $A$ negative platelets is currently not being recommended (despite rapidly increasing demand in the case of $A$ negative platelets) but may need to be considered again in 2018/19.

\section{Authors}

Dr Huw Williams

Director of Diagnostic and Therapeutic Services

Mark Taylor

Assistant Finance Director - Planning and Performance

\author{
Responsible Director \\ Dr Huw Williams \\ Director of Diagnostic and Therapeutic Services
}


Appendix 1 - National Prices
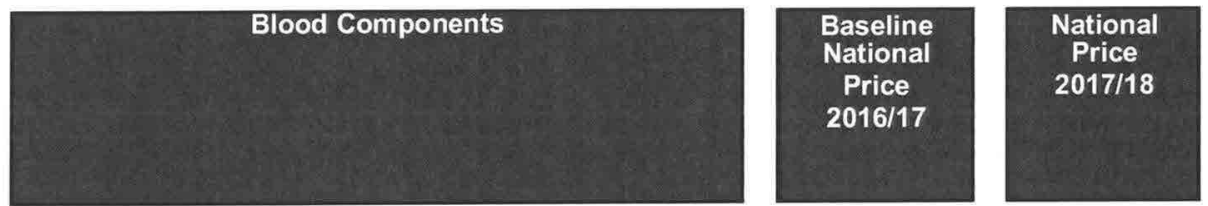

Price

Movement

Post

Inflation

\section{Red Cell Components}

Standard Red Cells Other Groups

Standard Red Cell O Rh D negative (Private Hospitals only)

Neonatal Red Cells

Frozen Red Cells, Thawed \& Washed

Red Cells for Exchange Transfusion

Large Volume Neonates \& Infants

Red Cells for Intra-Uterine Transfusion

\section{Red Cell Added Value Services}

Premium for CMV -ve Red Cells

Premium for Irradiated Red Cells

Premium for Cell Washing

Premium HLA selected red cells

\section{Platelet Components}

Platelets (1.0 ATD) Pooled

Platelets (1.0 ATD) CD

Platelets (1.0 ATD) Rh A neg Pooled

Platelets (1.0 ATD) Rh A neg CD

Neonatal Platelets

Platelets for Intra-Uterine Transfusion

Platelet Added Value Services

Premium for CMV -ve Platelets

Premium for Irradiated Platelets

Premium for Cell Washing

Premium for HLA Selected Platelets

Premium for HPA Selected Platelets

\section{Plasma Components}

Clinical FFP (UK sourced)

Paediatric MBFFP (non-UK Sourced)

Neonatal MBFFP (non-UK Sourced)

\section{Cryoprecipitate}

Cryoprecipitate (UK Sourced)

Pooled cryoprecipitate (UK Sourced)

MB Cryoprecipitate-Neonatal (non-UK Sourced)

MB Cryoprecipitate-Pooled (non-UK Sourced)

Other Components and Services

Optimised Pooled Granulocyte

Buffy Coats

Premium for HEV neg
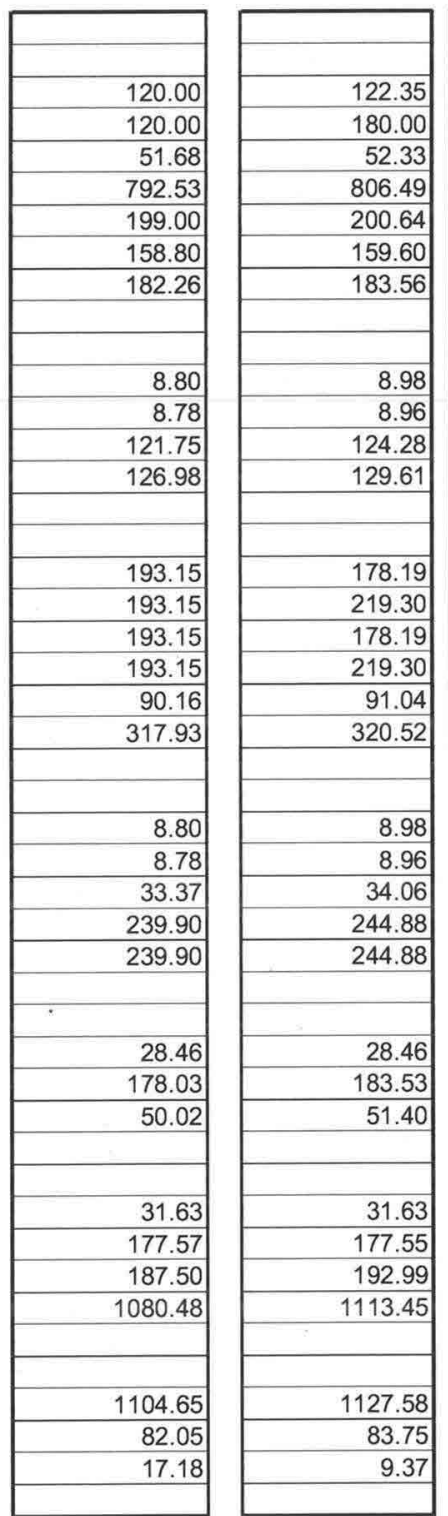

\section{Total ( $\mathrm{Em}$ 's) [price $\mathrm{x}$ volume issued]}

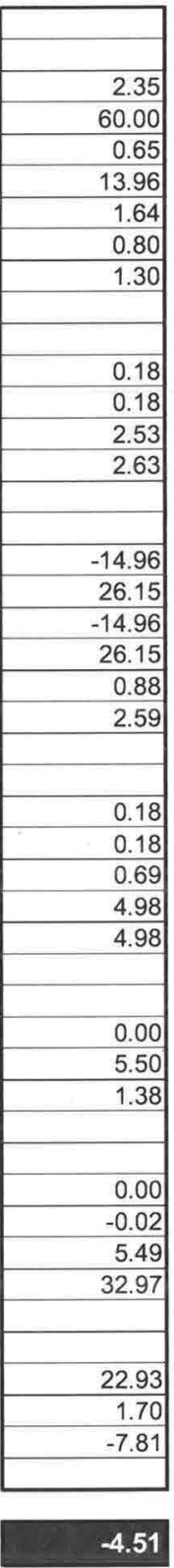


Appendix 3

NHS England Patient Blood Management Notification Letter Header 


\section{Patient Blood Management}

An evidence-based approach to patient care

\section{Foreward \\ On behalf of NHS England, I am delighted to support the National Blood Transfusion Committee's Patient Blood Management recommendations.}

Blood components are used to save and improve thousands of lives each year. Red blood cell usage in England has decreased by over $20 \%$ in the last 14 years, but national and large regional audits consistently show that $15-20 \%$ of red blood cell transfusion is not compliant with national guidelines. Recent meta-analyses show that restrictive red blood cell transfusion reduces mortality and morbidity. Everyone involved in blood transfusion needs to take responsibility for ensuring that blood transfusion is used appropriately.

Patient Blood Management is an evidence-based, multidisciplinary approach to optimising the care of patients who might need transfusion. It encompasses measures to avoid transfusion such as anaemia management without transfusion, cell salvage and the use of anti-fibrinolytic drugs to reduce bleeding as well as restrictive transfusion. It ensures that patients receive the optimal treatment, and that avoidable, inappropriate use of blood and blood components is reduced.

Patient Blood Management needs leadership and support at every level, from trust management, health professionals in hospitals, NHS Blood \& Transplant and the National and Regional Blood Transfusion Committees. I commend these guidelines to all, and offer our thanks to the many professionals involved in their development.

Jo Martin

Professor JE Martin MA MB BS PhD FRCPath

National Clinical Director of Pathology, NHS England

Date: Thursday, 26 June 2014

Copies of this document are available on: 


\title{
Patient Blood Management
}

\author{
An evidence-based approach to patient care
}

\begin{abstract}
Summary
Patient Blood Management: The Future of Blood Transfusion conference was held on 18 June 2012. The event was jointly hosted by the Department of Health, the National Blood Transfusion Committee (NBTC) and NHS Blood and Transplant (NHSBT) and supported by Professor Sir Bruce Keogh, NHS Medical Director.
\end{abstract}

The aim of the multi-disciplinary conference was to share views on how blood transfusion practice could be improved to:

- Build on the success of previous Better Blood Transfusion initiatives and to further promote appropriate use of blood components.

- Improve the use of routinely collected data to influence transfusion practice.

- Provide practical examples of high quality transfusion practice and measures for the avoidance of transfusion, wherever appropriate.

- Consider the resources needed to deliver better transfusion practice including support from NHSBT.

- Understand the patient perspective on transfusion practice.

This document provides initial recommendations from the National Blood Transfusion Committee about how the NHS should start implementing Patient Blood Management, which is a multidisciplinary, evidence-based approach to optimising the care of patients who might need blood transfusion.

A toolkit to assist NHS Trusts will be developed and posted on the NBTC website: http://www.transfusionguidelines.org.uk/transfusion-practice

\section{Rationale}

Patient Blood Management is an evidence-based, multidisciplinary approach to optimising the care of patients who might need transfusion. It puts the patient at the heart of decisions made about blood transfusion to ensure they receive the best treatment and avoidable, inappropriate use of blood and blood components is reduced. It represents an international initiative in best practice for transfusion medicine.

National, regional and local audits in England consistently show inappropriate use of all blood components; $15-20 \%$ of red cells and $20-30 \%$ of platelets/plasma. Evidence shows that the implementation of Patient Blood Management improves patient outcomes by focussing on measures for the avoidance of transfusion and reducing the inappropriate use of blood and therefore can help reduce health-care costs.

\section{Why does Patient Blood Management matter? Patient benefit}

Increases in the use of blood components are projected due to a number of factors such as medical advances and an ageing population. Only $4 \%$ of the eligible population give blood, and new donors are always needed to replace regular donors who can no longer donate.

Patient Blood Management improves patient care by reducing inappropriate transfusion and also helps to ensure the availability of blood components for those patients where there are no transfusion alternatives. 


\section{Cost to the NHS}

Previous Better Blood Transfusion initiatives have been very successful, for example by reducing red cell usage by over $20 \%$ over the last ten years. Through sharing data on blood usage, providing examples of best practice and overcoming barriers to change, it should be possible to reduce the current high level of inappropriate use of blood components described above. NHS Blood and Transplant recovers the cost of collecting and processing blood from the hospitals that use it so the NHS will save money by using only the blood that patients need.

\section{Who needs to be involved?}

Everyone involved in blood transfusion needs to take responsibility for ensuring that blood components are used appropriately for the benefit of patients. Patient Blood Management needs leadership and support at every level, including national and regional leaders, hospital management, and health professionals.

\section{Survey of Patient Blood Management}

In October 2013 all NHS Trusts in England were sent a form surveying their preparedness for Patient Blood Management (PBM) and their current activities.

146/149 (98\%) Trusts sent a response, and a summary of the key findings is provided below:-

- 40\% (59/146) of Hospital Transfusion Committees do not include PBM in their remit or mention the development of a PBM working group

- $96 \%$ Trusts have a consultant haematologist responsible for transfusion but only $81 \%$ provided information about the number of assigned programmed activities for transfusion; $46 \%$ of those that did respond indicated their haematologists have no assigned programmed activities for transfusion

- $17 \%$ Trusts have $<1$ whole time Transfusion Practitioner

- $75 \%$ of Transfusion Practitioners spend $30 \%$ or less of their time on PBM activities

- Trusts responding to the survey have 36 different types of transfusion laboratory IT; many have poor functionality to support PBM e.g. only $24 \%$ of Trusts use electronic order communications for blood ordering and only $69 \%$ of blood transfusion laboratory systems record the reason for transfusion to facilitate audit

- Only $43 \%$ of Trusts have a process for reporting blood usage to clinical teams

- Only $53 \%$ of Trusts undertake local audits of blood use

- Most Trusts offer training to the majority of clinicians, but $19 \%$ did not comment on the training of their FY doctors, and $23 \%$ did not send data on how they trained their Core or Specialist trainees.

- Fewer than $65 \%$ of Trusts provide information about blood transfusion and document consent in the majority of their patients who might need transfusion

- Only $68 \%$ of Trusts provide arrangements for the identification and management of anaemia before elective surgery 
- Only $25 \%$ of Trusts use near patient haemostasis testing

- Only $21 \%$ of Trusts have a policy to minimise the volume and frequency of blood samples to minimise iatrogenic anaemia

- $27 \%$ of Trusts are not using tranexamic acid for trauma patients, and $30 \%$ are not using tranexamic acid for surgical patients

- There is patchy use of intraoperative cell salvage, for example $55 \%$ of Trusts use it for orthopaedic surgery

- Only $29 \%$ of Trusts have implemented a policy of transfusing one unit of red cells at a time in non-bleeding patients followed by reassessment of further need for transfusion 


\section{A. General considerations}

\begin{tabular}{|l|}
\hline $\begin{array}{l}\text { Establishment of PBM programme and raising awareness amongst clinicians and } \\
\text { patients }\end{array}$ \\
\hline - All NHS Trusts should establish a multidisciplinary PBM programme through the \\
Hospital Transfusion Committee (HTC) or as a subgroup of the HTC \\
- Education of all clinicians involved in the decision to transfuse blood components should \\
be provided to enhance clinician awareness about good patient blood management \\
including avoidance of blood wherever possible \\
\hline - Education of patients for whom transfusion may be a treatment option about \\
individualised blood management and blood avoidance should be an integral part of \\
relevant care pathways \\
\hline Issues in patient testing \\
\hline The volume and frequency of blood samples should be minimised to prevent iatrogenic \\
anaemia \\
\hline Use of near patient haemostasis and haemoglobin (Hb) testing should be undertaken to \\
guide blood component therapy in patients with haemorrhage in conjunction with the \\
Trust Point of Care Testing (POCT) committee/Pathology laboratory \\
Use of appropriate dose and thresholds for transfusion \\
- Use locally agreed triggers for transfusion based on national guidelines and use \\
National Blood Transfusion Committee (NBTC) indication codes when requesting blood \\
from the transfusion laboratory and when prescribing blood components \\
Develop systems and protocols that empower transfusion laboratory staff to question \\
requests that do not conform with these triggers and where inadequate clinical \\
explanation is given \\
Regularly audit transfusion requests against these triggers \\
Transfuse one dose of blood component at a time e.g. one unit of red cells or platelets \\
in non-bleeding patients and reassess the patient clinically and with a further blood \\
count to determine if further transfusion is needed
\end{tabular}

\section{B. Specific aspects of surgical PBM}

\section{Preoperative Management of Anaemia and Haemostasis}

- Provide arrangements for the timely identification and correction of anaemia before elective surgery which is likely to involve significant blood loss using WHO definitions of anaemia i.e. $\mathrm{Hb}$ in adult males $<130 \mathrm{~g} / \mathrm{L}$ and adult females $<120 \mathrm{~g} / \mathrm{L}$

- Develop and implement protocols for the management of patients taking anticoagulants and anti-platelet drugs that may increase the risk of bleeding

- Avoid transfusion for managing anaemia if alternatives are available e.g. oral iron for iron deficiency anaemia and intravenous iron for functional iron deficiency

Intraoperative Management

- Use intraoperative cell salvage for appropriate procedures

- Use pharmacologic agents to reduce blood loss e.g. tranexamic acid

- Maintain physiologic homeostasis (normothermia, acid-base management, normocalcemia, avoid over-treatment with intravenous fluid )

- Use controlled hypotension whenever indicated and safe

- Position patients to minimise central venous pressure and capillary oozing

- Minimise surgical blood loss through use of new technologies (argon beam coagulator, radiofrequency dissecting sealer, etc.) 


\begin{tabular}{|l|}
\hline Postoperative Management \\
\hline - Use postoperative blood salvage (washed, unwashed) where indicated \\
\hline - Consider alternatives to transfusion for postoperative anaemia management (volume \\
expanders, intravenous iron)
\end{tabular}

\section{Specific aspects of medical PBM}

\begin{tabular}{|l|}
\hline Management of abnormal haemostasis \\
\hline - \\
Develop and implement a protocol for the management of reversal of warfarin, including \\
the use of vitamin K and prothrombin complex concentrates \\
\hline $\begin{array}{l}\text { Develop and implement a protocol for the management of abnormal haemostasis in } \\
\text { patients with major haemorrhage e.g. acute upper gastrointestinal haemorrhage }\end{array}$ \\
\hline - Develop and implement a protocol for the management of bleeding in patients taking \\
novel anticoagulants (e.g. dabigatran, rivaroxaban and apixiban) and potent antiplatelet \\
agents (e.g. prasugrel and ticagrelor) \\
\hline - Use anti-fibrinolytics, e.g. tranexamic acid, for major bleeding \\
Develop and implement a protocol for the management of severe thrombocytopenia in \\
patients undergoing stem cell transplantation or intensive chemotherapy for malignant \\
\hline Management of anaemia \\
\hline Identify and correct the underlying cause of the anaemia before considering transfusion, \\
wherever possible \\
\hline $\begin{array}{l}\text { Avoid transfusion for managing anaemia if alternatives are available e.g. oral iron for } \\
\text { iron deficiency anaemia, intravenous iron for functional iron deficiency }\end{array}$ \\
- $\begin{array}{l}\text { Make individualised plans for patients needing regular transfusion and consider the } \\
\text { potential for complications of transfusion such as red cell alloimmunisation and iron } \\
\text { overload and their management }\end{array}$ \\
\hline
\end{tabular}

\section{Implementation of PBM}

\begin{tabular}{|l|}
\hline Implementation of good practice for blood avoidance and the use of blood \\
\hline - Analyse casemix and clinical services to determine the main targets for PBM \\
\hline - \\
\hline Estentify PBM champions to help educate staff and patients \\
Committee) to oversee the PBM programme \\
\hline - Obtain a mandate for PBM from hospital management \\
\hline - Educate clinicians about PBM and evidence-based transfusion practice \\
to guidelines for blood avoidance and the use of blood, including the use of \\
benchmarking to identify clinicians/clinical teams who are consistently well outside of \\
average blood use for a specific procedure
\end{tabular}




\section{Responsibilities of staff involved in Patient Blood Management (PBM) at hospital level}

\section{Transfusion medicine physician}

- Have comprehensive knowledge of technical and clinical aspects of transfusion science and blood component preparation and storage

- Be an expert in evidence-based utilisation guidelines, accreditation standards and policies

- Develop constructive working relationships with hospital major blood users

- Serve as clinical champion for PBM to peers and junior medical staff

- Advise on appropriate management of anaemia and haemostatic disorders

- Work with IT departments and others to develop IT systems to support PBM

\section{Surgery/Anaesthesia clinicians}

- Serve as clinical champions for PBM to peers and junior medical staff

- Advise on implementing intra- and postoperative cell salvage and other blood sparing techniques

- Identify and eliminate non-evidence based or wasteful transfusion practice

- Assist with establishing preoperative haemoglobin and haemostasis optimisation clinics, point of care testing and blood utilisation audit and benchmarking

\section{Haematology/General Medicine physicians}

- Serve as clinical champions for PBM to peers and junior medical staff

- Assist in establishing and maintaining haemoglobin and haemostasis optimisation clinics, and point of care testing

- Assist in reducing the amount and frequency of blood sample collection both for laboratory and point of care testing

- Advise on and implement appropriate management of anaemia and haemostatic disorders.

\section{Transfusion nurse/practitioner}

- Provide and/or facilitate transfusion-related education including for PBM throughout the hospital

- Ensure clinical transfusion incidents, transfusion reactions, specimen labelling errors are investigated

- Submit data to haemovigilance programmes

- Develop constructive working relationships with the many clinical users of blood products, and assist with the implementation of PBM programme

- Support local, regional and national transfusion audits by involving appropriate stakeholders to undertake data collection and implement quality improvements arising from audits.

\section{Hospital management}

- Ensure awareness of transfusion-related hospital accreditation requirements (CPA, MHRA, NHSLA, CQC)

- Identify ways of circumventing or eliminating barriers to change

- Provide liaison with hospital executive committee when necessary

- Provide information to support business cases for PBM including the expected savings of the implementation of PBM initiatives

- Provide information to transfusion laboratory and blood services regarding major changes planned to services that may affect the amount of blood components used 
- Provide support for the use of IT systems to provide sustainable data for blood transfusion key performance indicators.

6. Transfusion Laboratory Manager

- Have comprehensive knowledge of technical and clinical aspects of transfusion science and blood component preparation and storage

- Be responsible for blood stock control and availability

- Be the key contact for queries/issues in the blood transfusion laboratory

- Support the provision of data for blood utilisation audit and benchmarking (and work with IT department/IT specialists)

- Empower laboratory staff to challenge clinicians about apparently inappropriate requests for blood components.

\section{HTC/PBM subcommittee Chair}

- Establish and lead the committee to oversee the PBM programme.

- Ensure engagement and support from senior management for PBM initiatives

\section{Other specialists who should participate in PBM include:-}

- Information technology specialists: Help with access to essential data for process improvement, assist in setting up computerised physician order entry programmes (CPOE) in with educational and reporting functions

- Patient advocate/expert.

- Clinical governance department/committee: Assist with the monitoring of quality standards and patient safety.

- Trust Board representative: Be a champion for PBM. 
Issues to consider when implementing Patient Blood Management (PBM), including what data should be collected and how to measure progress

- Establish what PBM measures have already been implemented e.g. guidelines for appropriate use of blood in different clinical settings and pre-operative anaemia management.

- Establish mechanisms for determining how blood components are used e.g. by major medical and surgical diagnostic groups and by clinical team and individual clinician.

- Audit the use of blood components against local and national guidelines and benchmark with other hospitals of similar size and case mix.

- Develop the tools and opportunities for presenting blood usage and audit data back to clinical teams and individual clinicians.

- Measure baseline data and establish mechanisms for monitoring parameters of PBM such as:

- Proportion of red cell, platelet and plasma units with pre-transfusion blood count/haemostasis testing and the clinical indication documented

- Proportion of adult patients undergoing elective surgery where transfusion may be needed e.g. cardiac and orthopaedic surgery, and where preoperative anaemia screening was carried out at least 2 weeks before surgery

- Proportion of adult patients undergoing elective surgery where transfusion may be needed e.g. cardiac and orthopaedic surgery, and where preoperative blood group and antibody screening was completed before surgery

- Proportion of patients undergoing surgery where transfusion may be needed where intraoperative cell salvage and tranexamic acid were used

- Proportion of medical staff trained in blood ordering 


\section{Work needed to support the implementation of Patient Blood Management (PBM)}

The need for further work to support the implementation of Patient Blood Management was highlighted at the Patient Blood Management: The Future of Blood Transfusion conference.

Examples of the work needed include:-

- The development of a minimum dataset for patients receiving blood transfusion

- The development of standard terms for the collection of data on the reason for transfusion, as hospital coding information is not reliable for this purpose

- The development of key performance indicators for hospital transfusion practice

- Further development of electronic systems in hospitals for the collection of data to monitor the appropriate use of blood and measures for blood avoidance

- The development of a central mechanism for benchmarking blood usage and transfusion practice in hospitals

- The development of a tool to assess the resources, both staff and non-staff, required to implement Patient Blood Management at Trust level

- The development of national training and educational materials for Patient Blood Management, including e-learning programmes

- Continued development of patient information leaflets and transfusion awareness tools

- The development of NICE guidelines for transfusion.

- Commissioning of high quality clinical research (systematic reviews and clinical trials) on safe and effective transfusion practice including alternatives to blood transfusion

Several of these activities are already in initial development and will be placed on the Patient Blood Management Toolkit when progressed. 
Appendix 4

US AABB Patient Blood Management Poster 


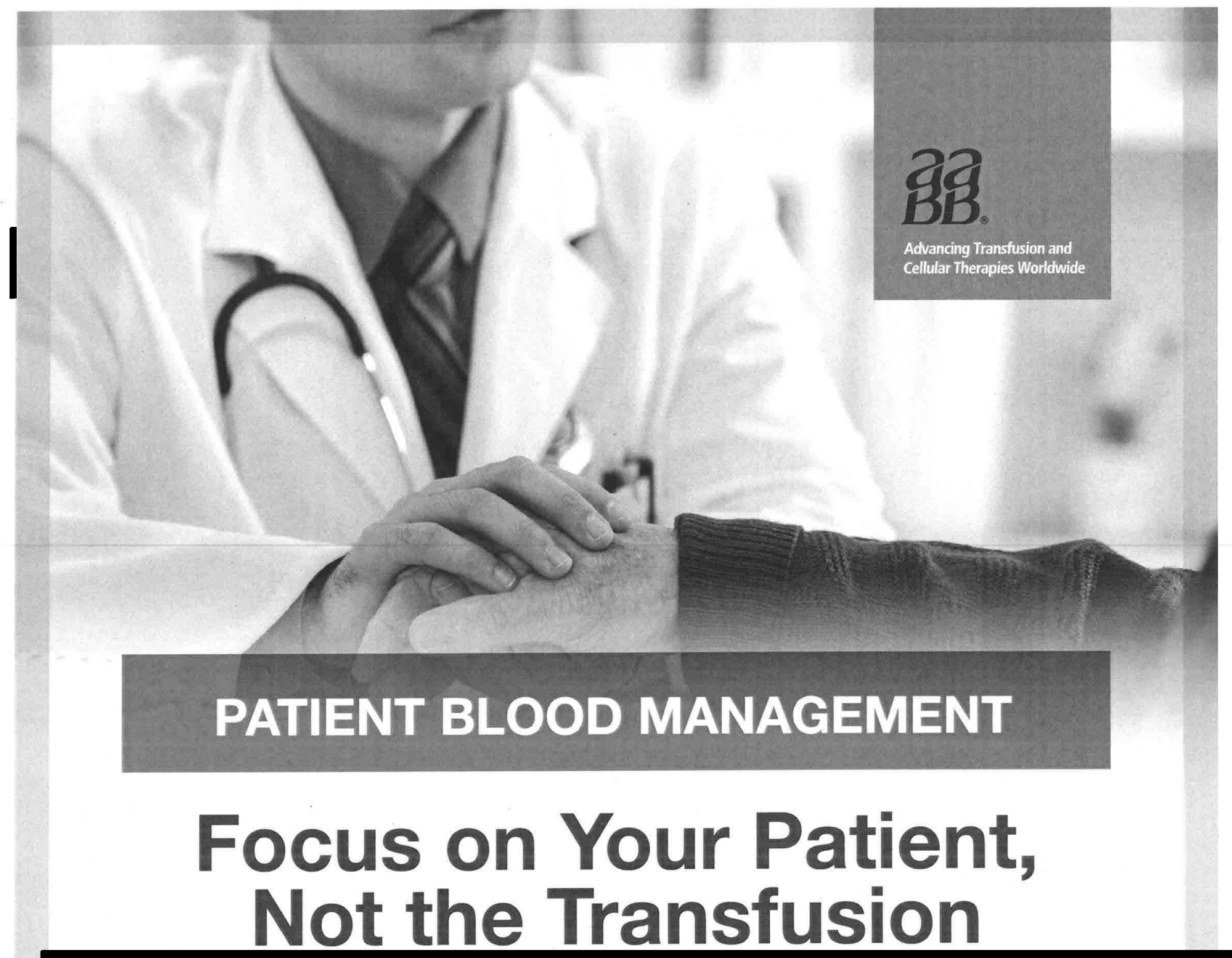




\section{PATIENT BLOOD MANAGEMENT}

IMPROVES PATIENT OUTCOMES

LOWERS RISKS

PEDURES EOSTS

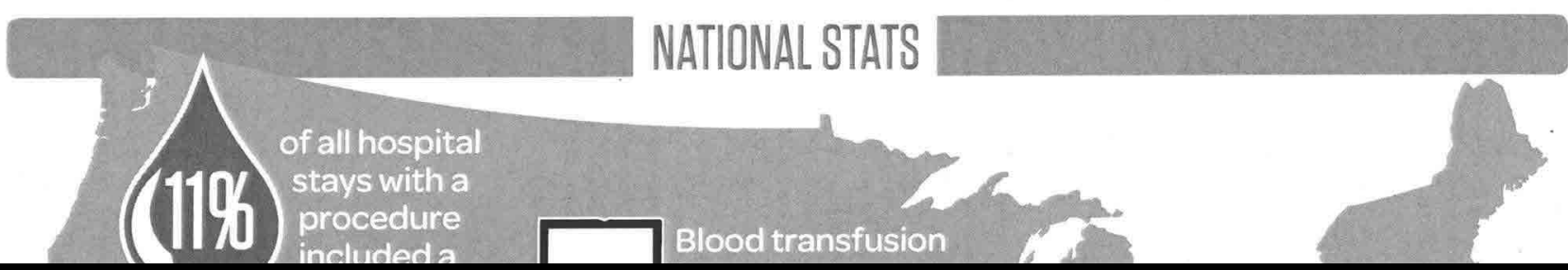

\section{WHAT'S YUUR BLUUUUSALE?}




\section{Appendix 5}

European Blood Alliance Questionnaire Summary Schedule 


\section{NHSBT Finance Directorate \\ Cell Salvage Project}

\section{Economic and Financial Impacts of an Expansion in Cell Salvage Utilisation}

\section{Background}

There is continued interest in analysing the costs associated with cell salvage as a means of minimising the expenditure on allogeneic blood. The majority of studies emphasise the main savings as being the difference between the costs of setting up a cell salvage programme and the avoidance of expenditure on the (ever-increasing) cost of allogeneic blood.

A recent study at the Cleveland Clinic Foundation, Cleveland, $\mathrm{OH} .{ }^{1}$ cited potential savings of $\$ 1.5 \mathrm{~m}$ utilising 5,500 cases on an initial capital outlay of $\$ 104,000$. This is the most up to date study available and is written from an accountancy standpoint, focusing on the costs and benefits of a hospital operating within a market environment.

\section{UK Experience}

UK health provision operates in a different environment to the US in relation to the provision of allogeneic blood. Public sector hospitals are part of the National Health Service (NHS) with the blood collection agencies (NHS Blood and TransplantNHSBT, being the body for England and North Wales) being part of the same organisation.

An expansion in cell salvage would therefore require a focus on the cost structures of both the hospitals and NHSBT. An internal market exists for allogeneic blood with a transfer price of approximately $€ 190$ per unit. This transfer price will net off when analysing aggregated income and expenditure at a corporate NHS level. Thus, in the short term, an expansion in cell salvage at hospital level will result in lower expenditure at hospital level but disproportionately higher expenditure in NHSBT due to the differing cost structure of the two organisations.

In economists' terms costs are more variable at the hospital level. In the short term therefore the combined costs of expanding cell salvage utilisation would lead to aggregated higher costs to the NHS as a whole. This may partly explain why the UK significantly lags behind Western Europe and North America in cell salvage utilisation.

Few studies have focused on quantifying and analysing this, possibly unique, cost issue. Initial thoughts are that this is a potential disincentive for the NHS to encourage the expansion of cell salvage caused by the nature of the organisation of collection and provision of allogeneic blood in the UK health "mixed economy".

\section{International Dimension-Brief Questionnaire}

The author wishes to pursue further studies in the cost implications of cell salvage with the support of Swansea University's Department of Health Economics. An outline of the differing "markets" for allogeneic blood has been suggested as a start point to assess whether overseas experiences can be used to develop a model for a UK wide potential expansion in cell salvage. 
For your particular country:

3.1. What organisation is responsible for the collection of blood from donors?

3.2. Generally, what commercial relationships exist for hospitals to buy in allogeneic blood?

3.3. Is this a public or private sector organisation?

3.4. How much do hospitals pay for a unit of blood?

3.5. Is there any recent study relating to the proportion of allogeneic blood replaced by cell salvage in your country?

3.6. Is cell salvage equipment available for emergency admissions in hospitals?

3.7. Are patients offered the choice of whether they wish to have their elective operation undertaken utilising cell salvage?

Many studies potentially overstate the costs associated with operating cell salvage systems by e.g. assuming extra operating department staff are required. In your country:

3.8. Do student-training programmes for work in operating theatres (medical, nursing or practitioner staff) include training in operating cell salvage equipment?

My current thoughts are around the UK "mixed economy" model making the financial benefits of an expansion less obvious than for a hospital buying in blood like any other healthcare product. This would allow the hospital more short-term flexibility in choosing between the alternatives to an allogeneic blood transfusion.

There seems therefore to be less obvious financial incentives for the UK NHS to expand the cell salvage programme. An international comparison would assist in developing a research question.

I would be grateful for your responses to the above questions and any other information you feel is relevant.

Thank you

Bernard Crotty

National Finance Manager-Capital Planning

NHSBT UK

5 October 2007

bernard.crotty@nhsbt.nhs.uk

Ref [1] Waters JR, Meier HH, Waters JH. An Economic Analysis of Costs Associated with Development of a Cell Salvage Program. Anesth Analg. 2007 Apr;104(4):86975. 


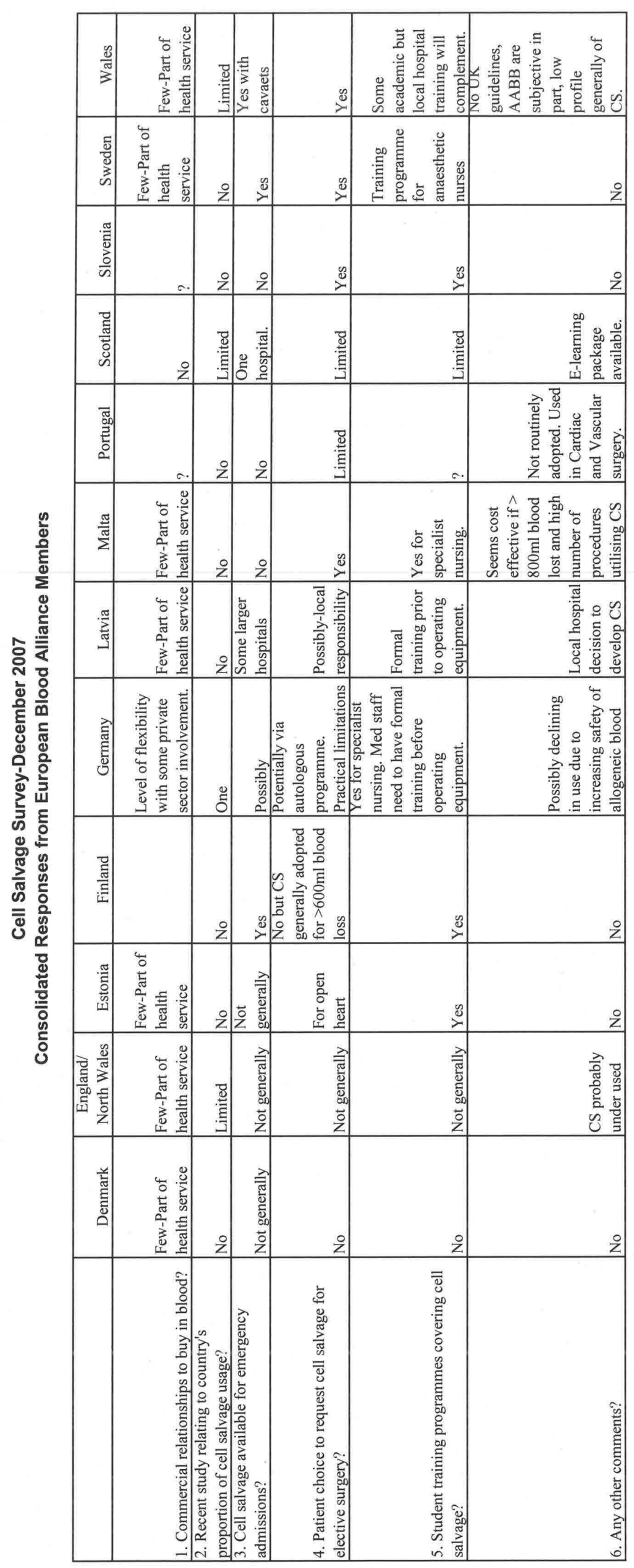




\section{Appendix 6}

ABM Pre-Operative Assessments Questionnaire 


\section{Ymddiriedolaeth Prifysgoi GIG Abertawe Bro Morgannwg University NHS Trust}

\section{Anaesthetic / surgical fitness for elective surgery}

\begin{tabular}{|lll|}
\hline Height & Weight & BMI \\
Pulse & BP & Resp. rate \\
\hline
\end{tabular}

Addressograph.

Telephone number.

Available at short notice $\mathrm{Y} / \mathrm{N}$

History of presenting complaint

\section{Proposed operation:}

Date of assessment:

Past medical history Previous operations / illnesses No / Yes

\begin{tabular}{|c|c|c|}
\hline Date & Operation /illness & Hospital \\
\hline & & \\
\hline & & \\
\hline
\end{tabular}

Any previous problems with $\quad$ Details of problem (Refer unless nausea and vomiting) anaesthetic No / Yes 


\begin{tabular}{|c|c|c|c|}
\hline Cardiovascular assessment & No & Yes & Comments \\
\hline Have you had a heart attack? & & & Refer if in last year \\
\hline Do you have a Pacemaker? & & & $\begin{array}{l}\text { Type............... } \\
\text { Last checked.................Refer }\end{array}$ \\
\hline $\begin{array}{l}\text { Do you have Angina? Or chest } \\
\text { pain on exercise/exertion }\end{array}$ & & & Fill out supplementary chest pain sheet \\
\hline NYHA Grade 1 & & & $\begin{array}{l}\text { No limitation of activity, no symptoms from ordinary } \\
\text { activity }\end{array}$ \\
\hline NYHA Grade 2 & & & $\begin{array}{l}\text { Slight, mild limitation of activity } \\
\text { Comfortable at rest or with mild exertion. }\end{array}$ \\
\hline NYHA Grade 3 & & & $\begin{array}{l}\text { Comfortable only at rest, marked limitation of } \\
\text { activity. Refer }\end{array}$ \\
\hline NYHA Grade 4 & & & $\begin{array}{l}\text { Any physical activity brings on discomfort, symptoms } \\
\text { occur at rest. Refer }\end{array}$ \\
\hline Do you have a heart murmur? & & & - \\
\hline $\begin{array}{l}\text { Do you have high blood } \\
\text { pressure? }\end{array}$ & & & \\
\hline Do you get palpitations? & & & Details \\
\hline $\begin{array}{l}\text { Do you get or have swollen } \\
\text { ankles or lower legs? }\end{array}$ & & & \\
\hline $\begin{array}{l}\text { Do you get short of breath } \\
\text { lying down flat? }\end{array}$ & & & $\begin{array}{l}\text { How many pillows do you need? } \\
\text { Refer if has orthopnoea }\end{array}$ \\
\hline $\begin{array}{l}\text { Do you wake at night short of } \\
\text { breath? }\end{array}$ & & & Refer \\
\hline
\end{tabular}

\begin{tabular}{|c|c|c|c|}
\hline Respiratory assessment & No & Yes & Comments \\
\hline Do you have asthma? & & & Well controlled? Yes / no \\
\hline $\begin{array}{l}\text { Do you have chronic bronchitis } \\
\text { or emphysema? }\end{array}$ & & & \\
\hline $\begin{array}{l}\text { Do you have any other chest } \\
\text { problems, if so what? }\end{array}$ & & & \\
\hline $\begin{array}{l}\text { Have you been admitted to hospital } \\
\text { for your chest problems? }\end{array}$ & & & \\
\hline $\begin{array}{l}\text { Have you taken steroid tablets for } \\
\text { your chest problems? }\end{array}$ & & & \\
\hline $\begin{array}{l}\text { Do you get short of breath walking } \\
\text { on the flat? }\end{array}$ & & & $\begin{array}{l}\text { How far? } \\
\text { Refer if less than } 200 \mathrm{~m}\end{array}$ \\
\hline $\begin{array}{l}\text { Do you get short of breath and } \\
\text { have to stop on a flight of stairs? }\end{array}$ & & & Refer \\
\hline Do you have sleep apnoea? & & & $\begin{array}{l}\text { Refer, and use Epworth Sleepiness Score } \\
\text { sheet }\end{array}$ \\
\hline Do you currently smoke? & & & $\begin{array}{l}\text { How many per day? } \\
\text { Would you like help to stop? No /Yes-refer } \\
\text { When did you stop? }\end{array}$ \\
\hline
\end{tabular}

Comments and investigations 


\begin{tabular}{|l|l|l|l|}
\hline \multicolumn{1}{|c|}{ Other conditions/ illnesses } & No & Yes & \multicolumn{1}{|c|}{ Comments } \\
\hline $\begin{array}{l}\text { Have you had a stroke, mini } \\
\text { stroke or TIA? }\end{array}$ & & & Refer if within 12 months \\
\hline $\begin{array}{l}\text { Do you have epilepsy, have } \\
\text { you had fits or blackouts? }\end{array}$ & & & Refer if within last year or uncontrolled \\
\hline $\begin{array}{l}\text { Have you had blood clots, in } \\
\text { your legs or lungs? (DVT or PE) }\end{array}$ & & & Refer if still being treated \\
\hline $\begin{array}{l}\text { Do you have diabetes? } \\
\text { Have you had liver disease or } \\
\text { jaundice? }\end{array}$ & & & Refer if uncontrolled \\
\hline $\begin{array}{l}\text { How much alcohol do you } \\
\text { drink in a week? }\end{array}$ & & Refer if severe or ongoing \\
\hline $\begin{array}{l}\text { Do you have kidney disease? } \\
\text { Do you have thyroid disease? }\end{array}$ & & & $\begin{array}{l}\text { Refer if yes } \\
\text { blood test }\end{array}$ \\
\hline $\begin{array}{l}\text { Do you have a hiatus hernia, } \\
\text { do you get heartburn or acid } \\
\text { indigestion? }\end{array}$ & & & \\
\hline $\begin{array}{l}\text { Do you have anaemia or a } \\
\text { blood disorder? }\end{array}$ & & & $\begin{array}{l}\text { If possible sickle cell trait, have they } \\
\text { been tested? Refer if positive }\end{array}$ \\
\hline $\begin{array}{l}\text { Do you get prolonged bleeding } \\
\text { after cutting yourself or } \\
\text { following operations? }\end{array}$ & & $\begin{array}{l}\text { Eg when cut / with dental extractions } \\
\text { Refer with clotting screen }\end{array}$ \\
\hline \begin{tabular}{l} 
Do you have bad arthritis? \\
\hline
\end{tabular} & & \begin{tabular}{l} 
Refer If neck movement restricted \\
\hline
\end{tabular} & \\
\hline
\end{tabular}

Medication history. What medication or drugs do you take?
Include over the counter drugs, inhalers, HRT, eye drops, topical medication, recreational/
illicit drugs, complimentary medicine etc




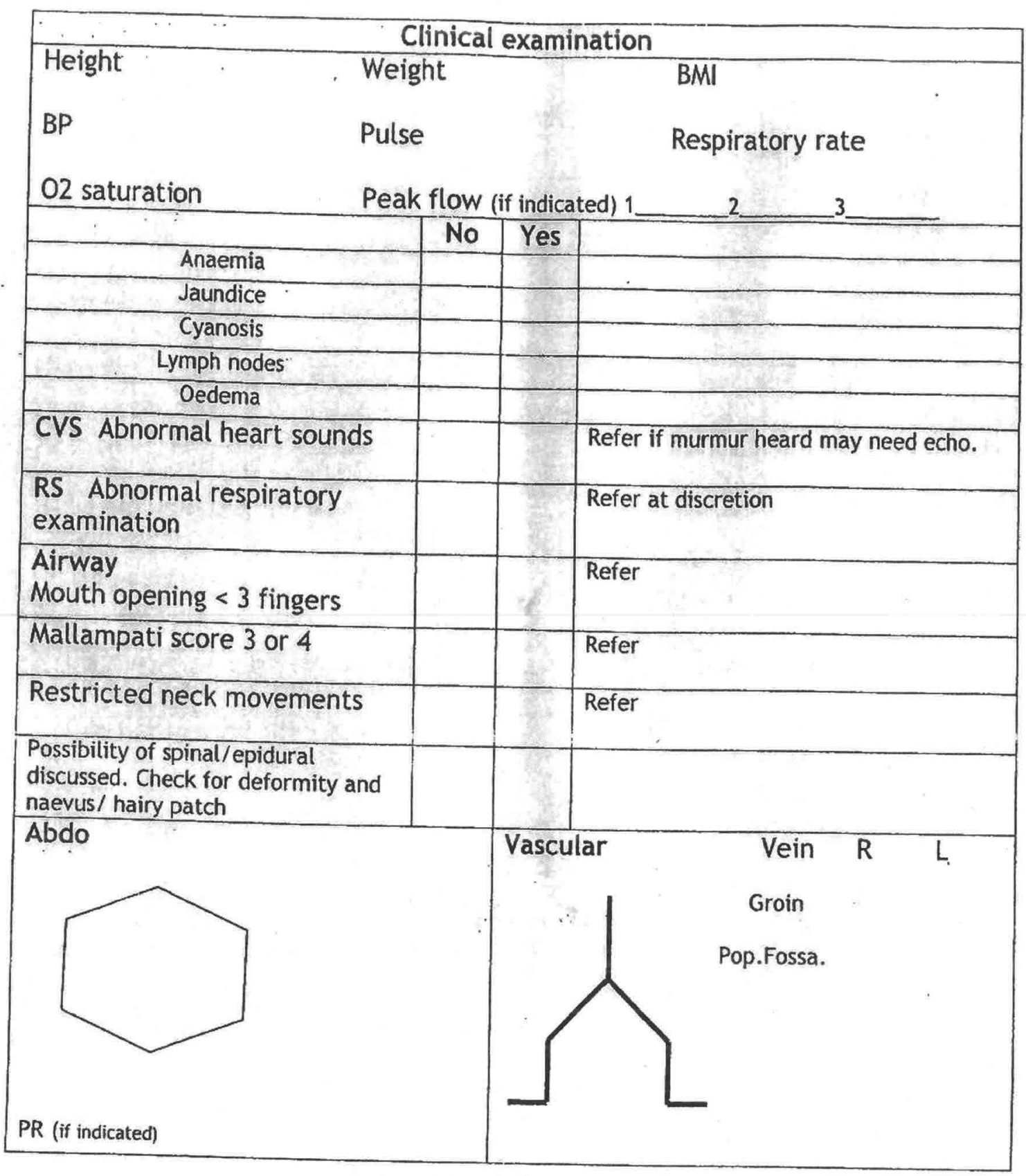

What is the ASA?

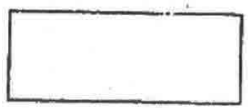

Class I. Normal healthy individual.

Class II. Systemic disease that does not limit activity. Eg hypertension

Class III. Severe systemic disease that limits activity, but not incapacitating. Eg CCF

Class IV. Severe systemic disease which is constantly life threatening.

Class V. Moribund, not expected to survive 24 hours without surgery.

ASA $3 / 4$ are likely to be picked up from the above questions, but as a general rule, all ASA $3 / 4$ should be discussed with an anaesthetist.

All Gynae patients to have urine bottle. YES

Written information given: Yes No Assessed by.

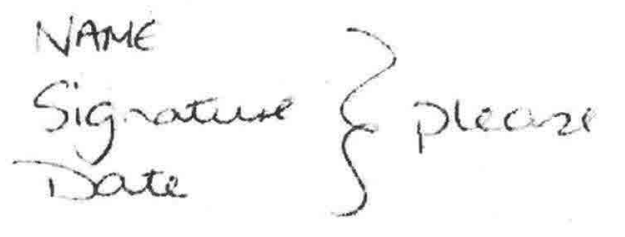


Appendix 7a

Literature Review-Summary of Comments to 2013 


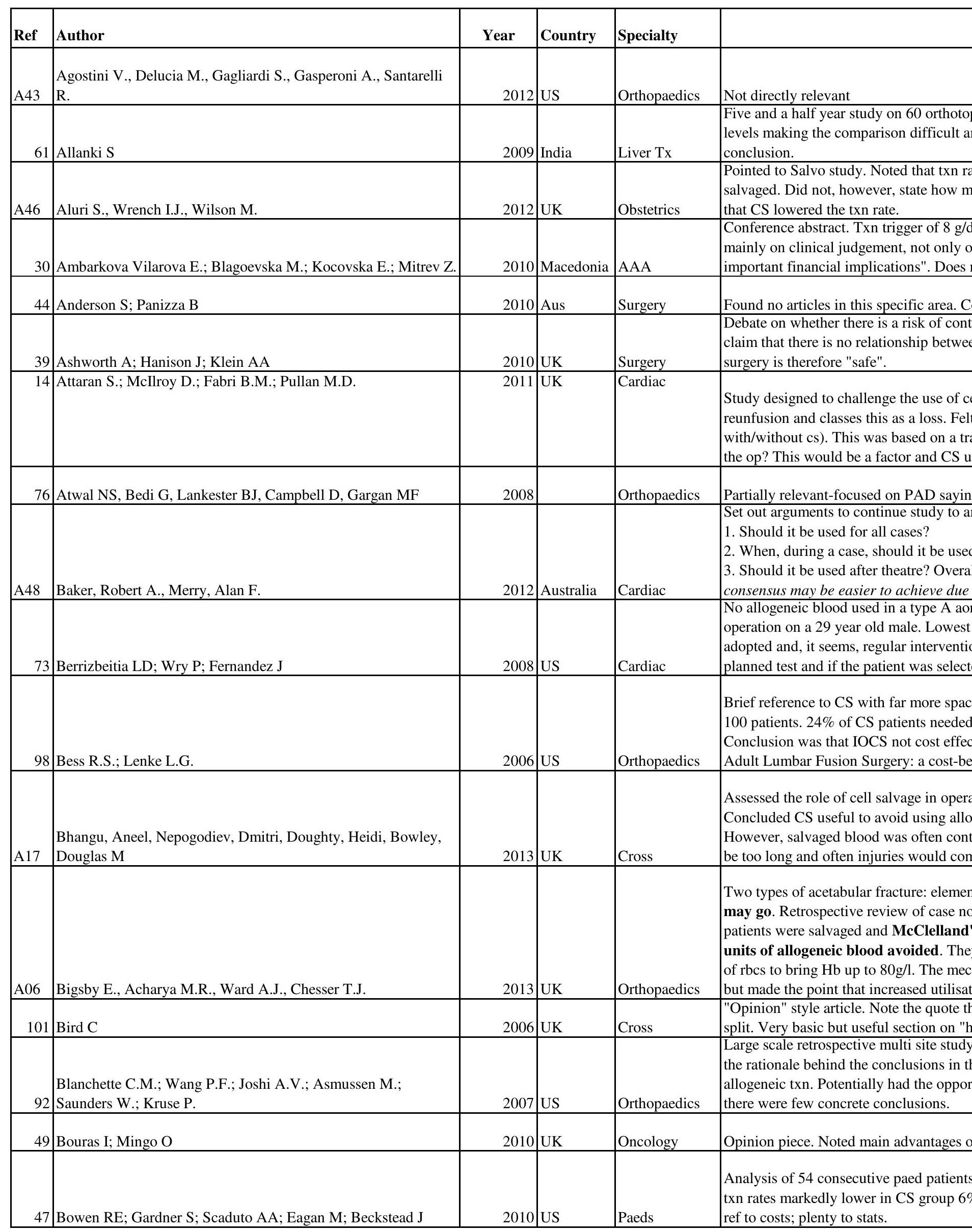


Brief Summary of

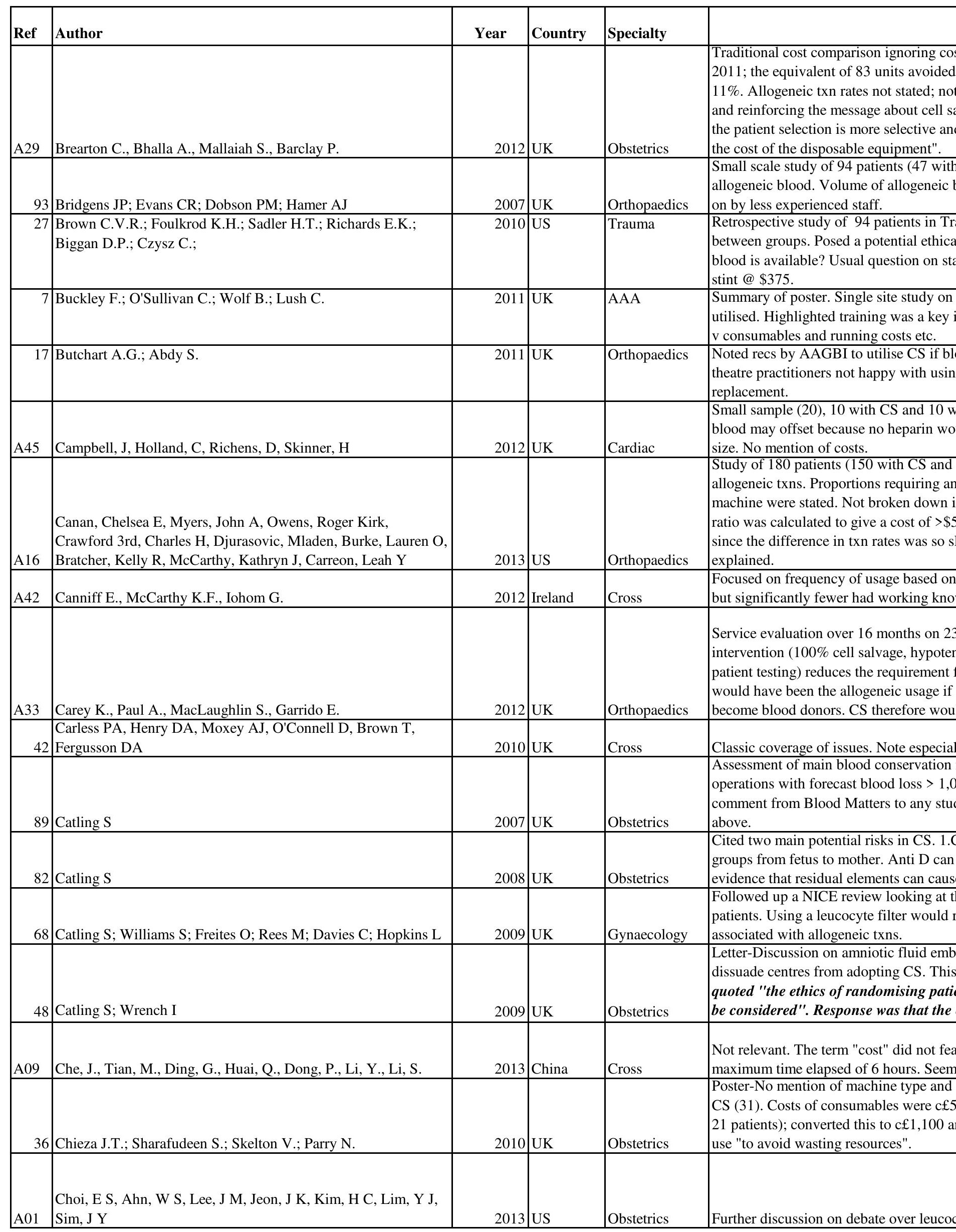


Brief Summary of

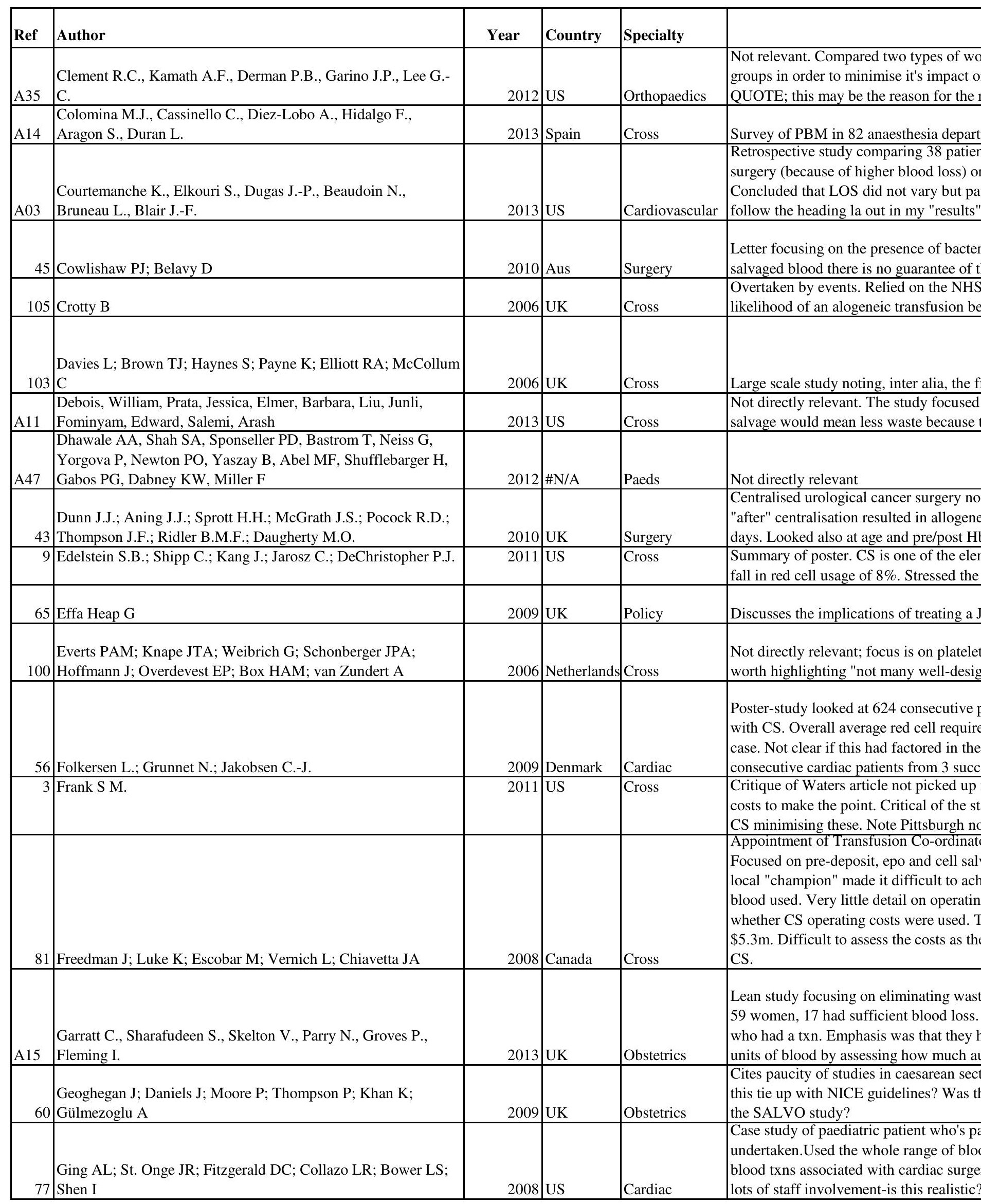


Brief Summary of

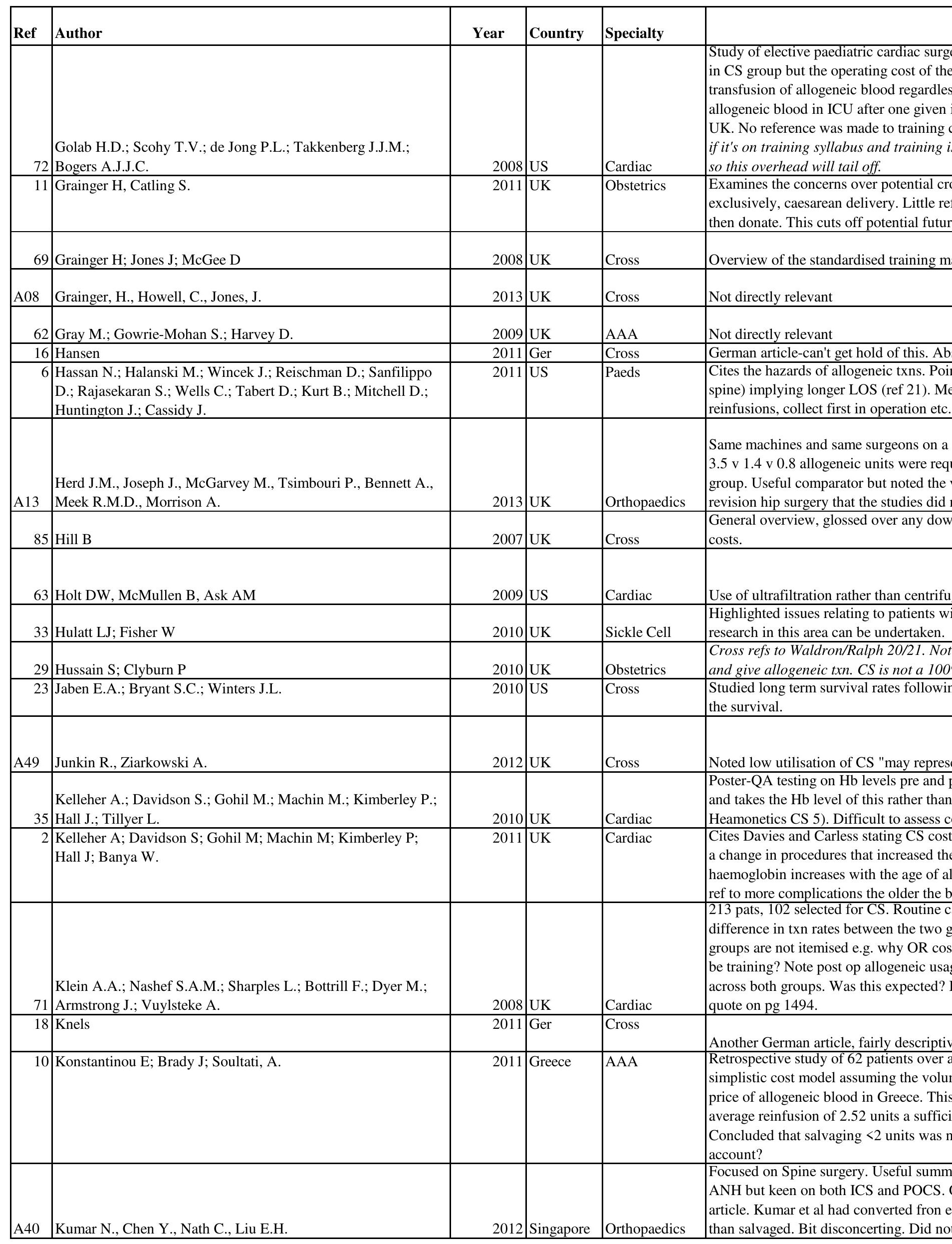


Brief Summary of

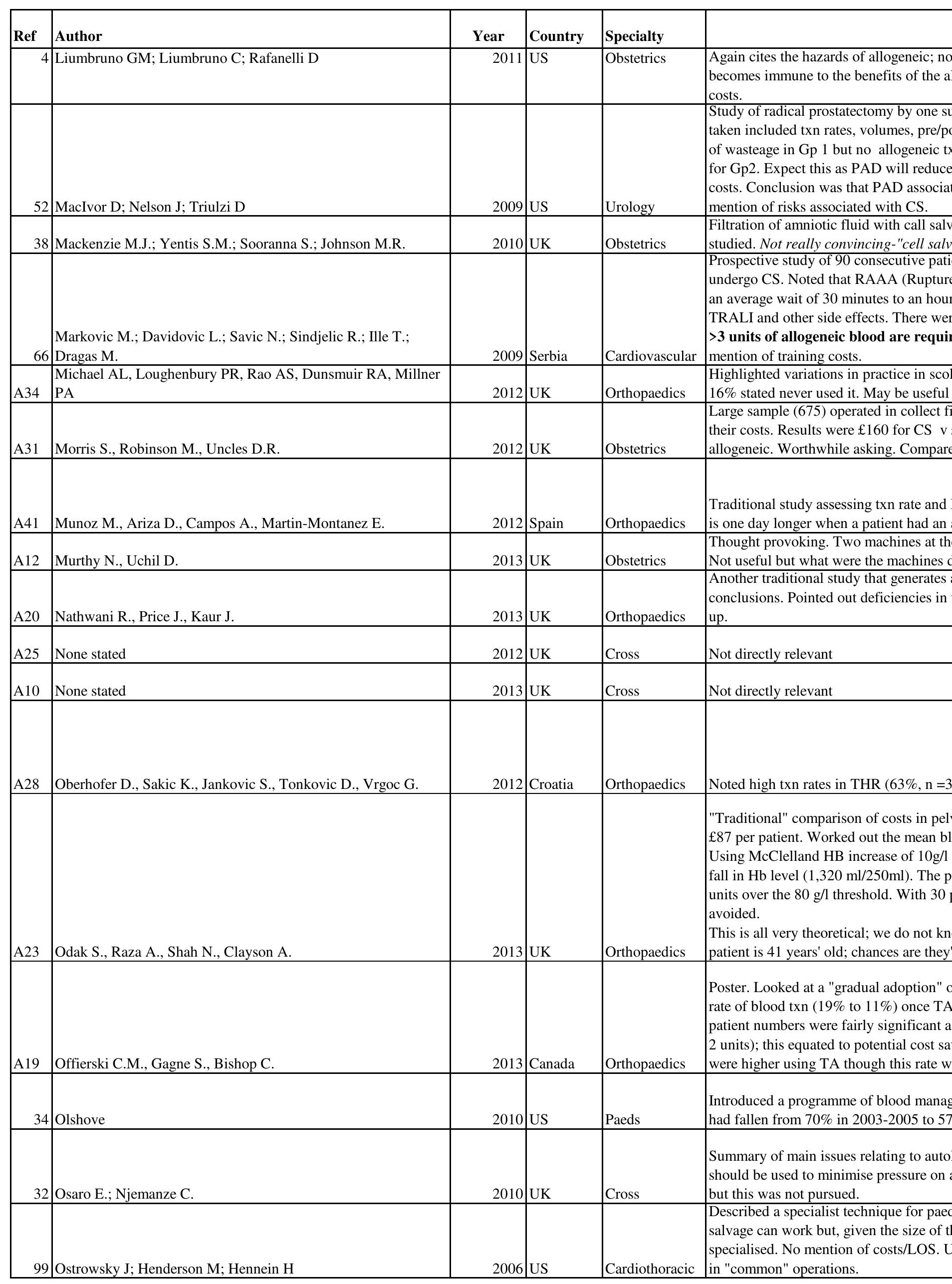




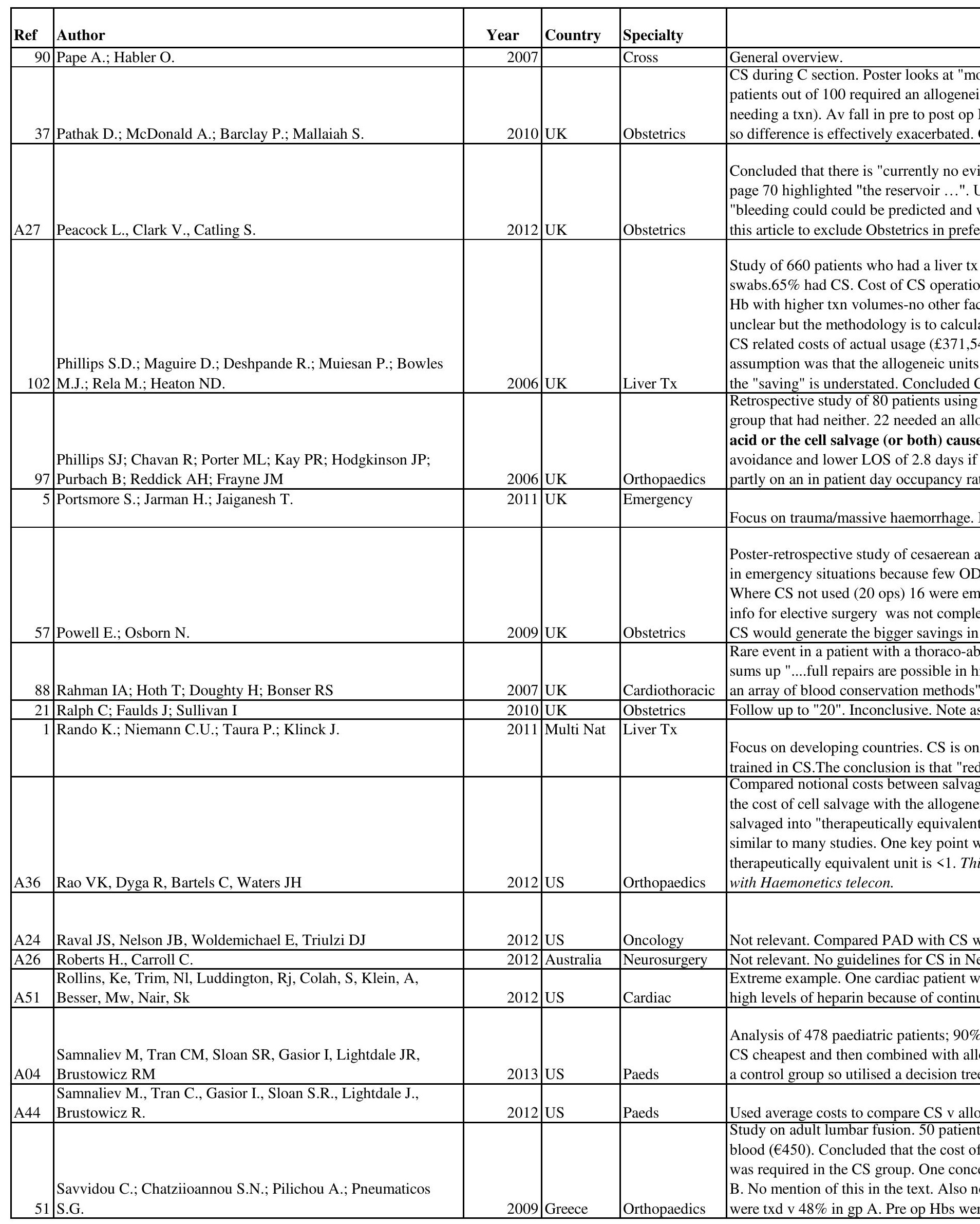




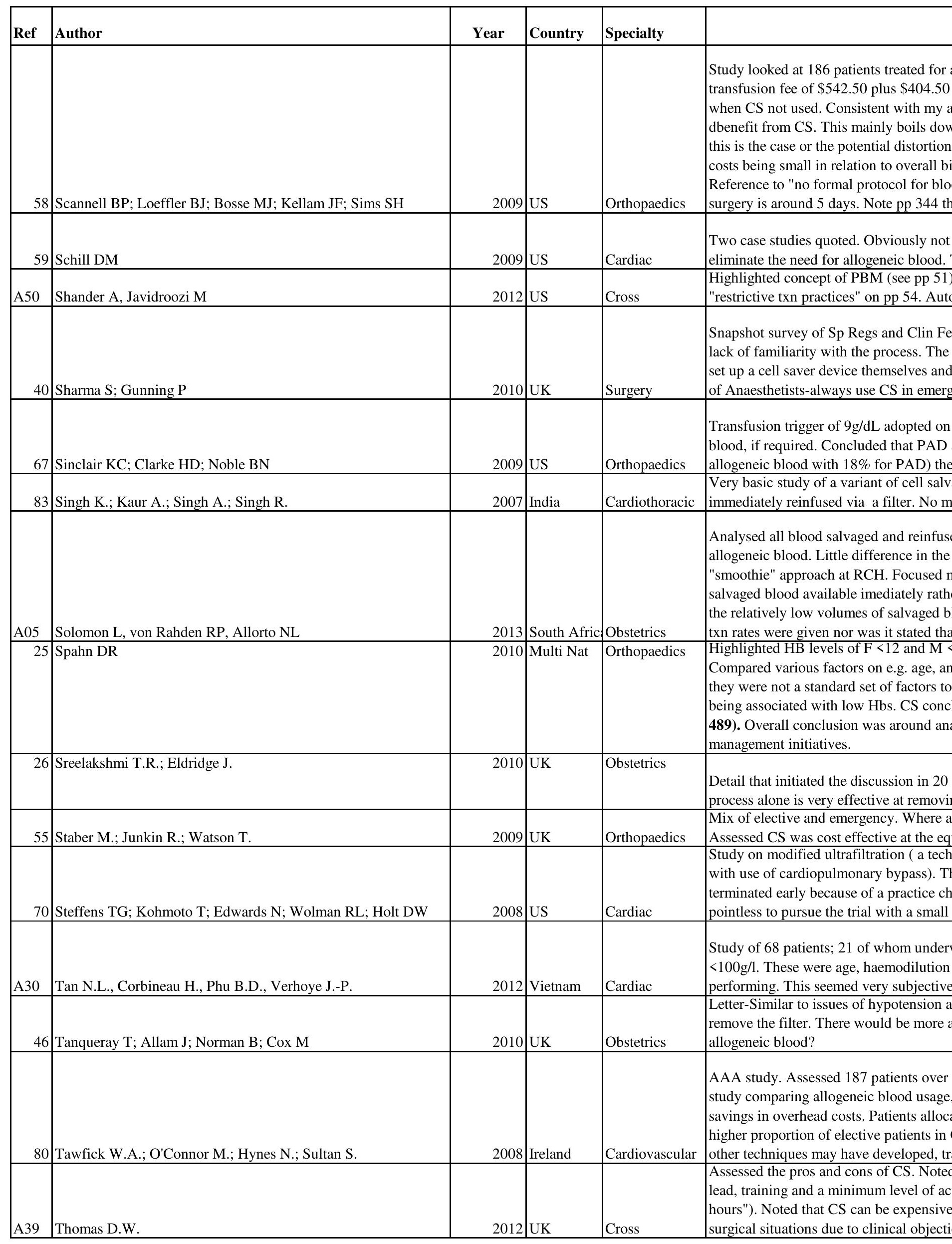




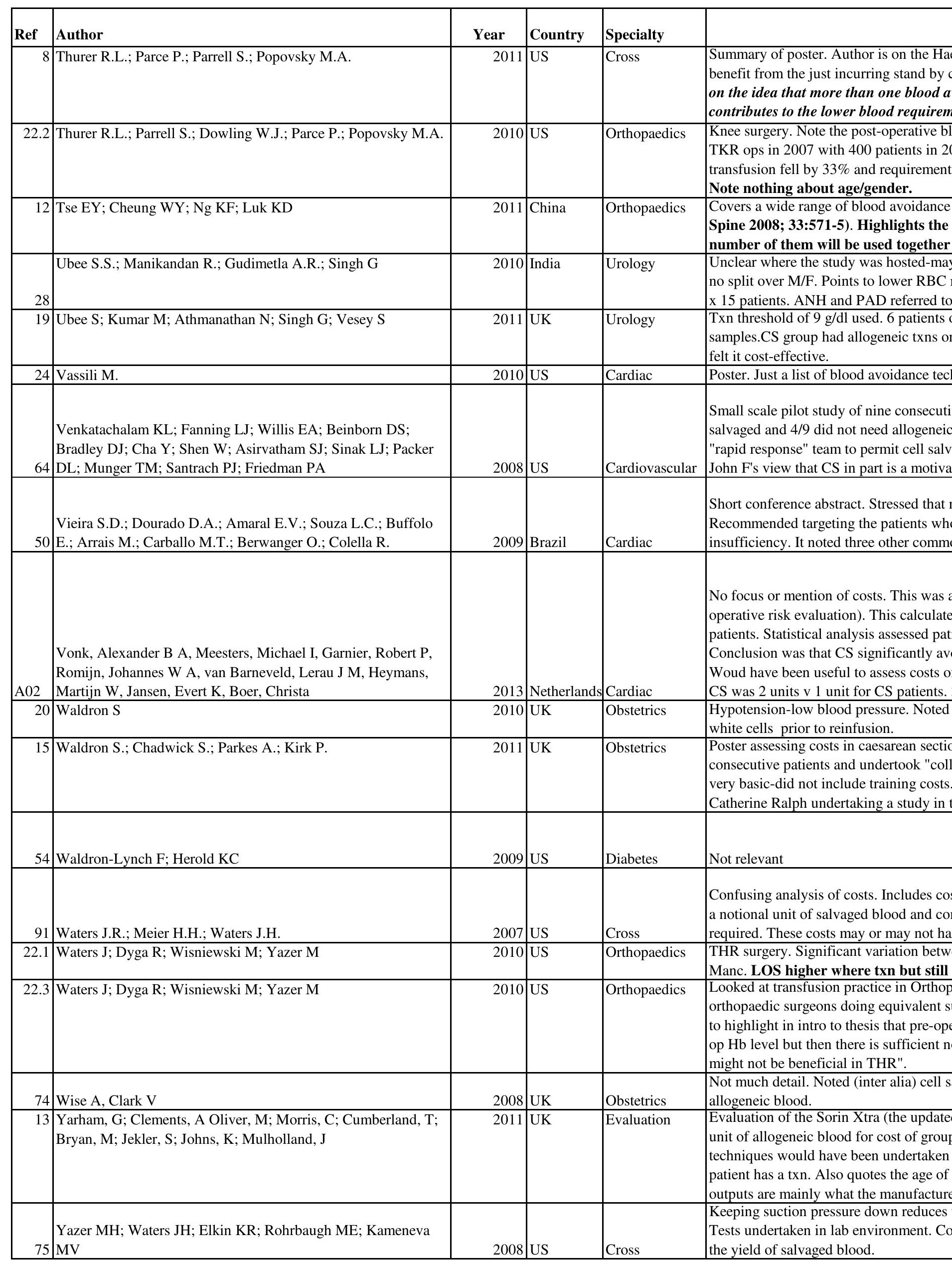


Brief Summary of

\begin{tabular}{|r|l|r|l|l|l|}
\hline Ref & Author & Year & Country & Specialty & \\
\hline & & & & & \\
96 & Kulej J; Wall A; Dragan S; Krawczyk A; Romaszkiewicz P & 2006 & & Cross & Eastern European. Focused on PAD \\
\hline 87 & Boulton F; James V; Stainsby D & & & & Cross \\
\hline & Gomez M; Vives E; Garcia-Erce J; Sanchez C; Llach X & 2007 & & & Not relevant-All PAD \\
95 & Spanish article. Only summary translated \\
\hline
\end{tabular}




\section{Appendix 7b}

Literature Review-Additional Comments to 2016 


\section{Lit Review Notes for Recent Articles 2014-16}

\section{Background}

1.1. A search was performed on NHS Athens on 3 January 2017 using the same search criteria as for the previous searches. 71 articles including 16 duplicates. 29 were considered to be at least partially relevant. Key articles are listed below.

\section{Key Articles}

\begin{tabular}{|c|c|c|c|}
\hline Ref & $\begin{array}{l}1^{\text {st }} \\
\text { Author }\end{array}$ & Spec & Information \\
\hline 1 & Tio M et al & Ortho & $\begin{array}{l}\text { Post op CS in TKA. CS would avoid allogeneic txn in } 1 \text { in } 7 \text { patients. } \\
\text { Costs } 10 \times \text { greater. Difficulty in spotting/predicting the "right" patients to } \\
\text { salvage. }\end{array}$ \\
\hline 2 & $\begin{array}{l}\text { So-Osman } \\
\text { C et al }\end{array}$ & Ortho & $\begin{array}{l}\text { Implied greater post-operative complications when patient salvaged. } \\
\text { Likely to impact on LOS but not seemingly the case at } \mathrm{RCH} \text { where the } \\
\text { LOS is similar to SOC. }\end{array}$ \\
\hline 3 & Cote et al & Cardiac & ICS "associated with a cost benefit of $\$ 116$ per patient". Cardiac. \\
\hline 4 & Stone N & Ortho & $\begin{array}{l}\text { Scoliosis-twisting of the spine-rarely emergency. CS reduces the demand } \\
\text { for allogeneic txns-one unit less per operation. Not clear if this is an } \\
\text { average of one unit over every patient. }\end{array}$ \\
\hline 9 & $\begin{array}{l}\text { Lemke et } \\
\text { al }\end{array}$ & Liver & Liver resection. Worked up a model-ICS cost minimising \\
\hline 11 & $\begin{array}{l}\text { Yeung S et } \\
\text { al }\end{array}$ & Obs & $\begin{array}{l}\text { Volume of blood salvage not sufficient to increase Hb levels but regular } \\
\text { use of cell savers keeps "the team up to date with the skills required". } \\
\text { Need further studies. }\end{array}$ \\
\hline 12 & $\begin{array}{l}\text { Pawasker } \\
\text { A et al }\end{array}$ & Orth & TKA. Meta-analysis. Concluded auto txn cost effective. \\
\hline 13 & $\begin{array}{l}\text { Elmalky M } \\
\text { et al }\end{array}$ & Orth & $\begin{array}{l}\text { IOCS with leucodepletion filter cost effective in metastatic spine tumour } \\
\text { surgery. }\end{array}$ \\
\hline 14 & $\begin{array}{l}\text { Theusinger } \\
\text { O et al }\end{array}$ & Orth & Pointed to joint impacts of other PBM techniques \\
\hline 17 & Guzel et al & Orth & $\begin{array}{l}\text { TKA compared TXA with POCS and routine drainage. TXA more cost } \\
\text { effective. Philosophical-if you combine CS and TXA then this is best for } \\
\text { the patient but the separate benefits cannot be isolated unless you } \\
\text { separate like in this study. Would you want to use both in targeted } \\
\text { patients? }\end{array}$ \\
\hline 20 & $\begin{array}{l}\text { Kelly } P \text { et } \\
\text { al }\end{array}$ & Orth & $\begin{array}{l}\text { Another spine. Same conclusion that CS not cost effective but may do so } \\
\text { if it's usage is targeted. }\end{array}$ \\
\hline 24 & $\begin{array}{l}\text { Crossland } \\
\text { C et al }\end{array}$ & Obs & $\begin{array}{l}\text { CS more expensive. May be "untold benefits in keeping staff trained for } \\
\text { unexpected haemorrhages, avoiding risks of allogeneic txn and improved } \\
\text { patient outcomes". Sledgehammer to crack the nut? }\end{array}$ \\
\hline 29 & $\begin{array}{l}\text { Goucher et } \\
\text { al }\end{array}$ & Obs & CS cost effective where high blood loss predictable. \\
\hline 33 & Taylor et al & Obs & $\begin{array}{l}\text { Titled "too much blood". Txns undertaken with } \mathrm{Hb}>100 \mathrm{~g} / \mathrm{l} \text {. Note one of } \\
\text { the co-authors was Paula Joy who undertook the highly critical } \\
\text { orthoaedics study in Royal Gloucs. Useful back up for RCH restrictive } \\
\text { blood practice. }\end{array}$ \\
\hline 34 & $\begin{array}{l}\text { Rajkumar } \\
\text { A }\end{array}$ & Orth & $\begin{array}{l}\text { CS increased in PHR. Allogeneic txns fell markedly. Get copy of article. } \\
\text { Any other contributors (e.g. TXA). }\end{array}$ \\
\hline 35 & $\begin{array}{l}\text { Pendry } \mathrm{K} \\
\text { et al }\end{array}$ & Cross & $\begin{array}{l}\text { PBM. Useful to note how everything is being brought together under the } \\
\text { PBM umbrella. }\end{array}$ \\
\hline 36 & Xie Y et al & Cardiac & $\begin{array}{l}\text { ICS generally safe in cardio by pass and cost effective in developed } \\
\text { countries but not in China }\end{array}$ \\
\hline 41 & $\mathrm{Li} \mathrm{J}$ et al & Trauma & Seemed to pinch Carless et al's conclusion on "large, multicentre..." etc. \\
\hline 45 & Dhariwal S & Obs & Inconclusive. Pointed to SALVO study. \\
\hline
\end{tabular}




\begin{tabular}{|l|l|l|l|}
\hline Ref & $\begin{array}{l}\mathbf{1}^{\text {st }} \\
\text { Author }\end{array}$ & Spec & Information \\
\hline 46 & $\begin{array}{l}\text { Nemani V } \\
\text { et al }\end{array}$ & Orth & $\begin{array}{l}\text { Spine surgery. Concluded POCS kept Hb levels higher in early post op } \\
\text { period but does not significantly reduce requirements for allogeneic } \\
\text { blood. May be useful to quote in the LOS issue in that higher Hb may well } \\
\text { point to lower LOS. }\end{array}$ \\
\hline 49 & $\begin{array}{l}\text { Albright et } \\
\text { al }\end{array}$ & Obs & $\begin{array}{l}\text { Consider when "predictability high probability" of transfusion or when "a } \\
\text { massive transfusion is reasonably likely". }\end{array}$ \\
\hline 50 & $\begin{array}{l}\text { Ratcliffe A } \\
\text { et al }\end{array}$ & Orth & $\begin{array}{l}\text { Revision hips at RCH. 13 day LOS with txn v 7 days without. "Believe" } \\
\text { level of causation between allogeneic blood and LOS. }\end{array}$ \\
\hline 52 & $\begin{array}{l}\text { England E } \\
\text { et al }\end{array}$ & Orth & $\begin{array}{l}\text { Noted national average txn rate of 25\%. Seems very high. Track down } \\
\text { the article. May be useful to quote. Increased cost associated with LOS } \\
\text { looks like average costs. Noted TXA reduced Hb drop but not LOS. } \\
\text { Causation and impact/influence of CS. }\end{array}$ \\
\hline 53 & $\begin{array}{l}\text { Grainger H } \\
\text { et al }\end{array}$ & Cross & $\begin{array}{l}\text { Referred to Welsh database. Implied more "prudent" use of resources } \\
\text { needed. }\end{array}$ \\
\hline 57 & Son M & Gynae & $\begin{array}{l}\text { CS only cost effective when reinfused. This is stating the obvious but } \\
\text { useful to stress. Noted the difficulty in predicting which patient will require } \\
\text { reinfusion to avoid allogeneic txn. }\end{array}$ \\
\hline 60 & $\begin{array}{l}\text { Font Gaul } \\
\text { A et al }\end{array}$ & $\begin{array}{l}\text { Ortho } \\
\text { Tagha- } \\
\text { et al }\end{array}$ & $\begin{array}{l}\text { Review of PBM one year on. Slight translation issue but txn rates fell with } \\
\text { the implementation of PBM. }\end{array}$ \\
\hline 64 & Bellam S & Obtho & $\begin{array}{l}\text { Highlighted beneficial impact of TXA and high pre-op Hb levels. Note a } \\
\text { limitation of my study is that I only have the word of the leads that TXA } \\
\text { was administered in all cases. }\end{array}$ \\
\hline 65 & $\begin{array}{l}\text { Herd J } \\
\text { Equivalent unit calculation used. Low consumables costs but may not } \\
\text { have VAT on them. }\end{array}$ \\
\hline
\end{tabular}

Bernard Crotty 6 January 2017 
Appendix 8

Donor Questionnaire Results 2013 


\begin{tabular}{|c|c|c|c|}
\hline \multicolumn{4}{|c|}{$\begin{array}{l}\text { PAGE: RECENT ATTENDANCE } \\
\text { 1. Have you attended a blood donation session or clinic in the last four months? }\end{array}$} \\
\hline & \multirow[b]{3}{*}{ 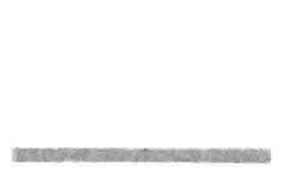 } & \multirow{2}{*}{$\begin{array}{l}\text { Response } \\
\text { Percent }\end{array}$} & \multirow{2}{*}{$\begin{array}{l}\text { Response } \\
\text { Count }\end{array}$} \\
\hline & & & \\
\hline & & $76.7 \%$ & 891 \\
\hline No & anase & $23.3 \%$ & 270 \\
\hline \multicolumn{3}{|c|}{ answered question } & 1,161 \\
\hline \multicolumn{3}{|c|}{ skipped question } & 0 \\
\hline
\end{tabular}

PAGE: REASON NOT ATTENDED

2. Which of reasons below best explains why you haven't attended a blood donation session in the last four months (Tick all that apply)?

\begin{tabular}{|c|c|c|c|}
\hline \multirow{3}{*}{$\begin{array}{l}\text { I was too busy on the donation } \\
\text { day. }\end{array}$} & \multirow{2}{*}{\multicolumn{2}{|c|}{$\begin{array}{l}\text { Response } \\
\text { Percent }\end{array}$}} & \multirow{2}{*}{$\begin{array}{l}\text { Response } \\
\text { Count }\end{array}$} \\
\hline & & & \\
\hline & $m$ & $189 \%$ & 50 \\
\hline $\begin{array}{l}\text { Haven't thought about it } \\
\text { forgot. }\end{array}$ & a & $4.2 \%$ & 11 \\
\hline $\begin{array}{l}\text { Location of the donation } \\
\text { session was not convenient for } \\
\text { me. }\end{array}$ & $=$ & $9.4 \%$ & 25 \\
\hline Moved home/ work. & " & $3.8 \%$ & 10 \\
\hline $\begin{array}{l}\text { Lifestyle reason (E.g. have } \\
\text { recently been to malarial } \\
\text { country). }\end{array}$ & a & $5.3 \%$ & 14 \\
\hline $\begin{array}{l}\text { No appointments available } \\
\text { when I wanted to donatel } \\
\text { session full. }\end{array}$ & $\operatorname{man}$ & $170 \%$ & 45 \\
\hline $\begin{array}{l}\text { The times of the donation } \\
\text { session were not convenient } \\
\text { for me. }\end{array}$ & ans & $14.7 \%$ & 39 \\
\hline $\begin{array}{l}\text { Health reason (E.g medication, } \\
\text { had operation that prevents me } \\
\text { from giving). }\end{array}$ & comenes & $29.8 \%$ & 79 \\
\hline $\begin{array}{l}\text { Had bad experience at previous } \\
\text { donation session. }\end{array}$ & 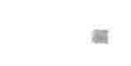 & $5.3 \%$ & 14 \\
\hline \multirow[t]{3}{*}{$\begin{array}{l}\text { Other (please specify) } \\
\text { Sthow repplies }\end{array}$} & meconer & $24.9 \%$ & 66 \\
\hline & \multicolumn{2}{|c|}{ answered question } & 265 \\
\hline & \multicolumn{2}{|c|}{ skipped question } & 896 \\
\hline
\end{tabular}

PAGE: REASON ATTENDED

3. Which of the statements belaw applies to you and your reasons for attending your last donation session (Tick ail that apply to you)?

Response Response
Percent Count

I always give biood when l'm

https://www.research.net/sr.aspx?sm=N2mMgw9sX8JCe5riohzsEc1VZErC_2fC9kY... 15/05/2013 


\begin{tabular}{|c|c|c|c|}
\hline due. & 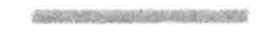 & $64.9 \%$ & 573 \\
\hline I had an appointment. & 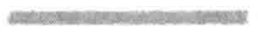 & $71.5 \%$ & 631 \\
\hline $\begin{array}{l}\text { I had been meaning to give } \\
\text { blood for a while. }\end{array}$ & sase & $10.3 \%$ & 91 \\
\hline $\begin{array}{l}\text { I was able to give blood after a } \\
\text { period of being unable to. }\end{array}$ & 䧿 & $6.3 \%$ & 56 \\
\hline Someone I knew needed blood. & 1 & $1.8 \%$ & $\uparrow 6$ \\
\hline $\begin{array}{l}\text { Someone ! knew was going } \\
\text { was going to the donation } \\
\text { session. }\end{array}$ & 4 & $2.5 \%$ & 22 \\
\hline $\begin{array}{l}\text { The location of the donation } \\
\text { session was convenient for me. }\end{array}$ & 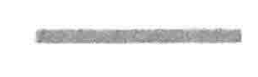 & $61.6 \%$ & 544 \\
\hline $\begin{array}{l}\text { The time of the donation } \\
\text { session was convenient for me. }\end{array}$ & 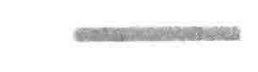 & $50.1 \%$ & 442 \\
\hline $\begin{array}{l}\text { If was a work-based donation } \\
\text { session. }\end{array}$ & 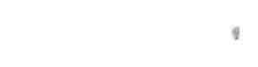 & $32 \%$ & 28 \\
\hline \multicolumn{3}{|c|}{$\begin{array}{c}\text { Other (please specify) } \\
\text { Show iupties }\end{array}$} & 30 \\
\hline \multicolumn{3}{|c|}{ answered question } & 283 \\
\hline \multicolumn{3}{|c|}{ skipped question } & 278 \\
\hline
\end{tabular}

PAGE: GIVE BLOOD AGAIN

4. How likely are you to give blcod in the future?

\begin{tabular}{|c|c|c|c|}
\hline & & Response & Response \\
\hline & & Percent & Count \\
\hline $\begin{array}{l}\text { I definitely will not give blood in } \\
\text { the future. }\end{array}$ & 3 & $31 \%$ & 36 \\
\hline $\begin{array}{l}\text { I probabily will not give blood in } \\
\text { the future. }\end{array}$ & & $0.6 \%$ & 7 \\
\hline $\begin{array}{l}\text { I am not sure whether I will give } \\
\text { blood in the future or not. }\end{array}$ & it & $1.9 \%$ & 22 \\
\hline $\begin{array}{l}\text { I probably will give blood in the } \\
\text { future. }\end{array}$ & 28 & $6.0 \%$ & 69 \\
\hline $\begin{array}{l}\text { I definitely will give blood in the } \\
\text { future. }\end{array}$ & 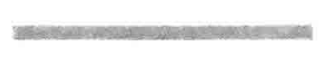 & $88.3 \%$ & 1,012 \\
\hline \multicolumn{3}{|c|}{ answered question } & 1,146 \\
\hline \multicolumn{3}{|c|}{ skipped question } & 15 \\
\hline
\end{tabular}

PAGE: CONMITMENT QUESTIONS

5. On a scale of one to ten, where one is strongly disagree and ten is strongly agree, please say how strongly you agree with the following statements

\begin{tabular}{|c|c|c|c|c|c|c|c|c|c|c|c|c|}
\hline & 1 & 2 & 3 & 4 & 5 & 6 & 7 & 8 & 9 & 10 & $\begin{array}{l}\text { Rating } \\
\text { Average }\end{array}$ & $\begin{array}{l}\text { Rating } \\
\text { Count }\end{array}$ \\
\hline $\begin{array}{l}\text { 'Giving biood is very } \\
\text { important to me'. }\end{array}$ & $\begin{array}{r}1.2 \% \\
(14)\end{array}$ & $\begin{array}{r}0.4 \% \\
(5)\end{array}$ & $\begin{array}{r}0.5 \% \\
(6)\end{array}$ & $\begin{array}{r}0.3 \% \\
(3)\end{array}$ & $\begin{array}{r}1.2 \% \\
(14)\end{array}$ & $\begin{array}{r}2.5 \% \\
(28)\end{array}$ & $\begin{array}{r}5.9 \% \\
(67)\end{array}$ & $\begin{array}{r}13.3 \% \\
(151)\end{array}$ & $\begin{array}{r}14.0 \% \\
(159)\end{array}$ & $\begin{array}{r}60.6 \% \\
(687)\end{array}$ & 9.06 & 1,134 \\
\hline $\begin{array}{l}\text { 'I have so many } \\
\text { commitments it is } \\
\text { sometimes hard to give }\end{array}$ & $\begin{array}{r}28.2 \% \\
(320)\end{array}$ & $\begin{array}{r}12.1 \% \\
(137)\end{array}$ & $\begin{array}{l}9.7 \% \\
(110)\end{array}$ & $\begin{array}{r}5.2 \% \\
(59)\end{array}$ & $\begin{array}{l}93 \% \\
(106)\end{array}$ & $\begin{array}{r}6.3 \% \\
(72)\end{array}$ & $\begin{array}{l}3.9 \% \\
(101)\end{array}$ & $\begin{array}{r}10.8 \% \\
(123)\end{array}$ & $\begin{array}{r}4.7 \% \\
(53)\end{array}$ & $\begin{array}{r}4.7 \% \\
(53)\end{array}$ & 4.25 & 1,134 \\
\hline
\end{tabular}


blood'.

\begin{tabular}{|c|c|c|c|c|c|c|c|c|c|c|c|}
\hline \multirow[t]{3}{*}{$\begin{array}{l}\text { I really enjoy giving } \\
\text { blood'. }\end{array}$} & $\begin{array}{r}2.3 \% \\
(26)\end{array}$ & $\begin{array}{r}4.2 \% \\
(48)\end{array}$ & $\begin{array}{r}5.8 \% \\
(66)\end{array}$ & $\begin{array}{r}4.9 \% \\
(55)\end{array}$ & $\begin{array}{r}15.6 \% \\
(177)\end{array}$ & $\begin{array}{r}6.4 \% \\
(73)\end{array}$ & $\begin{array}{r}10.6 \% \\
(120)\end{array}$ & $\begin{array}{r}14.9 \% \\
(169)\end{array}$ & $\begin{array}{r}10.8 \% \\
(123)\end{array}$ & $\begin{array}{r}24.4 \% \\
(277)\end{array}$ & 1,134 \\
\hline & & & & & & & & & \multicolumn{2}{|r|}{ answered question } & 1,134 \\
\hline & & & & & & & & & \multicolumn{2}{|r|}{ skipped question } & 27 \\
\hline
\end{tabular}

PAGE:

3. How many minutes did you spend travelling to your last donation session from your starting point?

\begin{tabular}{|c|c|c|c|}
\hline & & Response & Response \\
\hline & & Percent & Count \\
\hline Less than 5 minutes & som & $15.8 \%$ & 178 \\
\hline $5-10$ minutos & 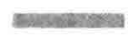 & $33.4 \%$ & 377 \\
\hline $11-15$ minutes & nawas & $21.2 \%$ & 240 \\
\hline 16.20 minutes & $\sin$ & $14.5 \%$ & 164 \\
\hline $21-25$ minutes & ๘ & $5.0 \%$ & 57 \\
\hline $26-30$ minutes & $a$ & $4.2 \%$ & 48 \\
\hline \multirow[t]{3}{*}{ More than 30 minutes } & $=$ & $5.8 \%$ & 66 \\
\hline & \multicolumn{2}{|c|}{ answered question } & 1,130 \\
\hline & \multicolumn{2}{|c|}{ skipped question } & 31 \\
\hline
\end{tabular}

PAGE:

7 How many minutes did you spend traveling from your last donation session to your destination?

\begin{tabular}{|c|c|c|c|}
\hline & & Response & Response \\
\hline & & Percent & Count \\
\hline Less than 5 minutes & wasa & $159 \%$ & 179 \\
\hline $5-10$ minutes & 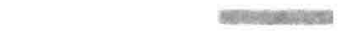 & $34.3 \%$ & 385 \\
\hline $11-15$ minutes & ackasian & $215 \%$ & 242 \\
\hline 16-20 minutes & wasere & $14.2 \%$ & 160 \\
\hline $21-25$ minutes & $\approx$ & $5.3 \%$ & 60 \\
\hline $26-30$ minutes & $s$ & $3.7 \%$ & 42 \\
\hline More than 30 minutes & $\approx$ & $4.9 \%$ & 55 \\
\hline \multicolumn{3}{|c|}{ answered question } & 1,123 \\
\hline \multicolumn{3}{|c|}{ skipped question } & 38 \\
\hline
\end{tabular}

PAGE:

8. What was your main mode of transport to your last donation session?

Response Response
Percent it/ Count




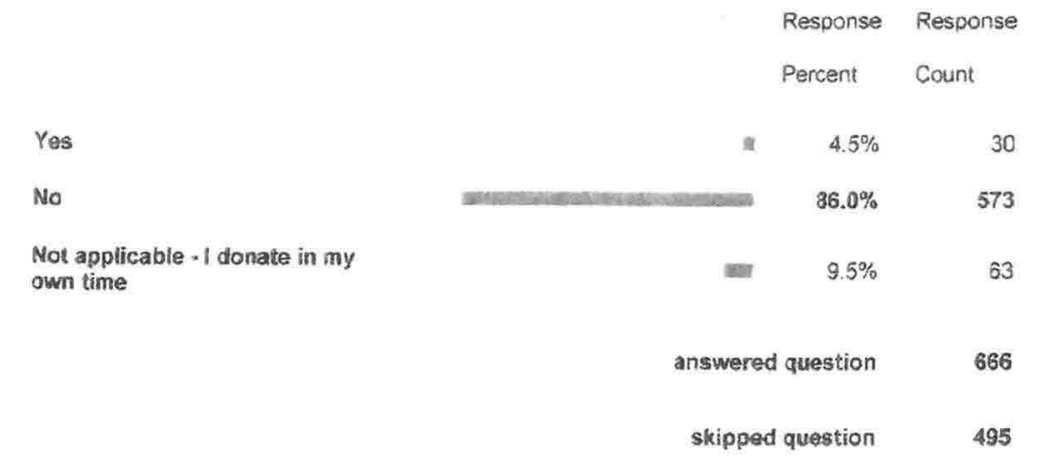

\section{PAGE:}

12. Are you expected to make up the time in your work for attending a blood donation session?

\begin{tabular}{|c|c|c|c|}
\hline \multirow[b]{3}{*}{ Yes } & & Response & Response \\
\hline & & Percent & Count \\
\hline & wanguse & $309 \%$ & 201 \\
\hline \multirow[t]{3}{*}{ No } & 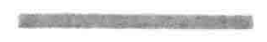 & $69.1 \%$ & 449 \\
\hline & \multicolumn{2}{|c|}{ answered question } & 650 \\
\hline & \multicolumn{2}{|c|}{ skipped question } & 511 \\
\hline
\end{tabular}

PAGE:

13. What actual costs did you incur in order to allow you to donate at your last donation session (Tick as many as relevant)?

\begin{tabular}{|c|c|c|c|}
\hline & & Response & Response \\
\hline & & Percent & Count \\
\hline Specific child care & & $0.3 \%$ & 2 \\
\hline Lost pay & 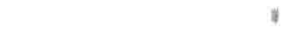 & $3.2 \%$ & 19 \\
\hline Parking ticket & nes: & $13.4 \%$ & 81 \\
\hline $\begin{array}{l}\text { Magazine/ newspaper to amuse } \\
\text { myself }\end{array}$ & $=$ & $8.6 \%$ & 52 \\
\hline $\begin{array}{l}\text { Other (please specify) } \\
\text { show replies }\end{array}$ & 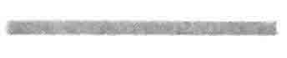 & $79.1 \%$ & 477 \\
\hline \multicolumn{3}{|c|}{ answered question } & 603 \\
\hline \multicolumn{3}{|c|}{ skipped question } & 558 \\
\hline
\end{tabular}

https://www.research.net/sr.aspx?sm=N2mMgw9sX8.JCe5ri0hzsEc1VZErC_2fC9kY ... 15/05/2013 
